\title{
PRISE: PETROLEUM RESOURCE INVESTIGATION SUMMARY AND EVALUATION
}

\author{
A Thesis \\ by \\ SARA OLD \\ Submitted to the Office of Graduate Studies of \\ Texas A\&M University \\ in partial fulfillment of the requirements for the degree of \\ MASTER OF SCIENCE
}

August 2008

Major Subject: Petroleum Engineering 


\title{
PRISE: PETROLEUM RESOURCE INVESTIGATION SUMMARY AND EVALUATION
}

\author{
A Thesis \\ by \\ SARA OLD
}

\begin{abstract}
Submitted to the Office of Graduate Studies of
Texas A\&M University

in partial fulfillment of the requirements for the degree of

MASTER OF SCIENCE
\end{abstract}

\begin{abstract}
Approved by:
Chair of Committee, Stephen Holditch

Committee Members, Walter Ayers

Duane McVay

David Wiltschko

Head of Department, Stephen Holditch
\end{abstract}

August 2008

Major Subject: Petroleum Engineering 


\begin{abstract}
PRISE: Petroleum Resource Investigation Summary and Evaluation.

(August 2008)

Sara Old, B.S., Texas A\&M University

Chair of Advisory Committee: Dr. Stephen Holditch
\end{abstract}

As conventional resources are depleted, unconventional gas (UG: gas from tight sands, coal beds, and shale) resources are becoming increasingly important to U.S and world energy supply. The volume of UG resources is generally unknown in most international basins. However, in 25 mature U.S. basins, UG resources have been produced for decades and are well characterized in the petroleum literature. The objective of this work was to develop a method for estimating recoverable UG resources in target, or exploratory, basins. The method was based on quantitative relations between known conventional and unconventional hydrocarbon resource types in mature U.S. basins.

To develop the methodology to estimate resource volumes, we used data from the U.S. Geological Survey, Potential Gas Committee, Energy Information Administration, National Petroleum Council, and Gas Technology Institute to evaluate relations among hydrocarbon resource types in the Appalachian, Black Warrior, Greater Green River, Illinois, San Juan, Uinta-Piceance, and Wind River basins. We chose these seven basins because they are mature basins for both conventional and unconventional 
oil and gas production. We assumed that a seven basin study would be sufficient for preliminary gas resource analysis and assessment of the new methodology. We developed a methodology we call PRISE, which uses software that investigates relationships among data published for both conventional and unconventional resources in the seven mature U.S. basins. PRISE was used to predict recoverable UG resources for target basins, on the basis of their known conventional resources. Input data for PRISE were cumulative production, proved reserves, growth, and undiscovered resources. We used published data to compare cumulative technically recoverable resources for each basin. For the seven basins studied, we found that $10 \%$ of the recoverable hydrocarbon resources are conventional oil and gas, and 90\% are from unconventional resources.

PRISE may be used to estimate the volume of hydrocarbon resources in any basin worldwide and, hopefully, assist early economic and development planning. PRISE methodology for estimating UG resources should be further tested in diverse sedimentary basin types. 


\section{DEDICATION}

I dedicate this work to those whom I owe my life, my parents. Without their strength and dedication as parents and mentors, I would not have been able to achieve any of my goals or dared to have dreams. I am blessed to have such wonderful people as a part of my life. Thank you for your endless support. I love you both.

I would also like to dedicate this work to my Pappaw. He is the reason for my decision in career and educational paths. Words cannot describe the respect, love, and admiration I have for a man who still continues to do great things.

Finally, I am dedicating this to my brother Bob, whom I miss dearly. I can only hope I have the positive impact on others as you had on me. You truly made the world a better place. 


\section{ACKNOWLEDGEMENTS}

I would like to thank my committee chair, Dr. Holditch, and my committee members, Dr. Ayers, Dr. McVay, and Dr. Wiltschko, for their guidance and support throughout the course of this research.

Thanks also go to my friends and colleagues in the Unconventional Resources Group and the department faculty and staff for making my time at Texas A\&M University a great experience. I would especially like to thank my close friend and colleague, Nick Groves, for project support and consultation. Also, I would like to express gratitude to Pavan Lanka and Yunan Wei for collaboration on the software programming. Great appreciation goes to the Crisman Institute for supporting this research. In addition, I would like to thank the undergraduate students who put great effort into data collection for the UCR Group projects. Also, I would like to thank the USGS, PGC, NPC, and EIA for data, feedback, and interest.

Finally, thanks to my fiancé, Luke, for his patience, love, and encouragement and to my family for believing in me and respecting my dedication to work and time at Texas A\&M University. I also want to extend my gratitude to Texas A\&M University, RPSEA/Schlumberger, and Chevron Corporation for providing me with financial assistance and generous scholarships. 


\section{NOMENCLATURE}

\begin{tabular}{|c|c|}
\hline AAPG & American Association of Petroleum Geologists \\
\hline APPB & Appalachian Basin \\
\hline BASIN & Basin Analog System Investigation \\
\hline $\mathrm{BBO}$ & Billion Barrels of Oil \\
\hline BWB & Black Warrior Basin \\
\hline Conv & Conventional Resources \\
\hline ConvGas & Conventional Gas \\
\hline ConvOil & Conventional Oil \\
\hline CBM & Coalbed Methane \\
\hline CGPC & Canadian Gas Potential Committee \\
\hline $\mathrm{cm}$ & Centimeter \\
\hline $\mathrm{cm}^{2}$ & Squared Centimeters \\
\hline $\mathrm{cm}^{3}$ & Cubic Centimeters \\
\hline CSD & Committee on Statistics and Drilling \\
\hline CSM & Colorado School of Mines \\
\hline CTRRI & Conventional Total Recoverable Resource Input \\
\hline $\mathrm{C} 100$ & 100\% Confidence Resource Volume Will Be Recovered \\
\hline $\mathrm{C} 90$ & 90\% Confidence Resource Volume Will Be Recovered \\
\hline C50 & $50 \%$ Confidence Resource Volume Will Be Recovered \\
\hline $\mathrm{C} 10$ & $10 \%$ Confidence Resource Volume Will Be Recovered \\
\hline
\end{tabular}




$\begin{array}{ll}\text { DOE } & \text { Department of Energy } \\ \text { DOI } & \text { Department of Interior } \\ \text { EIA } & \text { Energy Information Administration } \\ \text { F5 } & 5 \% \text { Chance the Resource Volume Exists } \\ \text { F50 } & 50 \% \text { Chance the Resource Volume Exists } \\ \text { F95 } & 95 \% \text { Chance the Resource Volume Exists } \\ \text { g } & \text { Grams } \\ \text { g/cm } & \text { Grams per Cubic Centimeter } \\ \text { GRB } & \text { Green River Basin } \\ \text { GTI } & \text { Gas Technology Institute } \\ \text { HC } & \text { Hydrocarbons } \\ \text { HI } & \text { Hydrogen Index, mg Hydrocarbons/mass Total Organic Content } \\ \text { IB } & \text { Illinois Basin } \\ \text { MMS } & \text { Mineral Management Service } \\ \text { NPC } & \text { National Petroleum Council } \\ \text { OGRC } & \text { Society of Petroleum Engineers Oil and Gas Reserves Committee } \\ \text { PGC } & \text { Potential Gas Committee } \\ \text { PRISE } & \text { 50\% }\end{array}$




$\begin{array}{ll}\text { P70 } & \text { 70\% Probability of Resource Occurrence } \\ \text { P90 } & 90 \% \text { Probability of Resource Occurrence } \\ \text { P95 } & 95 \% \text { Probability of Resource Occurrence } \\ \text { Ratio }_{100} & \text { Ratio of C100 to C10 } \\ \text { Ratiog0 } & \text { Ratio of C90 to C10 } \\ \text { Ratio }_{50} & \text { Ratio of C50 to C10 } \\ R_{O}^{75} & 75^{\text {th }} \text { Percentile of the Range of Vitrinite Reflectance } \\ \text { RR } & \text { Resource Ratio } \\ \text { SG } & \text { Shale Gas } \\ \text { SJB } & \text { San Juan Basin } \\ \text { SPE } & \text { Society of Petroleum Engineers } \\ \text { SR } & \text { Source Rock } \\ \text { TAMU } & \text { Texas A\&M University } \\ \text { Tcfe } & \text { Trillion Cubic Feet Equivalent } \\ \text { TGS } & \text { Tight Gas Sand } \\ \text { TOC } & \text { Total Organic Content } \\ \text { TRR } & \text { Total Recoverable Resource } \\ \text { UG } & \text { Unconventional Gas } \\ \text { UGA } & \text { URA }\end{array}$


USGS United States Geological Survey

VBA

Visual Basic Application

VRMOC

Vitrinite Reflectance Measured Organic Content

WRB

Wind River Basin 


\section{TABLE OF CONTENTS}

Page

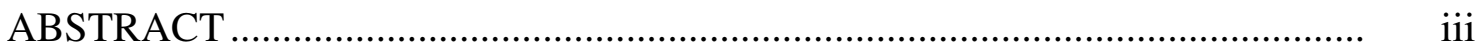

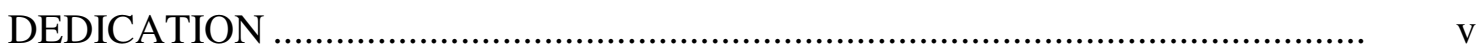

ACKNOWLEDGEMENTS ................................................................ vi

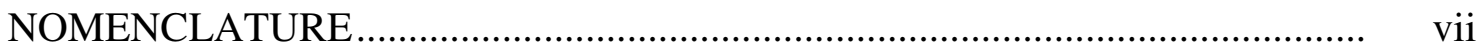

TABLE OF CONTENTS ...................................................................... xi

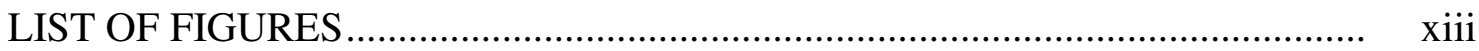

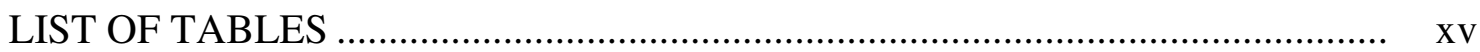

CHAPTER

I INTRODUCTION ............................................................. 1

1.1 BASIN History ............................................................ 2

1.2 PRISE Significance ......................................................... 6

II OBJECTIVE AND METHODS ................................................... 11

2.1 Resource Triangle Concept ................................................ 12

2.2 PRISE Idea ..................................................................... 13

III DEFINING THE RESOURCE TRIANGLE …............................. 15

3.1 Potential Gas Committee................................................... 17

3.2 National Petroleum Council .................................................... 19

3.3 Gas Technology Institute .................................................... 20

3.4 United States Geological Survey........................................ 21

3.5 Energy Information Agency .......................................... 22

3.6 PRISE Definitions ........................................................... 24

IV QUANTIFICATION AND VALIDATION OF THE RESOURCE

TRIANGLE .................................................................................. 34 
CHAPTER Page

4.1 Agency Assessment Data ...................................................... 34

4.2 PRISE Quantification Method ........................................... 40

4.3 PRISE Quantification Results ............................................ 44

V ESTIMATING RESOURCES IN TARGET BASINS ..................... 49

5.1 Source Rock Evaluation ...................................................... 49

5.2 Methods for Estimating Recoverable Resources .................. 58

5.3 PRISE Software.......................................................... 65

5.3.1 PRISE Test .............................................................. 66

VI CONCLUSIONS AND RECOMMENDATIONS ........................... 83

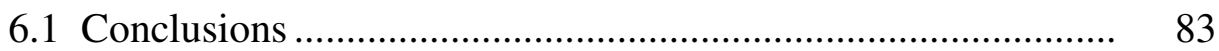

6.1.1 Limitations ............................................................. 84

6.2 Recommendations ............................................................ 86

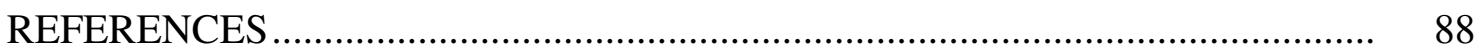

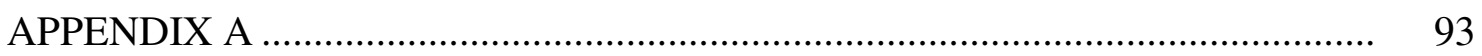

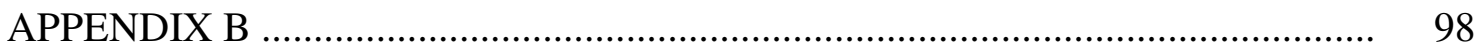

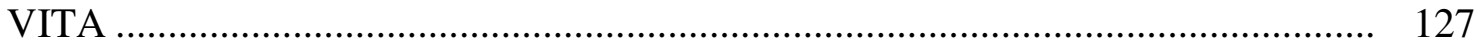




\section{LIST OF FIGURES}

FIGURE $\quad$ Page

1.1 Unconventional Gas Advisor Workflow .............................................. 8

1.2 PRISE Resource Categories ...................................................... 10

1.3 PRISE Resource Tree .................................................................. 10

$2.1 \quad$ Resource Triangle .......................................................................... $\quad 12$

3.1 Total Unconventional Gas Potential for Lower 48 United States............. 16

3.2 PGC Resource Classification and Organization.................................... 18

3.3 EIA Resource Classification and Organization................................... 23

3.4 "Mapped" Data Agencies ................................................................ 29

3.5 Primary PRISE Data Sources .................................................... 30

3.6 PRISE and SPE Resource Classification Comparison .......................... 32

4.1 The USGS and PGC Undiscovered Resources Probability Comparison... 38

4.2 The USGS and PGC Growth Probability Comparison …....................... 39

4.3 NPC Growth and Undiscovered Resource Probability Comparison......... 39

4.4 San Juan Basin Resource Tree ............................................................. 44

4.5 Total Recoverable Resource Volumes in the Seven Reference Basins

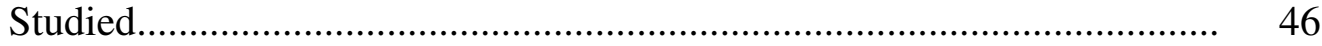

4.6 Conventional and Unconventional Resource Triangle for the Seven Reference Basins Studied.................................................................... 46

4.7 Percent of Conventional and Unconventional Total Recoverable Resource Volumes in Seven Reference Basins ........................................ 4

4.8 Percent of the Five Resource Types in Seven Reference Basins ............. 48 
5.1 Relationship between Vitrinite Reflectance Measured Organic Content (VRMOC) and Total Recoverable Resource (TRR) Volumes.

5.2 Relationship between Total Organic Content (TOC) and Total Recoverable Resource (TRR) Volumes

5.3 Anticipated Relationship between VRMOC and TRR Volumes

5.4 Anticipated Relationship between TOC and TRR Volumes.

5.5 Source Rock (VRMOC) Estimation Method for Top Ranked Analog Reference Basin

5.6 Conventional TRR Input Estimation Method for Top Ranked Analog Reference Basin

5.7 PRISE Data Input Screen

5.8 PRISE: Estimated Resource Curves in the San Juan Target Basin.....

5.9 PRISE: Estimated Conventional Resource Curves in the San Juan Target Basin.

5.10 PRISE: Estimated Unconventional Resource Curves in the San Juan Target Basin .....

5.11 PRISE: Estimated Tight Gas Sand Resource Curves in the San Juan Target Basin ......

5.12 PRISE: Estimated Coalbed Methane Resource Curves in the San Juan Target Basin

5.13 PRISE: Estimated Shale Gas Resource Curves in the San Juan Target Basin.

5.14 PRISE: Estimated Conventional Gas Resource Curves in the San Juan Target Basin .....

5.15 PRISE: Estimated Conventional Oil Resource Curves in the San Juan Target Basin ..... 


\section{LIST OF TABLES}

TABLE Page

1.1 North American Reference Basins ....................................................... 3

1.2 BASIN Data Parameters............................................................ 5

3.1 Agency Purpose, Data Sources, and Considerations............................... 25

3.2 Summary of Agency Resource Definitions for Assigned PRISE Resource Categories...................................................................................... 26

3.3 PRISE Resource Category Definitions ............................................ 28

4.1 Agency Statistical Data Reporting Process and Descriptions ................. 36

4.2 PRISE Confidence Definitions........................................................... 37

4.3 San Juan Basin Coalbed Methane Agency Data Comparison.................. 41

4.4 Agency and PRISE Data for San Juan Basin Coalbed Methane Resources ......................................................................................... 43

5.1 PRISE Resource Ratio Definitions .................................................... 60

5.2 San Juan Basin Tight Gas Sand Ratio 90 .......................................... 60

5.3 PRISE: Estimated Resource Volumes in the San Juan Target Basin........ 69

5.4 PRISE: Estimated Conventional Resource Volumes in the San Juan Target Basin ............................................................................ 71

5.5 PRISE: Estimated Unconventional Resource Volumes in the San Juan Target Basin ................................................................................. 73

5.6 PRISE: Estimated Tight Gas Sand Resource Volumes in the San Juan Target Basin ......................................................................................... $\quad 74$

5.7 PRISE: Estimated Coalbed Resource Volumes in the San Juan Target Basin 
5.8 PRISE: Estimated Shale Gas Resource Volumes in the San Juan Target Basin

5.9 PRISE: Estimated Conventional Gas Resource Volumes in the San Juan

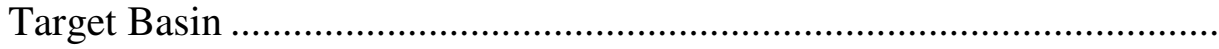

5.10 PRISE: Estimated Conventional Oil Resource Volumes in the San Juan Target Basin 


\section{CHAPTER I}

\section{INTRODUCTION}

World energy supply must continue to grow to satisfy increasing world energy demands. In North America, unconventional resources already play a major role in fulfilling national energy needs, but internationally, unconventional resources are not a major contributor to world energy supply. International conventional resources are widely explored, but with growing demand, international unconventional resources must also be explored and developed. We define unconventional hydrocarbon resources as those oil and gas accumulations that, owing to their special reservoir rock properties (i.e., low matrix permeability, presence of natural fractures), charge (adsorbed gas in self-sourced reservoirs, methane clathrates), and/or fluids characteristics (high viscosity), are economically exploitable only by using advanced technologies, massive stimulation treatments, and/or special recovery processes. ${ }^{1,2}$ Unconventional resources include tight gas sands, coalbed methane, shale gas, and heavy oil. ${ }^{1,2}$

In Chapters III and IV, we explain our methodology and show how to use publicly available data to determine the distribution of natural gas resources in a basin. Also, we explain in Chapter V how to use those data to estimate the volume of unconventional gas (UG) resources in any basin around the world where very little data exist on the UG resources. Finally, we indicate how to use basin analogs and formation

This thesis follows the style of Society of Petroleum Engineering Journal. 
analogs to improve the overall success in exploring for and developing UG resources both inside and outside of North America.

\subsection{BASIN History}

In 2006, Singh ${ }^{1}$ developed a computer software model, BASIN, to help determine if one basin or petroleum system is analogous to another. The BASIN software contains a database and the related petroleum system parameters for 25 North American basins. BASIN can be used to find an analog basin or petroleum system in these North American basins for another basin, based on the similarities in geologic parameters. Reasons for the selection of the 25 basins were described in Singh's papers on basin analog investigation. ${ }^{1,2}$ However, in summary, the 25 basins were chosen because they contain significant unconventional gas resources and there are substantial data published in the SPE and AAPG literature for those basins.

The 25 North American basins are referred to as reference basins because they are being used as a reference for any basin analog determination. BASIN determines which 25 reference basins are the best analogs for any target basin. Table 1.1 lists the North American basins that are characterized in the BASIN database.

Singh defines a target basin as any basin where very little exploration for unconventional resources has been undertaken, but he refers to them as "frontier" basins. ${ }^{1}$ Frontier basin is an indicator of exploratory conditions; however some development must have been done in order to know source and reservoir rock data. We will refer to basins lacking in unconventional resource development as target basins. Determining that one of the 25 North American reference basins is an analog for a target 
basin may allow us to infer reservoir characteristics and hydrocarbon resources in the target basin.

Table 1.1: North American Reference Basins. Modified from Singh².

\begin{tabular}{|c|c|c|}
\hline 1 & Anadarko & OK, TX \\
\hline 2 & Appalachian & $\begin{array}{c}\text { PA, NY, WV, TN } \\
\text { VA, AL, OH, KT } \\
\text { GA }\end{array}$ \\
\hline 3 & Black Warrior & $\mathrm{AL}$ \\
\hline 4 & Cherokee & OK, KS \\
\hline 5 & East Texas & TX \\
\hline 6 & Piceance & $\mathrm{CO}$ \\
\hline 7 & San Juan & $\mathrm{NM}, \mathrm{CO}$ \\
\hline 8 & Uinta & UT \\
\hline 9 & Arkoma & $\mathrm{AK}, \mathrm{OK}$ \\
\hline 10 & Big Horn & WY, MT \\
\hline 11 & Denver & $\mathrm{CO}, \mathrm{WY}, \mathrm{NE}$ \\
\hline 12 & Permian & TX, NM \\
\hline 13 & Powder River & WY, MT \\
\hline 14 & Williston & $\mathrm{ND}, \mathrm{SD}, \mathrm{MT}$ \\
\hline 15 & Wind River & WY \\
\hline 16 & Forest City & $\mathrm{KS}, \mathrm{MO}$ \\
\hline 17 & Fort Worth & $\mathrm{TX}$ \\
\hline 18 & Green River & WY \\
\hline 19 & Raton & $\mathrm{NM}, \mathrm{CO}$ \\
\hline 20 & Western Canada Sedimentary & $A B, S K, B C$ \\
\hline 21 & Illinois & IL, IN, KT, TN \\
\hline 22 & Louisiana Mississippi Salt & LA, MS, AL \\
\hline 23 & Michigan & MI \\
\hline 24 & Paradox & UT, CO, AZ \\
\hline 25 & Western Gulf & TX, LA \\
\hline
\end{tabular}

The characterized reference basins contain significant data. For each basin or petroleum system, as many as 72 geologic parameters are recorded in the BASIN database and are used in the software for analog comparisons. The parameters are divided into three main categories: general basin; source rock; and reservoir parameters. Source rock and reservoir parameters are available on the individual formation or 
member level; general basin parameters are single values representing the entire basin. Table 1.2 lists the parameters that were used to populate for the BASIN database. The BASIN software allows the user to input known data for the parameters shown in Table 1.2 for the target basin. The known data in the target basin are then compared to the corresponding data parameters for all reference basins in North America. The analog basin is the reference basin with the closest relationship (most alike) with the known data for the target basin. BASIN compares each data parameter for the target basin with the corresponding parameter in all 25 North American reference basins. The highest ranked analog has the most parameters in common with the target basin. The analog basin can then be used as a means for inferring unknown reservoir types and characteristics in the target basin. Inferring unknown reservoir types and characteristics in target basins can be done by assuming that the reservoir characteristics in the analog basins are similar to what should be known in the target basin. An analog is determined based on comparing what data is known in the target basin to fully characterized basins. Then what is unknown in the target basin should be similar to the analog basin, if the analog is determined properly. Being able to infer reservoir types and characteristics from the analog basin can allow further research into development and planning of gas resources in the target basin. A more detailed description of BASIN methodology is in Singh's study. 1,2 
Table 1.2: BASIN Data Parameters. These data are captured in 25 reference basins and input data captured for target basins. Modified from Singh ${ }^{2}$.

\begin{tabular}{|c|c|}
\hline No. & Category/Parameter \\
\hline & General Basin \\
\hline 1 & Basin Type \\
\hline 2 & Basin Area Min \\
\hline 3 & Basin Area Max \\
\hline 4 & Fill Thickness Min \\
\hline 5 & Fill Thickness Max \\
\hline \multirow[t]{2}{*}{6} & Deforming Stress Type \\
\hline & Source Rock \\
\hline 1 & Rock Type \\
\hline 2 & Age Min \\
\hline 3 & Age Max \\
\hline 4 & Depth Min \\
\hline 5 & Depth Max \\
\hline 6 & Thickness Min \\
\hline 7 & Thickness Max \\
\hline 8 & Kerogen Type \\
\hline 9 & Vitrinite reflectance Min \\
\hline 10 & Vitrinite reflectance Max \\
\hline 11 & Total Organic Content Min \\
\hline \multirow[t]{2}{*}{12} & Total Organic Content Max \\
\hline & Reservoir \\
\hline 1 & Lithology \\
\hline 2 & Age Min \\
\hline 3 & Age Max \\
\hline 4 & Depositional System \\
\hline 5 & Present Depth Min \\
\hline 6 & Present Depth Max \\
\hline 7 & Gross Thickness Min \\
\hline 8 & Gross Thickness Max \\
\hline 9 & Net Thickness Min \\
\hline 10 & Net Thickness Max \\
\hline 11 & Pressure Min \\
\hline 12 & Pressure Max \\
\hline 13 & Pressure Regime \\
\hline 14 & Porosity Min \\
\hline 15 & Porosity Max \\
\hline 16 & Permeability Min \\
\hline 17 & Permeability Max \\
\hline 18 & Water Saturation Min \\
\hline
\end{tabular}

\begin{tabular}{|c|c|}
\hline 19 & Water Saturation Max \\
\hline 20 & Migration Distance Min \\
\hline 21 & Migration Distance Max \\
\hline 22 & Migration Direction \\
\hline 23 & Seals \\
\hline 24 & Traps Type \\
\hline 25 & Fluid Type \\
\hline 26 & Oil API Min \\
\hline 27 & Oil API Max \\
\hline 28 & Sulfur content Min \\
\hline 29 & Sulfur content Max \\
\hline 30 & $\mathrm{CO} 2$ content Min \\
\hline 31 & CO2 content Max \\
\hline 32 & $\mathrm{H} 2 \mathrm{~S}$ content Min \\
\hline 33 & H2S content Max \\
\hline 34 & Heavy gas (C2-C5) Min \\
\hline 35 & Heavy gas (C2-C5) Max \\
\hline 36 & Oil-in-place Min \\
\hline 37 & Oil-in-place Max \\
\hline 38 & Oil recoverable Min \\
\hline 39 & Oil recoverable Max \\
\hline 40 & Oil reserve Min \\
\hline 41 & Oil reserve Max \\
\hline 42 & Gas-in-place Min \\
\hline 43 & Gas-in-place Max \\
\hline 44 & Gas recoverable Min \\
\hline 45 & Gas recoverable Max \\
\hline 46 & Gas reserves Min \\
\hline 47 & Gas reserves Max \\
\hline 48 & EUR Min \\
\hline 49 & EUR Max \\
\hline 50 & Natural Fractures \\
\hline 51 & Fracture Type \\
\hline 52 & Temperature Min \\
\hline 53 & Temperature Max \\
\hline 54 & Geothermal Gradient \\
\hline
\end{tabular}


BASIN provides some insight for a first step to exploring unconventional gas resources in target areas. Once Singh ${ }^{1,2}$ demonstrated that the BASIN model could compare the geologic setting for unconventional resources in a target basin to a reference basin, it was apparent that further steps were needed to advance the evaluation of the target and reference basins. The next logical step is to compare the volumes of recoverable unconventional and conventional gas resources in target basins to the volumes of recoverable unconventional and conventional gas resource volumes in the same reference basins used in BASIN.

\subsection{PRISE Significance}

Expert systems can be used to help geologists and engineers make important decisions. The BASIN software is a starting point for target basin exploration and development of unconventional resources. To start, we are only characterizing North American basins for BASIN and PRISE. Once we have characterized these basins, then we will start adding international basins, that are mature in development, to our database. Version 1.0 of the BASIN analog software is complete; however, data are continuously being loaded into the database for the 25 reference basins. Research is being done to develop expert advisors to provide advice on how to drill, complete, stimulate, and produce tight gas, shale gas, and coalbed methane reservoirs on the basis of the basin comparison and formation analysis.

PRISE software is a single application that is part of a software package called Unconventional Gas Advisor (UGA). Fig. 1.1 represents a reasonable work flow of how development of project decision making should proceed if target basins are being 
evaluated and compared to North American reference basins. Fig. 1.1 is also an outline of the different applications in UGA. A typical application of UGA begins with BASIN, where the user inputs all known geological data for the target basin and individual source rocks and reservoirs. BASIN determines two analog types based on the known target data. One analog type is the basin analog and the other is the formation analog. The basin analog is one of the 25 North American reference basins listed in the database. The formation analog is a single petroleum system within a reference basin. Both analog types are determined using the method previously discussed. PRISE uses the reference basin from the BASIN evaluation to estimate technically recoverable resources in the target basin. The other three applications in UGA use the formation analog from the BASIN result to give advice for best engineering practices in the target basin. These engineering applications use a database with best practices that are being used in formations within the reference basins and suggest those best practices that should be used in the target basin formation. 


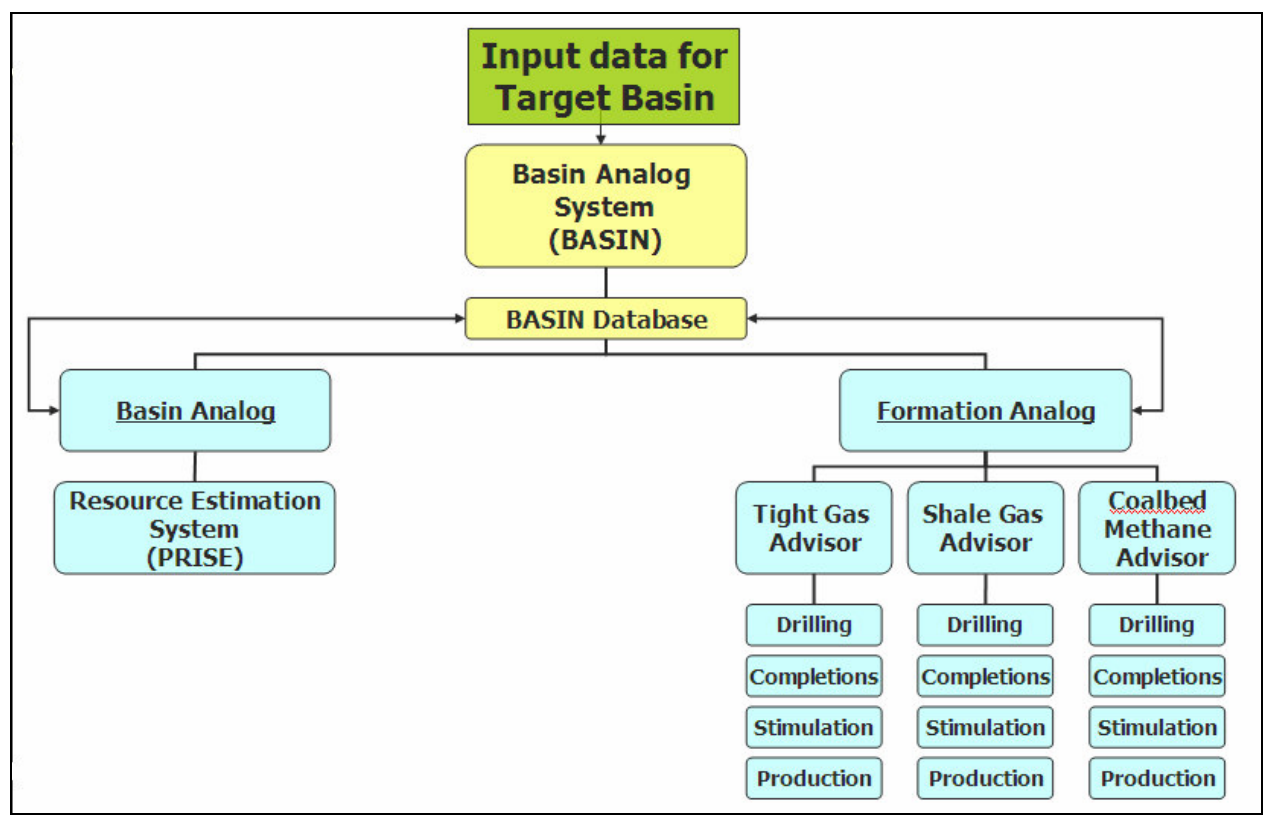

Fig. 1.1: Unconventional Gas Advisor Workflow.

Several government and private industry agencies routinely evaluate gas resources to estimate the amount of gas that may be recoverable in North American basins. We know that gas resources are greater than those that can be booked as proven reserves. Even though uncertainty increases with a decrease in availability of geologic and engineering data, we would like to know the full range of oil and gas resources in a basin, because that knowledge drives exploration and investment. As exploration continues and data are collected, the uncertainty surrounding reserves and resources in a basin will be reduced.

In this research, we are working to evaluate the volume of technically recoverable unconventional and conventional gas resources in North American basins so we can better estimate technically recoverable unconventional gas potential in target basins around the world. The purpose of being able to estimate technically recoverable 
unconventional resources in target basins is to help make early economic and development decisions, whether it is drilling, facilities, or long term asset investment decisions. Many organizations and agencies such as the National Petroleum Council (NPC), Potential Gas Committee (PGC), Gas Technology Institute (GTI), Energy Information Agency (EIA), and the United States Geological Survey (USGS) routinely evaluate gas resources in North American basins. They achieve their estimates by evaluating known gas resources under specified economic conditions and technology levels. The different organizations use different statistical risk analysis methods to generate their results. The work done by such agencies can be useful as a starting point in estimating potential gas resources in target basins. We can use previously published resource data from these agencies to build a North American resource database for conventional and unconventional gas resources. We built our own database using multiple agencies data because we wanted to maximize possible data choices and compare resource volumes from multiple agencies.

The resource quantification system that we built for this research uses the published data previously discussed for different levels of uncertainty in resource potential. Those data filled the database for the basins we studied. The database was classified into four different resource categories (Fig. 1.2). The resource categories will complete a resource tree for five different resource types: conventional oil, conventional gas, tight gas sand (TGS), coalbed methane (CBM), and shale gas (SG) (Fig. 1.3). We acknowledge that unconventional resources may encompass more reservoir types other than CBM, SG, and TGS, but for the purposes of this project, the total unconventional resource will only consist of these three resource types (Fig. 1.3). 


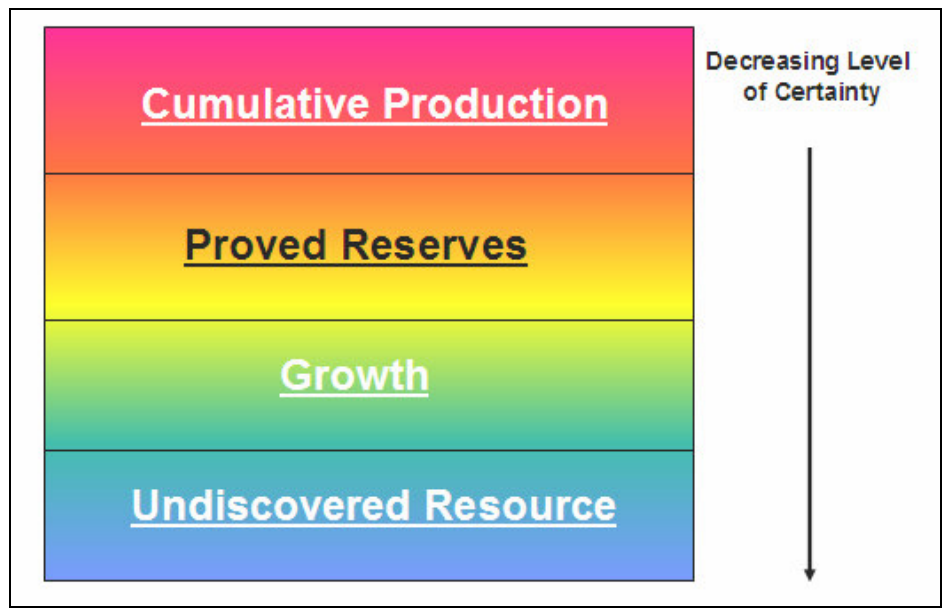

Fig. 1.2: PRISE Resource Categories. The categories are used for completing the reference basin recoverable resource database.

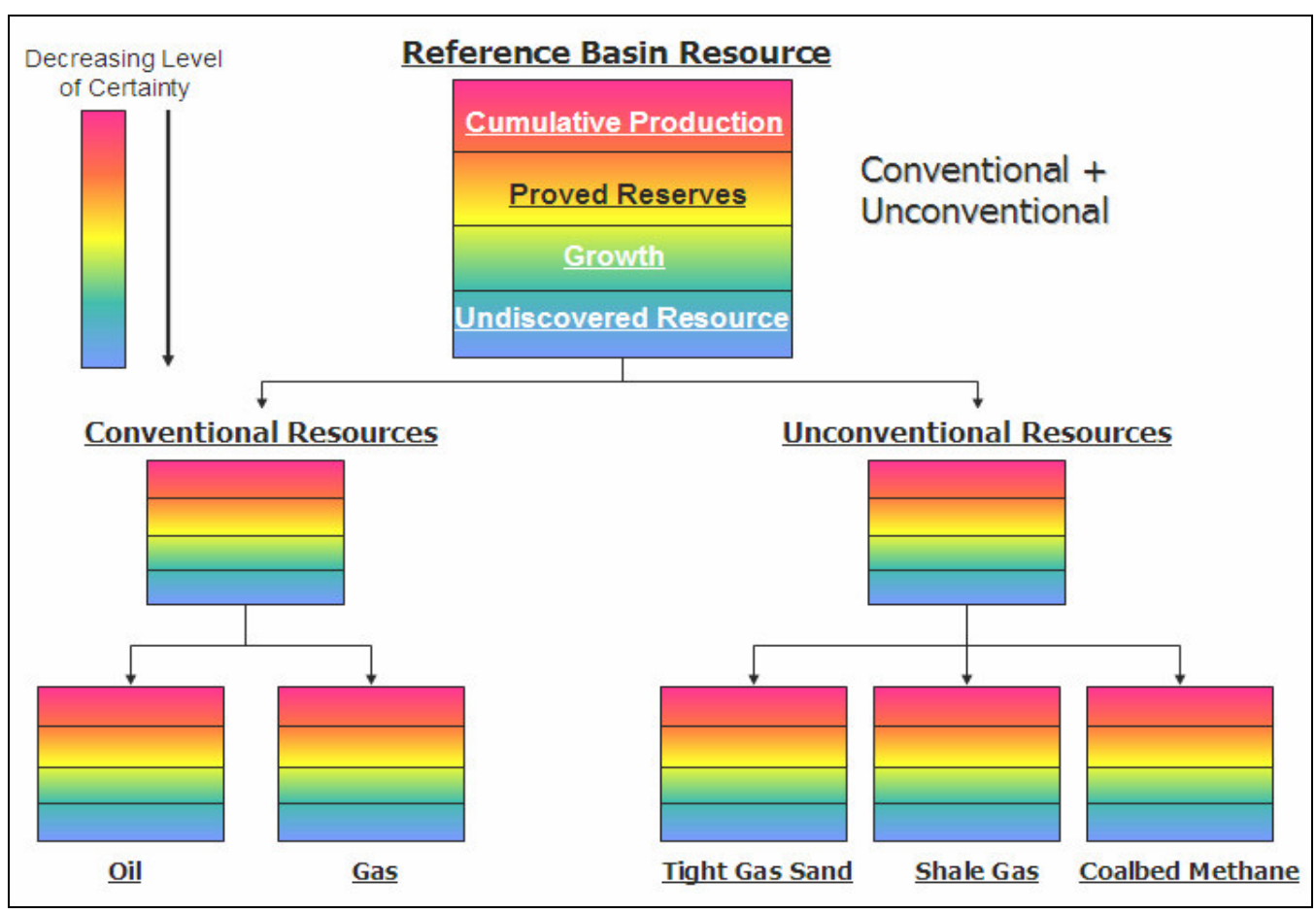

Fig. 1.3: PRISE Resource Tree. This includes the four resource categories and five resource types for the basin. 


\section{CHAPTER II}

\section{OBJECTIVE AND METHODS}

PRISE is an acronym for Petroleum Resource Investigation Summary and Evaluation. The primary objective of developing PRISE was to establish a methodology for estimating unconventional recoverable resources in basins with no, or very little, unconventional resource development or data. A second objective was to create a system the industry can use to better understand the potential of unconventional resources in the target basins around the world. Armed with such estimates and understanding, the industry can better justify its future development activities or, in some cases, change course. For this study, published resource information from the USGS, PGC, NPC, EIA, and GTI were used to quantify recoverable resources in seven North American basins.

PRISE assesses unconventional gas resources by first querying the BASIN database. The user inputs data for all known details for source rocks and reservoirs (Table 1.2), and queries BASIN for North American analogs. Then, the total recoverable resources (TRR) of oil and gas in a target basin are calculated on the basis of resource distribution of conventional and unconventional resource types in the reference basin. Resource calculations are done using two methods; one method uses a mathematical relationship of source rock volume, weight organic content, and thermal maturity; whereas, the second method uses the relationship between conventional and unconventional TRR for each basin. Both methods are discussed in Chapter V. 


\subsection{Resource Triangle Concept}

The concept that hydrocarbon resource types can be assigned to various resource classes that reflects their abundance, the reservoir quality, and the technology required for recovery was proposed by Masters, who used a triangle to represent this concept (Fig.

2.1). ${ }^{3,4}$ To test and quantify the concept of a North American resource triangle for various basins, one must verify the concept and determine whether it can be used to estimate known resources in target basins. The resource triangle theory suggests that resource volumes are log normally distributed in nature, where the apex of the triangle represents the conventional resource volume and the base of the triangle is unconventional resource volume. ${ }^{1,2}$ One of the objectives of the project is to quantify the North American resource triangle at the basin level. To be useful, we clearly defined resource categories to quantify the resource triangle (Fig. 1.2).

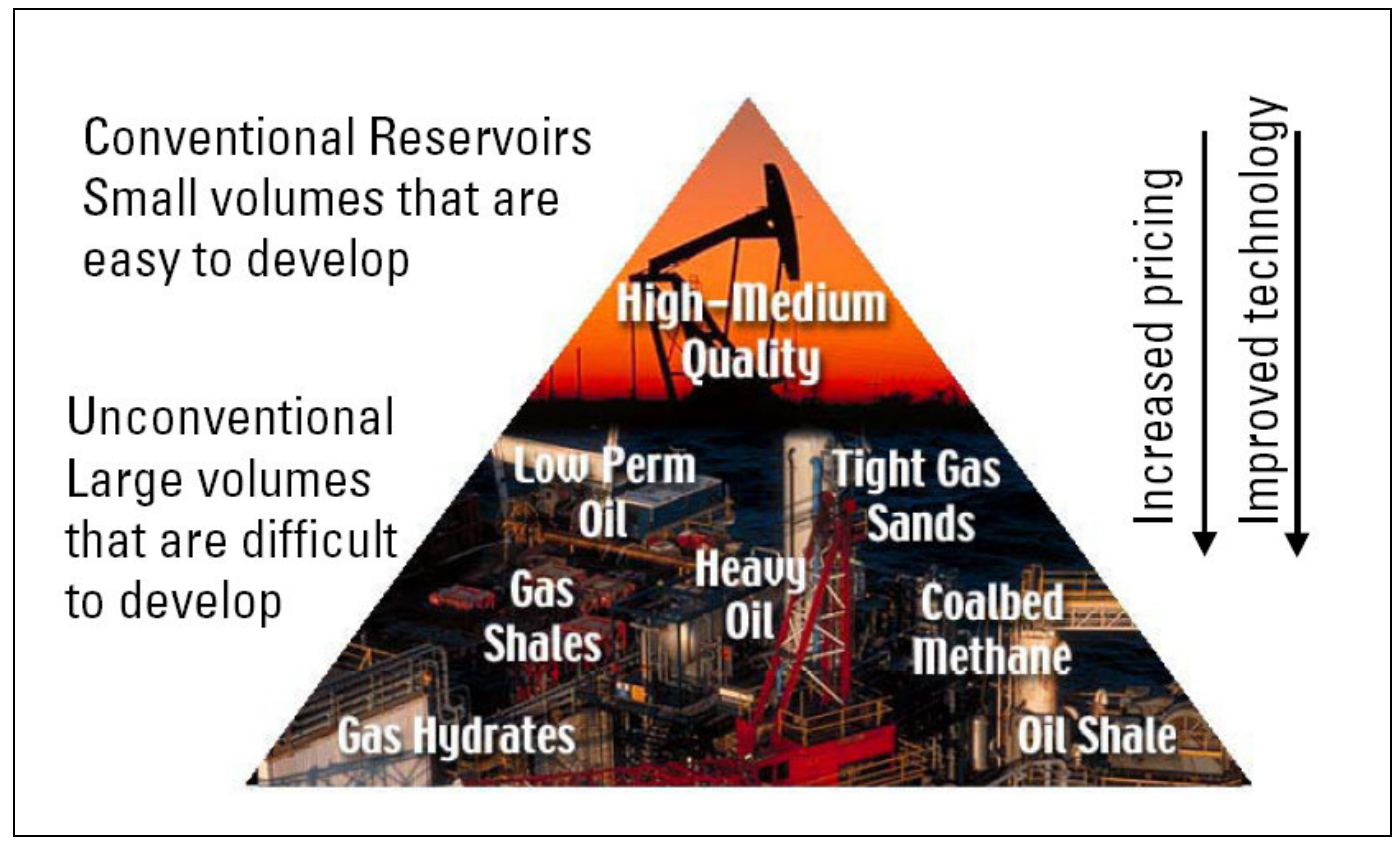

Fig. 2.1: Resource Triangle. From Holditch $2004^{4}$ 
As a first step in this research, we established the resource definitions that we would use to classify the gas resources. We started by evaluating definitions of the NPC, EIA, PGC, USGS, and GTI to find out how resource terms have been used and how each agency presents its resource database. Resource categories used by these agencies differ, and thus we studied of each organizations purpose, considerations, and methodologies. We then established the definitions for each resource category that we use in PRISE.

\subsection{PRISE Idea}

Expert systems or advisors can be developed as software scoping tools to be used by all levels of professionals in the petroleum industry. ${ }^{5}$ The software packages currently being developed by our research group are shown schematically in Fig. 1.1. PRISE is the resource quantification software in the second level of the expert system package and is the part of the overall package that was developed in this research. The software was being designed with several goals in mind. These were to:

1. Develop a useful methodology for resource estimates;

2. Ensure that a minimum level of expertise is required of the user;

3. Provide a navigable software interface; and

4. Give observable, rapid results.

To evaluate the amount of unconventional gas in a target basin, we must first determine if an analogous basin can be found in North America. If the analogous North American basin has quantified volumes of conventional and unconventional resources, we can use the data in the two basins to estimate the TRR in the target basin. So far, we have quantified the volume of gas resources in seven North American basins. We will be 
adding data for other basins in the coming months. We use these estimates to determine the TRR in target basins. Once North American oil and gas resources have been identified and quantified, we can combine the geologic analog from BASIN and use PRISE to develop a realistic unconventional gas resource estimate. 


\section{CHAPTER III}

\section{DEFINING THE RESOURCE TRIANGLE}

To determine the resource triangle layout for PRISE, we had to understand how other agencies defined and categorized their gas resources. Therefore, after outlining the project objectives, we reviewed published resource information from the USGS, PGC, NPC, EIA, and GTI agencies. Each agency routinely evaluates gas resources in North American basins. They achieve their estimates by evaluating known gas resources under specified economic conditions and technology levels. The big problem is that different agencies use different definitions and methodologies to determine gas resource, so comparing resource data between any two agencies can be difficult and time consuming. Curtis and Montgomery ${ }^{6}$ conducted a summary analysis of recoverable natural gas estimates between some of the previously mentioned agencies. Fig. 3.1 illustrates the great variability that exists in unconventional resource estimates. We had to establish where varying levels of confidence lie within the published data. In Fig. 1.2 we defined specific resource categories in order to quantify the resource triangle used for PRISE. 


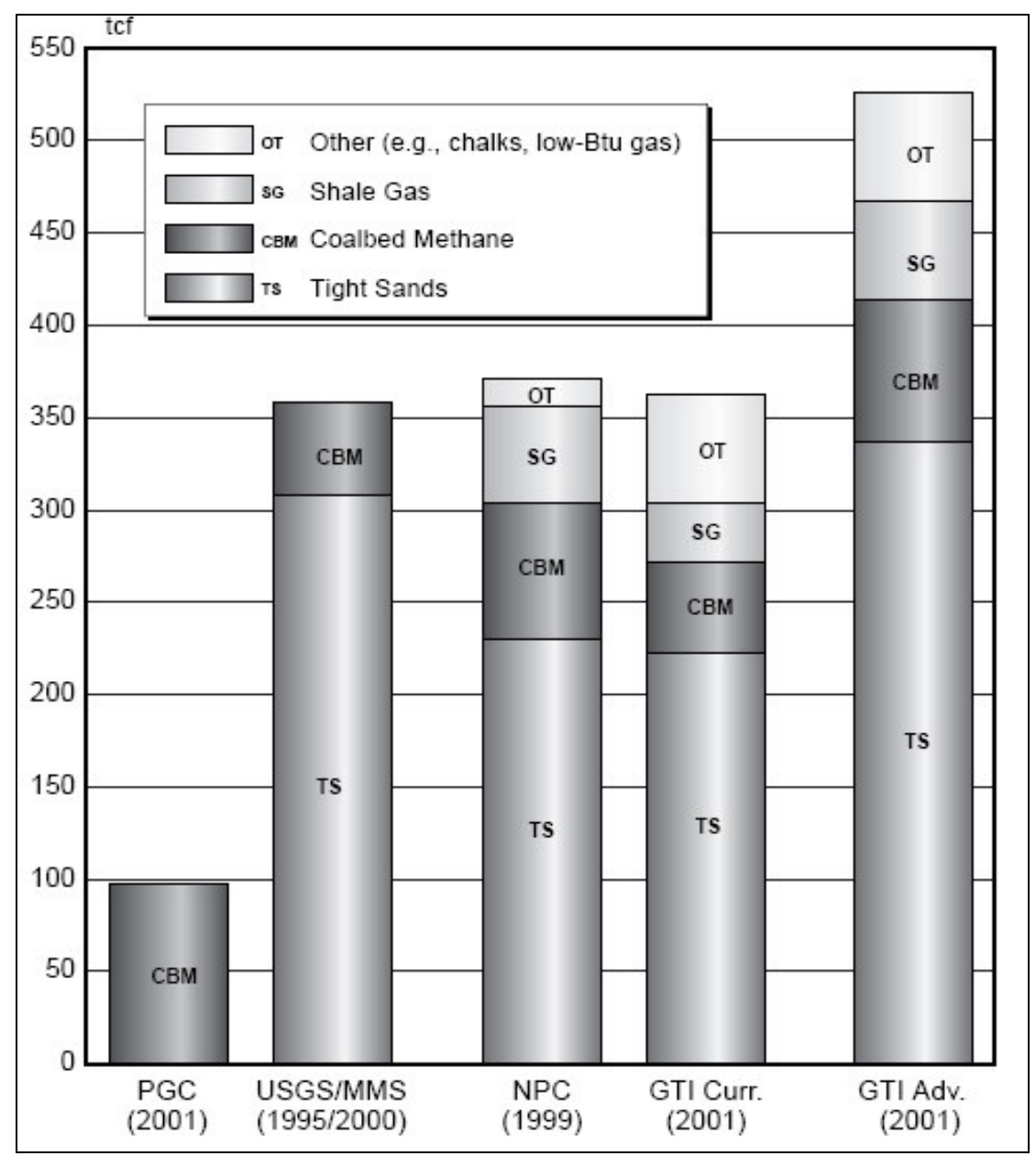

Fig. 3.1: Total Unconventional Gas Potential for Lower 48 United States. Taken from Curtis and Montgomery, $2002^{6}$.

From these data it is clear that there is substantial variability among resource estimates. In their 2001 report, PGC recorded CBM as the only unconventional gas resource, whereas USGS includes CBM and TGS as unconventional gas resources. The NPC and GTI include CBM and TGS, as well as shale gas (SG) and other existing resources. Not only are there differences among the agencies, but there are different resource estimates within the agencies themselves. For example, from Fig. 3.1, GTI gave estimates for two conditions in 2001, one under current technology and the other for improved future technology. ${ }^{6}$ From this summary analysis by Curtis, we decided that we 
must do an in depth study of all agencies definitions of potential gas resources and the methodologies used to determine the resource values, in order to understand why there is such great variability in numbers. In the following sections, we discuss the observed definitions and methodologies used by each agency previously mentioned.

\subsection{Potential Gas Committee}

The PGC produces a report every other year of gas resources in North America. Fig. 3.2 illustrates the PGC categorizes gas resources. The PGC reports explain that potential gas resources are determined to be recoverable under 1) adequate economic incentives and 2) current and foreseeable technology. ${ }^{7}$ The PGC only generates estimates for only three categories of resources: Probable, Possible, Speculative Resources. Those three resource categories and undiscovered gas resources are defined as follows:

- Probable resources: Associated with known fields and are the most assured of potential supplies. Large amounts of geological and engineering information are available for aid in resource estimation. ${ }^{7}$

- Possible resources: Exist outside known fields, but they are associated with a productive formation in a productive province. Projection of plays of a producing formation into a less well-explored area. ${ }^{7}$

- Speculative resources: Expected to be found in formations or geologic provinces that have not yet proven productive. ${ }^{7}$ 
- Unconventional gas resource: Gas present in low-permeability gas reservoirs with matrix permeability generally less than 0.1 millidarcy. ${ }^{7}$ Includes sandstones, siltstones, coal beds, and shales. ${ }^{7}$

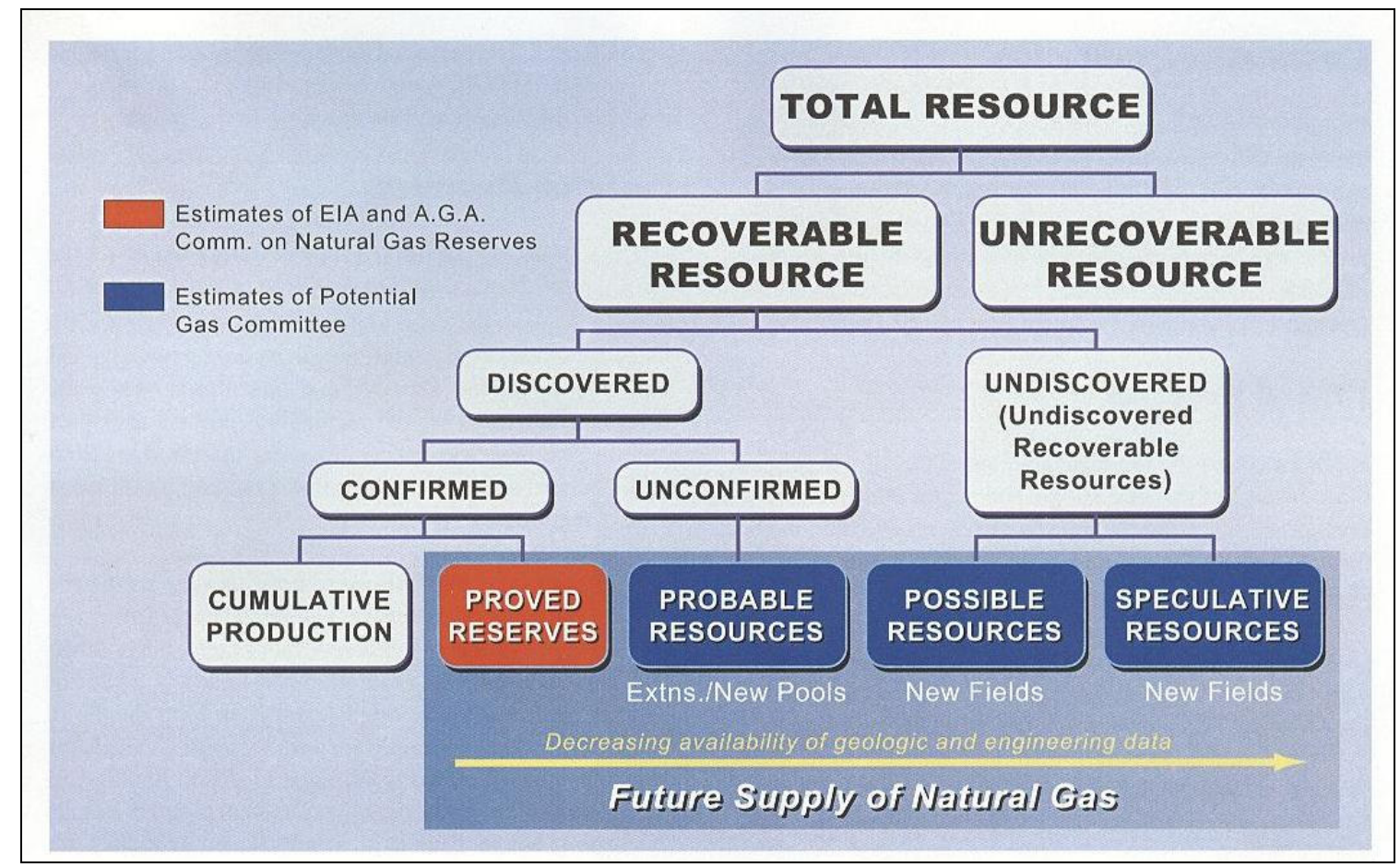

Fig. 3.2: PGC Resource Classification and Organization. ${ }^{7}$

From the PGC 2006 report $^{7}$ and Curtis and Montgomery ${ }^{6}$, the PGC does not separately report information for unconventional resources other than coalbed methane. In their reports, the PGC has used three categories for publishing potential gas resources: (1) traditional gas resources; (2) coalbed gas resources; (3) and total gas resources, which are a combination of 1 and 2. The PGC does, however, recognize coalbed methane, shale gas, and tight gas as unconventional resources in the 2006 report. $^{7}$ 
Traditional resources include all conventional gas, tight gas, and shale gas. ${ }^{7}$ Coalbed methane is reported separately because it cannot be completed using 'traditional' methods. $^{7}$

\subsection{National Petroleum Council}

The NPC also divides gas resources into different categories. NPC defines potential gas resources as follows:

- Technical resource: That quantity of gas recoverable with current technology without regard to the economics of doing so. ${ }^{8,9}$

- Undiscovered resource: The total volume of natural gas expected to be found in the future that is not due to growth of existing fields. It assumes current technology and is not necessarily economic. Undiscovered resource is sometimes termed new field or yet-to-find.,

- Proved reserves: Reserves that have a high confidence of being produced, and by implication, they are already economic., ${ }^{8,9}$

- Growth: The estimated technical resource remaining in a field above the current estimate of proved reserves. ${ }^{8,9}$

- Remaining technical resource: Include proved reserves, proved growth, and undiscovered, or yet-to-be-found, resources. ${ }^{8,9}$

- Non-conventional Gas Resources: Cover large areas, have no identifiable hydrocarbon water contact, low permeability, in close proximity to self sourcing reservoirs or source rocks, and are often abnormally pressured. ${ }^{8,9}$ 
NPC does use a definition system that can be described like that of the PGC. The NPC divides Total Technical Resource in two major groups: discovered and undiscovered, which can be further divided into proved reserves and growth, and undiscovered conventional and undiscovered non-conventional resources, respectively. The NPC includes coalbed methane, shale gas, and basin centered gas as nonconventional resources. ${ }^{8,9}$ The NPC classifications have some disadvantages for use because in the future they no longer will produce regular resource assessments, only at the request of the Secretary of Energy. ${ }^{5}$

\subsection{Gas Technology Institute}

The GTI had a resource evaluation group that was disbanded after the 2001 Baseline Projection and Evaluation. ${ }^{5,10}$ The following are the definitions used by GTI in their last report:

- Undiscovered: The amount of resource that may potentially be discovered with economic and technological advances. ${ }^{10}$

- Resource: Total amount of gas in place; may not be recoverable. ${ }^{10}$

- Unconventional Resources: Include tight gas sands, shale gas, and coalbed methane. $^{10-12}$

It is unknown whether GTI considered undiscovered resources a part of the recoverable category or not. Also, GTI considered potential resource as the total amount of gas in place, regardless of recoverability, whereas the PGC and NPC consider all potential resource as only the resources that are considered recoverable..$^{7-10}$ 


\subsection{United States Geological Survey}

The USGS does not evaluate North American resources on a regular basis. Instead USGS only evaluates basins of great interest to the oil and gas industry. This type of approach is good for providing information in basins with active development. 5 , ${ }^{13}$ This approach, however, may provide some pitfalls for the purposes of PRISE. PRISE will need resource data for every North American basin not just basins that USGS is currently evaluating. If we need resource data for a basin that is not being evaluated by the USGS, then data may be outdated. USGS does not describe unconventional resources as such; they refer to them as 'continuous resources'. USGS defines resources as follows:

- Recoverable resources: Able to be produced using conventional recovery technologies, without regard to present economic viability. Therefore, only part of the USGS undiscovered recoverable is economically recoverable now. ${ }^{13}$

- Undiscovered: The amount of resource outside of known fields. ${ }^{13}$

- Continuous Resource: 1) Consist of large volumes of rock pervasively charged with oil or gas, 2) They do not depend on the buoyancy of oil and gas in water for their existence. ${ }^{13}$ Continuous resource include coalbed methane, tight gas, basin-centered gas, oil and gas in fractured shale and chalk, gas hydrates, and shallow biogenic gas. ${ }^{13}$

The USGS assesses only technically recoverable resources with the expectations that they may be added to the reserve base with time. Undiscovered resources are determined through a system of testing cells (specific areas within the basin). The 
categories of cells tested are: (1) cells already tested by drilling; (2) untested cells; and (3) untested cells having potential to contribute to reserves in the time period of the forecast. $^{13}$

\subsection{Energy Information Agency}

Although the EIA was not mentioned in Curtis and Montgomery's ${ }^{5}$ study, it is an agency that must be included in this comparison. The EIA provides energy statistics for the U.S. Department of Energy. Fig. 3.3 illustrates the resource classification of the EIA. The total resource base, defined below, is divided into recoverable and non-recoverable resources. Recoverable resources are evaluated for potential and are further divided as seen in Fig. 3.3. The definitions of the resources are as follows:

- Total Resource: The total resource base of oil and gas is the entire volume formed and trapped in-place within the Earth before any production. $(\text { recoverable and non-recoverable })^{14}$

- Recoverable Resources: Of societal and economic interest. ${ }^{14}$

- Recoverable Discovered Resource: Economically recoverable quantities of oil and gas for which specific locations are known. They consist of cumulative production and proved reserves. ${ }^{14}$

- Recoverable Undiscovered Resource: Are not yet known, they are believed to exist in geologically favorable settings. USGS undiscovered data and methodology are used by the EIA. ${ }^{14}$ 


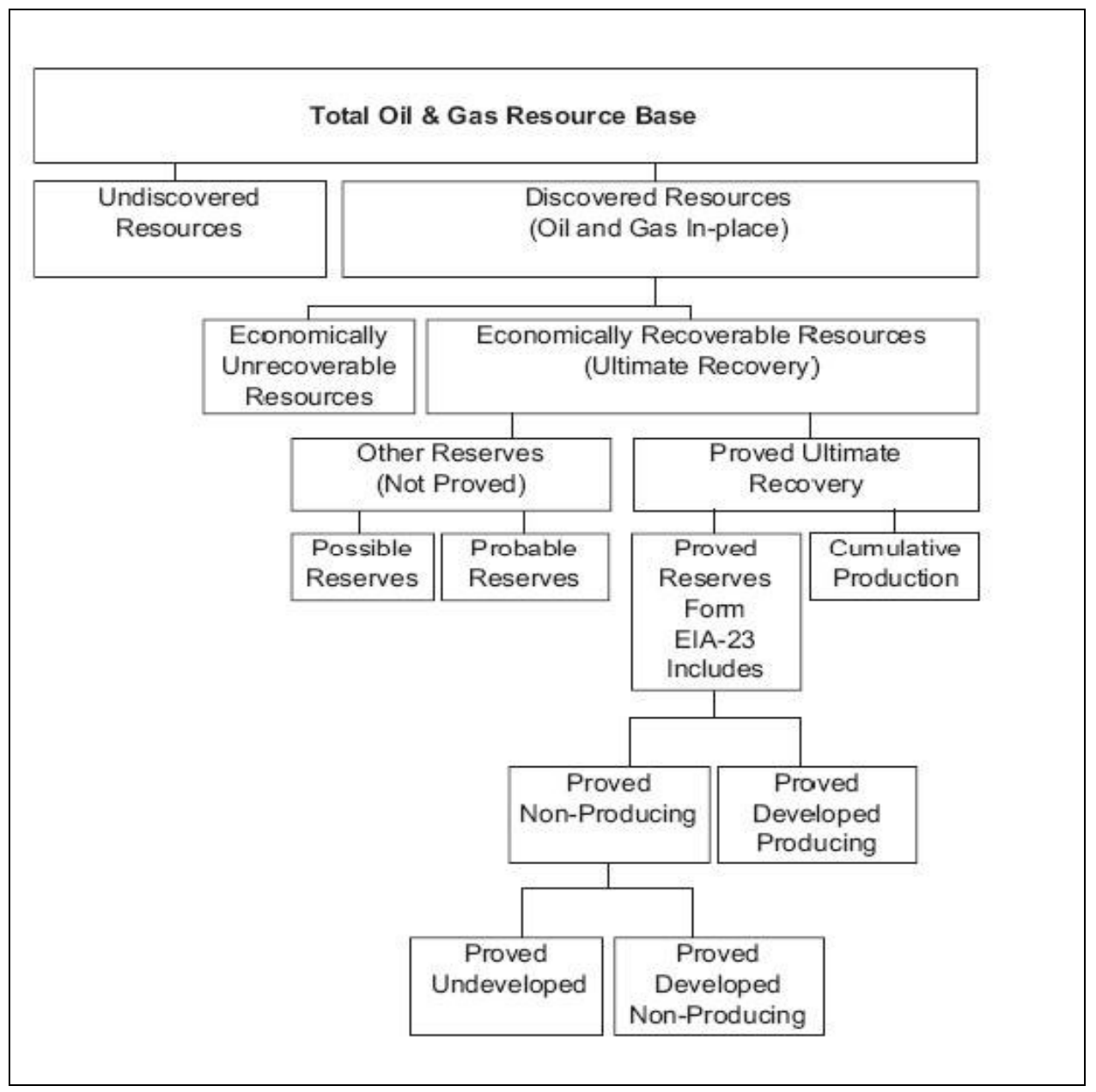

Fig. 3.3: EIA Resource Classification and Organization. ${ }^{14}$

The EIA publishes technically recoverable resource data from two agencies, USGS and MMS. ${ }^{14}$ The EIA considers resources of value to be economically recoverable, and only a percentage of technically recoverable resources are economically recoverable at the current time. ${ }^{14}$ Since EIA publishes technically recoverable resources data from the USGS, we assume that the considerations for unconventional resources are in line with the USGS continuous resources. 


\subsection{PRISE Definitions}

The large variability in resource terminology and definitions led us to assess the agency information for clarification. We conducted a "mapping" project of all of the agencies to see how or if they could be linked to one another. The concept of the "mapping" project came from the SPE 2005 reserves mapping project conducted by the

Oil and Gas Reserves Committee (OGRC). ${ }^{15}, 16$ The SPE project compared all reserves and resource definitions of several international data organizations, including USGS. ${ }^{15,16}$ To start the "mapping" project, we began at the foundation of each agency to determine their organization purpose, considerations for resource assessments, and data sources for resource assessments. $^{7-14,17}$ Table 3.1 states this information in summary. Table 3.2 states each agencies definition for the assigned resource category terminology used in PRISE. 
Table 3.1: Agency Purpose, Data Sources, and Considerations. ${ }^{7-14,17}$

\begin{tabular}{|c|c|c|c|}
\hline Organization & Purpose & Data Sources & Considerations \\
\hline $\begin{array}{l}\text { PGC } \\
(2006)\end{array}$ & $\begin{array}{c}\text { Independent Study by Industry } \\
\text { To provide estimates, based on expert } \\
\text { knowledge, of the potential supply of natural } \\
\text { gas, which, together with estimates of proved } \\
\text { reserves of natural gas, make possible an } \\
\text { appraisal of the nation's long-range gas } \\
\text { supply. }\end{array}$ & $\begin{array}{l}\text { Production Data: IHS } \\
\text { Proved Reserves: EIA } \\
\text { Resource Data: In } \\
\text { house; PGC, PGA, } \\
\text { CSM, \& Industry }\end{array}$ & $\begin{array}{l}\text { Potential gas resources can be } \\
\text { recovered by future drilling under } \\
\text { conditions of: } \\
\text { 1.adequate economic incentives in } \\
\text { terms of price/cost relationships } \\
\text { 2. current and foreseeable } \\
\text { technology }\end{array}$ \\
\hline $\begin{array}{l}\text { NPC } \\
(2007)\end{array}$ & $\begin{array}{c}\text { By request of the Secretary of Energy } \\
\text { Purpose is to provide advice to the federal } \\
\text { government. More specifically aid in } \\
\text { determining future energy supply and } \\
\text { demand, energy growth to meet demands, } \\
\text { and recommendations to US government to } \\
\text { ensure greater economic stability with the oil } \\
\text { and gas supply. }\end{array}$ & $\begin{array}{l}\text { Production Data: IHS, } \\
\text { EIA, NRG } \\
\text { Proved Reserves: EIA } \\
\text { Resource Data: USGS } \\
\text { (US onshore), IHS } \\
\text { (Mexico), CGPC } \\
\text { (Canada), MMS (US } \\
\text { offshore) }\end{array}$ & \begin{tabular}{|} 
Undiscovered gas resources are \\
based on an extension of discovered \\
resource fields operating under \\
current technology. \\
Reserves growth is determined by \\
modeling trends of EUR by field \\
discovery age, number and age of \\
completions. These trends are \\
extrapolated until an EL is reached.
\end{tabular} \\
\hline $\begin{array}{c}\text { EIA } \\
(2007)\end{array}$ & $\begin{array}{c}\text { By request of the DOE } \\
\text { EIA is the only source of comprehensive } \\
\text { domestic proved reserves estimates. Used by } \\
\text { Congress, Federal and state agencies, } \\
\text { industry, and other interested parties to obtain } \\
\text { accurate estimates of the Nation's proved } \\
\text { reserves of crude oil, natural gas, and natural } \\
\text { gas liquids. }\end{array}$ & $\begin{array}{l}\text { Production Data: IHS } \\
\text { Proved Reserves: } \\
\text { Proprietary US DOE } \\
\text { data } \\
\text { Resource Data: USGS } \\
\text { (US onshore) \& MMS } \\
\text { (US offshore) }\end{array}$ & \begin{tabular}{|} 
Reserves: Economically recoverable \\
Undiscovered resources: technically \\
recoverable (compile USGS and \\
MMS data)
\end{tabular} \\
\hline $\begin{array}{l}\text { USGS } \\
\text { (2006) }\end{array}$ & $\begin{array}{l}\text { By request of the DOI } \\
\text { The main objective of the NOGA Project is to } \\
\text { assess the potential for undiscovered oil and } \\
\text { natural gas resources of the onshore US. To } \\
\text { assess the natural gas endowment and the } \\
\text { reserve growth potential of the US, exclusive } \\
\text { of Federal waters (assessed my MMS) }\end{array}$ & $\begin{array}{l}\text { Production Data: IHS \& } \\
\text { NRG Associates } \\
\text { Proved Reserves: IHS } \\
\text { \& NRG Associates } \\
\text { Resource Data: Own } \\
\text { assessment }\end{array}$ & $\begin{array}{l}\text { Undiscovered resources are an } \\
\text { estimate based on the evaluation of } \\
\text { what is considered to be technically } \\
\text { recoverable under current or } \\
\text { foreseeable technology. }\end{array}$ \\
\hline $\begin{array}{l}\text { GTI } \\
(2001)\end{array}$ & \begin{tabular}{|l} 
To Develop a database of basin and formation \\
level historical gas statistics for publication
\end{tabular} & $\begin{array}{l}\text { Production Data: IHS \& } \\
\text { all state agencies } \\
\text { Proved Reserves: State } \\
\text { agencies }\end{array}$ & $\begin{array}{c}\text { Compilation of state agency and IHS } \\
\text { data }\end{array}$ \\
\hline
\end{tabular}


Table 3.2: Summary of Agency Resource Definitions for Assigned PRISE Resource Categories. $^{7-14}$

\begin{tabular}{|c|c|c|c|}
\hline Organization & Proved Reserves & Growth & Undiscovered Resource \\
\hline $\begin{array}{l}\text { PGC } \\
(2006)\end{array}$ & $\begin{array}{l}\text { The quantities of petroleum } \\
\text { which, by analysis of geological } \\
\text { and engineering data, can be } \\
\text { estimated with reasonable } \\
\text { certainty to be commercially } \\
\text { recoverable, from a given date } \\
\text { forward, from known reservoirs } \\
\text { and under current economic } \\
\text { conditions, operating methods, } \\
\text { and government regulations. }\end{array}$ & $\begin{array}{l}\text { Associated with known fields } \\
\text { and are the most assured of } \\
\text { potential supplies. Large } \\
\text { amounts of geological and } \\
\text { engineering information are } \\
\text { available for aid in resource } \\
\text { estimation. }\end{array}$ & \begin{tabular}{|l} 
Exist outside known fields, but they are \\
associated with a productive formation \\
in a productive province. Projection of \\
plays of a producing formation into a \\
less well-explored area. Expected to be \\
found in formations or geologic \\
provinces that have not yet proven \\
productive. Geologic analogs are \\
developed in order to ensure \\
reasonable evaluation of these \\
unknown quantities.
\end{tabular} \\
\hline $\begin{array}{l}\text { NPC } \\
(2003)\end{array}$ & $\begin{array}{l}\text { Reserves that have a high } \\
\text { confidence of being produced, } \\
\text { and by implication, they are } \\
\text { already economic }\end{array}$ & $\begin{array}{l}\text { The estimated technical } \\
\text { resource remaining in a field } \\
\text { above the current estimate of } \\
\text { proved reserves. }\end{array}$ & \begin{tabular}{|} 
The total volume of natural gas \\
expected to be found in the future that is \\
not due to growth of existing fields. It \\
assumes current technology and is not \\
necessarily economic. Undiscovered \\
resource is sometimes termed new field \\
or yet-to-find
\end{tabular} \\
\hline $\begin{array}{c}\text { EIA } \\
(2007)\end{array}$ & \begin{tabular}{|c||} 
The volumes of oil and gas that \\
geological and engineering data \\
demonstrate with reasonable \\
certainty to be recoverable in \\
future yeas from known \\
reservoirs under existing \\
economic and operating \\
conditions.
\end{tabular} & $\begin{array}{c}\text { Ultimate Recovery Appreciation } \\
\text { (Take from USGS) }\end{array}$ & $\begin{array}{l}\text { Undiscovered Resource } \\
\text { (Take from USGS) }\end{array}$ \\
\hline $\begin{array}{l}\text { USGS } \\
(2006)\end{array}$ & $\begin{array}{l}\text { The volumes of oil and gas that } \\
\text { geological and engineering data } \\
\text { demonstrate with reasonable } \\
\text { certainty to be recoverable in } \\
\text { future yeas from known } \\
\text { reservoirs under existing } \\
\text { economic and operating } \\
\text { conditions. }\end{array}$ & \begin{tabular}{|c||} 
Identified economically \\
recoverable resource, over both \\
measured and indicated \\
reserves that will be added to \\
proved reserves in the future \\
through extensions, revisions, \\
and the discovery of new pay \\
zones. Resources added to \\
known fields as they are further \\
developed and produced.
\end{tabular} & $\begin{array}{l}\text { The total volume of oil or natural gas } \\
\text { expected to be found in the future that is } \\
\text { not due to growth of existing fields. } \\
\text { Undiscovered resource is sometimes } \\
\text { termed new field or yet-to-find. }\end{array}$ \\
\hline $\begin{array}{c}\text { GTI } \\
(2001)\end{array}$ & $\begin{array}{c}\text { Defined by what operators report } \\
\text { to state agencies. }\end{array}$ & \begin{tabular}{|l||} 
The amount of resource that is \\
considered economically and \\
technically recoverable in the \\
foreseeable future. (Generally \\
use NPC, PGC, and USGS \\
recoverable estimates)
\end{tabular} & $\begin{array}{l}\text { Oil and gas that exists outside of known } \\
\text { fields and is not considered economic or } \\
\text { recoverable in the foreseeable future }\end{array}$ \\
\hline
\end{tabular}


We observed that some agencies use other agencies data as a starting point for their own resource assessments. Based on similarities in language used for descriptions, we felt confident that all agencies could be "mapped" to one another, allowing us to have more data for resource quantification. Fig. 3.4 illustrates each agencies terminology, data sources, and how the resource categories of each agency correlate to each other. In Fig. 3.4, the arrows point to the agency using the other agencies information and resource category equivalents. PGC equates probable resource and the sum of possible and speculative to EIA's ultimate recovery appreciation and undiscovered resources, respectively. PGC also equates them with NPC's growth and undiscovered resources, respectively. Because both the EIA and NPC use the USGS data for these categories then, by proxy, PGC probable resource and the sum of possible and speculative resources can be equated to USGS reserves growth and undiscovered resource.

PGC states in the 2006 report that their estimates for unconventional gas estimates are equal to the continuous type resources reported by the EIA. ${ }^{7}$ Since EIA uses USGS continuous resource estimates for undiscovered resource, and then we can essentially equate PGC unconventional resources with USGS continuous resources.

From the summary of data sources in Table 3.1 and Fig. 3.4, the PRISE data sources were selected. The terms cumulative production, proved reserves, growth, and undiscovered resource were chosen for PRISE because we believe that they are the most universal. We did not want to limit our data to one source, if possible, so we created our own definitions that would allow us to use data from any of the primary data sources 
(Table 3.3 and Fig. 3.5). Growth and undiscovered resources for PRISE quantification come from the USGS, PGC, and NPC. Proved reserves come from the EIA and the USGS, when available; otherwise, they come from state agencies. Production comes from the HPDI database. The definitions of growth and undiscovered resource are a combination of NPC, USGS, and PGC values (Table 3.3). In 2006, EIA adopted the SPE definition of proved reserves ${ }^{14}$ so we use the SPE definition of proved reserves because we are using reserves information from EIA, when available.

Table 3.3: PRISE Resource Category Definitions. ${ }^{7-13}$

\begin{tabular}{|c|c|c|c|}
\hline Organization & Proved Reserves & Growth & Undiscovered Resource \\
\hline PRISE & $\begin{array}{l}\text { The quantities of petroleum which, by } \\
\text { analysis of geological and engineering } \\
\text { data, can be estimated with reasonable } \\
\text { certainty to be commercially } \\
\text { recoverable, from a given date forward, } \\
\text { from known reservoirs and under } \\
\text { current economic conditions, operating } \\
\text { methods, and government regulations. } \\
\text { If probabilistic methods are used, there } \\
\text { should be at least a } 90 \% \text { probability } \\
\text { that the quantities actually recovered } \\
\text { will equal or exceed the estimate. } \\
\text { Adopt from SPE }\end{array}$ & $\begin{array}{l}\text { The amount petroleum that is } \\
\text { associated with known fields } \\
\text { and reservoirs that could be } \\
\text { recovered under current } \\
\text { technology and economic } \\
\text { conditions through thorough } \\
\text { geologic and engineering } \\
\text { analysis (including analogs) } \\
\text { but have not yet been } \\
\text { developed. } \\
\text { Combination of USGS, PGC, } \\
\text { and NPC }\end{array}$ & $\begin{array}{c}\text { The amount of petroleum } \\
\text { expected to be found outside } \\
\text { known fields or reservoirs that } \\
\text { could be recovered under current } \\
\text { or foreseeable technology. This } \\
\text { may or may not be economical at } \\
\text { current economic conditions, but } \\
\text { may become economic in the } \\
\text { future. } \\
\text { Combination of USGS, PGC, and } \\
N P C^{6,78,10}\end{array}$ \\
\hline
\end{tabular}




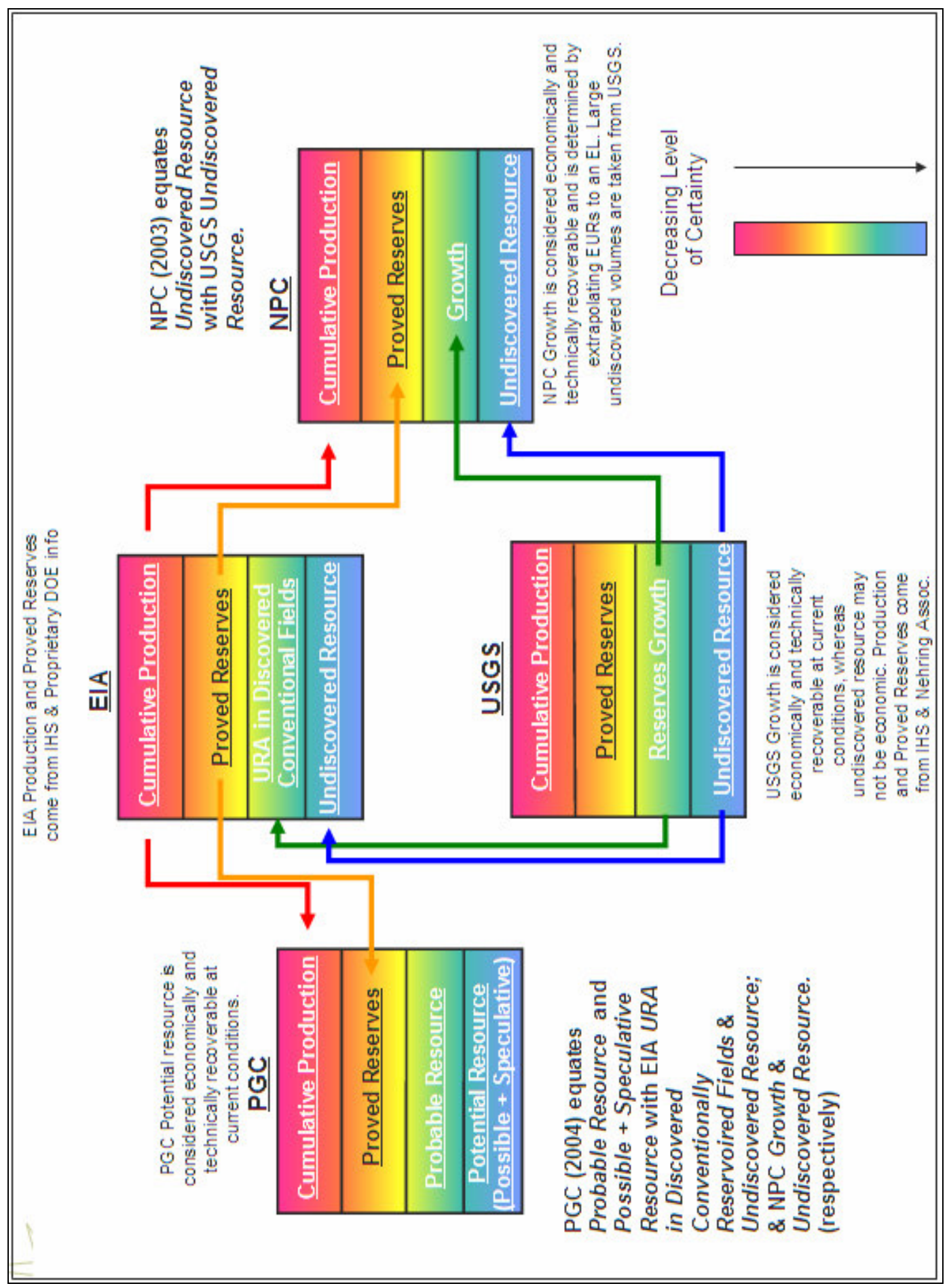

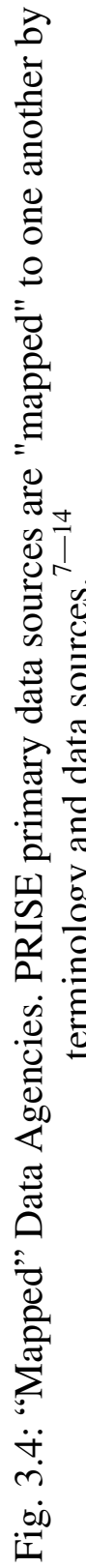




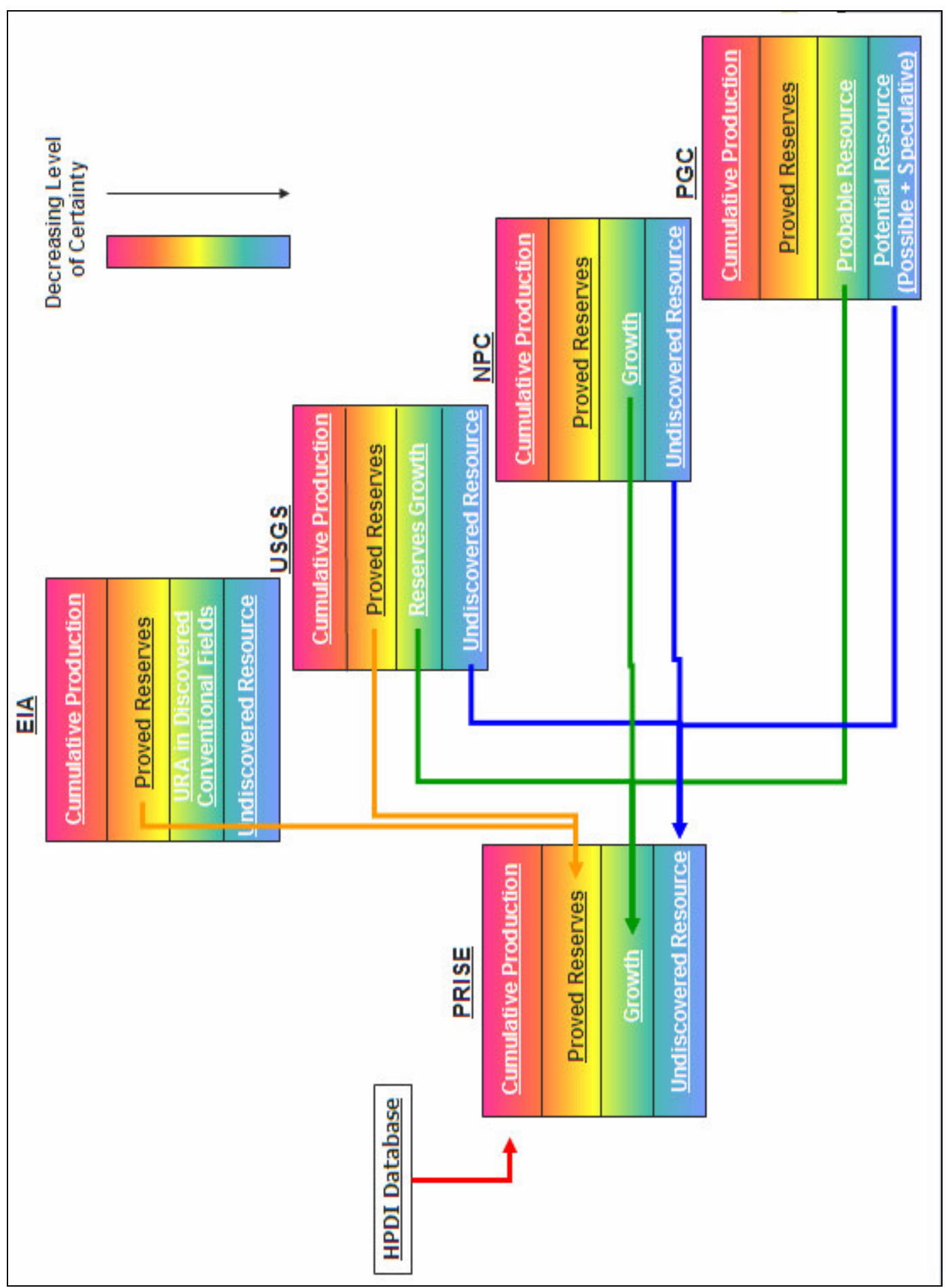

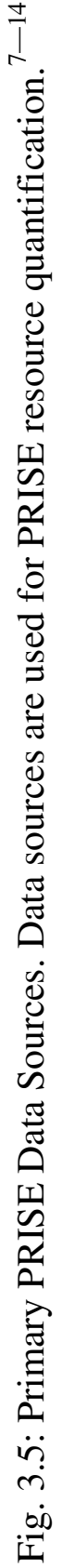


Because we use the SPE definition of proved reserves and we used their concept of resource definition "mapping," we "mapped" PRISE resource categories to SPE resource categories (Fig. 3.6). PRISE cumulative production and proved reserves are equivalent to SPE cumulative production and the proved section, $1 \mathrm{P}$, of reserves. PRISE growth is equal to probable and possible, $2 \mathrm{P}$ and $3 \mathrm{P}$ less $1 \mathrm{P}$, reserves. The undiscovered resource category is equal to the SPE prospective resources. At this time, we are considering the SPE contingent resources to undiscovered resources for the PRISE model. The PRISE growth category is considered economic under current conditions and SPE contingent resources are sub-economic. Therefore, on the basis of economics, contingent resources can be considered undiscovered resources in the PRISE model. All quantified resources used in PRISE are considered technically recoverable, but undiscovered resources may not necessarily be economic under current conditions 


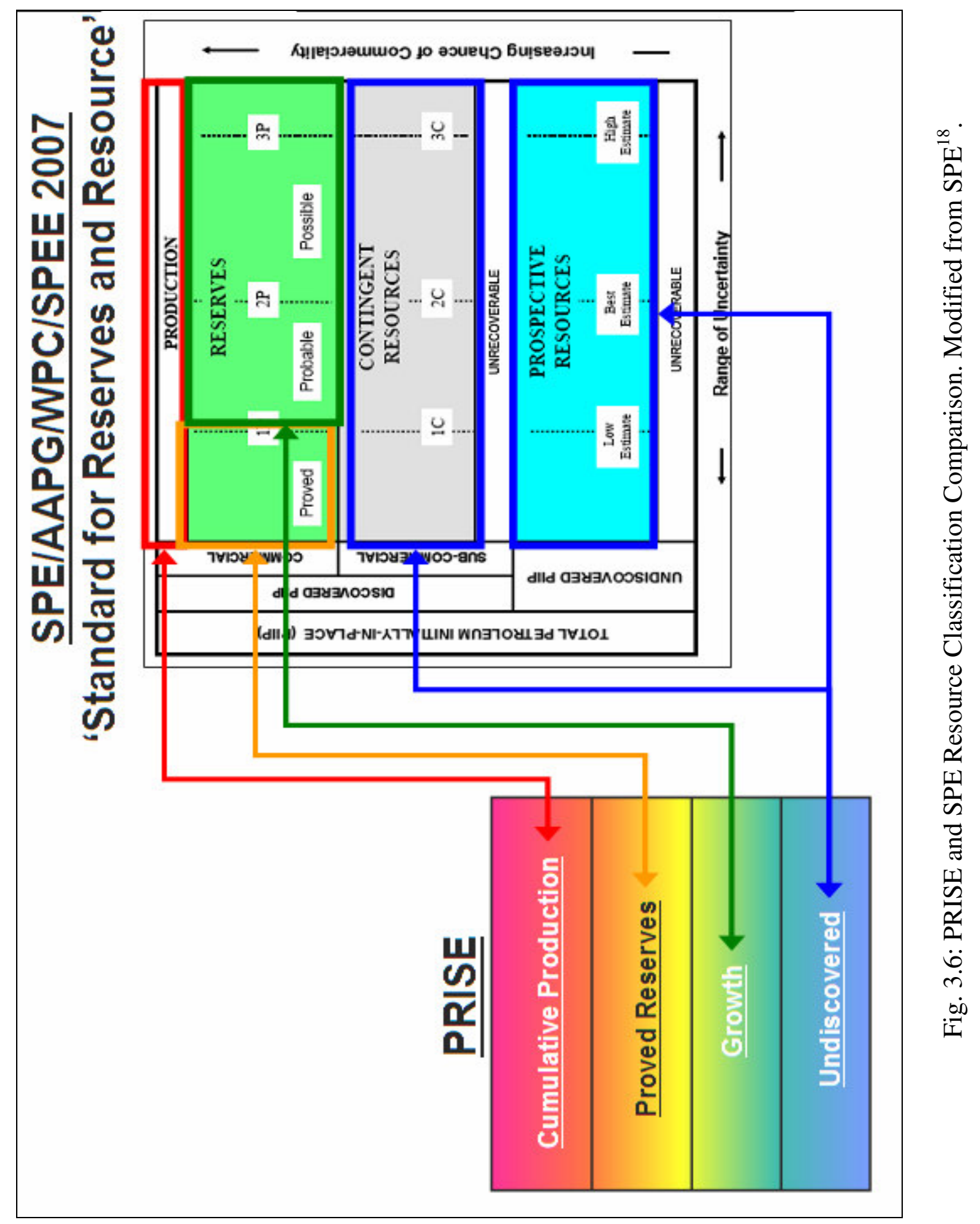


because the undiscovered resource assessments done by USGS are reportedly technically recoverable, but may or may not be economic at the time of the assessment. ${ }^{13}$

In summary, PRISE resource categories are 1) cumulative production, 2) proved reserves, 3) growth, and 4) undiscovered resource. Data for these resource categories will be collected for all five resource types; 1) conventional oil, 2) conventional gas, 3) tight gas sands, 4) coalbed methane, and 5) shale gas. 


\section{CHAPTER IV}

\section{QUANTIFICATION AND VALIDATION OF THE RESOURCE TRIANGLE}

PRISE is set up for basin-scale comparisons using distributions of quantified resources for cumulative production, proved reserves, growth, and undiscovered resource (Fig. 1.2). We quantified the resources for the Appalachian, Black Warrior, Greater Green River, Illinois, San Juan, Uinta-Piceance, and Wind River basins, which are mature basins for both conventional and unconventional gas production. For these seven reference basins, we have quantified the resource triangle, and we are continuing to quantify the triangle for other reference basins. Although the BASIN database divided the Uinta-Piceance basin into two separate basins, we quantified them as one for the PRISE database because the USGS, PGC, and NPC combine them for gas resource assessments. The HPDI database was our source of production data, and proved reserves information came from a combination of EIA, USGS, and state agencies.

\subsection{Agency Assessment Data}

Because we are using USGS, PGC, and NPC as our major data sources for growth and undiscovered resources, we compared the published data from each agency. The three agencies report their data in a variety of statistical terms. For undiscovered

resource, the USGS reports four assessment values; F95, F50, F5, and mean. ${ }^{19,20}$ These values are statistically determined and represent chance of occurrence; F95 is at least a $95 \%$ chance that volume exists, F50 is at least a 50\% chance of existing, F5 is at least a 
$5 \%$ chance of existing. ${ }^{19}$ PGC reports assessments volumes for probable (growth), possible, and speculative (undiscovered) resources. ${ }^{7}$ Minimum, maximum, most likely, and mean values are reported for each resource category. ${ }^{7}$ Again, these values are statistically determined through risk analysis and represent probability of occurrence. PGC states that the minimum resource estimate is "almost $100 \%$ probability that at least that volume will exist," the maximum is "almost $0 \%$ probability that at most that volume will exist," and the most likely value is the statistical mode, or $50 \%$ probability of occurrence. $^{7}$ We presume that the phrase "almost $100 \%$ or $0 \%$ probability of occurrence" can be translated at a $95 \%$ and $5 \%$ probability of occurrence, respectively. ${ }^{7}$ The 2003 NPC does an assessment for a high value, P10, and a low value, P90, where P90 means there is a 90\% chance in that volume existing. ${ }^{8,9}$ The NPC reports also does an assessment for a most likely value. The three values are assessed for growth and undiscovered resources. The most likely estimate is what is reported for growth and undiscovered resources for individual North American basins. ${ }^{8,9}$ All agencies do basin scale analysis. Table 4.1 summarizes the methods that the agencies use for presenting resource assessment volumes. 
Table 4.1: Agency Statistical Data Reporting Process and Descriptions. ${ }^{7-9,13}$

\begin{tabular}{|c|c|c|c|c|c|}
\hline \multicolumn{2}{|c|}{ USGS } & \multicolumn{2}{|c|}{ PGC } & \multicolumn{2}{c|}{ NPC } \\
\hline $\begin{array}{c}\text { Statistical } \\
\text { Data } \\
\text { Presentation }\end{array}$ & Description & $\begin{array}{c}\text { Statistical } \\
\text { Data } \\
\text { Presentation }\end{array}$ & Description & $\begin{array}{c}\text { Statistical } \\
\text { Data } \\
\text { Presentation }\end{array}$ & Description \\
\hline F5 & $\begin{array}{c}5 \% \text { chance that } \\
\text { volume exists }\end{array}$ & P5 & $\begin{array}{c}5 \% \text { probability } \\
\text { occurrence }\end{array}$ & P10 & $\begin{array}{c}10 \% \text { chance that } \\
\text { volume exists }\end{array}$ \\
\hline F50 & $\begin{array}{c}50 \% \text { chance that } \\
\text { volume exists }\end{array}$ & P50 & $\begin{array}{c}50 \% \text { probability } \\
\text { occurrence }\end{array}$ & P50 & $\begin{array}{c}50 \% \text { chance that } \\
\text { volume exists }\end{array}$ \\
\hline F95 & $\begin{array}{c}95 \% \text { chance that } \\
\text { volume exists }\end{array}$ & P95 & $\begin{array}{c}95 \% \text { probability } \\
\text { occurrence }\end{array}$ & P90 & $\begin{array}{c}90 \% \text { chance that } \\
\text { volume exists }\end{array}$ \\
\hline
\end{tabular}

The PRISE values for growth and undiscovered resource are primarily taken from the USGS, PGC, and NPC resource assessments. In some cases, the GTI data were included in the analysis. We "mapped" each resource category and definition to each agency and PRISE, but to use their data, we had to determine a naming convention to account for the statistical distributions of the agencies assessments.

We did not use statistical analysis to determine the range of PRISE resources for quantifying resources of the reference basins, just the actual published data. The naming convention for PRISE is an assigned 'confidence level' for the each resource category. The confidence levels range from $10 \%$ to $100 \%$ for the entire basin TRR and are the confidence we have that at least that cumulative volume will be recovered. Cumulative production is $100 \%$ confidence of recovery, the sum of cumulative production and proved reserves have $90 \%$ confidence of recovery (to keep in line with SPE probability definition of proved reserves). Cumulative production plus proved reserves and growth have $50 \%$ confidence of recovery. The sum of cumulative production, proved reserves, 
growth, and undiscovered resources has $10 \%$ confidence of recovery. The PRISE definitions and naming convention of confidence levels are in Table 4.2.

Table 4.2: PRISE Confidence Definitions

\begin{tabular}{|c|c|}
\hline \multicolumn{2}{|r|}{ PRISE } \\
\hline $\begin{array}{l}\text { Naming Convention for } \\
\text { Resource Quantification }\end{array}$ & Definition \\
\hline C100 & $100 \%$ confidence that volume will be recovered. Cumulative Production \\
\hline C90 & $\begin{array}{l}90 \% \text { confidence that at least that volume will be recovered. Cumulative Production + } \\
\text { Proved Reserves }\end{array}$ \\
\hline C50 & $\begin{array}{l}50 \% \text { confidence that at least that volume will be recovered. Cumulative Production }+ \\
\text { Proved Reserves }+ \text { Growth }\end{array}$ \\
\hline C10 & $\begin{array}{l}10 \% \text { confidence that at least that volume will be recovered. Cumulative Production + } \\
\text { Proved Reserves }+ \text { Growth }+ \text { Undiscovered Resource = Total Recoverable Resource } \\
\text { (TRR) }\end{array}$ \\
\hline
\end{tabular}

The PGC, NPC, and the USGS do not state an overall probability range for the entire resource base as we did for PRISE TRR. Statistical probability distributions have to be done for individual assessments. We assumed the PGC and the USGS to have the same statistical probability ranges for their assessment results (Table 4.1). The PGC and the USGS undiscovered resource assessment probability ranges will be the maximum range for the PRISE 10\% through 50\% confidence (C10-C50) of resource recovery (Fig. 4.1). We used the agency probability ranges from the PGC and the USGS growth resource assessments as the maximum range for the PRISE 50\% through 90\% confidence (C50-C90) of resource recovery (Fig. 4.2).

We equate the PRISE growth category with SPE 2P-3P reserves, which SPE defines by $50 \%$ and $10 \%$ probability of occurrence, respectively. ${ }^{18}$ We are $50 \%$ confident that recovery will be greater than the sum of production, proved reserves, and 
growth. We are $10 \%$ confident that recovery will be greater than the cumulative resource for all four resource categories $(\mathrm{C} 10)$ and is equal to the TRR for the entire basin or corresponding resource type.

The NPC growth and undiscovered resource probability assessment results differ from the USGS and PGC. Fig. 4.3 shows how the NPC assessments results compare to the PRISE confidence range.

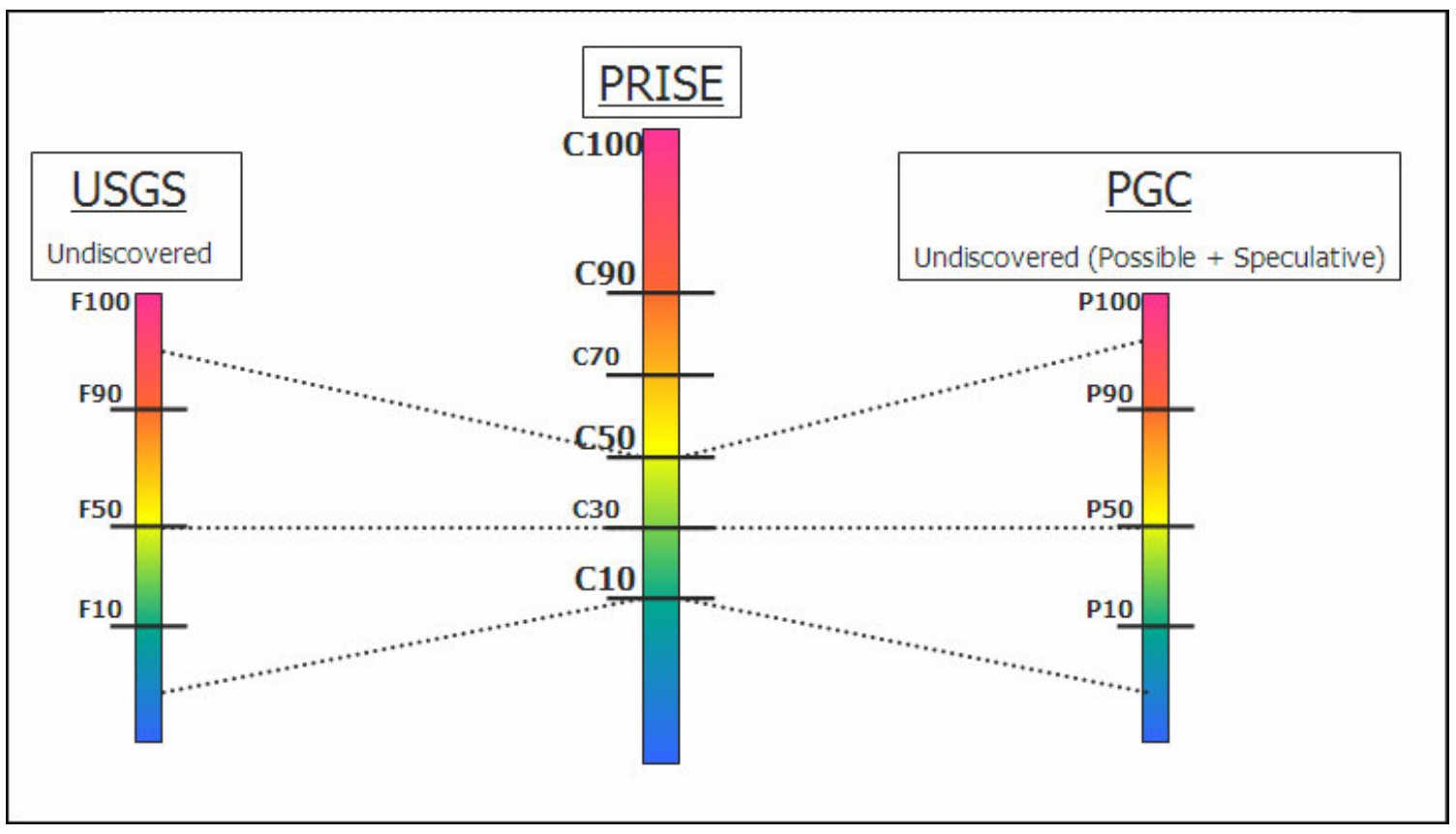

Fig. 4.1: The USGS and PGC Undiscovered Resource Probability Comparison. Assessment probabilities are compared to PRISE technically recoverable resource confidence levels. ${ }^{7,} 19$ 


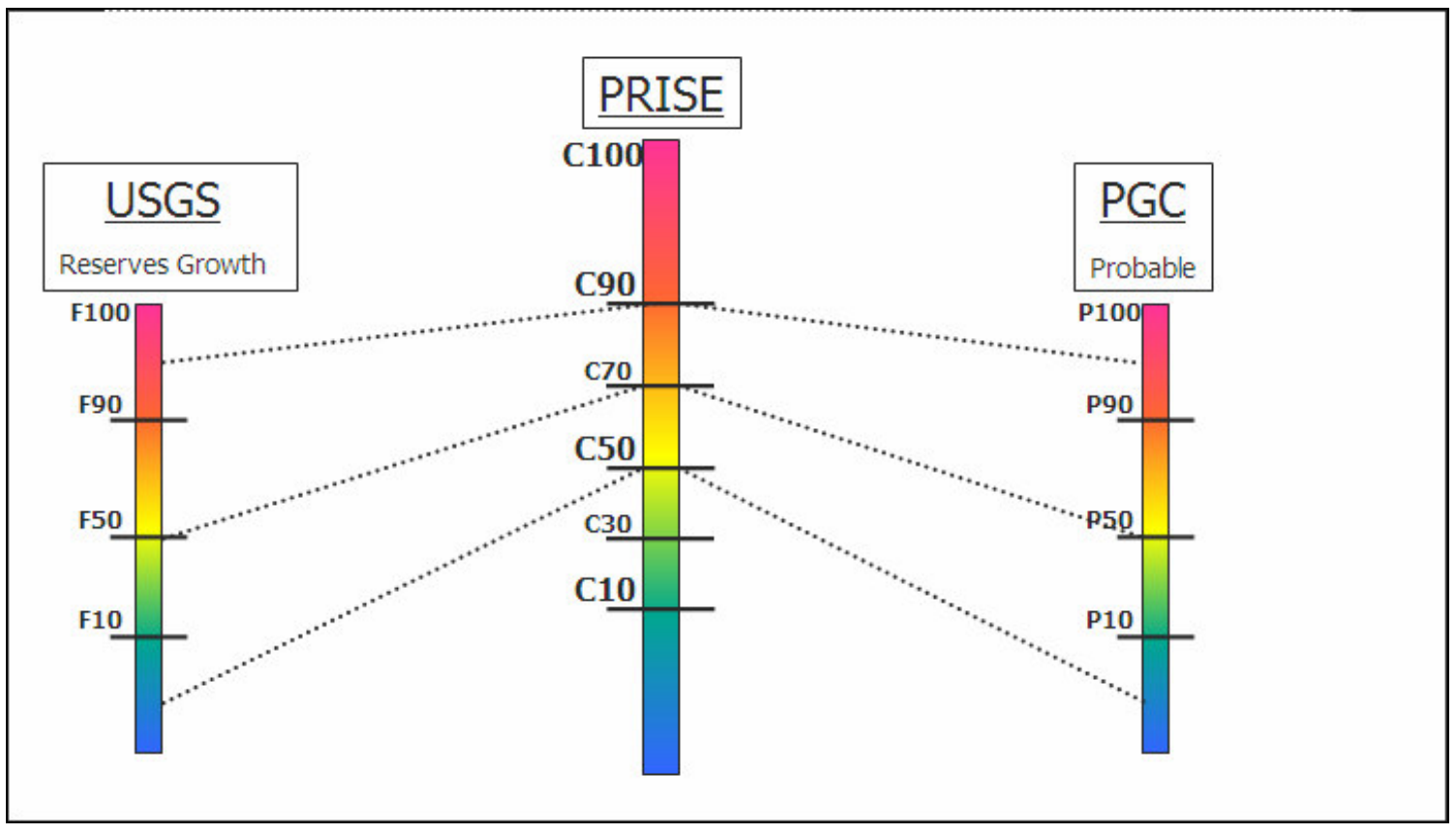

Fig. 4.2: The USGS and PGC Growth Probability Comparison. Assessment probabilities are compared to PRISE recoverable resource confidence levels. ${ }^{7}, 19$

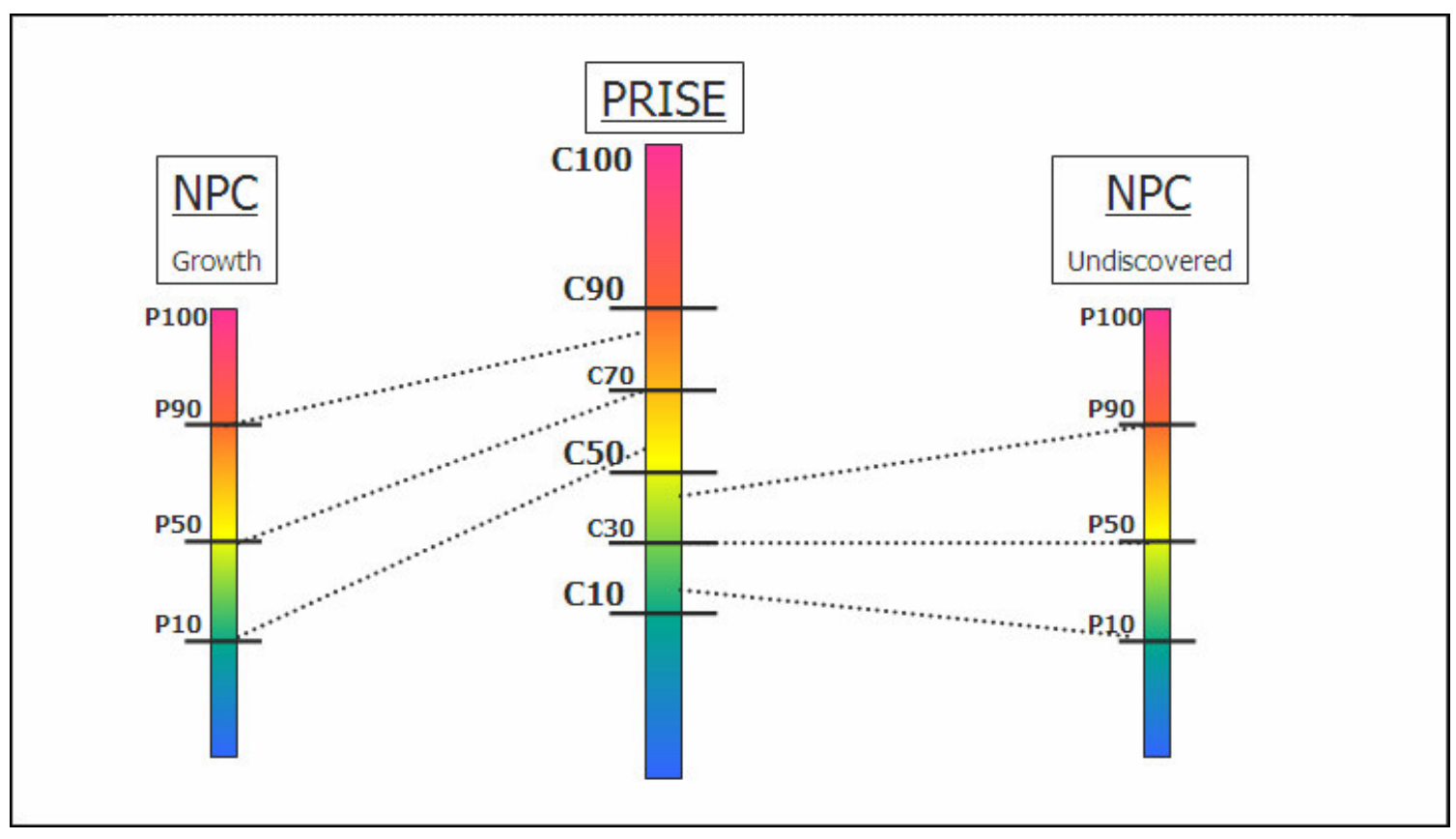

Fig. 4.3: NPC Growth and Undiscovered Resource Probability Comparison. Assessment probabilities are compared to PRISE recoverable resource confidence. ${ }^{8,9}$ 


\subsection{PRISE Quantification Method}

We see no real issues with the science or the policy in assessment methodologies of each agency, but there is a wide range in resource assessments that results from variable approaches of the difference agencies. Table 4.3 is an example of the range of assessment results from selected agencies for coalbed methane in the San Juan basin. The C100 volume in Table 4.3 is cumulative production data from HPDI database. C90 is cumulative production plus proved reserves volumes from EIA. ${ }^{21}$ The C70 volume is equivalent to each agencies most likely estimate of growth plus the C90 volume. The C50 volume is the F95 and P95 estimates for undiscovered resource from the USGS and PGC, respectively, plus the C90 volume. We used C50 volume based on the F95 and P95 estimates for undiscovered resource from both agencies instead of the C50 volume based F5 and P5 estimates for growth(Figs. 4.1 and 4.2). We did this because the C50 volume based on F95 and P95 volumes for undiscovered resource were larger than the estimates for C50 based on the F5 and P5 volumes for growth. Again, this is an example of maximizing the range of resources and uncertainty. The $\mathrm{C} 30$ volume is the most likely estimates for undiscovered resource from the USGS, PGC, and NPC plus the C50 volume. The $\mathrm{C} 10$ volume is the F5 and P5 estimates for undiscovered resource from the USGS and PGC, respectively, plus the C50 volume. With these variations in estimates in mind we had to address two issues: 1) does each agency cover the same geographical area for the basin assessment; and 2) how could we determine which assessment result is the correct choice for us to use in PRISE resource quantification? 
Table 4.3: San Juan Basin Coalbed Methane Agency Data Comparison. ${ }^{7,9,19-21}$

\begin{tabular}{|c|c|c|c|c|c|}
\hline \multicolumn{7}{|c|}{ Coalbed Methane (CBM) Resource, Tcfe } \\
\hline Confidence & $\underline{\text { USGS }}$ & $\underline{\text { NPC }}$ & $\underline{\text { PGC 2002 }}$ & $\underline{\text { PGC 2004 }}$ & $\underline{\text { PGC 2006 }}$ \\
\hline C100 & 14.1 & 14.1 & 14.1 & 14.1 & 14.1 \\
\hline C90 & 22.6 & 22.6 & 22.6 & 22.6 & 22.6 \\
\hline C70 & & 23.2 & 30.3 & 30.3 & 29.4 \\
\hline C50 & 43.2 & & 33.4 & 33.4 & 34.9 \\
\hline C30 & 67.3 & 32.5 & 36 & 36 & 36.4 \\
\hline C10 & 71.7 & & 36.7 & 36.7 & 36.8 \\
\hline
\end{tabular}

For the seven basins studied, we included all geographically equivalent areas. The spatial boundaries PGC uses for the continental United States resource assessments are the areas recognized by the Committee on Statistics and Drilling (CSD) of the American Association of Petroleum Geologists (AAPG). ${ }^{7}$ The USGS defines its spatial boundaries on the basis of major geological changes within a petroleum play area and tries to bound play areas corresponding to county outlines. ${ }^{22} \mathrm{NPC}$ derives spatial boundaries for onshore continental United States resource assessments from USGS play areas. ${ }^{8,}{ }^{17}$ For example, PGC combines the Greater Green River basin, Hanna-Laramie basin, and the Wyoming Thrust Zone for coalbed methane assessment of growth and undiscovered resource of the Greater Green River basin. ${ }^{7,23,24}$ USGS does separate assessments for the Greater Green River, Wyoming Thrust Zone, and Hanna-Laramie basins. ${ }^{25-27}$ To account for this difference, we included the Greater Green River basin, Hanna-Laramie basin, and the Wyoming Thrust Zone from the USGS assessment to be equivalent to the PGC assessment of the Greater Green River basin. 
For PRISE recoverable resource range quantification, we used a method of maximizing uncertainty. What we consider maximum uncertainty correlates to the variation in agency resource assessment data, even though we can adequately link each agency together by definitions and statistics. Considering the wide range of recoverable resources (Table 4.3), we maximize uncertainty by selecting the widest possible range of recoverable resources for a given resource category. For example, Table 4.4 shows the varying data for coalbed methane for San Juan basin. In the column for PRISE, we quantified data for confidence levels of 100, 90, 50, and 10\%. Again, C100 (production data) comes from the HPDI database, and the C90 value (sum of production and proved reserves) came from EIA. ${ }^{26}$ But for $\mathrm{C} 50$ and $\mathrm{C} 10$, we picked the widest range for that confidence level, USGS 2002 C50 volume and USGS 2002 C10 volume. We have more confidence in the cumulative recoverable resource by selecting the widest possible ranges for recoverable resources, because this process covers the total uncertainty of all agency estimates combined.

The "confidence" naming system works as fuzzy logic. ${ }^{28}$ The fuzzy math logic proposed by Zolotukhin suggests that levels of confidence can be assigned to any data parameter used in estimating resources, instead of using statistical methods for data analysis. ${ }^{28}$ For PRISE, the data parameters are the reference basin resource assessments published by the various agencies. The assigned confidence levels represent a percent chance of the volume of cumulative resources occurring as technically recoverable. ${ }^{28}$ According to Zolotukhin, fuzzy math can be used to better understand small amounts of data with great variation than statistical and probabilistic methods, in many instances. ${ }^{28}$ 
Because of the wide range of resource volumes and sometime small amounts of data, we use the idea of confidence levels associated with cumulative resources for PRISE data quantification in the seven study basins and the remaining seventeen North American reference basins. Fig. 4.4 is the total resource tree for the San Juan basin, using the aforementioned PRISE quantification process. The resource tree in Fig. 4.4 replicates the original intention for reference basin data quantification illustrated in Fig. 1.3. Table 4.4: Agency and PRISE Data for San Juan Basin Coalbed Methane Resources. ${ }^{7,9}$,

\begin{tabular}{|c|c|c|c|c|c|c|}
\hline \multicolumn{7}{|c|}{ Coan Juan Basin } \\
\hline$\underline{\text { Confidence }}$ & $\underline{\text { USGS }}$ & $\underline{\text { NPC }}$ & $\underline{\text { PGC 2002 }}$ & $\underline{\text { PGC 2004 }}$ & $\underline{\text { PGC 2006 }}$ & $\underline{\text { PRISE }}$ \\
\hline C100 & 14.1 & 14.1 & 14.1 & 14.1 & 14.1 & 14.1 \\
\hline C90 & 22.6 & 22.6 & 22.6 & 22.6 & 22.6 & 22.6 \\
\hline C50 & 43.2 & & 33.4 & 33.4 & 34.9 & 43.2 \\
\hline C10 & 71.7 & & 36.7 & 36.7 & 36.8 & 71.7 \\
\hline
\end{tabular}




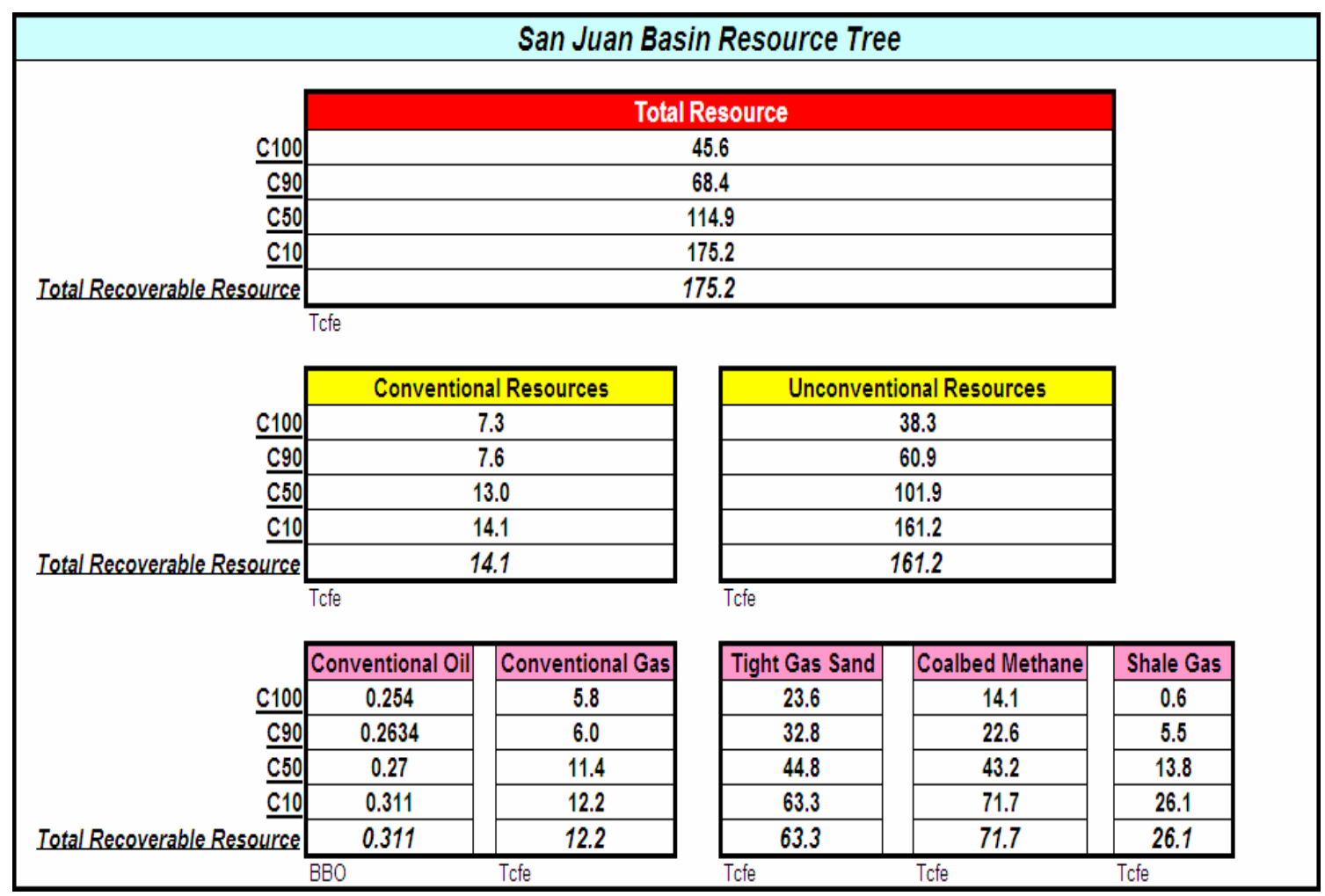

Fig. 4.4: San Juan Basin Resource Tree. 7, 9, 10, 19-21

\subsection{PRISE Quantification Results}

For the seven basins included in this study, we completed the resource tree and determined the TRR, resource triangle, for the five resource types: coalbed methane, tight gas sand, shale gas, conventional gas, and conventional oil. The resource trees are included in appendix A. The conventional oil resource value was converted to gas equivalent then added to conventional gas for the $\mathrm{C} 10$ volume of conventional resources; coalbed methane, tight gas sand, and shale gas were summed for the $\mathrm{C} 10$ volume of unconventional resources. Conventional and unconventional resources are summed for the basin wide TRR. All TRR values in PRISE are considered technically recoverable, but not necessarily economic (Table 3.3). 
The cumulative values are a summation of the individual resource categories for all five resource types (Fig. 1.3). The results of our analyses of the TRRs, by resource type, conventional, unconventional, and basin resource, for the seven basins are illustrated in Fig. 4.5, 4.6, and 4.7. For the seven basins studied thus far, approximately $10 \%$ of the hydrocarbon resources are conventional and about $90 \%$ are unconventional, which confirms and quantifies the concept of a hydrocarbon resource triangle Fig. 4.5. The exceptions are the Wind River and the Black Warrior basins. These two basins currently do not have a shale gas assessment included. However, both basins have shale gas potential. When shale gas assessments for these two basins are available, we will include them in the PRISE models. The USGS and PGC recognize shale gas resources in both of these basins, but the resources have not been quantitatively assessed. ${ }^{7,}{ }^{29}$ We will determine if conventional and unconventional resources will represent $10 \%$ and $90 \%$ of the resource triangle, respectively, when complete shale gas assessments have been done for the Black Warrior and the Wind River basins (Figs. 4.5 and 4.6). 


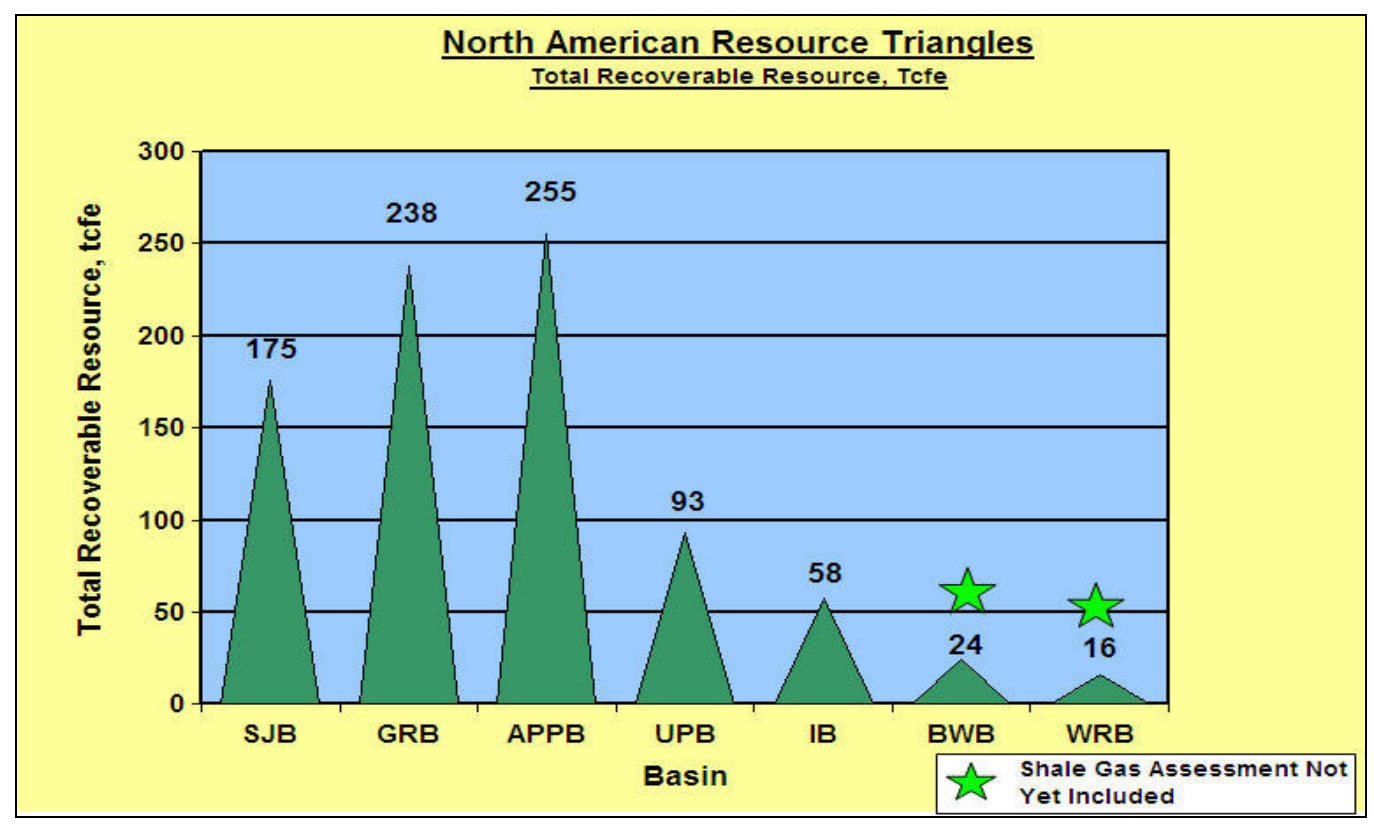

Fig. 4.5: Total Recoverable Resource Volumes in the Seven Reference Basins Studied. TRR volume in Tcfe.

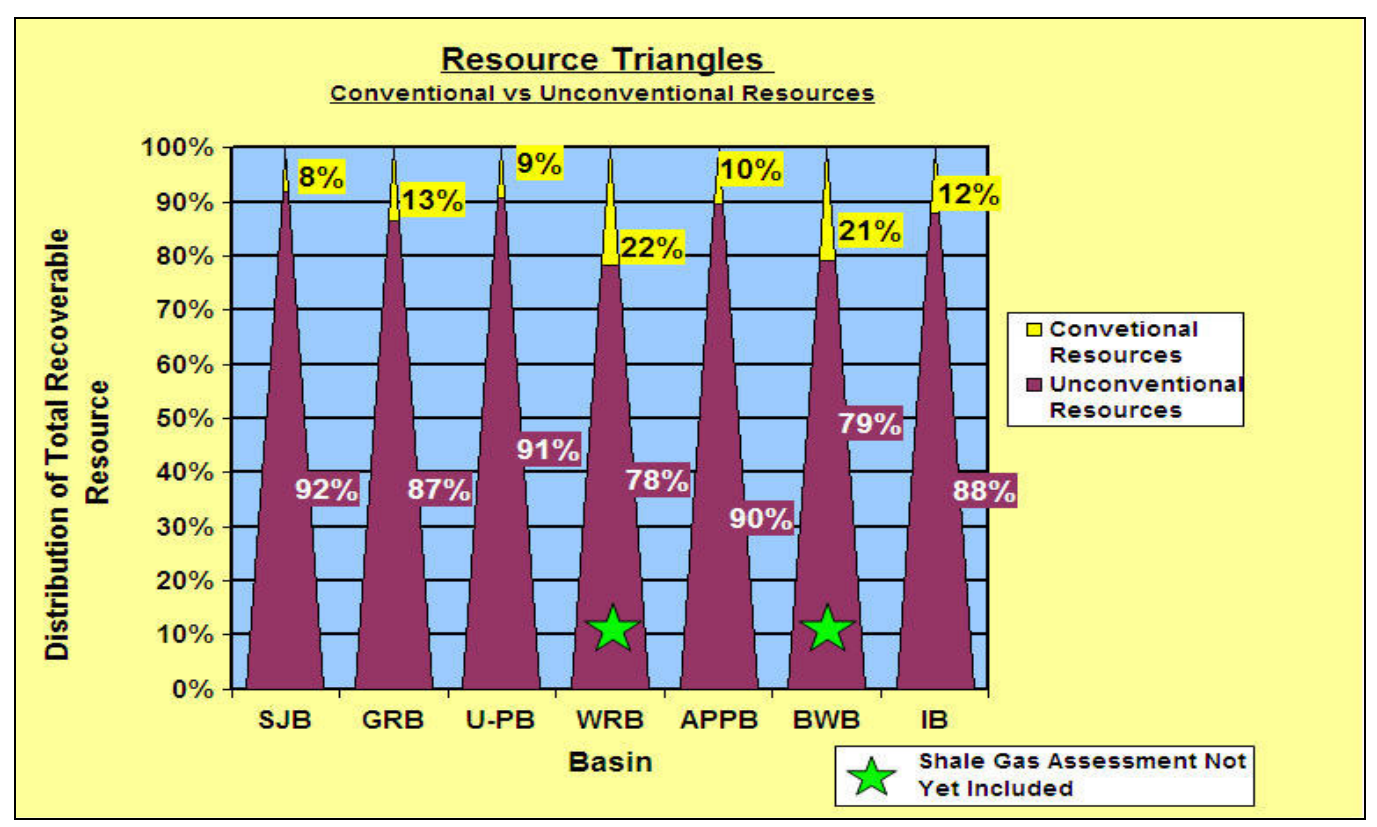

Fig. 4.6: Conventional and Unconventional Resource Triangle for the Seven Reference Basins Studied. 


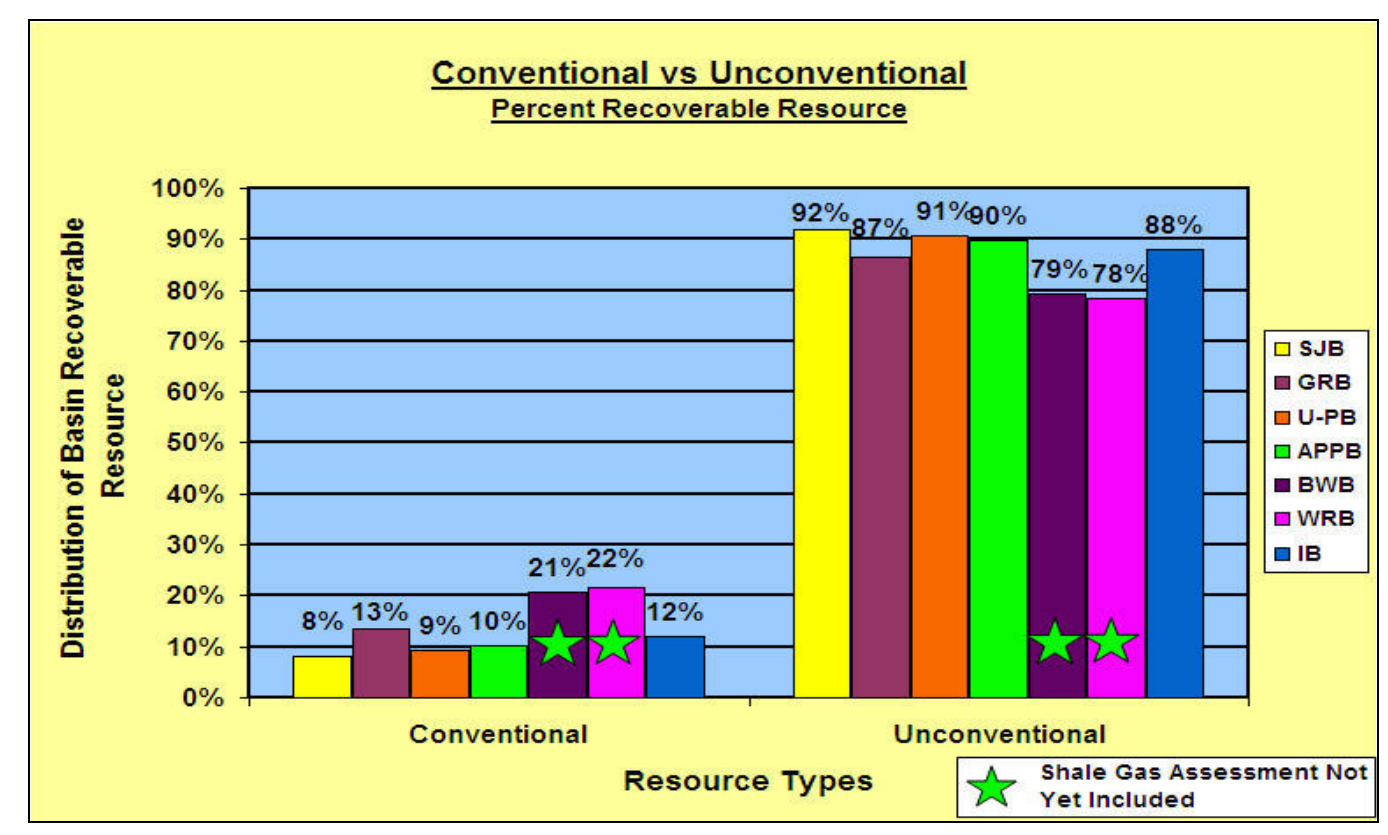

Fig. 4.7: Percent of Conventional and Unconventional Total Recoverable Resource Volumes in Seven Reference Basins.

Ranges of resource percentages for each hydrocarbon resource types are:

conventional oil, 1-10\%; conventional gas, 2-13\%; tight gas sand, 36-49\% (with the exception of the Illinois and Black Warrior basins); coalbed methane, 13-41\%; and shale gas $15-60 \%$ (Fig. 4.8) Tight gas sand is not recognized as a resource type in either the Black Warrior or the Illinois basin in the agency assessments. We did not address the reasons for lack of reported shale resources in those basins. Based on results of the PRISE experience, we conclude that we have shown that these basins are consistent with the resource triangle concept. 


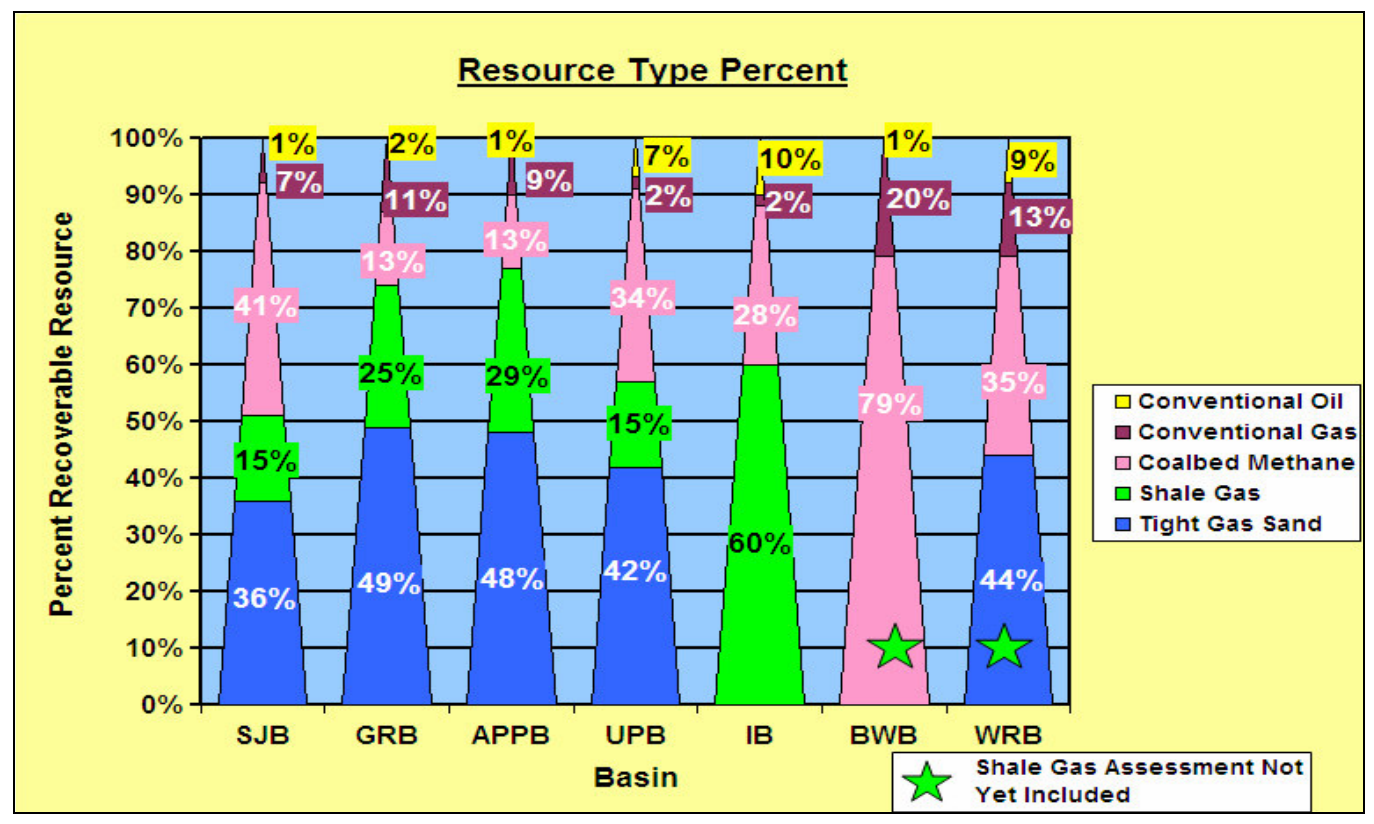

Fig. 4.8: Percent of the Five Resource Types in Seven Reference Basins. 


\section{CHAPTER V}

\section{ESTIMATING RESOURCES IN TARGET BASINS}

Having quantified the resource triangle and determined its use for estimating total recoverable resources, we used two methods for estimating UG and TRR in target basins. We call the methods: 1) Source Rock method (SR) and 2) Conventional TRR Input method (CTRRI). For each of the seven basins, we estimated recoverable resources using the mathematical methods and Resource Ratios (RR) as seen in Table 5.1 on page 60. We use BASIN to determine the top three reference basins most analogous to the target basins (Table 1.1). Then, PRISE is used to evaluate recoverable resources for the three-tiered resource tree of the target basin (Fig. 1.3 and Fig. 4.4). The three resource tree tiers are:

Tier 1 - Total Target Basin Recoverable Resource;

Tier 2 - Conventional and Unconventional Recoverable Resources;

Tier 3 - Five Resource Types (Conventional Oil, Conventional Gas, Coalbed Methane, Shale Gas, and Tight Gas Sand).

\subsection{Source Rock Evaluation}

The Source Rock method (SR) of estimating UG resources and TRR in a target basin was based on the relationships between TRR and source rock thickness, organic richness, and thermal maturity. This method was developed to evaluate the resource triangle theory and to provide an independent measure of TRR and UG resources in basins where conventional hydrocarbon resources are poorly known. Without good 
estimates of conventional resources in target basins, we can not evaluate UG from the resource triangle.

Although conventionally trapped hydrocarbon resources are not directly used in the SR equations, they may account for less than $10 \%$ of the TRR volume based on our study. The SR method appears to adequately capture TRR, including conventional resources and unconventional resource volumes, as is demonstrated in this chapter. In part, success of the SR method derives from the fact that many source rocks are selfsourced unconventional reservoirs that contribute greatly to the TRR. Thus, using the SR method, explained in this section, and the assumed distribution of $10 \%$ conventional and $90 \%$ unconventional hydrocarbons, an investigator may infer raw values of both conventional and unconventional resource volumes in a target basin.

To arrive at the source rock method for estimating UG resources in target basins, we evaluated the 72 geologic and engineering parameters that are captured in BASIN (Table 1.2) to determine what factors control the amount of recoverable resources in North American reference basins. We tentatively conclude that source rock characteristics are among the most important factors controlling the TRR for the Appalachian, Illinois, San Juan, Uinta-Piceance basins. Because shale gas resources have not been reported for the Black Warrior and Wind River basins, we determined TRR in those basins by assuming that when shale gas resource volumes are added to the cumulative resource that the distribution of conventional and unconventional resources will be 10:90. For example, the Black Warrior basin has 24 tcfe recoverable gas without shale gas volumes. The distribution of conventional and unconventional resources is 
20:80 without shale gas volumes. If we assume that the new distribution when shale gas is added is 10:90 then the 24 tcfe TRR will increase to 45 tcfe TRR. We used the same process to determine what the new TRR would be in the Wind River basin and the 16 tcfe TRR increased to 32 tcfe TRR. Green River basin source rock data has not yet been evaluated because it is not completely characterized in the BASIN database.

The first question to ask when doing resource assessments by the SR method is: What is the generative capacity in the source rocks in the basin? Source rock potential is the mechanism for generating hydrocarbons; without source rock potential there are no grounds for estimating in-place or recoverable hydrocarbon resources. Source rock potential includes factors such as: source rock volume, total organic content, kerogen type, hydrogen index, vitrinite reflectance, and burial history.

The quantified North American resource triangle in PRISE represents ultimate technically recoverable resource, and recoverability depends on many factors, such as reservoir properties, technology, and oil and gas prices. The USGS, PGC, and NPC all incorporate those factors as a part of their resource assessments. ${ }^{7-9,13}$ However, these types of data are not in the BASIN database. To link the BASIN analogs to PRISE estimates we must use only data in the BASIN database.

In 1994, Schmoker ${ }^{30}$ reported a method for calculating the mass of generated hydrocarbons using only five parameters: source rock volume, total organic content (TOC) in weight percent, formation density, original hydrogen index, and present hydrogen index. ${ }^{30}$ The source rock volume was multiplied by the TOC and formation density to determine the TOC mass of the source rock. Hydrogen index (HI) is a 
measure of the rock's ability to generate hydrocarbons and is measured in milligrams of hydrocarbons per gram of TOC (mg HC/g TOC). ${ }^{30}$ The difference between original HI and present day $\mathrm{HI}$ is a measure of hydrocarbons generated per mass TOC. Original HI is directly measured from a thermally immature rock sample, where present day HI is measured from a thermally altered sample. ${ }^{31}$ Multiplying calculated mass TOC by the change in $\mathrm{HI}(\Delta \mathrm{HI})$ results in total mass of hydrocarbons generated. ${ }^{30}$ This procedure $^{2}$ was performed for each source rock to account for variations in rock characteristics.

In BASIN (Table 1.2), there are source rock data for 1) rock type, 2) kerogen type, 3) minimum and maximum source rock thickness, 4) minimum and maximum vitrinite reflectance, and 5) minimum and maximum total organic content. Total basin area is the only area parameter for volumetric calculations in BASIN; there is no individual source rock area data. We do not input hydrogen index or formation density in BASIN. Kerogen type is an indicator of present day HI. ${ }^{31}$ Because we lack data concerning the original HI; we cannot directly calculate the mass of generated hydrocarbons using Schmoker's method. We need to be able to correlate source rock potential to resource volumes. Schmoker's method presents a direct relationship between source rock data and volume of hydrocarbons generated. For PRISE, we quantified recoverable resource volumes, not generated resource volumes. We want to use Schmoker's idea of direct method approach for source rock evaluation, but we used an indirect approach which utilizes vitrinite reflectance as the thermal maturity measure instead of HI. We can use our version of indirect source rock evaluation and determine a 
relationship between source rock potential and TRR for the North American basins in our study. This relationship will be used to estimate TRR in target basins.

In the SR method, we used the sum of individual average source rock thicknesses and average basin area to determine a generalized source rock volume of each source rock in specific basins (Eq. 5.1). Using these source rock volumes and Schmoker's method (Eq. 5.2, Eq. 5.3, and Eq. 5.4), mass TOC was determined for each source rock type using standard formation density. ${ }^{30}$ BASIN contains three source rock types: shale; carbonate; and coal. ${ }^{1,2}$ In Eqs. 5.2, 5.3, and 5.4 we used shale density of $2.65 \mathrm{~g} / \mathrm{cm}^{3}$, carbonate density of $2.71 \mathrm{~g} / \mathrm{cm}^{3}$, and coal density of $1.75 \mathrm{~g} / \mathrm{cm}^{3}$. Coal TOC data are not well characterized in BASIN, so we used an average of 85 weight percent TOC for coal mass TOC calculations. ${ }^{*}$ Also, we compensated for the fact that carbonate source rocks require approximately half the weight percent TOC of shale and coal to have equivalent generative capacity $(\mathbf{E q} \cdot \mathbf{5 . 3}) .^{32}$

$$
\begin{aligned}
& \text { Volume }, \mathrm{cm}^{3}=(\text { AverageThickness }, \mathrm{cm}) *\left(\text { AverageBasinArea }, \mathrm{cm}^{2}\right) \\
& \text { MassTOC }_{\text {Shale }}, g=\left(\text { Volume }, \mathrm{cm}^{3}\right) *[(\text { AverageTOC }, w t \%) / 100] * 2.65 \mathrm{~g} / \mathrm{cm}^{3} \\
& \text { MassTOC }_{\text {Carbonate }}, g=\left(\text { Volume }, \mathrm{cm}^{3}\right) *[(\text { AverageTOC }, w t \%) / 50] * 2.71 \mathrm{~g} / \mathrm{cm}^{3} \\
& \text { MassTOC }_{\text {Coal }}, g=\left(\text { Volume }, \mathrm{cm}^{3}\right) *[(85, w t \%) / 100] * 1.75 \mathrm{~g} / \mathrm{cm}^{3} \\
& R_{o}^{75}=\left(\left[\text { Maximum }_{o}-\text { Minimum }_{o}\right] * .75+\text { Minimum }_{o}\right) / 100 \\
& \text { VRMOC }=(\text { MassTOC, } g) * R_{o}^{75}
\end{aligned}
$$

*Personal communication with W.B. Ayers, Texas A\&M, College Station, Texas (2008) 
TotalBasinVRMOC $=\sum_{i=1}^{n} V R M O C, i=$ SourceRock

Using Eqs. 5.2-5.4, we calculated mass TOC, in grams, for each source rock. The next step was to apply the thermal maturity factor. Since we only have data for percent vitrinite reflectance $\left(\mathrm{R}_{\mathrm{o}}\right)$, we will incorporate that into our analyses of mass of hydrocarbons generated. $R_{\mathrm{o}}$ is measure of the percentage of incident light that is reflected from vitrinite particles within the rock. ${ }^{31}$ The greater the percentage of reflectance off vitrinite particles the more thermally mature the source rock and greater generation potential. In all calculations, we used the $75^{\text {th }}$ percentile value of the range of $R_{o}$ values (Eq. 5.5). We chose this percentile because it would better represent the overall thermal maturation of the source as a function of depth and burial, whereas an average value might be too low. We used a lower threshold of $0.6 \% \mathrm{R}_{\mathrm{o}}$ for the source rocks in all evaluated basins because $0.6 \%$ is the minimum $\mathrm{R}_{\mathrm{o}}$ required for hydrocarbon generation.

We cannot directly calculate the mass of hydrocarbons generated, but we can calculate Vitrinite Reflectance Measured Organic Content (VRMOC). We define VRMOC as the mass TOC multiplied by the $75^{\text {th }}$ percentile of the $R_{0}$ range $($ Eq. 5.6). If we were able to use a direct source rock evaluation like Schmoker's method then we would multiply the grams TOC by the HI thermal maturity indicator. However, we multiplied the $\mathrm{R}_{\mathrm{o}}$ thermal maturity indicator for an indirect evaluation. For each basin, 
VRMOC was calculated for each source rock and summed to get a total VRMOC for that basin (Eq. 5.7).

When VRMOC and mass TOC were tested as controlling parameters for TRR in the Appalachian, Illinois, San Juan, Uinta-Piceance basins, they resulted in a power function trend with regression values of 0.9997 and 0.9902, respectively (Fig. 5.1 and Fig. 5.2). To extend the VRMOC evaluation, we estimated the TRR volumes for Black Warrior and Wind River basins. For the estimates, we assumed that when shale gas values are added to the resource models. Therefore the Black Warrior and Wind River basins will have $90 \%$ unconventional and $10 \%$ conventional resources instead of $80 \%$ unconventional and 20\% conventional resources (Fig. 4.8). With addition of assumed shale gas resources, the estimated TRR volume for Black Warrior basin is 45 Tcfe, up from 24 Tcfe, and the Wind River basin TRR is 32 Tcfe up, from 16 Tcfe. Fig. 5.3 is the VRMOC relationship to TRR volumes with estimated shale volumes for Black Warrior and Wind River basins. Fig. $\mathbf{5 . 4}$ is the mass TOC relationship to TRR volumes with estimated shale volumes for Black Warrior and Wind River basins. The regression value is 0.9461 for the estimated VRMOC model and is .9208 for the mass TOC model. 


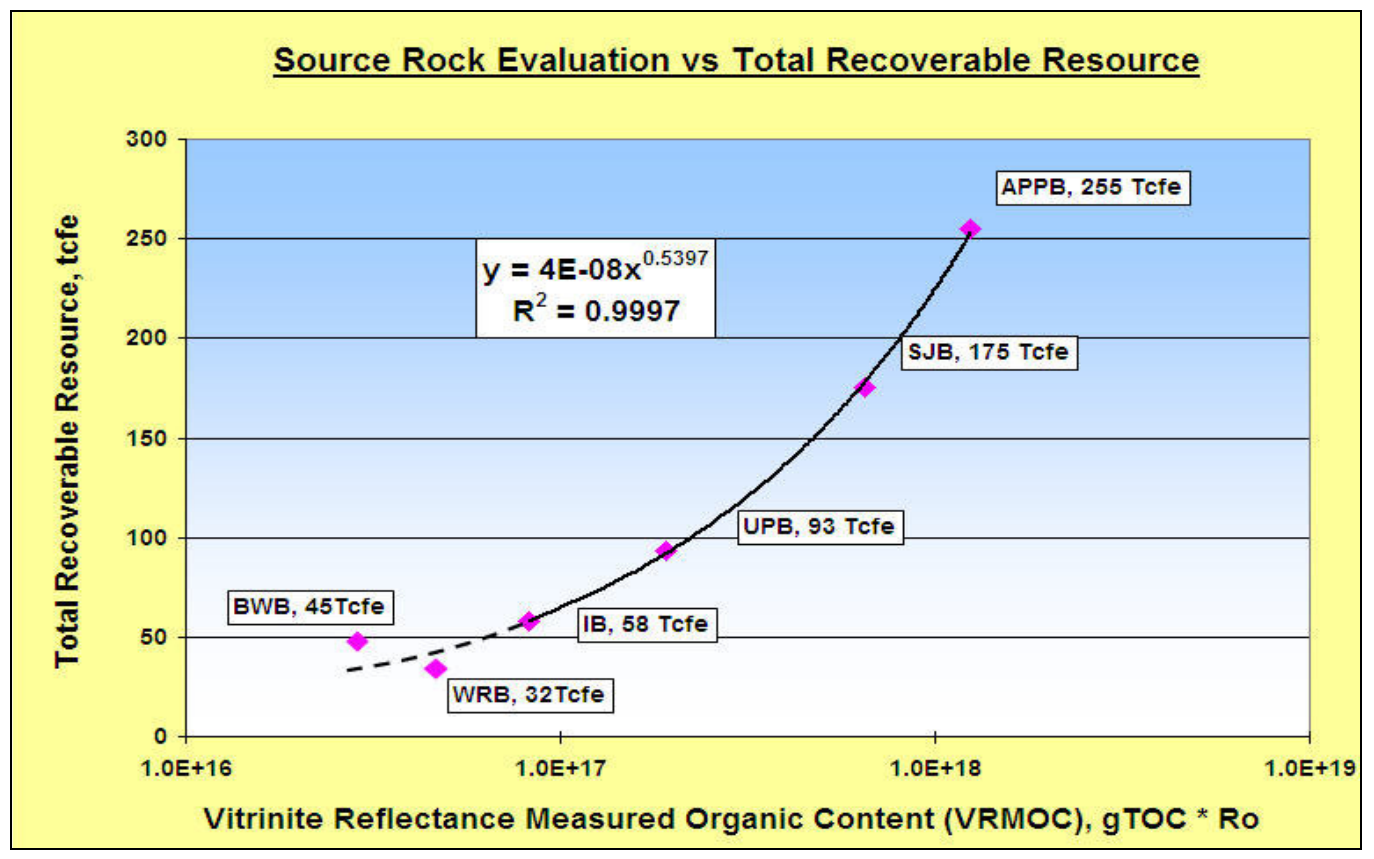

Fig. 5.1: Relationship between Vitrinite Reflectance Measured Organic Content (VRMOC) and Total Recoverable Resource (TRR) Volumes.

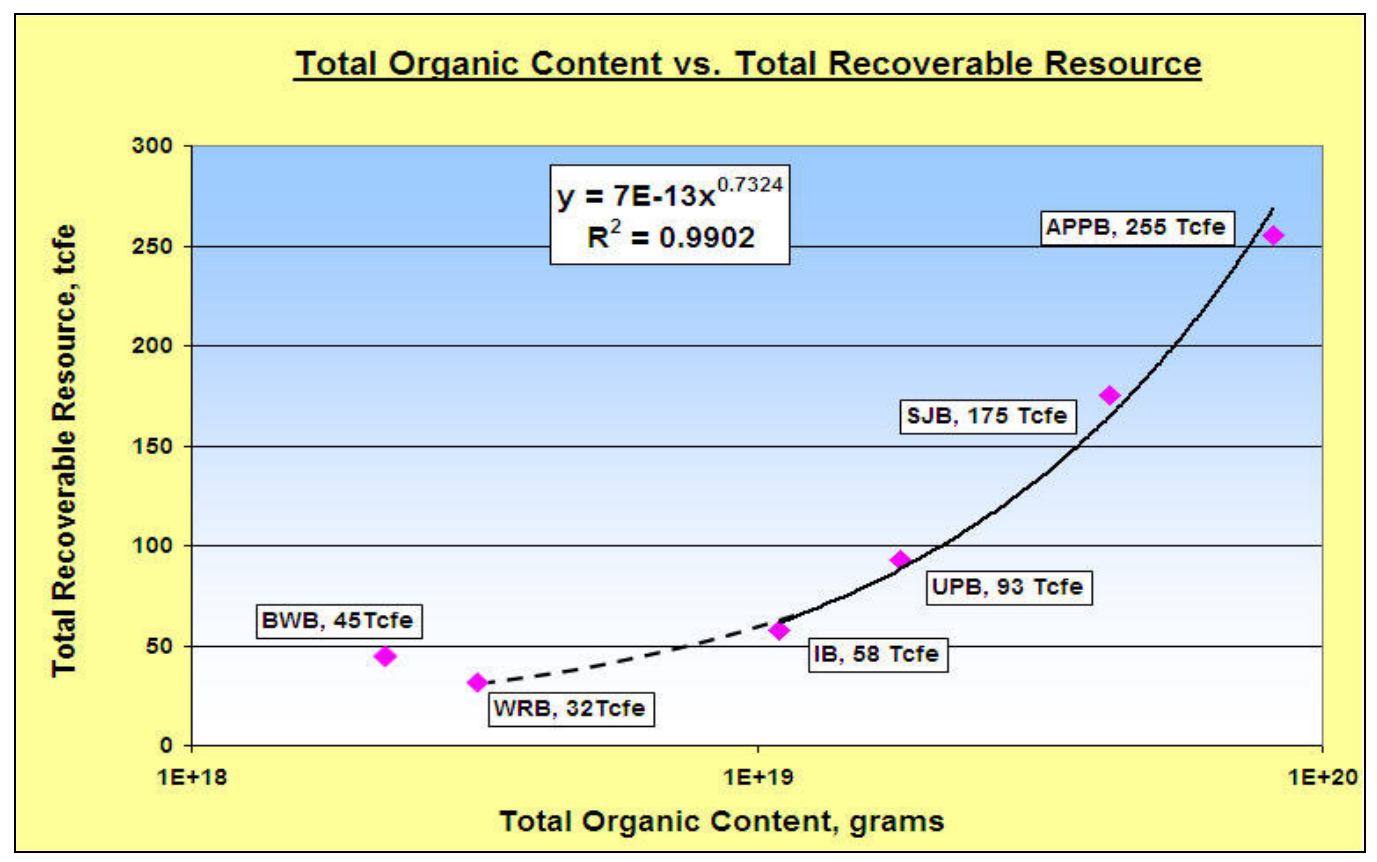

Fig. 5.2: Relationship between Total Organic Content (TOC) and Total Recoverable Resource (TRR) Volumes. 


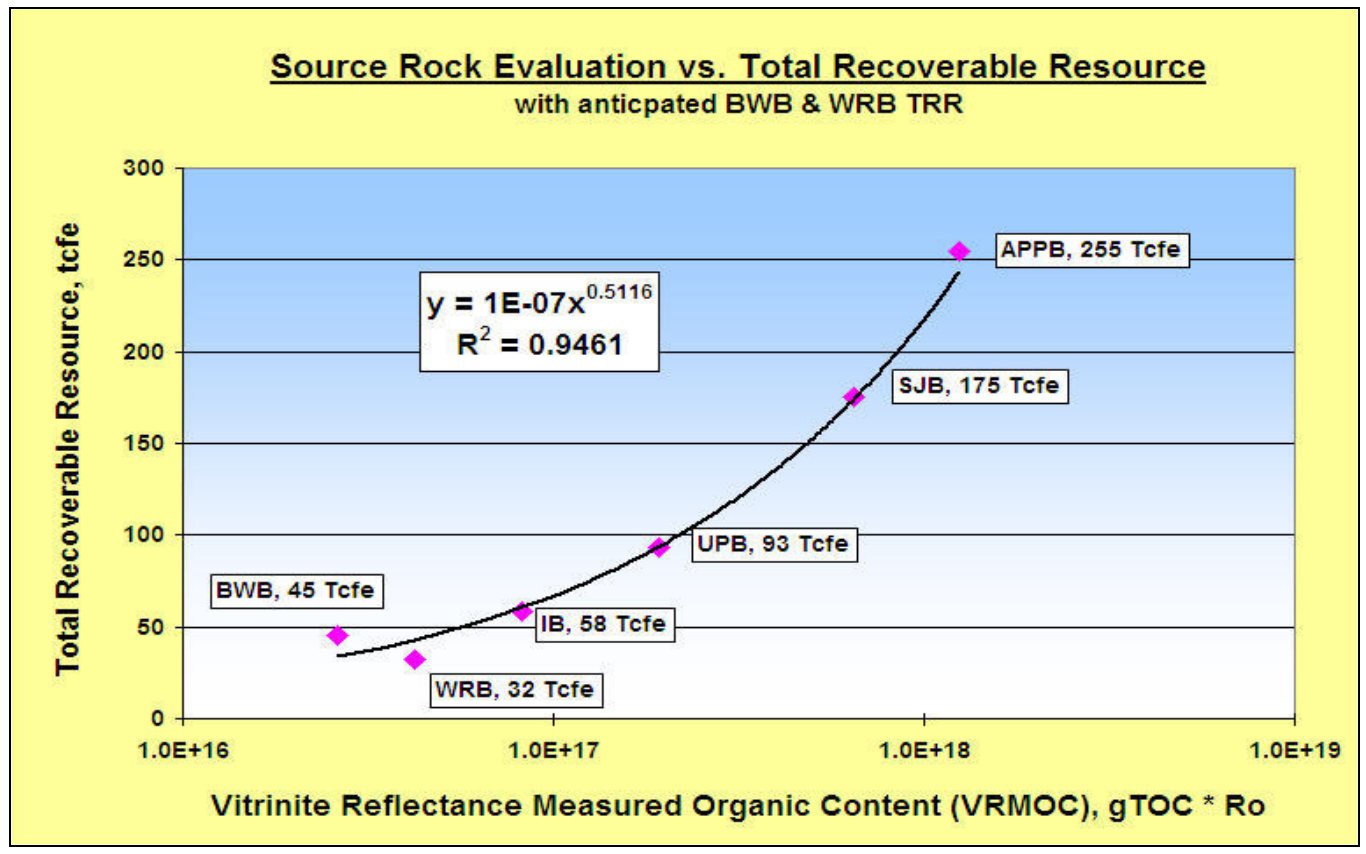

Fig. 5.3: Anticipated Relationship between VRMOC and TRR Volumes. Includes estimates for shale gas resources for the Black Warrior and Wind River basins.

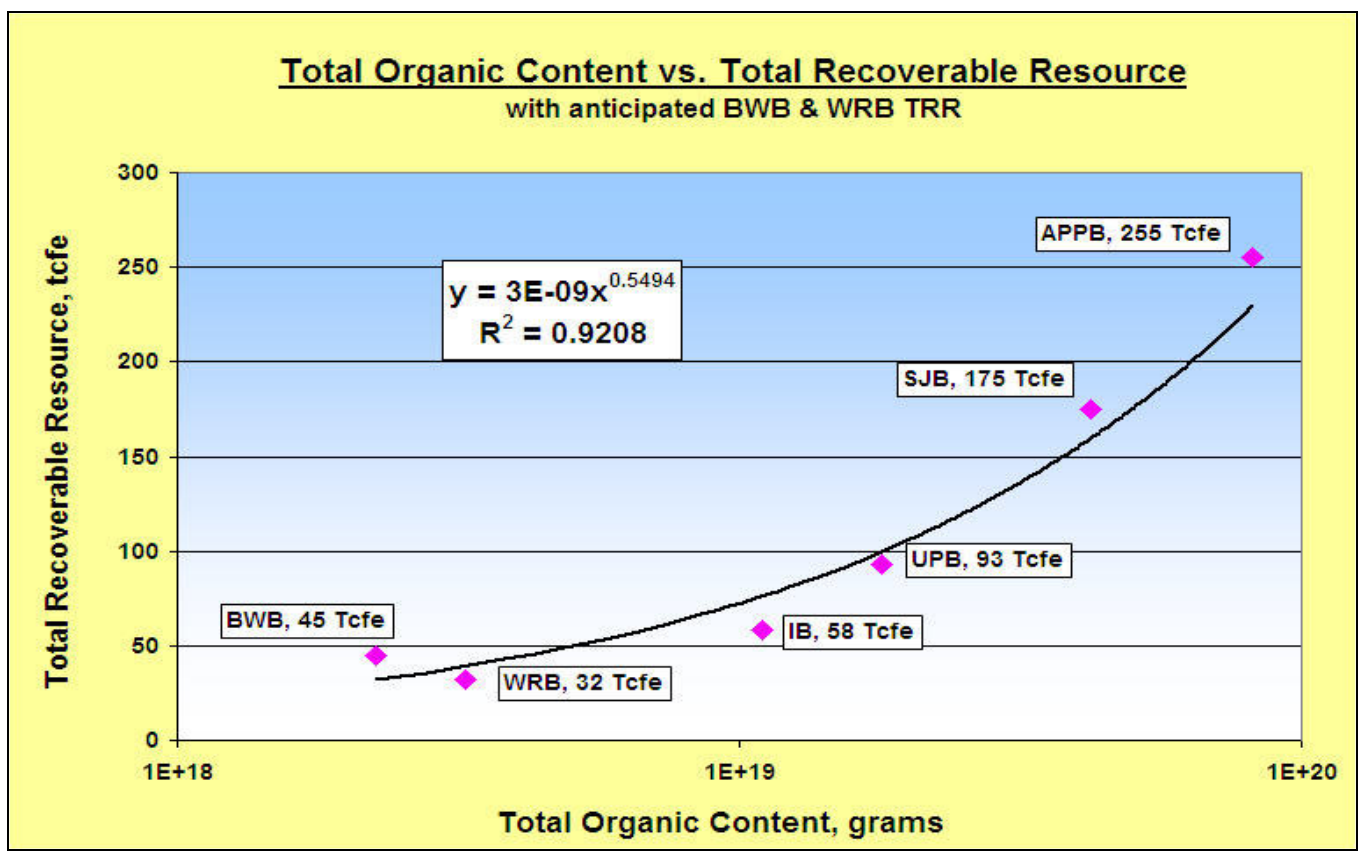

Fig. 5.4: Anticipated Relationship between TOC and TRR Volumes. Includes estimates for shale gas resources for Black Warrior and Wind River basins. 
The regression model results for the four basins with source rock data and the estimated shale gas resources for the Black Warrior and Wind River basins, suggest that mass TOC controls more than $90 \%$ of the TRR volume. Including the vitrinite reflectance parameter in the analysis (Fig. 5.3, VRMOC approach) it accounts for a 15\% improvement in TRR estimations, in comparison to the TOC approach (Fig. 5.4). Therefore, the VRMOC approach will be used in the SR method for estimating TRR volumes in target basins. The high regression values are an indicator that the indirect source rock evaluation is a good way to determine TRR values, based on our work so far.

\subsection{Methods for Estimating Recoverable Resources}

We are using the SR method (VRMOC approach) (Fig. 5.1) and CTRRI method (Conventional TRR Input, Fig. 4.7) for estimating recoverable resources in target basins. The SR method uses the VRMOC relationship determined from our indirect source rock evaluation and estimates a single TRR volume for the target basin. The CTRRI method uses known recoverable conventional resources for the target basin and estimates a single TRR volume. The SR method uses the relation between VRMOC and TRR and does not require conventional resource data, whereas the CTRRI method does require conventional resource data. Therefore, the SR method provides an independent measure of TRR and a way to "check" the CTRRI method of determining recoverable resources.

The process begins with BASIN. First, geologic data for the target basin are entered into BASIN and a hierarchy of basin reference analogs to the target basin is determined. Then, PRISE uses the top three analogs from the BASIN query to estimate 
resource distributions for the target basin. The two methods used for estimating recoverable resources in target basins are used.

The SR method assumes all source rock data needed to calculate VRMOC in the target basin are known and well characterized in BASIN. The SR method calculates VRMOC using Eqs. 5.1-Eq. 5.7 and the necessary target basin source rock data. The target basin TRR volume is calculated using the relationship in Eq. 5.8, which is based on the reference basin VRMOC analysis (Fig. 5.1). Three estimates will be determined using the SR method because three analog basins are used.

TargetBasinTRR,Tcfe $=\left(4 \times 10^{-08}\right) *$ TargetBasinVRMOC ${ }^{5397}$

The CTRRI method assumes the conventional C10 volume is known in the target basin. The $\mathrm{C} 10$ volume of conventional resources has to fit the PRISE definition of C10 for confidence (Table 4.2). To calculate target basin TRR volume, the target basin $\mathrm{C} 10$ conventional volume is divided by the fraction of conventional resources in the analog reference basin (Eq. 5.9). Three TRR volumes will be estimated using this method because there are three analog basins. The purpose for using three analog basins is to give multiple scenarios of TRR volumes and possible resource distributions for the target basin.

TargetBasinTRR,Tcfe $=$ TargetConvC10 $/($ ConvC10 $/$ BasinC10 $)$ 
The seven analog reference basins in our study have specific resource distributions from PRISE quantification. These distributions must be used in conjunction with the target basin TRR volumes estimated by the two methods. The reference basin resource distributions used to determine the shape of the target basin's resource curve are Resource Ratios (RRs). The RRs are cumulative resource volumes for a given confidence levels versus C10 volume for that specific resource type. Table $\mathbf{5 . 1}$ gives the definitions for the RRs used to determine the shape of the resource curve for the target basin. For example, Ratiog $_{90}$ for TGS estimation equals the TGS C90: TGS C10 ratio for the analog reference basin. Table 5.2 is an example calculation for TGS Ratio 90 for the San Juan basin.

Table 5.1: PRISE Resource Ratio Definitions. Resource Ratios are used for PRISE estimation calculations.

\begin{tabular}{|c|c|}
\hline Ratio & Definition \\
\hline Ratio $_{100}$ & (Cumulative Production)/(Resource Tier TRR (C10)) \\
\hline Ratio $_{90}$ & (Cumulative Production + Proved Reserves)/(Resource Tier TRR (C10)) \\
\hline Ratio $_{50}$ & (Cumulative Production + Proved Reserves + Growth)/(Resource Tier TRR (C10)) \\
\hline $\mathrm{C}_{10}$ & Cumulative Production + Proved Reserves + Growth + Undiscovered Resource (Resource Tier TRR) \\
\hline
\end{tabular}

Table 5.2: San Juan Basin Tight Gas Sand Ratio90. Resource volumes are from Fig. 4.4.

\begin{tabular}{|c|c|c|}
\hline \multicolumn{3}{|c|}{ San Juan Basin TGS Ratio 90} \\
\hline TGS C90 & TGS C10 (TGS TRR) & TGS Ratio $_{90}$ \\
\hline 32.8 Tcfe & 63.3 Tcfe & .517 \\
\hline
\end{tabular}


Both the SR and CTRRI methods use RRs to determine the resource type C10 volumes once the target basin TRR volume has been calculated using one of those two methods. Fig. 5.5 shows the step-by-step process of SR resource estimation for the top ranked analog reference basin for the target basin from the BASIN query. The same methods are used for the second and third ranked analogs reference basins.

The step-by-step estimation process for the SR method starts with:

1. Input geologic and engineering data into BASIN; these data are the only input needed for the SR estimation method (Fig. 5.5).

2. Determine, from BASIN, the top three analog basins. VRMOC is calculated from target basin source rock data.

3. The target basin TRR (target basin C10) is determined from the VRMOC approach (Fig. 5.5 and Eq. 5.8).

4. The target basin TRR (C10) is multiplied by the fraction resource type in the top-ranked analog reference basin to calculate resource type $\mathrm{C} 10$ volume (Fig. 5.5). This is the process for determining conventional, unconventional, TGS, CBM, and SG resources.

5. The top-ranked analog reference basin RRs are then multiplied by the resource type estimated $\mathrm{C} 10$ volume in the target basin to determine the corresponding confidence level resource volumes (Fig. 5.5). These last two steps are repeated for the other two analog reference basins. 


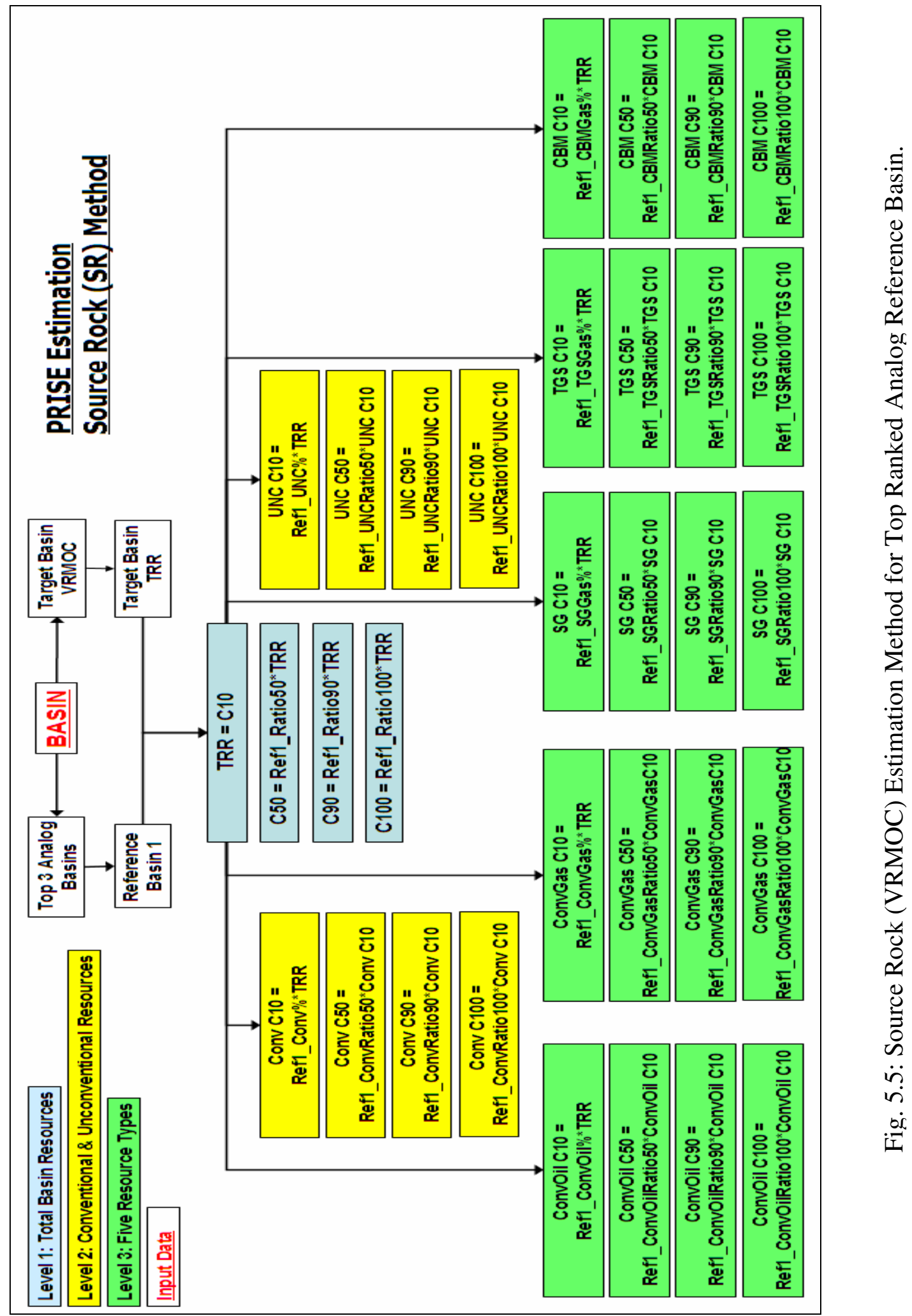


Fig. 5.6 shows the step-by-step process of CTRRI resource estimation for the top ranked analog reference basin for the target basin from the BASIN query. The same methods are used for the second and third ranked analogs reference basins.

The step-by-step estimation process for the CTRRI method starts with:

1. Input geologic and engineering data into BASIN (Fig. 5.6).

2. Determine, from BASIN, the top three analog basins.

3. Input conventional C10 volume into PRISE (Figs. 5.6 and 5.7).

4. The target basin TRR (target basin C10) is determined by dividing the conventional $\mathrm{C} 10$ input volume by the fraction conventional resource in the top-ranked analog reference basin (Fig. 5.6 and Eq. 5.9). This step is repeated for all the other two analog reference basins.

5. The target basin TRR (C10) is multiplied by the fraction resource type in the top-ranked analog reference basin to calculate resource type $\mathrm{C} 10$ volume (Fig. 5.5). This is the process for determining unconventional, TGS, CBM, and $\mathrm{SG}$ resources. The conventional $\mathrm{C} 10$ volume is equal to the conventional C10 input volume.

6. The top ranked analog reference basin RRs are then multiplied by the resource tier $\mathrm{C} 10$ volume in the target basin to determine the corresponding confidence level resource volumes (Fig. 5.6), except for the conventional C10 volume which is equal to the volume input into PRISE. These last two steps are repeated for the other two analog reference basins. 


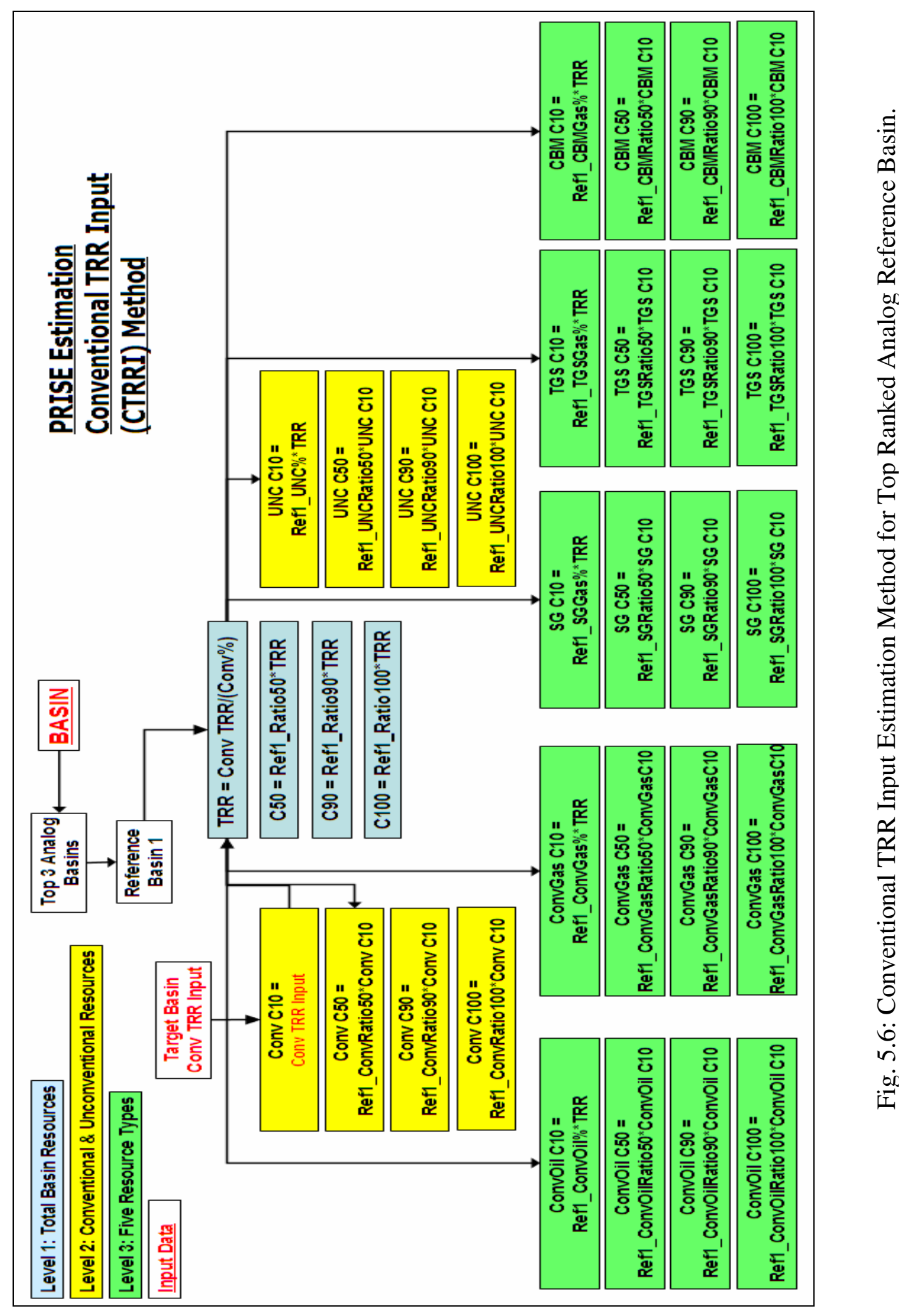




\subsection{PRISE Software}

PRISE can be used alone but, it will eventually work with a larger software package, Unconventional Gas Advisor (UGA), being developed in the Crisman Institute at Texas A\&M University. Fig. 1.1 outlines the different applications in UGA. A query of BASIN may be focused to determine one of two analog types based on the known target basin data. One analog type is the "basin" analog and the other is the "formation" analog. A basin query results in selection of three of the 25 North American reference basins listed in order of percent analog similarity. A "formation" query results in selection of a single petroleum system (reservoir and source rock pair) within a reference basin. Both analog types are determined using the method previously discussed in Section 1.1 of this thesis. PRISE uses the top three reference basins from the BASIN query to estimate TRR in the target basin. The preliminary version of PRISE is written as a Visual Basin Application (VBA) in Microsoft Excel $^{33}$ and the database of reference basin confidence ratios and percent resources are stored in an Excel spreadsheet.

PRISE prompts the user for two data types.

1. Have all the source rocks for the target basin been properly characterized?

2. Is there a good estimate for conventional $\mathrm{C} 10$ for the target basin?

Question 1 refers to the SR estimation method and question 2 refers to Conventional TRR Input estimation method. Both questions should be answered in order to utilize both estimation methods and increase confidence of the resource estimates. If both questions are answered "no" then no calculations will be performed. However, if only 
one question can be answered "yes", PRISE will use the corresponding method to estimate TRR in the target basin.

Once the TRR for the target basin has been established, the RRs of the top three ranked analogs from BASIN will be used to determine the resource volumes in the target basin. This procedure results in estimated resource volumes in the form of the resource curve for all resource types.

If both questions are answered yes, the final result will be six resources curves for all three tiers of resource tree. There is one resource curve for each reference basin for each method. Therefore, the user must use BASIN to derive the top three analogs for the target basin, if PRISE is to function effectively. Several steps that should be taken to produce a final outcome for resource estimates are as follows:

1. Input all known geologic data for the target basin into BASIN;

2. Run BASIN to determine the analog basin(s) in North America;

3. Use PRISE SR and CTRRI methods to determine the target basin TRR volumes and;

4. Use PRISE RRs to estimate the volume of technically recoverable resource for each resource type in the target basin.

\subsubsection{PRISE Test}

The objective of this run was to test both the SR and CTRRI methods for TRR determination. The results are for San Juan basin, as if it were a target basin. Reservoir data were modified in the San Juan "target" data set from the San Juan "reference" basin data set, but source rock data were kept the same for proper execution of the VRMOC 
calculation to test the SR method. We changed the reservoir data so that the San Juan reference basin would not be an exact (100\%) analog but the VRMOC calculation would remain valid. Fig. 5.7 is the PRISE startup and input screen. In this example, we selected "yes" from a drop down menu to both questions. Therefore both methods for estimating resources were employed. We entered the actual conventional C10 volume of $14.1 \mathrm{Tcfe}$ for the San Juan basin (Fig. 4.4).

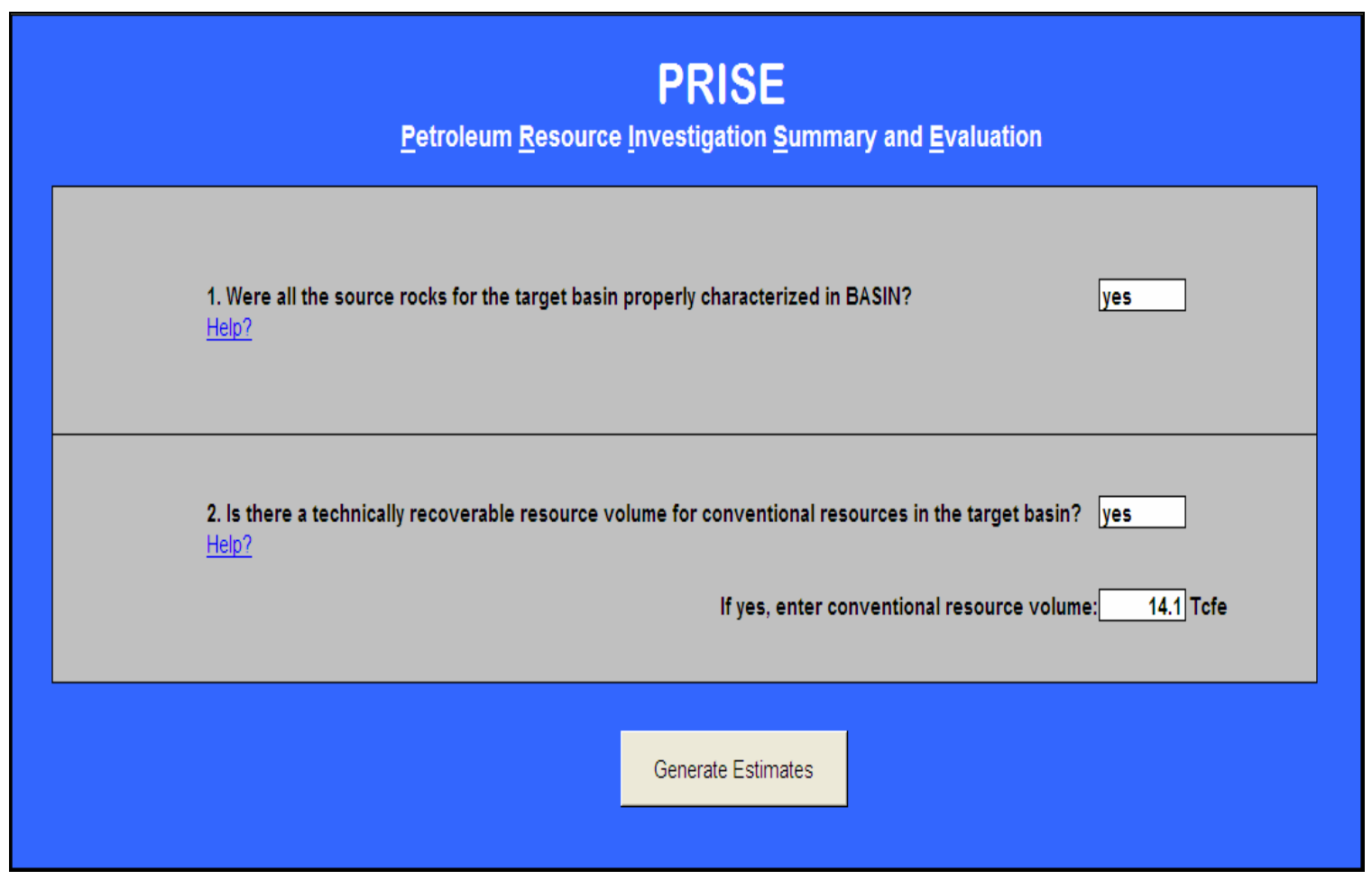

Fig. 5.7: PRISE Data Input Screen.

Fig. 5.8 shows all six resources curves for the San Juan target basin. Each curve is labeled with the reference basin, percent analog (BASIN output), method used, and corresponding estimate in Table 5.3. Table 5.3 is a summary of the estimated volumes 
for the San Juan target basin. From Fig. 5.8, the San Juan reference basin is about a 98\% match for a basin analog because we changed reservoir parameters. The percentage match is determined by BASIN. The Piceance basin is the second most analogous basin at $55 \%$, and Green River basin match is third at $54 \%$. The shape of each curve in Fig. 5.8 reflects the reference basin RRs determined from quantified basin resources.

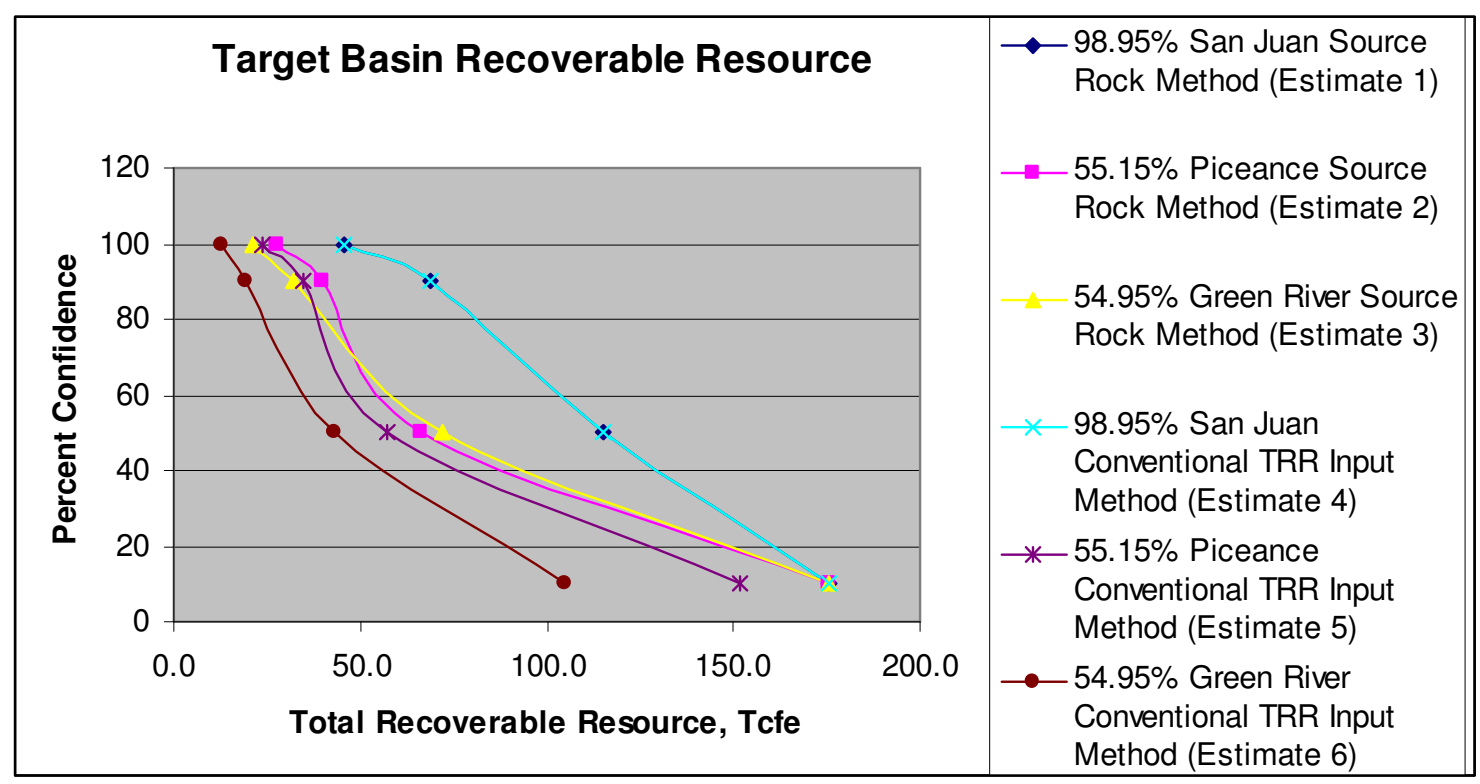

Fig. 5.8: PRISE: Estimated Resource Curves in the San Juan Target Basin. 
Table 5.3: PRISE: Estimated Resource Volumes in the San Juan Target Basin. The colors correspond to the colors of the curves in Fig 5.8.

\begin{tabular}{|c|c|c|c|c|}
\hline \multicolumn{5}{|c|}{\begin{tabular}{c}
\multicolumn{1}{c}{ San Juan Target } \\
Total Recoverable Resource
\end{tabular}} \\
\hline \multicolumn{5}{|c|}{ Recoverable Resource Volume } \\
\hline Confidence & Estimate 1 & Estimate 2 & Estimate 3 & \\
\hline 100 & 45.7 & 27.9 & 21.2 & \multirow{4}{*}{$\begin{array}{l}\text { Tcfe } \\
\text { Tcfe } \\
\text { Tcfe } \\
\text { Tcfe }\end{array}$} \\
\hline 90 & 68.6 & 40.1 & 32.4 & \\
\hline 50 & 115.2 & 66.4 & 72.3 & \\
\hline 10 & 175.6 & 175.6 & 175.6 & \\
\hline Confidence & Estimate 4 & Estimate 5 & Estimate 6 & \\
\hline 100 & 45.8 & 24.0 & 12.7 & Tcfe \\
\hline 90 & 68.7 & 34.6 & 19.4 & Tcfe \\
\hline 50 & 115.3 & 57.3 & 43.2 & Tcfe \\
\hline 10 & 175.8 & 151.6 & 104.9 & Tcfe \\
\hline
\end{tabular}

Estimates 1 and 4 in Table $\mathbf{5 . 3}$ verify that our methods compliment each other.

Estimates 1 and 4 are based on quantified resource volumes for the San Juan reference basin. Estimate 1 resulted in 175.6 Tcfe TRR (C10) from the SR (VRMOC) method for the San Juan target basin. Estimate 4 resulted in 175.8 Tcfe TRR (C10) from the CTRRI method for the San Juan target basin. The SR and CTRRI method are close to the PRISE quantified San Juan basin resource volume; 175 Tcfe (Fig. 4.6). The main reason for differences of the estimates is the small variability $(<1 \%)$ with the relationship of TRR to VRMOC (Fig. 5.1). Estimates 2 and 5 are based on the quantified PRISE Piceance reference basin resource volumes and use the SR and CTRRI methods, respectively. Estimates 3 and 6 are based on the PRISE Green River reference basin resource volumes and use the SR and CTRRI methods, respectively. The volumes in estimates 5 and 6 are different from the other estimates because the CTRRI method uses the fraction of 
conventional resources in the reference basin to calculate the $\mathrm{C} 10$ volumes (Fig. 5.5). Conventional resources are $8 \%$ of the San Juan, $9 \%$ of the Uinta-Piceance, and $13 \%$ of the Green River basin TRR volumes (Fig. 4.7). The small 1-5\% variation in the reference basin conventional resources can cause for large volumetric differences in the PRISE estimates. The large volume difference is why the 10:90 relationships between conventional and unconventional resources are only a proxy for TRR in the target basin, not an exact measure of the analog reference basin.

Fig. 5.9 and Table 5.4 report estimates of conventional TRR for the San Juan target basin. For this comparison we used the actual conventional TRR from Fig. 4.4 for conventional resource input volume; 14.1 Tcfe (question 2 on input window, Fig. 5.7). Again, the SR and CTRRI methods are validated with respect to the quantified San Juan basin (Table 5.4 and Fig. 5.9). The San Juan basin has 14.1 Tcfe of conventional TRR and estimates 4, 5, and 6 TRR (C10) volumes equal that input volume (Fig. 5.7).

Estimate 1 is the calculated C10 volume based on the TRR volume derived from the SR method VRMOC relationship (Fig. 5.1) and the conventional hydrocarbon resource percentage for the reference basin (Fig. 5.5), in this case the San Juan reference basin. The remaining output tables and charts can be evaluated the same way. Estimates 1 and 4 are the results for the San Juan target basin example, using the quantified San Juan basin resource distributions as the most analogous BASIN output.

If only question 1 (Fig. 5.7) had been answered "yes" then the only estimates generated would be 1, 2, and 3 by means of SR method. If only question 2 had been answered "yes" then the estimates would be 4,5 , and 6 by means of the CTRRI. 


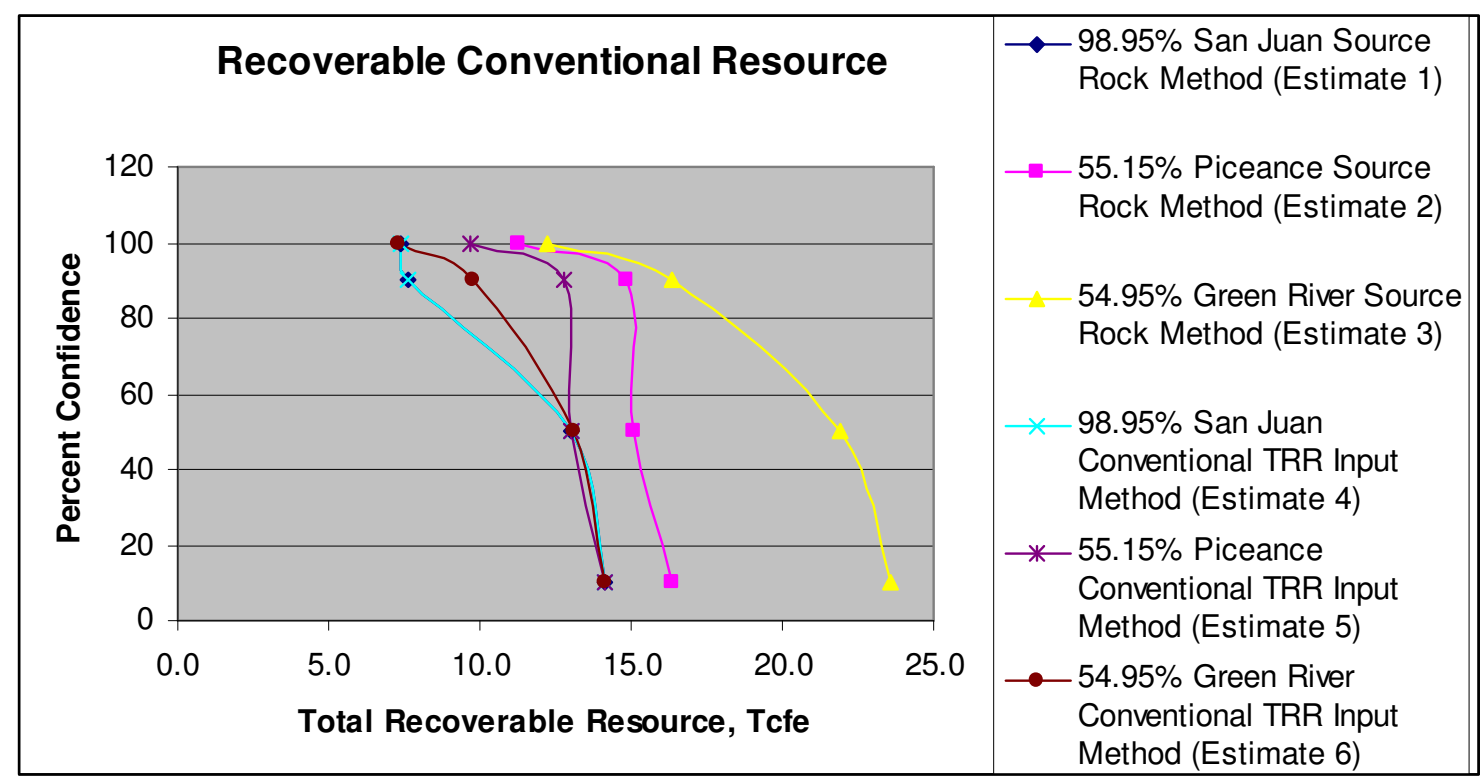

Fig. 5.9: PRISE: Estimated Conventional Resource Curves in the San Juan Target Basin.

Table 5.4: PRISE: Estimated Conventional Resource Volumes in the San Juan Target Basin. The colors correspond to the colors of the curves in Fig 5.9.

\begin{tabular}{|c|c|c|c|c|}
\hline \multicolumn{5}{|c|}{$\begin{array}{c}\text { San Juan Target } \\
\text { Recoverable Conventional Resource }\end{array}$} \\
\hline \multicolumn{5}{|c|}{ Recoverable Resource Volume } \\
\hline Confidence & Estimate 1 & Estimate 2 & Estimate 3 & \\
\hline 100 & 7.4 & 11.2 & 12.2 & \multirow{4}{*}{$\begin{array}{l}\text { Tcfe } \\
\text { Tcfe } \\
\text { Tcfe } \\
\text { Tcfe } \\
\end{array}$} \\
\hline 90 & 7.6 & 14.8 & 16.4 & \\
\hline 50 & 13.0 & 15.1 & 21.9 & \\
\hline 10 & 14.1 & 16.3 & 23.6 & \\
\hline Confidence & Estimate 4 & Estimate 5 & Estimate 6 & \\
\hline 100 & 7.4 & 9.7 & 7.3 & Tcfe \\
\hline 90 & 7.6 & 12.8 & 9.8 & Tcfe \\
\hline 50 & 13.1 & 13.0 & 13.1 & Tcfe \\
\hline 10 & 14.1 & 14.1 & 14.1 & Tcfe \\
\hline
\end{tabular}


Fig. 5.10 is the estimate for the San Juan target basin unconventional resource and provides the same validation as the previous estimates. The SR method for estimate 1 has the same result as the CTRRI method for estimate 4 (Table 5.5). Estimates 2 and 3 in Table 5.5 illustrate the SR method and estimates 5 and 6 are determined from the CTRRI method; they are based on the Piceance and Green River analog reference basins.

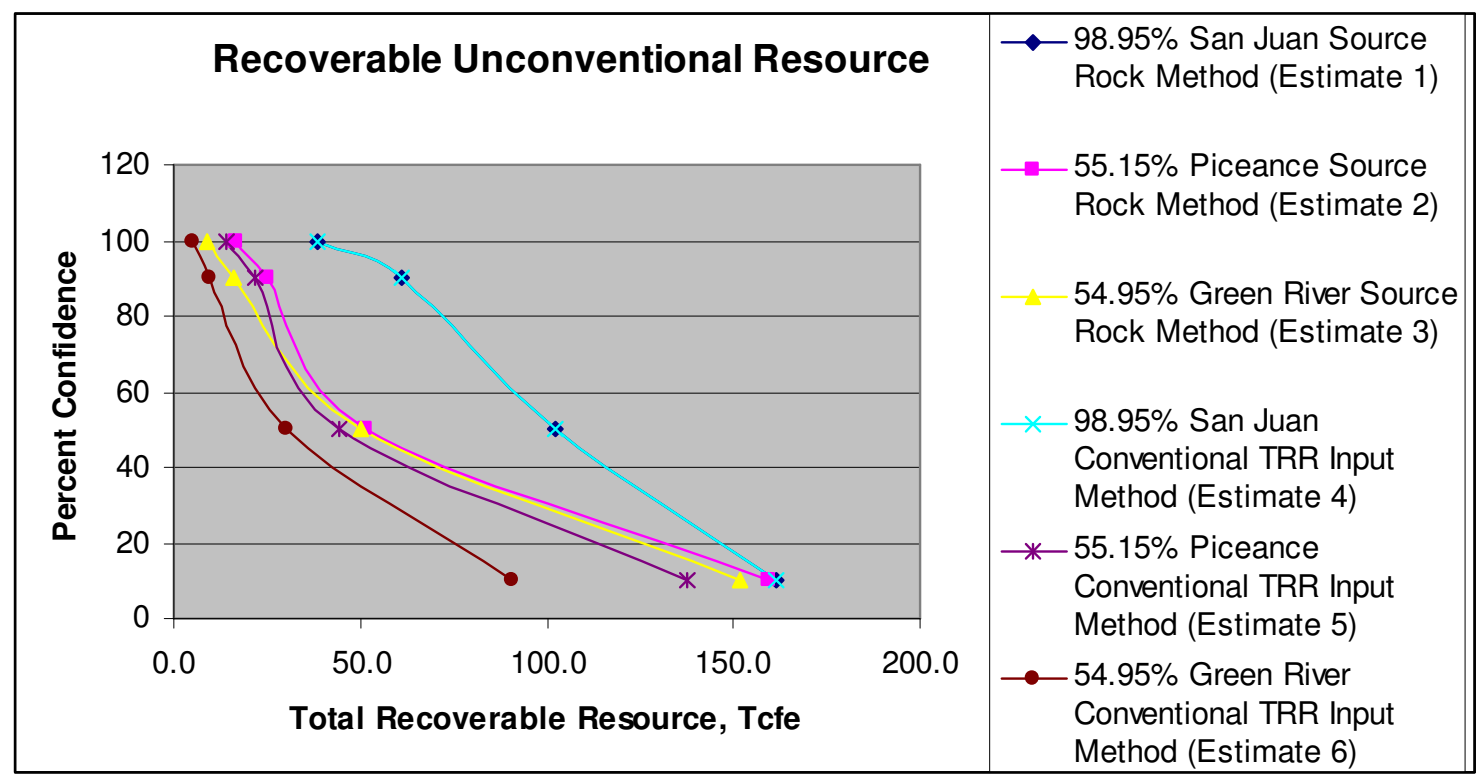

Fig. 5.10: PRISE: Estimated Unconventional Resource Curves in the San Juan Target Basin. 
Table 5.5: PRISE: Estimated Unconventional Resource Volumes in the San Juan Target Basin. The colors correspond to the colors of the curves in Fig 5.10.

\begin{tabular}{|c|c|c|c|c|}
\hline \multicolumn{5}{|c|}{$\underline{\text { San Juan Target }}$} \\
\hline \multicolumn{5}{|c|}{ Recoverable Resource Volume } \\
\hline Confidence & Estimate 1 & Estimate 2 & Estimate 3 & \\
\hline 100 & 38.4 & 16.6 & 9.0 & Tcfe \\
\hline 90 & 61.0 & 25.2 & 16.1 & Tcfe \\
\hline 50 & 102.1 & 51.3 & 50.4 & Tcfe \\
\hline 10 & 161.5 & 159.3 & 152.0 & Tcfe \\
\hline Confidence & Estimate 4 & Estimate 5 & Estimate 6 & \\
\hline 100 & 38.4 & 14.3 & 5.4 & Tcfe \\
\hline 90 & 61.1 & 21.8 & 9.6 & Tcfe \\
\hline 50 & 102.2 & 44.3 & 30.1 & Tcfe \\
\hline 10 & 161.7 & 137.5 & 90.8 & Tcfe \\
\hline
\end{tabular}

The estimates for the five individual resource types (TGS, CBM, SG, ConvGas, and ConvOil) are determined the same way as unconventional resources (Fig. 5.10 and Table 5.5). Estimates 1 and 4 for the San Juan target basin are approximately the same and are equal to the San Juan analog reference basin individual resource type volumes (Figs. 4.4).

TGS estimates are illustrated in Fig. 5.11 and Table 5.6. Again, estimates 1 and 4 are approximately the same and are equal the San Juan analog reference basin TGS volumes (Fig. 4.4). 


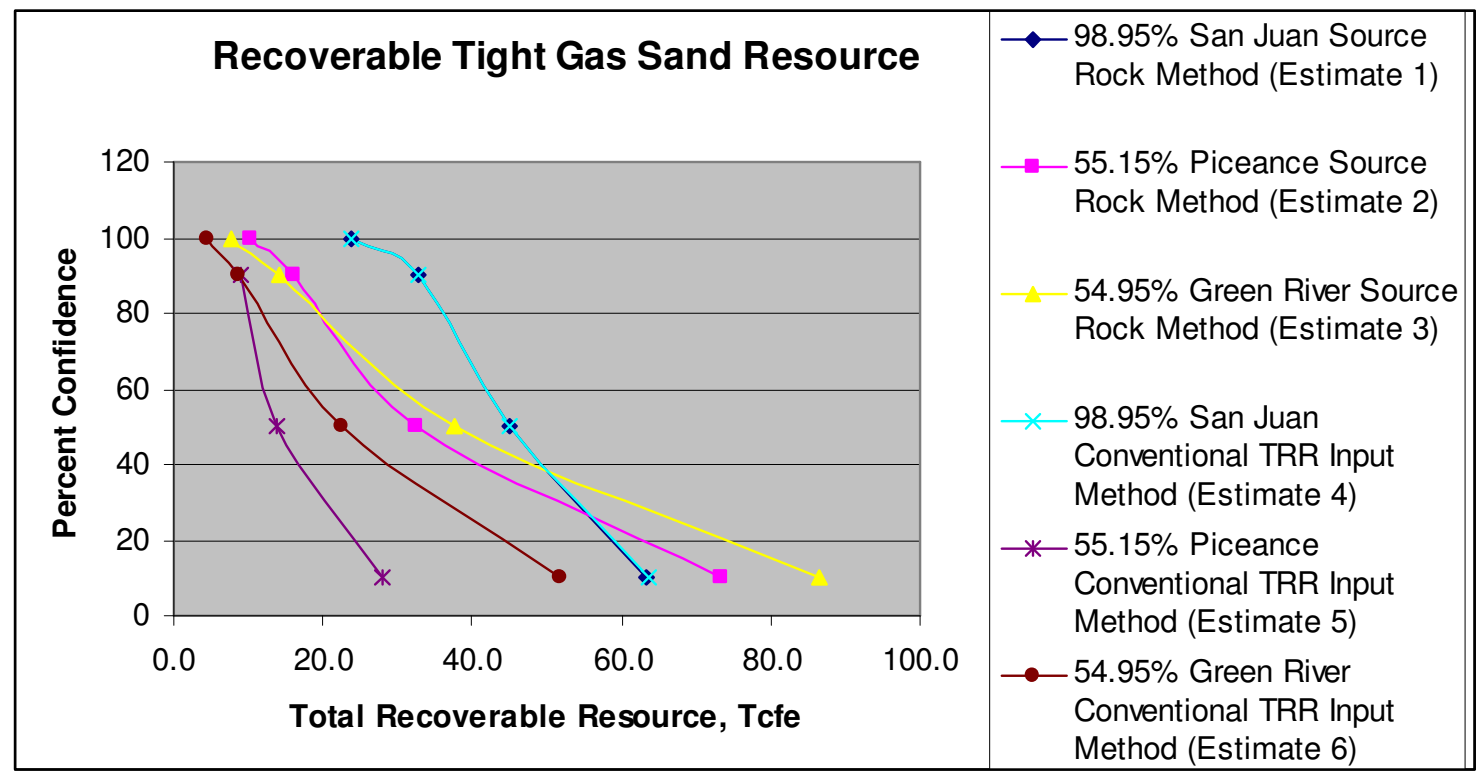

Fig. 5.11: PRISE: Estimated Tight Gas Sand Resource Curves in the San Juan Target Basin.

Table 5.6: PRISE: Estimated Tight Gas Sand Resource Volumes in the San Juan Target Basin. The colors correspond to the colors of the curves in Fig 5.11.

\begin{tabular}{|c|c|c|c|c|}
\hline \multicolumn{5}{|c|}{$\underline{\text { San Juan Target }}$} \\
\hline \multicolumn{5}{|c|}{ Recoverable Resource Volume } \\
\hline Confidence & Estimate 1 & Estimate 2 & Estimate 3 & \\
\hline 100 & 23.6 & 10.4 & 7.6 & Tcfe \\
\hline 90 & 32.8 & 16.2 & 14.3 & Tcfe \\
\hline 50 & 44.9 & 32.4 & 37.6 & Tcfe \\
\hline 10 & 63.5 & 73.3 & 86.4 & Tcfe \\
\hline Confidence & Estimate 4 & Estimate 5 & Estimate 6 & \\
\hline 100 & 23.7 & 8.9 & 4.6 & Tcfe \\
\hline 90 & 32.9 & 14.0 & 8.5 & Tcfe \\
\hline 50 & 45.0 & 27.9 & 22.5 & Tcfe \\
\hline 10 & 63.5 & 63.2 & 51.6 & Tcfe \\
\hline
\end{tabular}


CBM estimates are illustrated in Fig. 5.12 and Table 5.7. Estimates 1 and 4 are approximately the same and are equal the San Juan analog reference basin CBM volumes (Fig. 4.4).

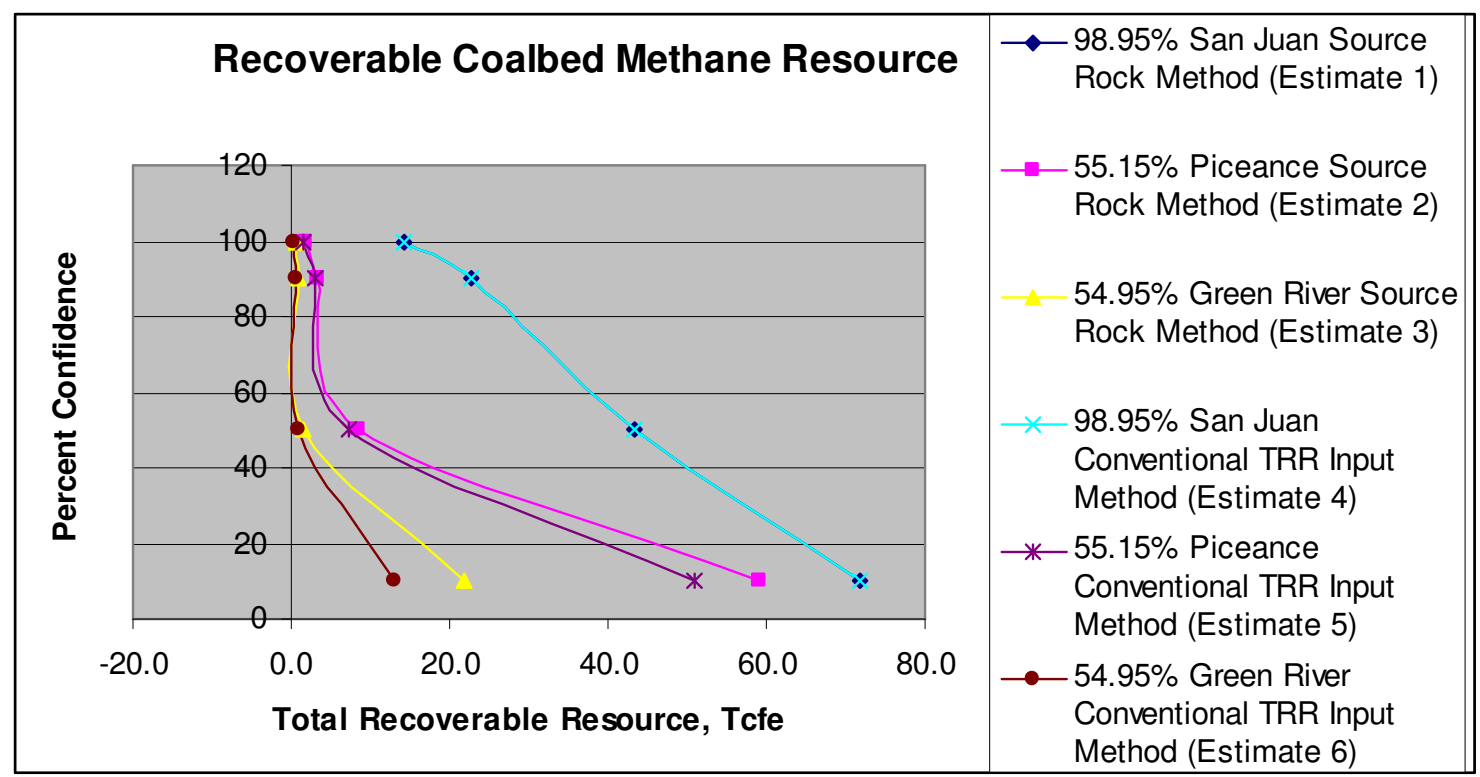

Fig. 5.12: PRISE: Estimated Coalbed Methane Resource Curves in the San Juan Target Basin. 
Table 5.7: PRISE: Estimated Coalbed Resource Volumes in the San Juan Target Basin. The colors correspond to the colors of the curves in Fig 5.12.

\begin{tabular}{|c|c|c|c|c|}
\hline \multicolumn{5}{|c|}{$\begin{array}{c}\text { San Juan Target } \\
\text { Recoverable Coalbed Methane Resource }\end{array}$} \\
\hline \multicolumn{5}{|c|}{ Recoverable Resource Volume } \\
\hline Confidence & Estimate 1 & Estimate 2 & Estimate 3 & \\
\hline 100 & 14.2 & 1.9 & 0.7 & Tcfe \\
\hline 90 & 22.6 & 3.4 & 0.8 & Tcfe \\
\hline 50 & 43.3 & 8.4 & 1.4 & Tcfe \\
\hline 10 & 71.9 & 59.0 & 21.7 & Tcfe \\
\hline Confidence & Estimate 4 & Estimate 5 & Estimate 6 & \\
\hline 100 & 14.2 & 1.7 & 0.4 & Tcfe \\
\hline 90 & 22.7 & 2.9 & 0.5 & Tcfe \\
\hline 50 & 43.4 & 7.2 & 0.8 & Tcfe \\
\hline 10 & 71.9 & 50.9 & 13.0 & Tcfe \\
\hline
\end{tabular}

SG estimates are illustrated in Fig. 5.13 and Table 5.8. Estimates 1 and 4 are approximately the same and are equal the San Juan analog reference basin SG volumes (Fig. 4.4).

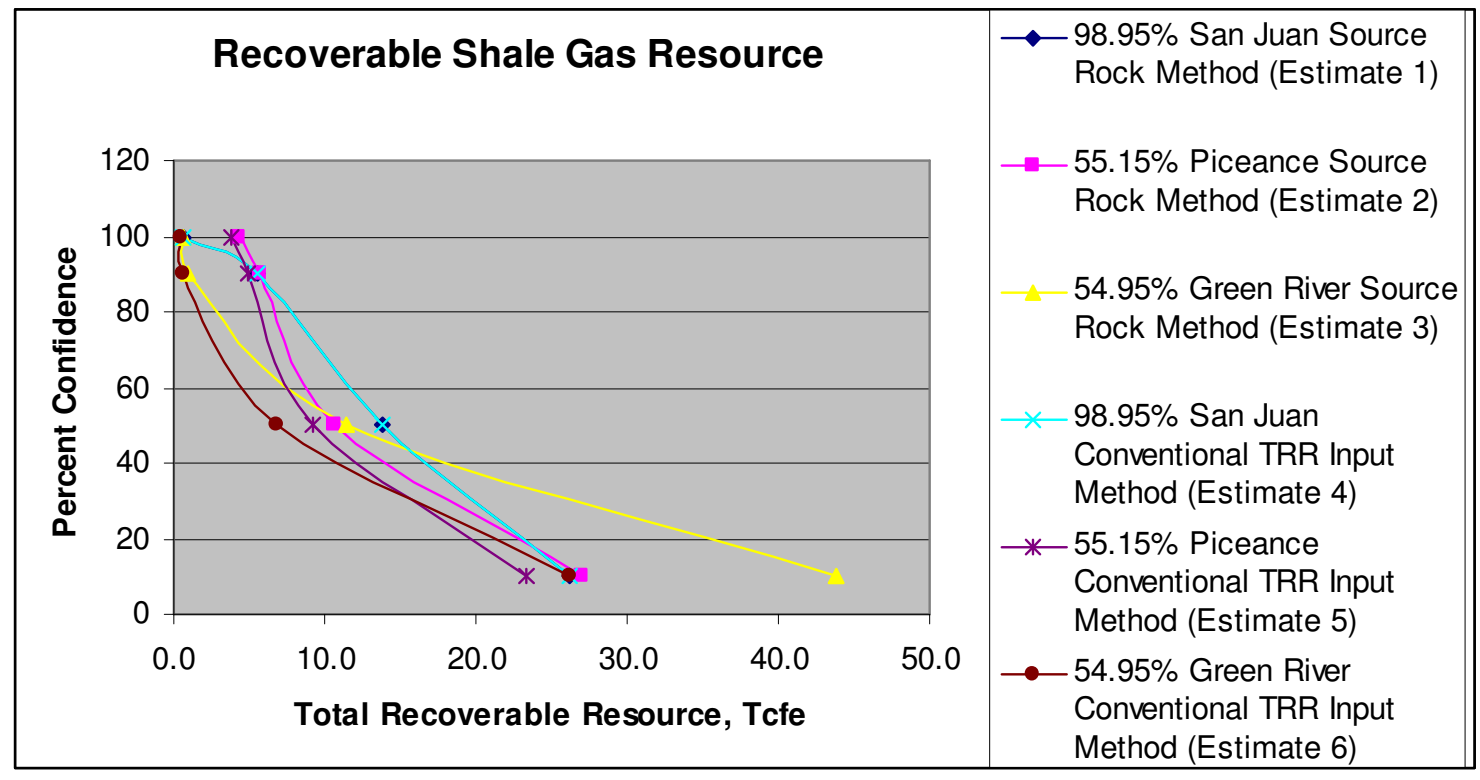

Fig. 5.13: PRISE: Estimated Shale Gas Resource Curves in the San Juan Target Basin. 
Table 5.8: PRISE: Estimated Shale Gas Resource Volumes in the San Juan Target Basin. The colors correspond to the colors of the curves in Fig 5.13.

\begin{tabular}{|c|c|c|c|c|}
\hline \multicolumn{5}{|c|}{$\underline{\text { San Juan Target }}$} \\
\hline \multicolumn{5}{|c|}{ Recoverable Resource Volume } \\
\hline Confidence & Estimate 1 & Estimate 2 & Estimate 3 & \\
\hline 100 & 0.6 & 4.3 & 0.7 & Tcfe \\
\hline 90 & 5.5 & 5.6 & 1.0 & Tcfe \\
\hline 50 & 13.9 & 10.6 & 11.5 & Tcfe \\
\hline 10 & 26.2 & 27.1 & 43.9 & Tcfe \\
\hline Confidence & Estimate 4 & Estimate 5 & Estimate 6 & \\
\hline 100 & 0.6 & 3.7 & 0.4 & Tcfe \\
\hline 90 & 5.5 & 4.9 & 0.6 & Tcfe \\
\hline 50 & 13.9 & 9.1 & 6.8 & Tcfe \\
\hline 10 & 26.2 & 23.3 & 26.2 & Tcfe \\
\hline
\end{tabular}

Conventional gas estimates are illustrated in Fig. 5.14 and Table 5.9. Estimates 1 and 4 are approximately the same and are equal the San Juan analog reference basin conventional gas volumes (Fig. 4.4). 


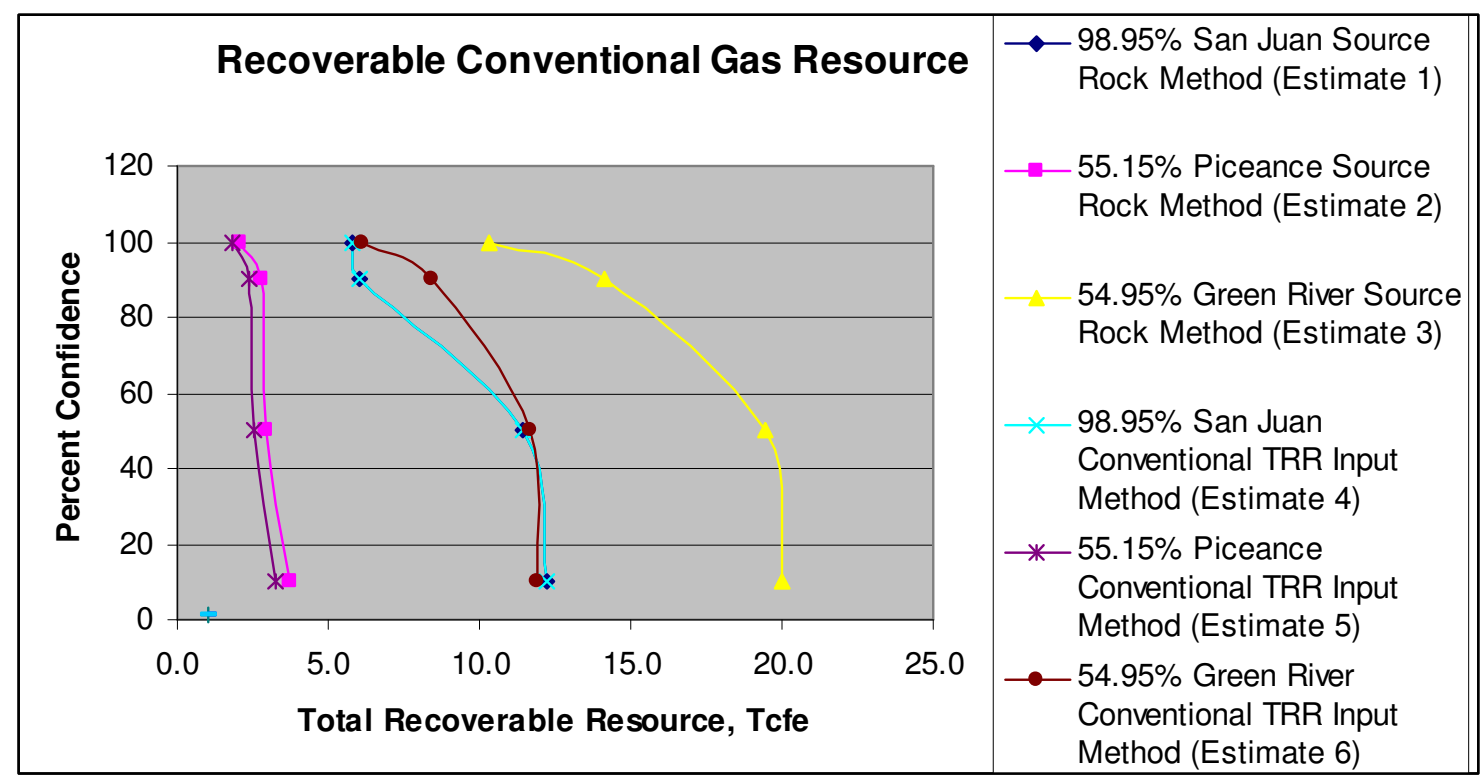

Fig. 5.14: PRISE: Estimated Conventional Gas Resource Curves in the San Juan Target Basin.

Table 5.9: PRISE: Estimated Conventional Gas Resource Volumes in the San Juan Target Basin. The colors correspond to the colors of the curves in Fig 5.14.

\begin{tabular}{|c|c|c|c|c|}
\hline \multicolumn{5}{|c|}{$\begin{array}{l}\text { San Juan Target } \\
\text { Recoverable Conventional Gas Resource }\end{array}$} \\
\hline \multicolumn{5}{|c|}{ Recoverable Resource Volume } \\
\hline Confidence & Estimate 1 & Estimate 2 & Estimate 3 & \\
\hline 100 & 5.8 & 2.1 & 10.3 & \multirow{4}{*}{$\begin{array}{l}\text { Tcfe } \\
\text { Tcfe } \\
\text { Tcfe } \\
\text { Tcfe } \\
\end{array}$} \\
\hline 90 & 6.0 & 2.8 & 14.1 & \\
\hline 50 & 11.4 & 2.9 & 19.5 & \\
\hline 10 & 12.2 & 3.8 & 20.0 & \\
\hline Confidence & Estimate 4 & Estimate 5 & Estimate 6 & \\
\hline 100 & 5.8 & 1.8 & 6.1 & Tcfe \\
\hline 90 & 6.0 & 2.4 & 8.4 & Tcfe \\
\hline 50 & 11.4 & 2.5 & 11.6 & Tcfe \\
\hline 10 & 12.2 & 3.2 & 11.9 & Tcfe \\
\hline
\end{tabular}


Conventional oil estimates are illustrated in Fig. 5.15 and Table 5.10. Estimates 1 and 4 are approximately the same and are equal the San Juan analog reference basin conventional oil volumes (Fig. 4.4).

The differences in estimated volumes based on the Piceance and Green River analog reference basin, relative to the San Juan analog reference basin, are due to differences in the percentages of the resource type in those reference basins.

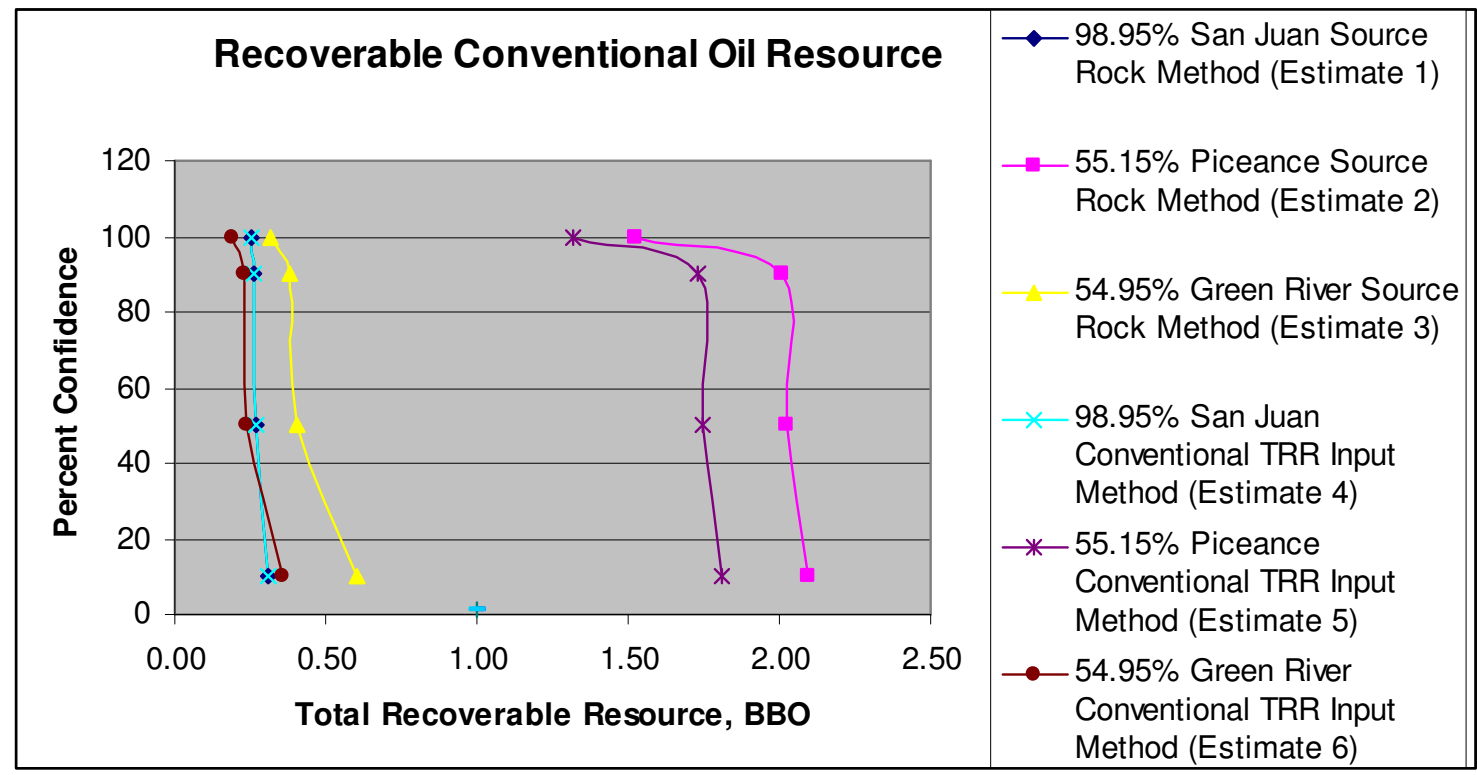

Fig. 5.15: PRISE: Estimated Conventional Oil Resource Curves in the San Juan Target Basin. 
Table 5.10: PRISE: Estimated Conventional Oil Resource Volumes in the San Juan

Target Basin. The colors correspond to the colors of the curves in Fig 5.15.

\begin{tabular}{|c|c|c|c|c|}
\hline \multicolumn{5}{|c|}{$\begin{array}{c}\underline{\text { San Juan Target }} \\
\text { Recoverable Conventional Oil Resource }\end{array}$} \\
\hline \multicolumn{5}{|c|}{ Recoverable Resource Volume } \\
\hline Confidence & Estimate 1 & Estimate 2 & Estimate 3 & \\
\hline 100 & 0.25 & 1.53 & 0.32 & BBO \\
\hline 90 & 0.26 & 2.01 & 0.38 & BBO \\
\hline 50 & 0.27 & 2.02 & 0.40 & BBO \\
\hline 10 & 0.31 & 2.10 & 0.60 & BBO \\
\hline Confidence & Estimate 4 & Estimate 5 & Estimate 6 & \\
\hline 100 & 0.25 & 1.32 & 0.19 & BBO \\
\hline 90 & 0.26 & 1.73 & 0.23 & BBO \\
\hline 50 & 0.27 & 1.74 & 0.24 & BBO \\
\hline 10 & 0.31 & 1.81 & 0.36 & BBO \\
\hline
\end{tabular}

In this test run for the San Juan target basin the SR and CTRRI methods in PRISE produced similar TRR results. A step-by-step process of each of the three estimates from the SR method can be seen in Fig. 5.5. The step-by-step process for the three estimates from the CTRRI method is in Fig. 5.6. Estimates 1-3 were determined by the SR method (Fig. 5.5), whereas estimates 4-6 were determined by the CTRRI method (Fig. 5.6). The final PRISE output from the SR and CTRRI run is a twelve-page, printable report containing figures and tables like those of Figs. 5.8 - Fig. 5.15 and Tables 5.3 - Table 5.10 for the San Juan target basin example. The final report includes the resource trees for the three analog reference basins, like Fig. 4.4.

PRISE should allow the user to input all known cumulative production volumes. When cumulative production is known then the estimated C100 values should equal cumulative production. If cumulative production is not known, then the $\mathrm{C} 100$ values 
should be zero. This will allow all six the estimated resource curves to have the same C100 value. This is more appropriate for building the resource curves because if there is any production it is known. Estimating C100 values does not provide meaning for the target basin unless it can be estimated as a function of time because production is a function of time and development. PRISE will be changed for future versions to use known cumulative production volumes for the target basin as an anchor point for the resource curves.

The San Juan target basin example, we just presented, should have the same C100 value for six estimates for all resource types because we have quantified and know the cumulative production volumes. The C100 value for the San Juan target basin should be 45.6 Tcfe from Fig. 4.4 for all six estimates in Fig. 5.8 and Table 5.3. The C100 value for conventional resources should be 7.3 Tcfe from Fig. 4.4 for all six estimates in Fig. 5.9 and Table 5.4. The C100 value for unconventional resources should be 38.3 Tcfe from Fig. 4.4 for all six estimates in Fig. 5.10 and Table 5.5. The C100 value for TGS resources should be 23.6 Tcfe from Fig. 4.4 for all six estimates in Fig. $\mathbf{5 . 1 1}$ and Table 5.6. The C100 value for CBM resources should be 14.1 Tcfe from Fig. $\mathbf{4 . 4}$ for all six estimates in Fig. 5.12 and Table 5.7. The C100 value for SG resources should be .6 Tcfe from Fig. 4.4 for all six estimates in Fig. 5.13 and Table 5.8. The C100 value for conventional gas resources should be 5.8 Tcfe from Fig. 4.4 for all six estimates in Fig. 5.14 and Table 5.9. The C100 value for conventional oil resources should be .254 BBO from Fig. 4.4 for all six estimates in Fig. 5.15 and Table 5.10. 
We did not use statistical analysis to generate the resource distributions. If we implement a method to properly quantify uncertainty it will make the resource distributions more meaningful. Using the confidence level naming convention, as a means for data comparison and analysis, works for the first version of PRISE resource distributions. 


\section{CHAPTER VI}

\section{CONCLUSIONS AND RECOMMENDATIONS}

\subsection{Conclusions}

Based on the results of this study, we conclude the following:

1. Public data can be used to estimate technically recoverable resources in target basins, on the basis of comparisons with analog reference basins.

2. Classifications of oil and gas resources vary among the reporting agencies, which made compilation of resources into common resource categories difficult. To develop resource categories for PRISE, we evaluated the reporting agencies' purposes, methodologies, terminology, data sources, and definitions by "mapping" resource categories among the agencies. We created PRISE resource categories and definitions that encompassed approaches used by the reporting agencies. These categories are cumulative production, proved reserves, growth, and undiscovered resources. Our definitions and results of the "mapping" project allowed us to use data from multiple agencies for a resource comparison and estimations.

3. Resource data were collected for the Appalachian, Black Warrior, Greater Green River, Illinois, San Juan, Uinta-Piceance, and Wind River basins.

4. We determined that $90 \%$ of the total recoverable resource (TRR) is unconventional resources (TGS, CBM, and SG). The consistent ratio of 
approximately $10 \%$ conventional and $90 \%$ unconventional TRR for the seven evaluated basins suggests that the resource triangle is a valid concept.

5. We developed two methods to estimated TRR in target basins. For the SR method, target basin source rock data are needed to calculate VRMOC and then Eq. 5.8 is used to determine the TRR for the target basin. The CTTRI method uses data input for the conventional $\mathrm{C} 10$ volumes in the target basin and Eq. 5.9 to estimate TRR for the target basin.

6. We developed a preliminary version of PRISE software that lists and graphs TRR results for target basin. It was validated against known resources in the San Juan basin, with the estimated resource volumes from both estimation methods equaling the PRISE quantified resource volumes.

\subsubsection{Limitations}

Although we successfully completed our objectives for this project, we know there may be some limitations in our results. PRISE estimate methods are based on our interpretation of agency data and our source rock evaluation. A limitation of this study may be that the results reflect the basins we chose to test the PRISE methodologies.

Another limitation is that we developed and justified these methods based on the conclusion that conventional resources are $10 \%$ of the TRR and unconventional resources are $90 \%$ of the TRR. So far, the data suggest that there is good reason to believe that these percentages will be the case for conventional and unconventional resources in other North American basins. However, further studies are needed to verify our conclusion. The source rock volume may be erroneous, since we can only use the 
basin area to determine source rock volume. Also, we modified Schmoker's hydrocarbon (HC) generation model to utilize vitrinite reflectance $\left(\mathrm{R}_{\mathrm{o}}\right)$, since we did not have data for hydrogen index (HI). The approach for calculating VRMOC requires proper analysis of all source rocks and continual updating with new basins. It could be improved by determining precise area of the individual source rocks and a more detailed analysis of TOC and $\mathrm{R}_{\mathrm{O}}$.

Another limitation is the VRMOC approach used in the SR method. The VRMOC relationship with TRR only considers source rock data for comparison. We did not consider drilling history, completion types, and $\mathrm{HC}$ trapping mechanisms. We know these subjects are important to understanding basin development, but we were able to demonstrate that VRMOC is more than 90 of the controlling factor on TRR (Figs. 5.1 and 5.3). Trapping mechanisms may not be as important as they were once considered because $90 \%$ of the TRR is unconventional resources. In many instances UNC resources are self sourced and self contained HC reservoirs that require no trapping mechanism. ${ }^{3}$ Therefore, trapping mechanisms are not as important because they are only needed for $10 \%$ of the TRR in North American basins. Also, the VRMOC approach may be an artifact of the data because we based the SR method on only four relationships between basin VRMOC and TRR (Fig. 5.1).

We will continue to improve the PRISE methodology. We know that the methods may change as more basins are quantified and added to the VRMOC relationship with TRR. Our methods can only reflect our interpretations of the data we have collected thus far. It is imperative more resource and source rock data are added to PRISE. The 
addition of more data will result in a more complete evaluation of North American basin resources and lead to better estimations of international UG resources.

\subsection{Recommendations}

Although the objectives stated in Chapter II were achieved in this research project, the quantification process, quality of agency data, and PRISE software can be improved. We recommend the following work to enhance PRISE:

1. Quantify oil and gas resources in the remaining North American reference basins and see if the TRR volumes are comprised of approximately $10 \%$ conventional and $90 \%$ unconventional resources;

2. Add the TRR volumes and source rock data to update and validate the relationship between VRMOC and TRR for North American basins, as oil and gas resources are quantified for additional basins;

3. Continually update the oil and gas resource volumes for all 25 reference basins as new data are published;

4. Mathematically determine if the technically recoverable resources in the resource triangle are log normally distributed;

5. Allow PRISE to let users enter cumulative production data for each resource type, if known. The cumulative production is equal the $\mathrm{C} 100$ volumes and should be the anchor for the estimated resource curves. This will make the C100 values more meaningful because they are volumes that are absolute values and should be known by the user and; 
6. We need to use a statistical model to quantify uncertainty in the resource distributions in future versions of PRISE. 


\section{REFERENCES}

1. Singh, K.: "Basin Analog Approach Answers Characterization Challenges of Unconventional Gas Potential in Frontier Basins," MS Thesis, Texas A\&M University, College Station, TX (2006).

2. Singh, K., Holditch, S.A., and Ayers, W.B.: "Basin Analog Investigations Answer Characterization Challenges of Unconventional Gas Potential in Frontier Basins," paper OMAE 2007-29688 presented at the $200726^{\text {th }}$ International Conference on Offshore Mechanics and Arctic Engineering, San Diego, CA, $10-15$ June.

3. Masters, J.A.: "Deep Basin Gas Trap, Western Canada," AAPG Bull. (February 1979) 63, No. 2, 152.

4. Holditch, S.A.: “The Effect of Globalization upon Petroleum Engineering Education," paper SPE 101637 presented at the 2004 SPE Annual Technical Conference and Exhibition, Houston, 26-29 September.

5. Xiong, H., Zillur, R., Holditch, S.A., and Lancaster, D.E.: “A New Approach to Develop Petroleum Engineering Software," paper SPE 36000 presented at the 1996 Petroleum Computer Conference, Dallas, 2-5 June.

6. Curtis, J.B. and Montgomery, S.L.: "Recoverable Natural Gas Resource of the United States: Summary of Recent Estimates," AAPG Bull. (October 2002) 86, No. 10, 1671. 
7. "Potential Supply of Natural Gas in the United States," Potential Gas Committee, Potential Gas Agency, Colorado School of Mines, Golden, CO (November 2007).

8. "Balancing Natural Gas Policy," National Petroleum Council, Library of Congress, Washington, DC (September 2003) 2.

9. "Balancing Natural Gas Policy," National Petroleum Council, Library of Congress, Washington, DC (September 2003) 4.

10. Gas Technology Institute, North American Coalbed Methane Resource Map, Chicago, IL, (2001).

11. Gas Technology Institute, North American Tight Gas Resource Map, Des Plaines, IL, (2001).

12. Gas Research Institute, United States Fractured Shale Gas Resource Map, Chicago, IL, (2000).

13. Schmoker, J.W.: "U.S. Geological Survey Assessment Concepts for Continuous Petroleum Accumulations," US Geological Survey Digital Data Series 69-D, (2005).

14. "U.S. Crude Oil, Natural Gas, and Natural Gas Liquids Reserves 2006 Annual Report," Energy Information Administration, http://www.eia.doe.gov/, October 2007, Downloaded 31 December 2007.

15. Etherington, J., Pollen, T., and Zuccolo, L.: “Comparison of Selected Reserves and Resource Classifications and Associated Definitions," http://www.spe.org/spe- 
site/spe/spe/industry/reserves/OGR_Mapping_Final_Report.pdf, December 2005, Downloaded 24 October 2007.

16. Etherington, J.R. and Ritter, J.E.: “The 2007 SPE/AAPG/WPC/SPEE Reserves and Resource Classification, Definitions, and Guidelines. Defining the Standard!" paper SPE 107693 presented at the 2007 SPE Hydrocarbon Economics and Evaluation Symposium, Dallas, 1-3 April.

17. "Facing the Hard Truths about Energy: A Comprehensive View to 2030 of Global Oil and Natural Gas", National Petroleum Council, Library of Congress, Washington, DC (September 2007).

18. “2007 Petroleum Resource Management System,” SPE, AAPG, WPC, and SPEE, http://www.spe.org/spe-app/spe/industry/reserves/prms.htm, October 2006, Downloaded 24 October 2007.

19. “Tabular Data and Graphical Images in Support of the U.S. Geological Survey National Oil and Gas Assessment -General Reference," United States Geological Survey-NOGA Online, http://certmapper.cr.usgs.gov/data/noga00/natl/tabular/readme.pdf, Downloaded 11 October 2007.

20. "Assessment of Undiscovered Oil and Gas Resources of the San Juan Basin, New Mexico and Colorado, 2002," US Geological Survey, http://pubs.usgs.gov/fs/fs-147-02/FS-147-02.pdf, November 2002, Downloaded 2 October 2007. 
21. "U.S. Coalbed Methane: The Past, Present, and Future, Panel 2 of 2," Energy Information Administration, http://www.eia.doe.gov/oil_gas/rpd/cbmusa2.pdf, November 2007, Downloaded 8 April 2008.

22. "1995 National Oil and Gas Assessment Province Boundaries: U.S. Geological Survey Digital Data Series DDS-30,” US Geological Survey, http://geonsdi.er.usgs.gov/metadata/digital-data/30/boundary.html, Downloaded 19 October 2007.

23. "Potential Supply of Natural Gas in the United States," Potential Gas Committee, Potential Gas Agency, Colorado School of Mines, Golden, CO (April 2003).

24. "Potential Supply of Natural Gas in the United States," Potential Gas Committee, Potential Gas Agency, Colorado School of Mines, Golden, CO (April 2005).

25. “Assessment of Undiscovered Oil and Gas Resources of the Southwestern Wyoming Province, 2002," US Geological Survey, http://pubs.usgs.gov/fs/fs145-02/FS-145-02.pdf, November 2002, Downloaded 24 March 2008.

26. "Assessment of Undiscovered Oil and Gas Resources of Wyoming Thrust Belt Province, 2003," US Geological Survey, http://pubs.usgs.gov/fs/2004/3025/fs2004-3025.pdf, February 2004, Downloaded 24 March 2008.

27. "2005 Assessment of Undiscovered Oil and Gas Resources in Hanna, Laramie, and Shirley Basins Province," US Geological Survey, http://pubs.usgs.gov/fs/2005/3125/pdf/FS-3125.pdf, January 2006, Downloaded 24 March 2008. 
28. Zolotukhin, A.B.: “A Novel Approach to Resources and Reserves

Determination", paper SPE 63199 presented at the 2000 SPE Annual Technical Conference and Exhibition, Dallas, 1-4 October.

29. "Assessment of Undiscovered Oil and Gas Resources in Wind River Basin Province, 2005," US Geological Survey, http://pubs.usgs.gov/fs/2005/3125/pdf/FS-3125.pdf, December 2005, Downloaded 24 March 2008.

30. Schmoker, J. W.: "Volumetric Calculations of Hydrocarbons Generated", The Petroleum System—from Source to Trap, L.B. Magoon and W.G. Dow (eds.), Memoir Series 60, AAPG, Tulsa (1994) Chap. 19, 323-326.

31. Peters, K.E. and Cassa, M.R.: “Applied Source Rock Geochemistry,” The Petroleum System-from Source to Trap, L.B. Magoon and W.G. Dow (eds.), Memoir Series 60, AAPG, Tulsa (1994) Chap. 5, 93-120.

32. Waples, D.W.: Organic Geochemistry for Exploration Geologists, Burgess Publishing Co. Minneapolis, MN, (1981) 1-151.

33. Microsoft Office Excel 2003, Version 11.0.6560, Microsoft Corporation, Redmond, WA (2003). 


\section{APPENDIX A}

\section{RESOURCE TREES}

Fig. A.1 Appalachian Basin Resource Tree

Fig. A.2 Black Warrior Basin Resource Tree

Fig. A.3 Green River Basin Resource Tree

Fig. A.4 Illinois Basin Resource Tree

Fig. A.5 San Juan Basin Resource Tree

Fig. A.6 Uinta-Piceance Basin Resource Tree

Fig. A.7 Wind River Basin Resource Tree 


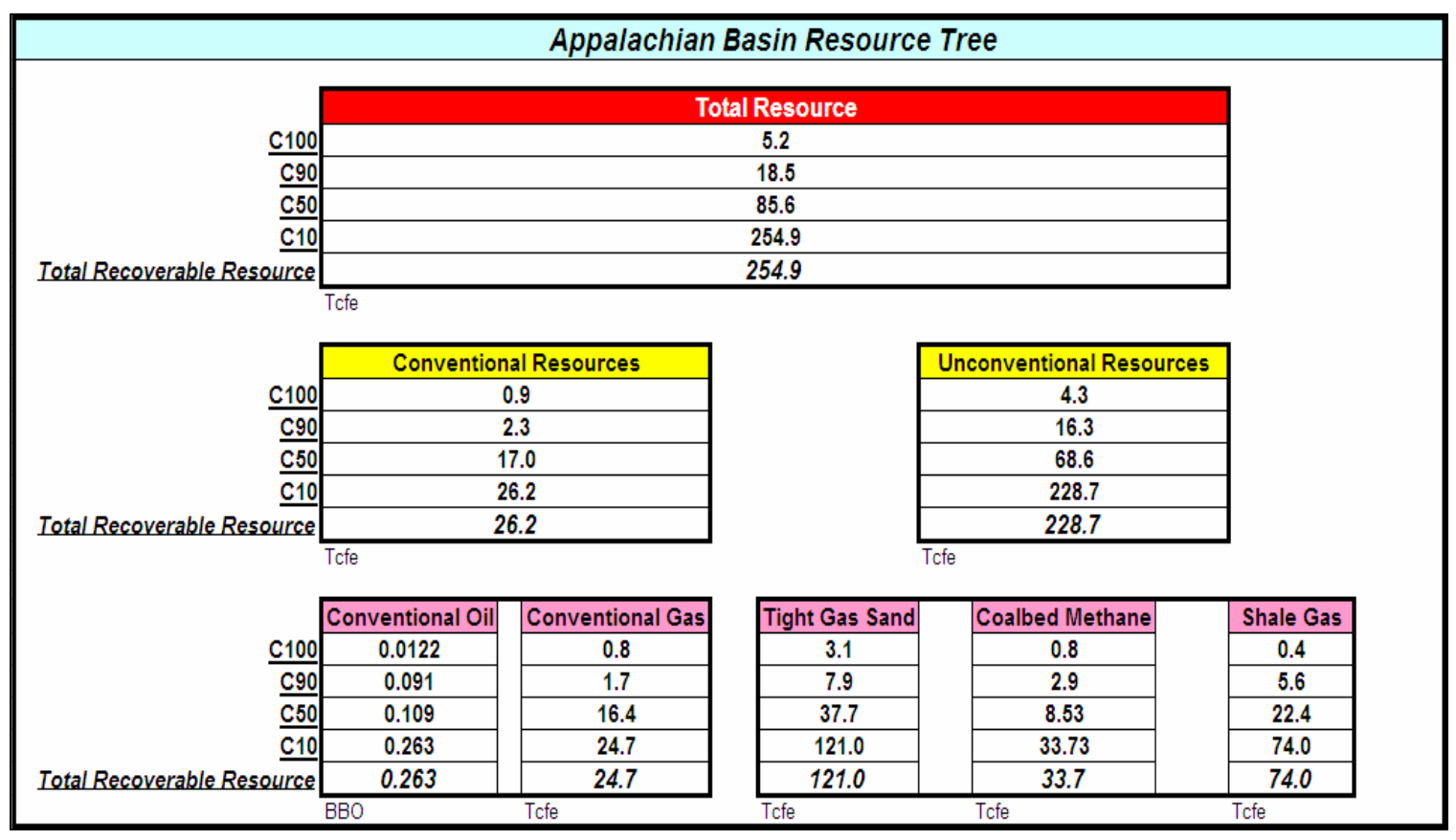

Fig. A.1: Appalachian Basin Resource Tree

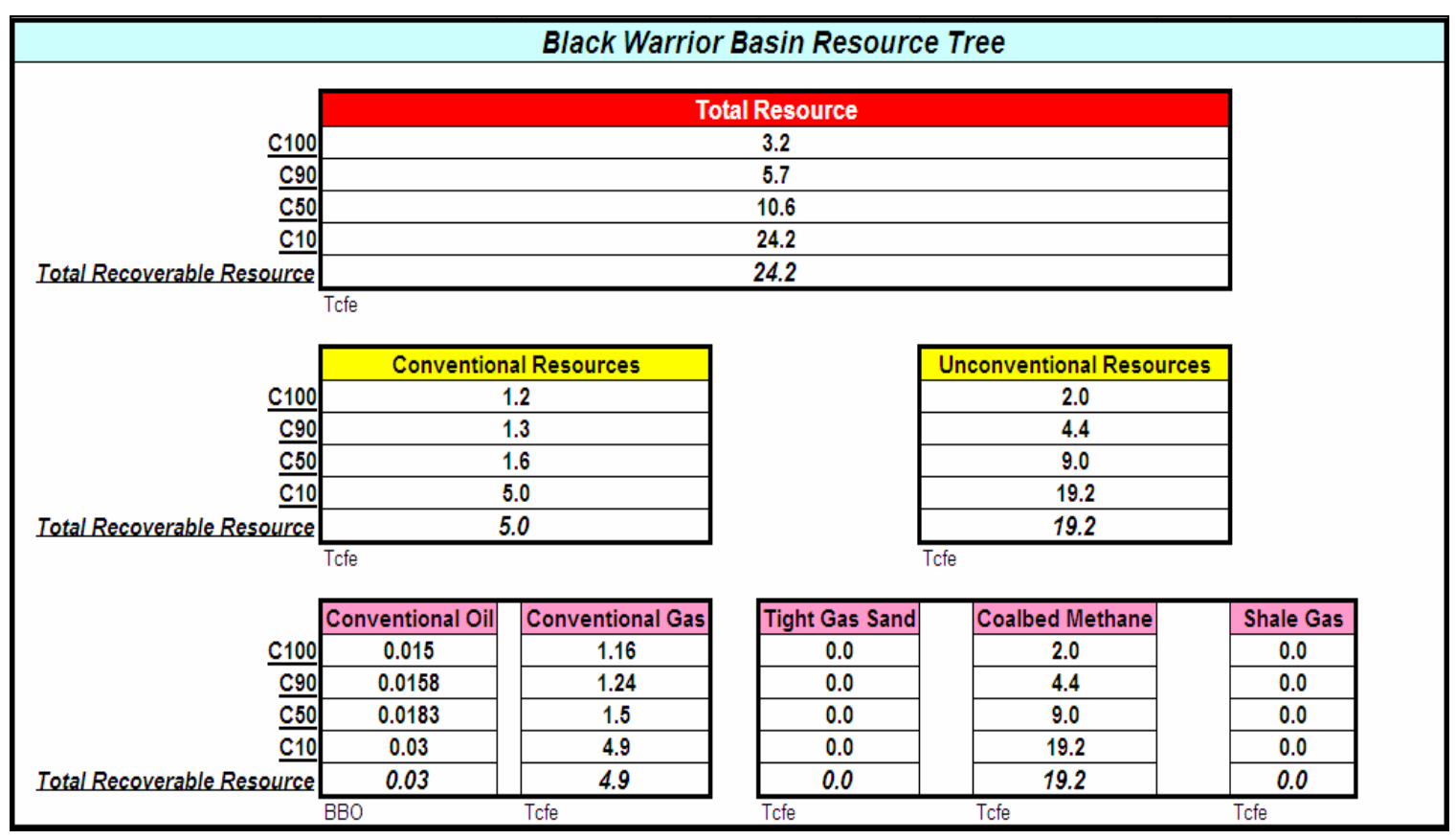

Fig. A.2: Black Warrior Basin Resource Tree 


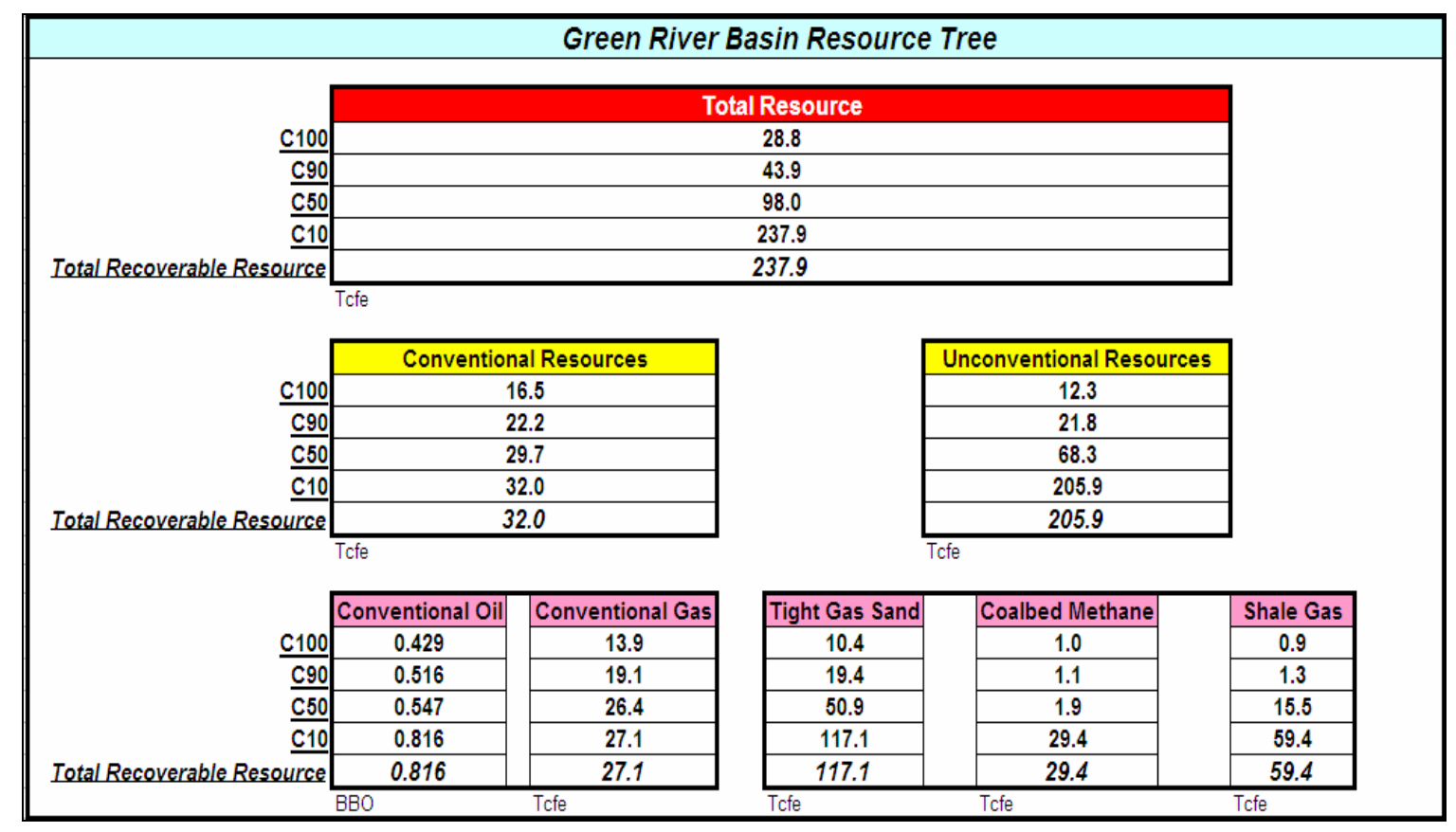

Fig. A.3: Green River Basin Resource Tree

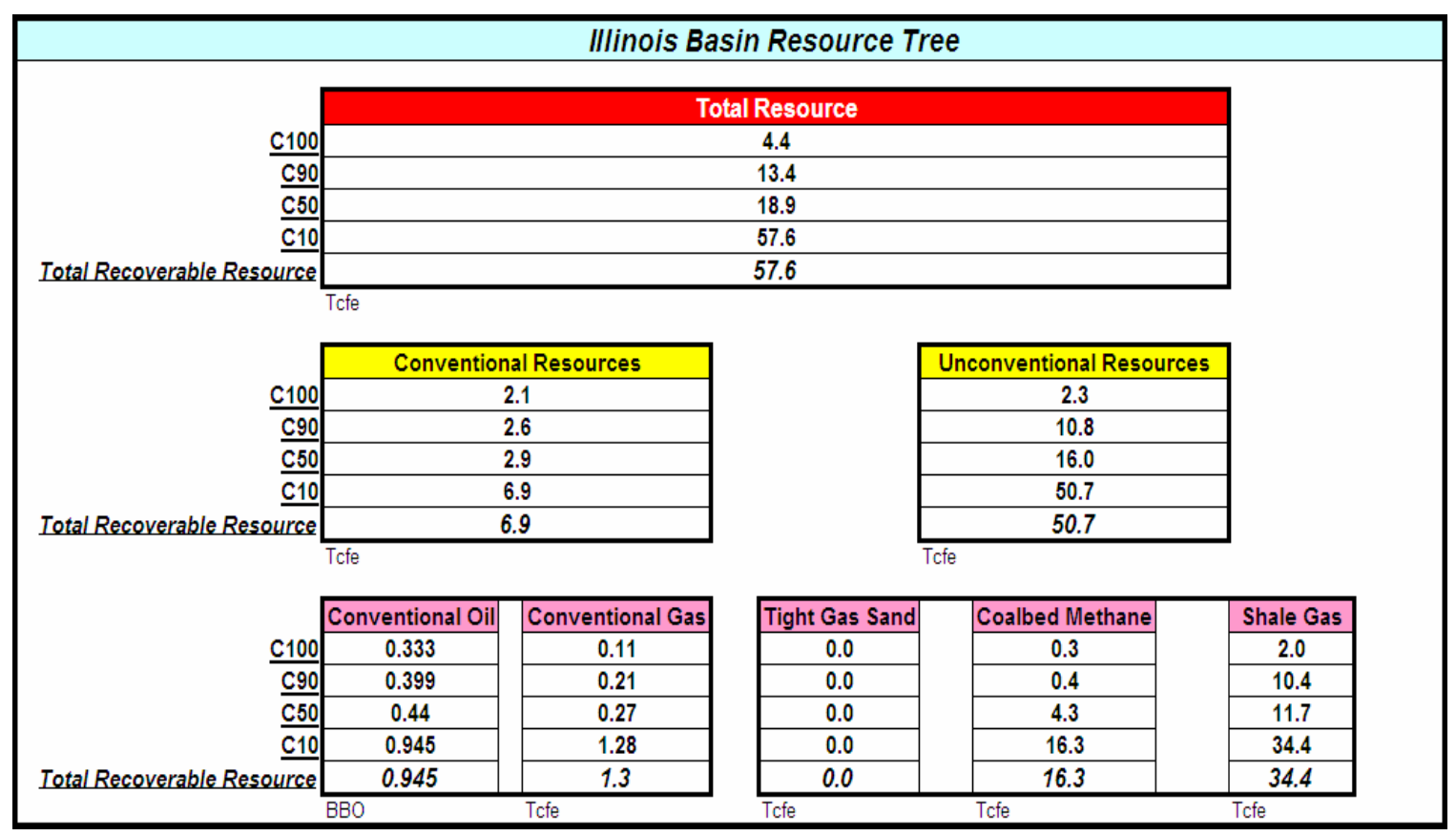

Fig. A.4: Illinois Basin Resource Tree 


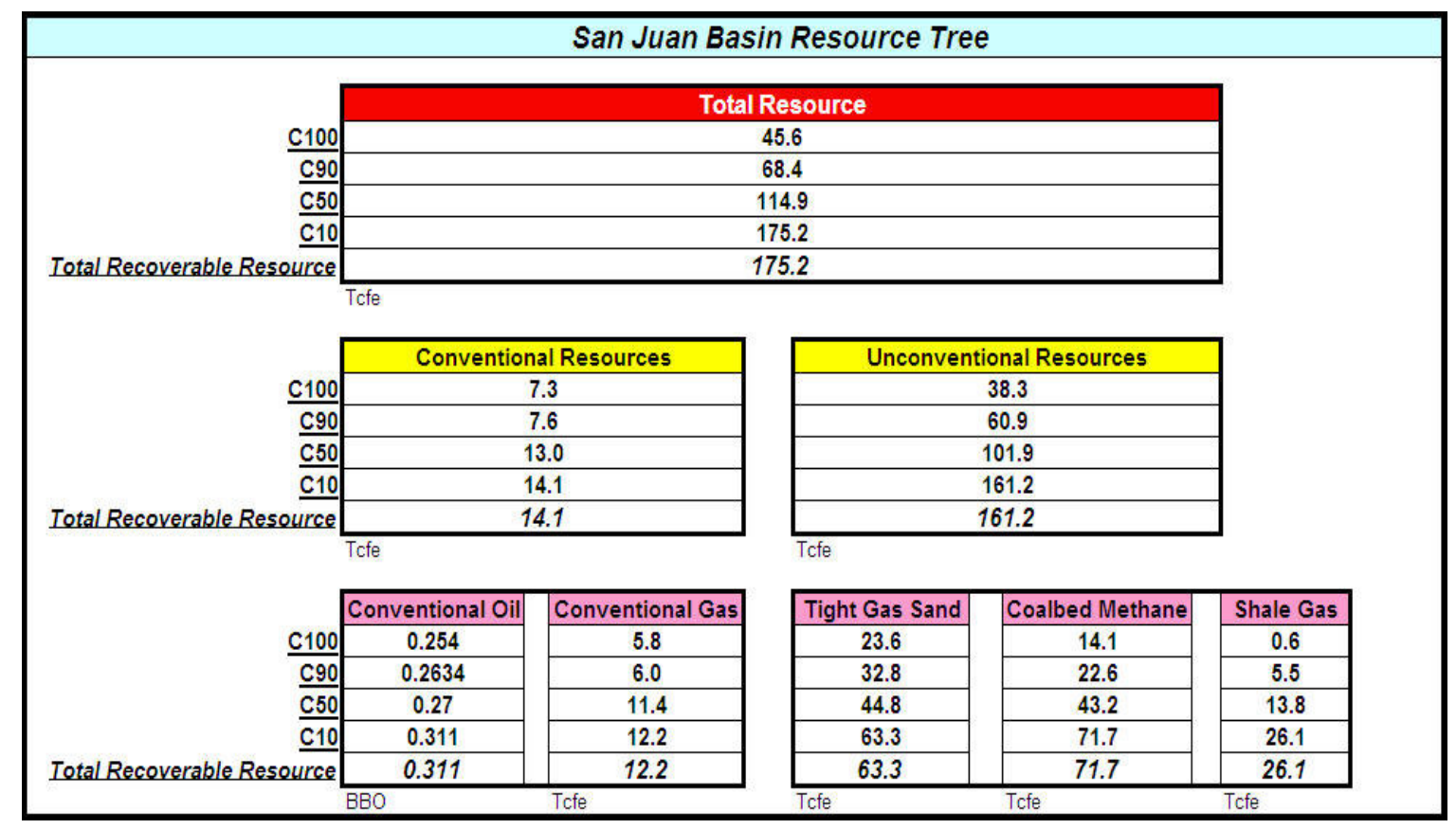

Fig. A.5: San Juan Basin Resource Tree

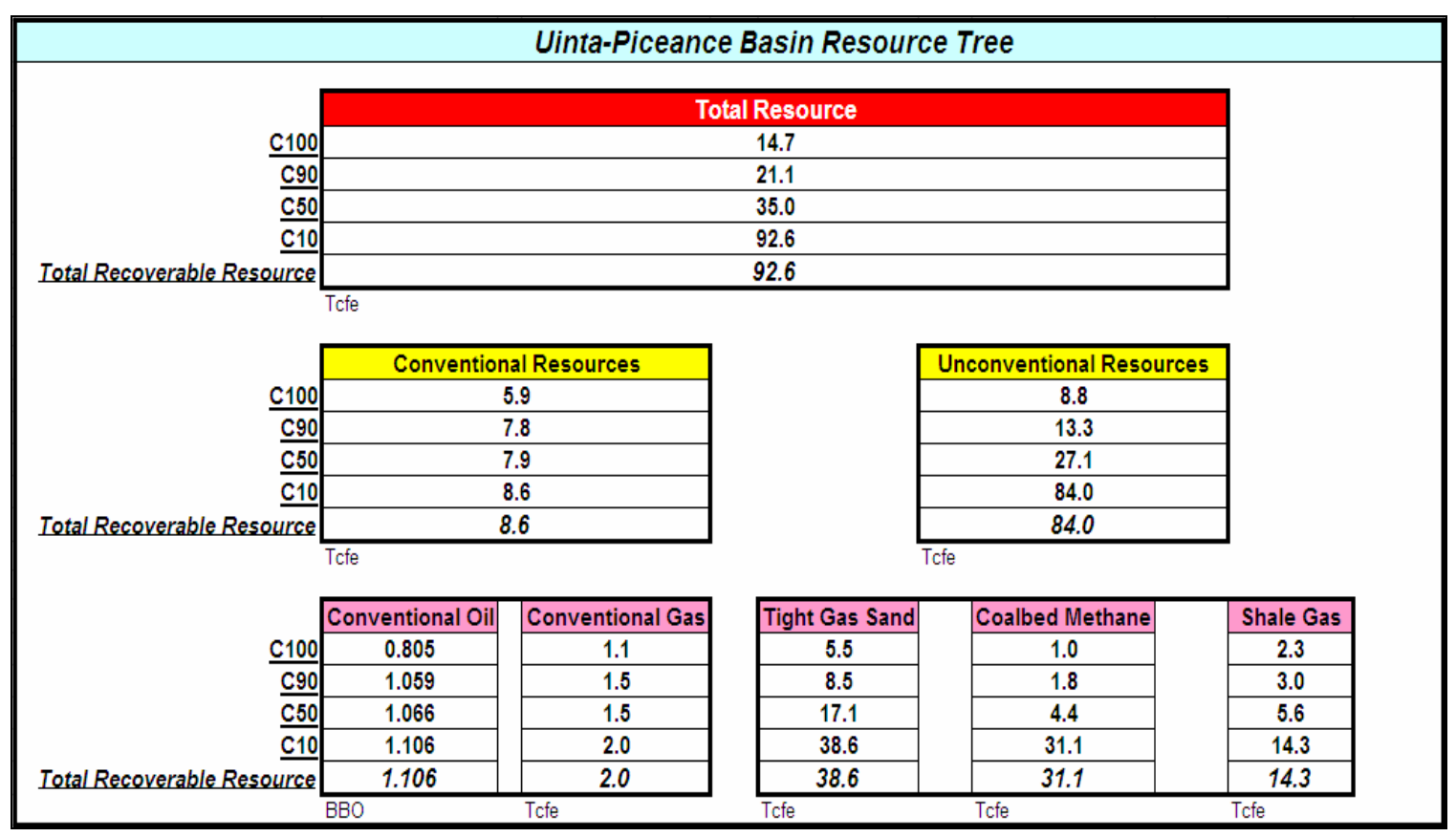

Fig. A.6: Uinta-Piceance Basin Resource Tree 


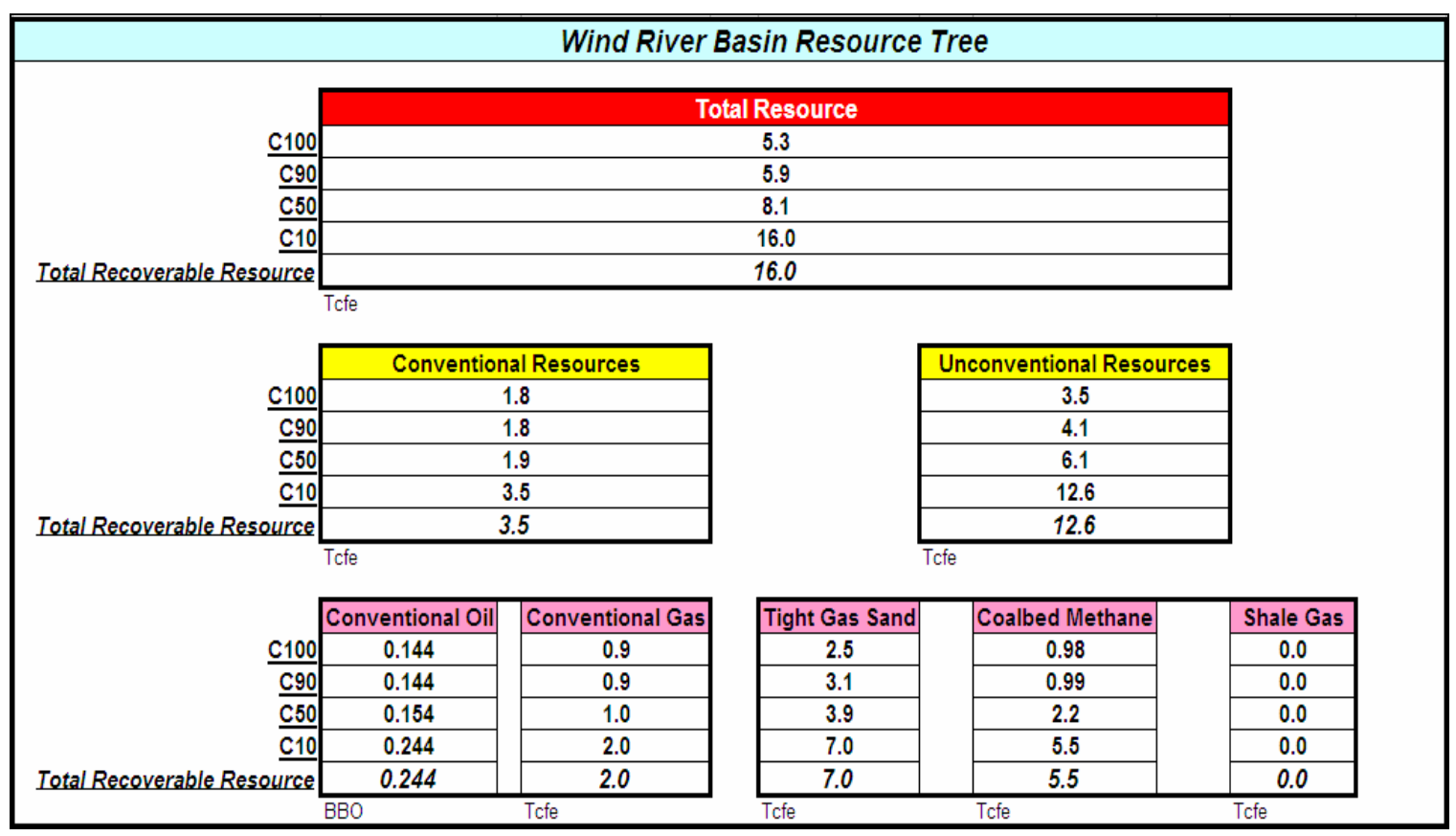

Fig. A.7: Wind River Basin Resource Tree 


\section{APPENDIX B RECOVERABLE RESOURCE CURVES}

Fig. B.1 Appalachian Basin Total Recoverable Resource Curve

Fig. B.2 Black Warrior Basin Total Recoverable Resource Curve

Fig. B.3 Green River Basin Total Recoverable Resource Curve

Fig. B.4 Illinois Basin Total Recoverable Resource Curve

Fig. B.5 San Juan Basin Total Recoverable Resource Curve

Fig. B.6 Uinta-Piceance Basin Total Recoverable Resource Curve

Fig. B.7 Wind River Basin Total Recoverable Resource Curve

Fig. B.8 Appalachian Basin Recoverable Conventional Resource Curve

Fig. B.9 Black Warrior Basin Recoverable Conventional Resource Curve

Fig. B.10 Green River Basin Recoverable Conventional Resource Curve

Fig. B.11 Illinois Basin Recoverable Conventional Resource Curve

Fig. B.12 San Juan Basin Recoverable Conventional Resource Curve

Fig. B.13 Uinta-Piceance Basin Recoverable Conventional Resource Curve

Fig. B.14 Wind River Basin Recoverable Conventional Resource Curve

Fig. B.15 Appalachian Basin Recoverable Unconventional Resource Curve

Fig. B.16 Black Warrior Basin Recoverable Unconventional Resource Curve

Fig. B.17 Green River Basin Recoverable Unconventional Resource Curve 
Fig. B.18 Illinois Basin Recoverable Unconventional Resource Curve

Fig. B.19 San Juan Basin Recoverable Unconventional Resource Curve

Fig. B.20 Uinta-Piceance Basin Recoverable Unconventional Resource Curve

Fig. B.21 Wind River Basin Recoverable Unconventional Resource Curve

Fig. B.22 Appalachian Basin Recoverable Conventional Gas Resource Curve

Fig. B.23 Black Warrior Basin Recoverable Conventional Gas Resource Curve

Fig. B.24 Green River Basin Recoverable Conventional Gas Resource Curve

Fig. B.25 Illinois Basin Recoverable Conventional Gas Resource Curve

Fig. B.26 San Juan Basin Recoverable Conventional Gas Resource Curve

Fig. B.27 Uinta-Piceance Basin Recoverable Conventional Gas Resource Curve

Fig. B.28 Wind River Basin Recoverable Conventional Gas Resource Curve

Fig. B.29 Appalachian Basin Recoverable Conventional Oil Resource Curve

Fig. B.30 Black Warrior Basin Recoverable Conventional Oil Resource Curve

Fig. B.31 Green River Basin Recoverable Conventional Oil Resource Curve

Fig. B.32 Illinois Basin Recoverable Conventional Oil Resource Curve

Fig. B.33 San Juan Basin Recoverable Conventional Oil Resource Curve

Fig. B.34 Uinta-Piceance Basin Recoverable Conventional Oil Resource Curve

Fig. B.35 Wind River Basin Recoverable Conventional Oil Resource Curve

Fig. B.36 Appalachian Basin Recoverable Tight Gas Sand Resource Curve 
Fig. B.37 Green River Basin Recoverable Tight Gas Sand Resource Curve

Fig. B.38 San Juan Basin Recoverable Tight Gas Sand Resource Curve

Fig. B.39 Uinta-Piceance Basin Recoverable Tight Gas Sand Resource Curve

Fig. B.40 Wind River Basin Recoverable Tight Gas Sand Resource Curve

Fig. B.41 Appalachian Basin Recoverable Coalbed Methane Resource Curve

Fig. B.42 Black Warrior Basin Recoverable Coalbed Methane Resource Curve

Fig. B.43 Green River Basin Recoverable Coalbed Methane Resource Curve

Fig. B.44 Illinois Basin Recoverable Coalbed Methane Resource Curve

Fig. B.45 San Juan Basin Recoverable Coalbed Methane Resource Curve

Fig. B.46 Uinta-Piceance Basin Recoverable Coalbed Methane Resource Curve

Fig. B.47 Wind River Basin Recoverable Coalbed Methane Resource Curve

Fig. B.48 Appalachian Basin Recoverable Shale Gas Resource Curve

Fig. B.49 Green River Basin Recoverable Shale Gas Resource Curve

Fig. B.50 Illinois Basin Recoverable Shale Gas Resource Curve

Fig. B.51 San Juan Basin Recoverable Shale Gas Resource Curve

Fig. B.52 Uinta-Piceance Basin Recoverable Shale Gas Resource Curve 


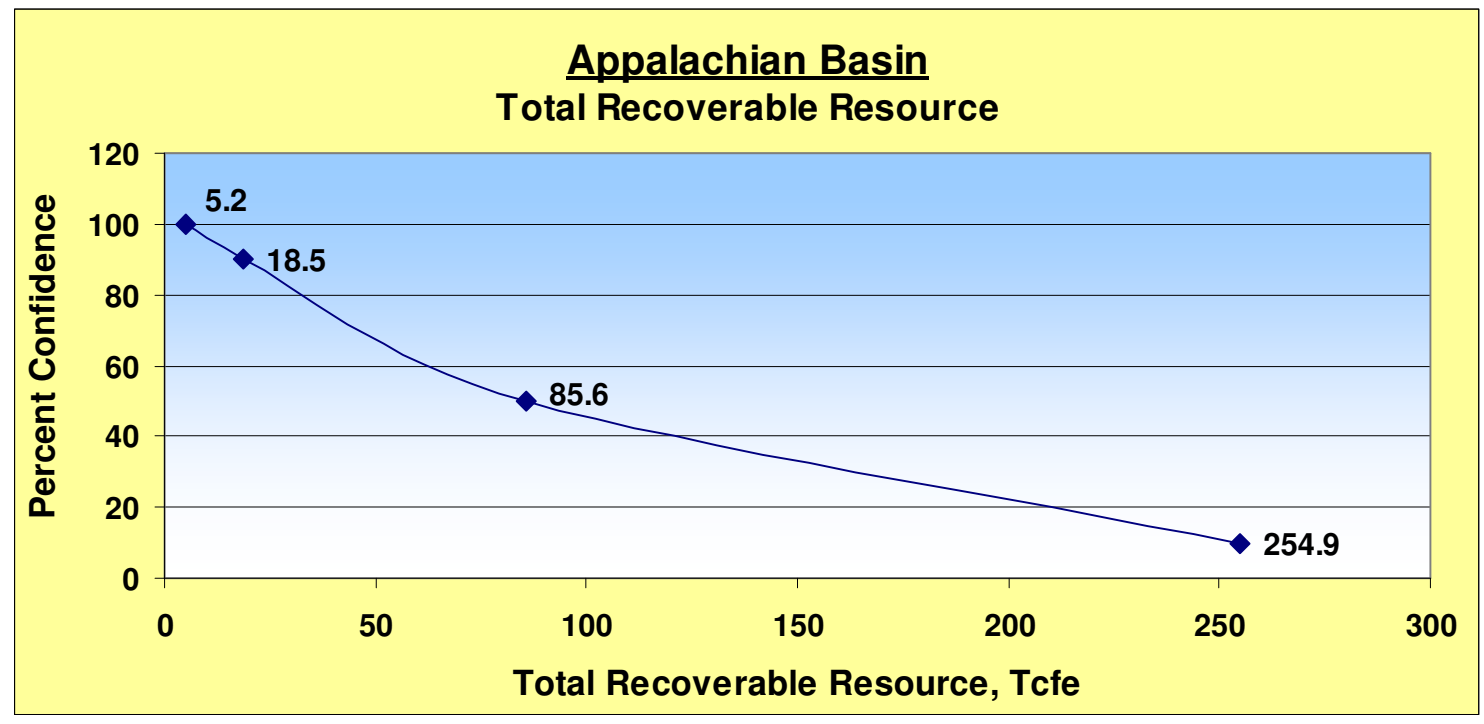

Fig. B.1: Appalachian Basin Total Recoverable Resource Curve

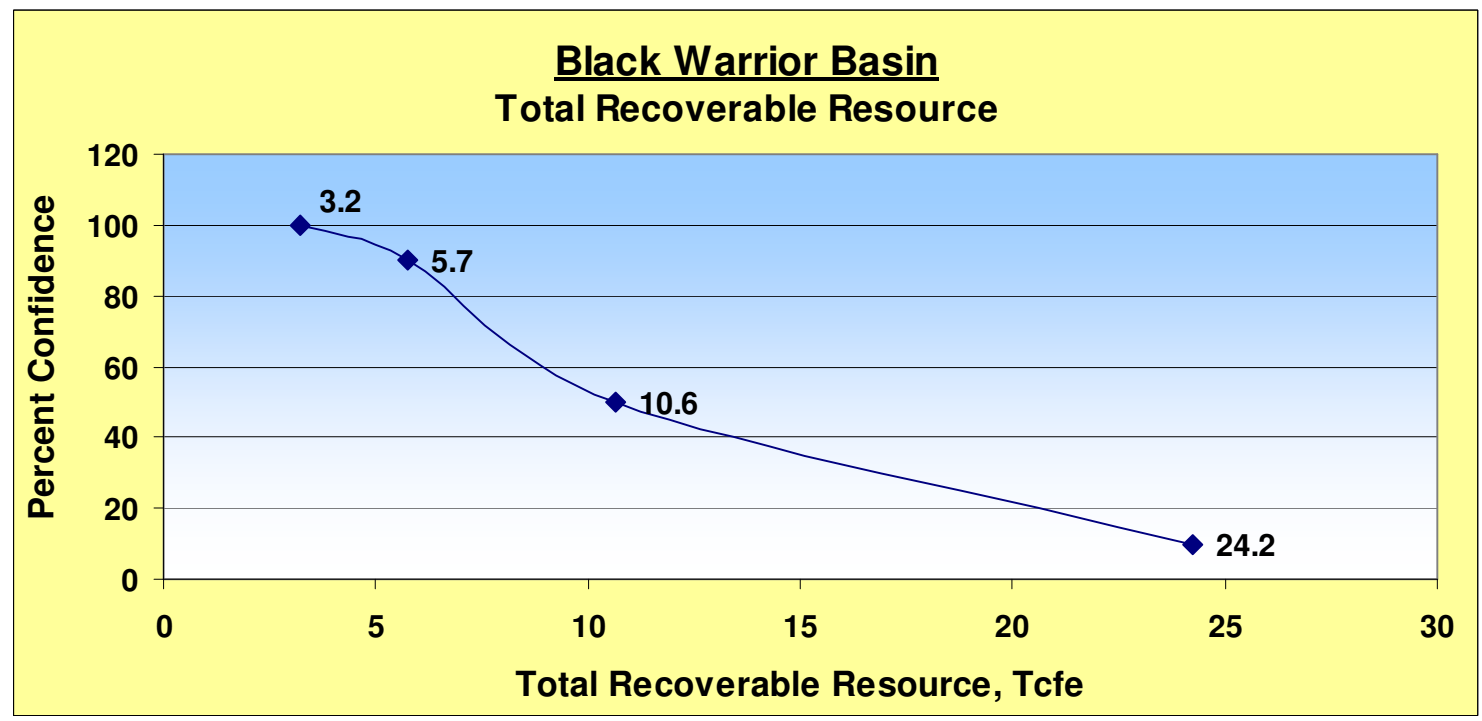

Fig. B.2: Black Warrior Basin Total Recoverable Resource Curve 


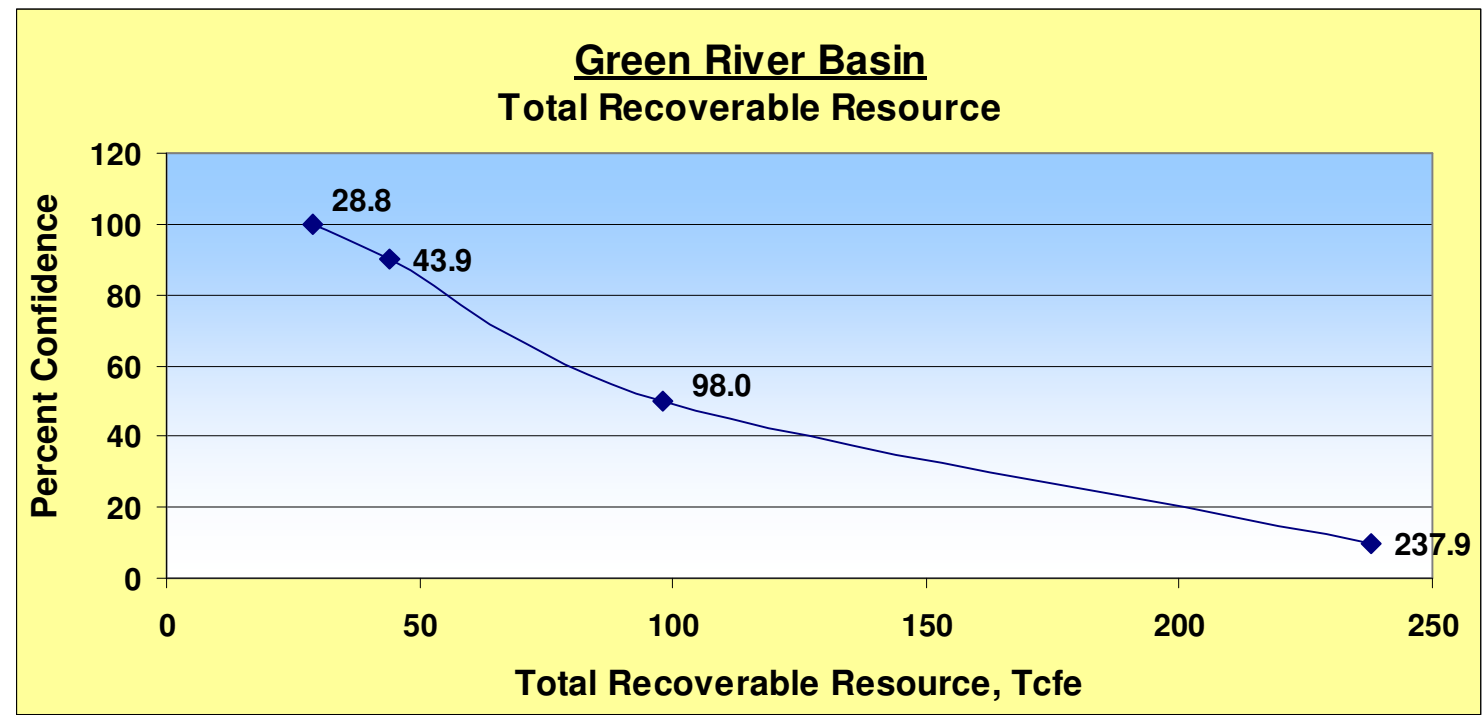

Fig. B.3: Green River Basin Total Recoverable Resource Curve

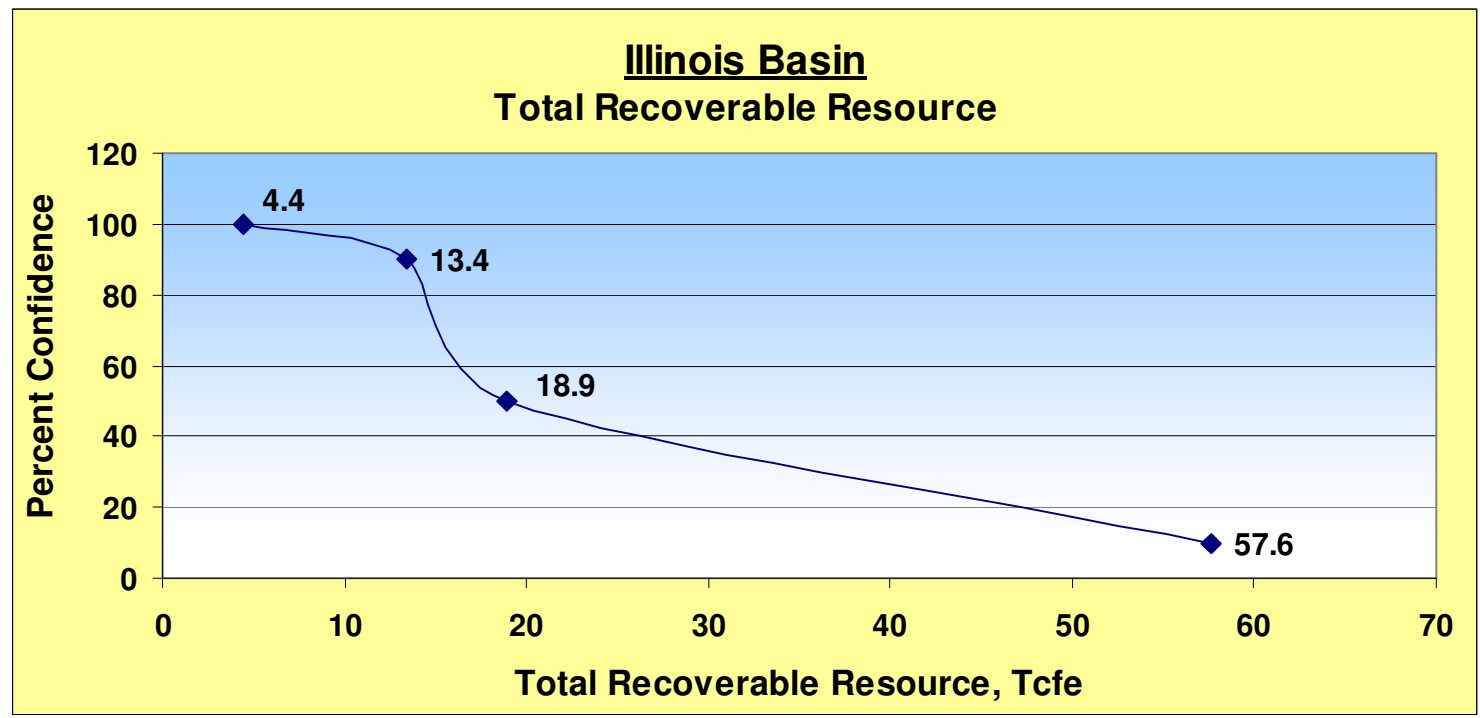

Fig. B.4: Illinois Basin Total Recoverable Resource Curve 


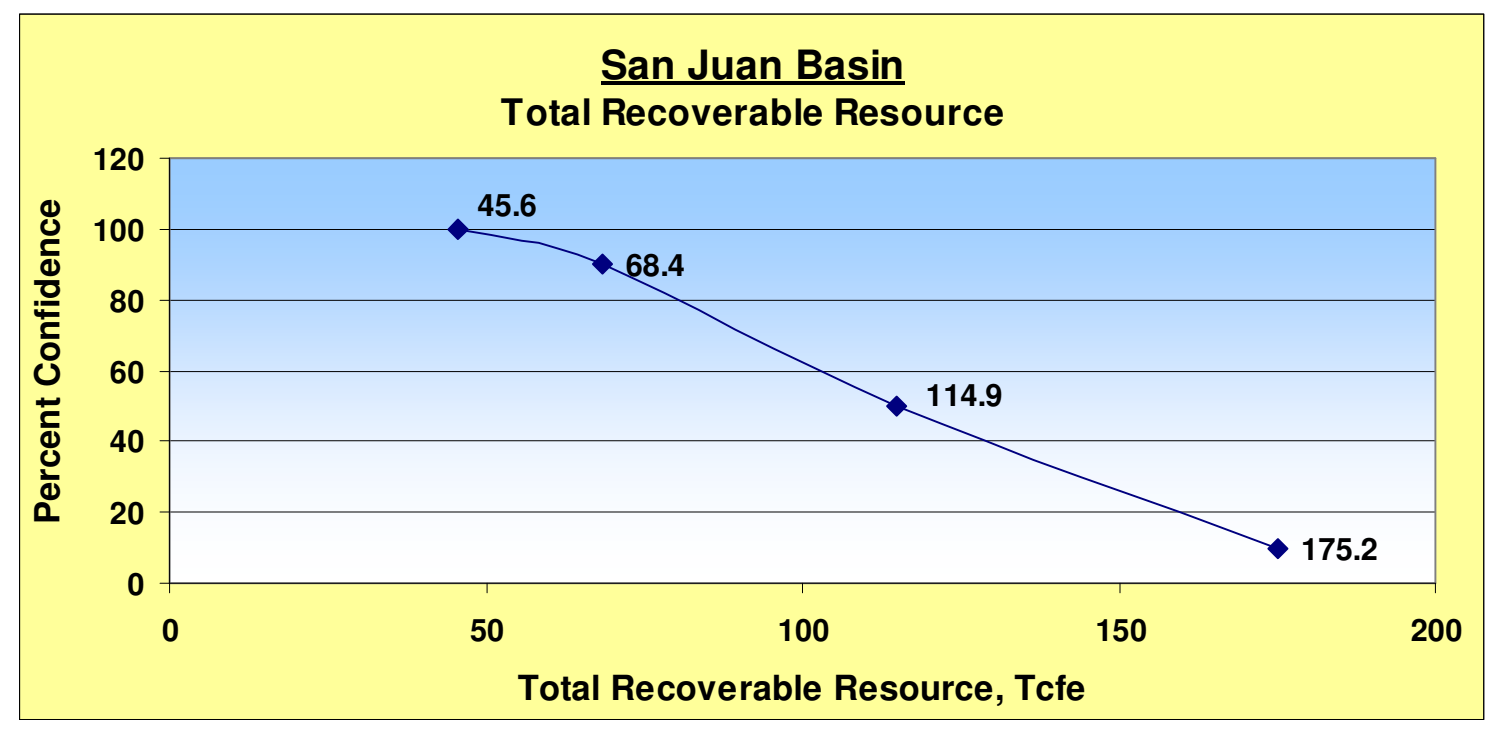

Fig. B.5: San Juan Basin Total Recoverable Resource Curve

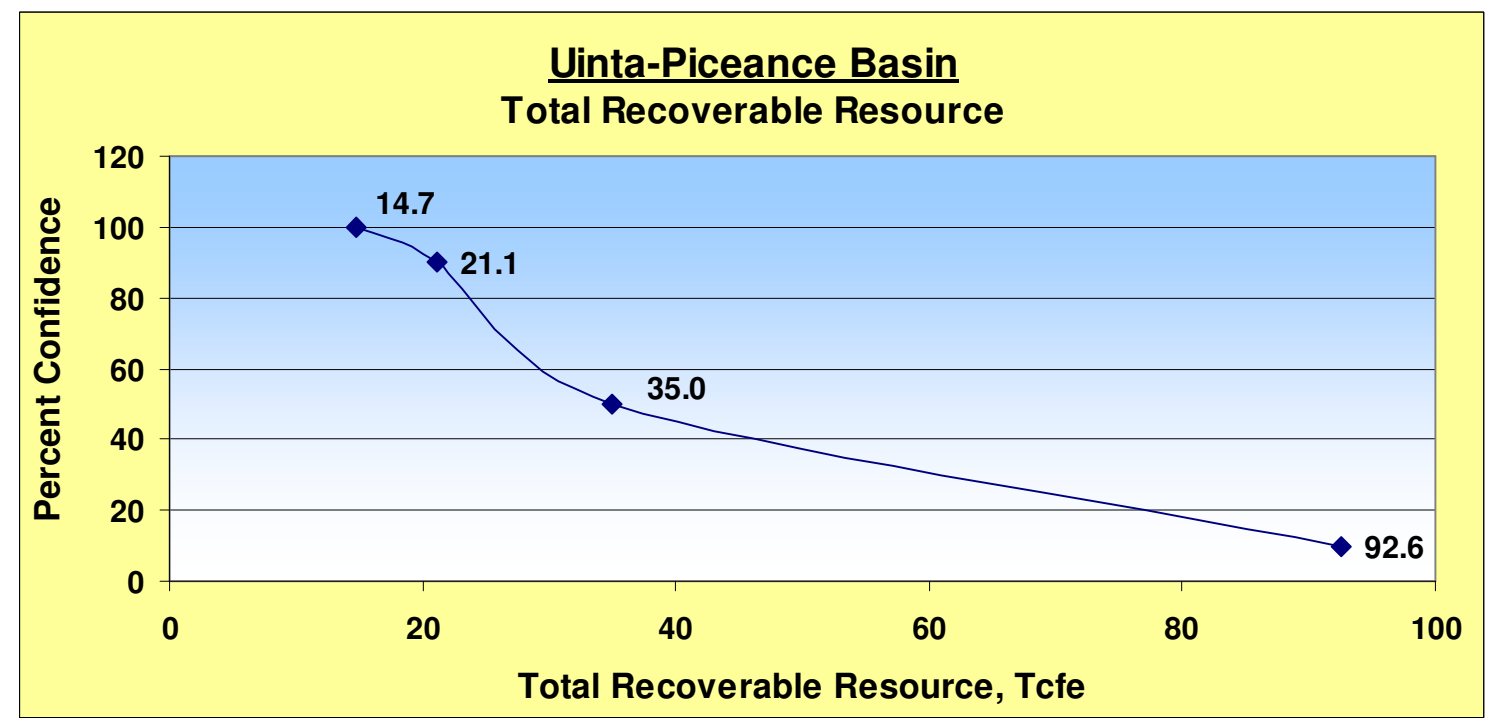

Fig. B.6: Uinta-Piceance Basin Total Recoverable Resource Curve 


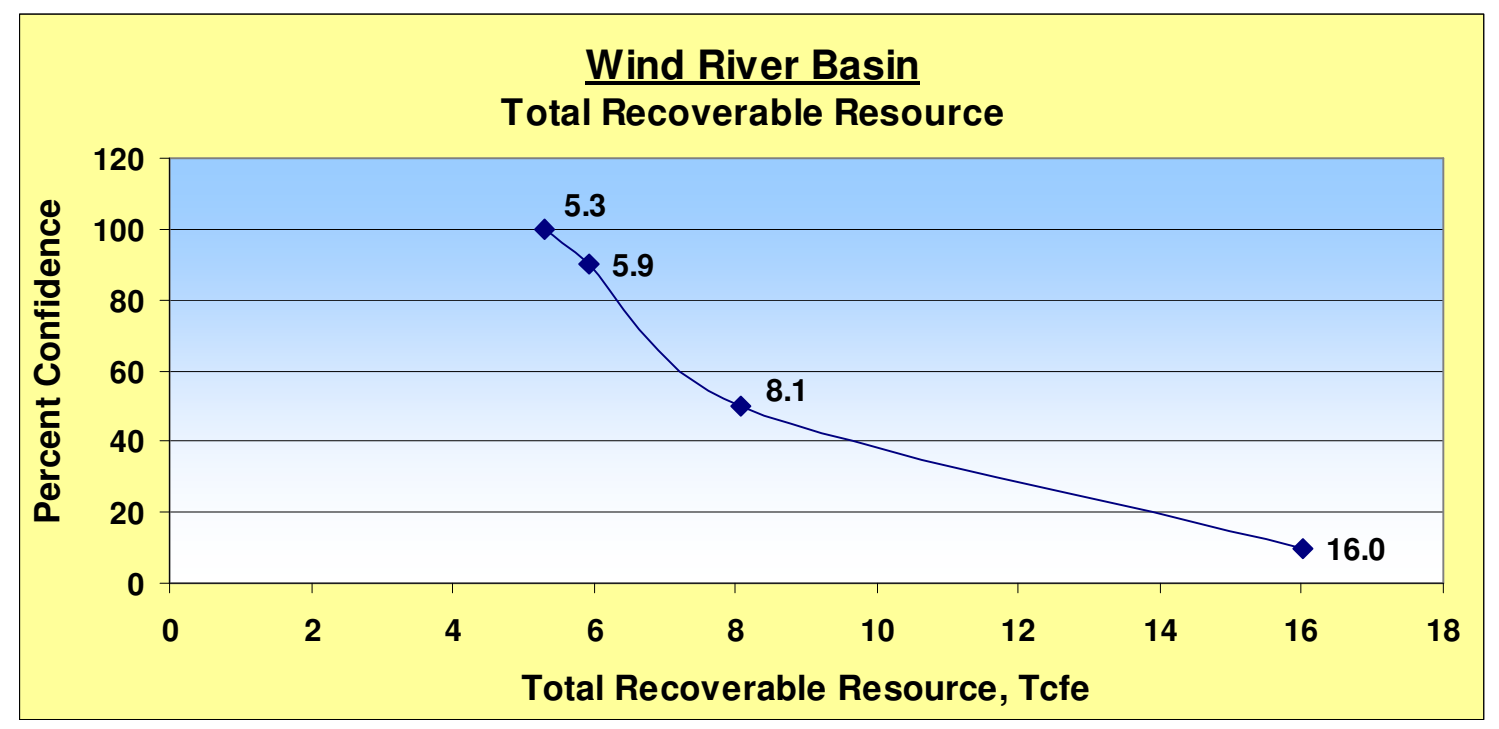

Fig. B.7: Wind River Basin Total Recoverable Resource Curve

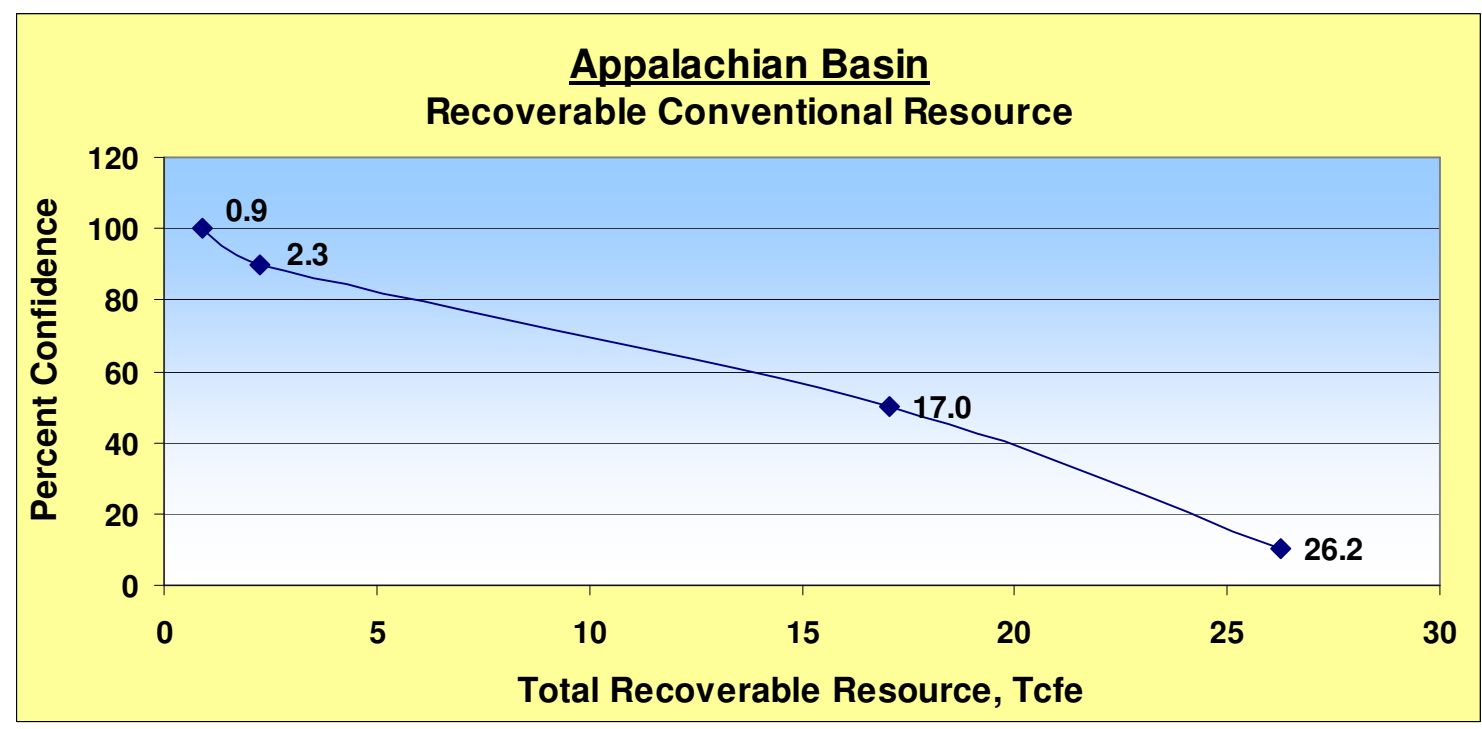

Fig. B.8: Appalachian Basin Recoverable Conventional Resource Curve 


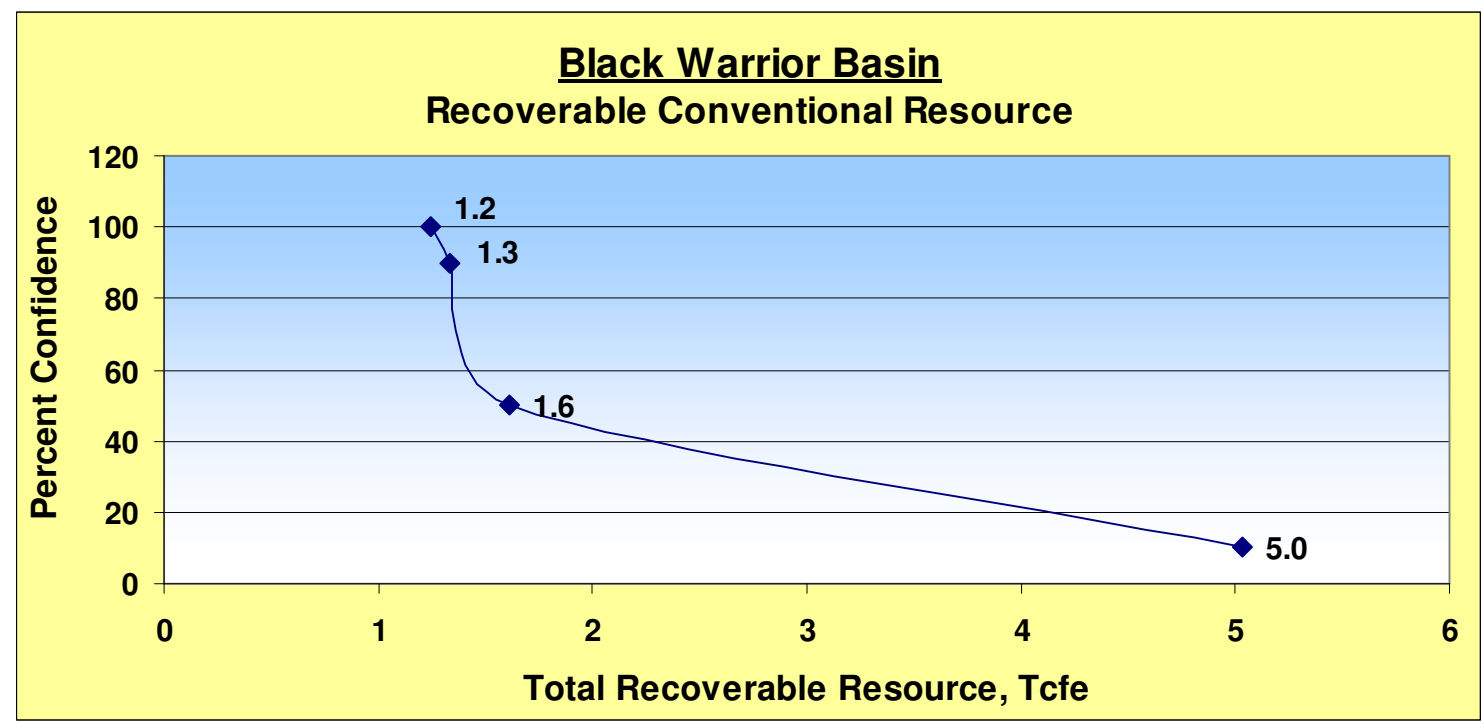

Fig. B.9: Black Warrior Basin Recoverable Conventional Resource Curve

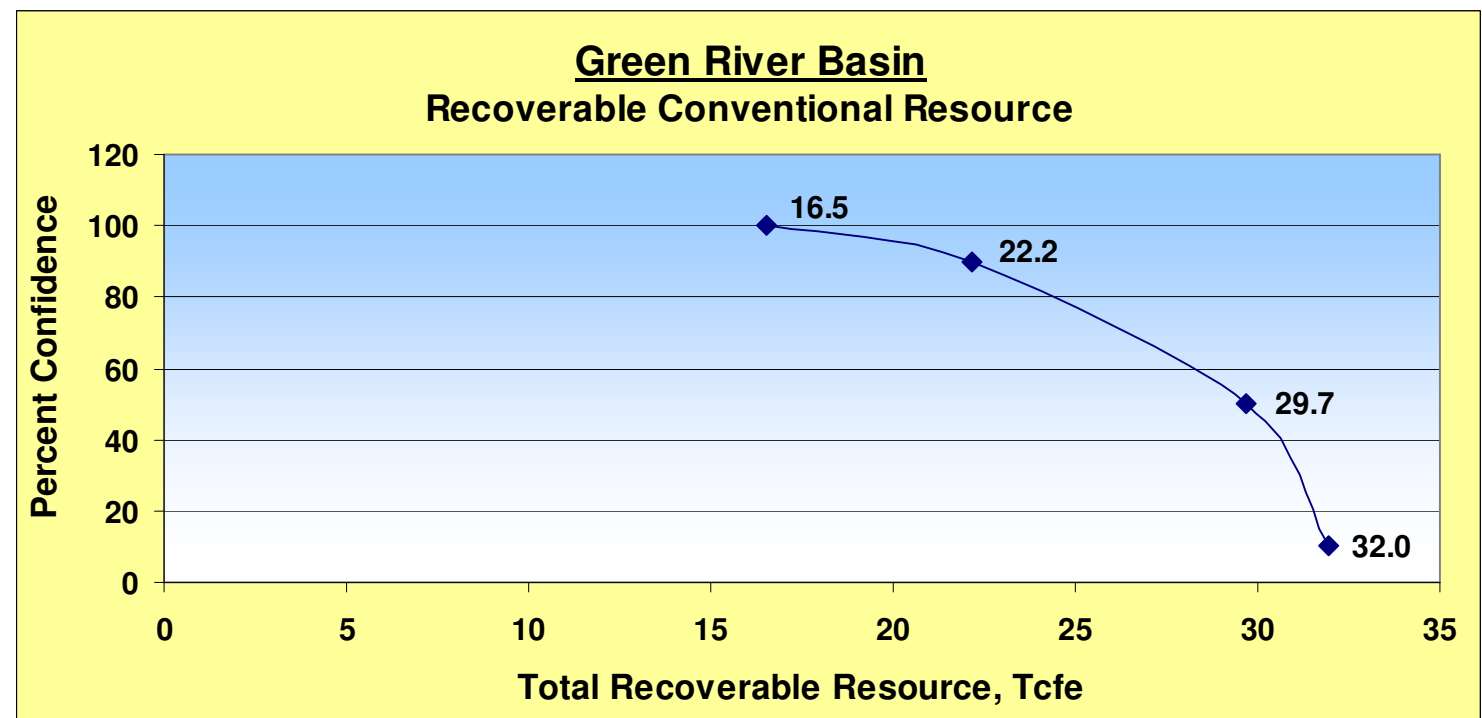

Fig. B.10: Green River Basin Recoverable Conventional Resource Curve 


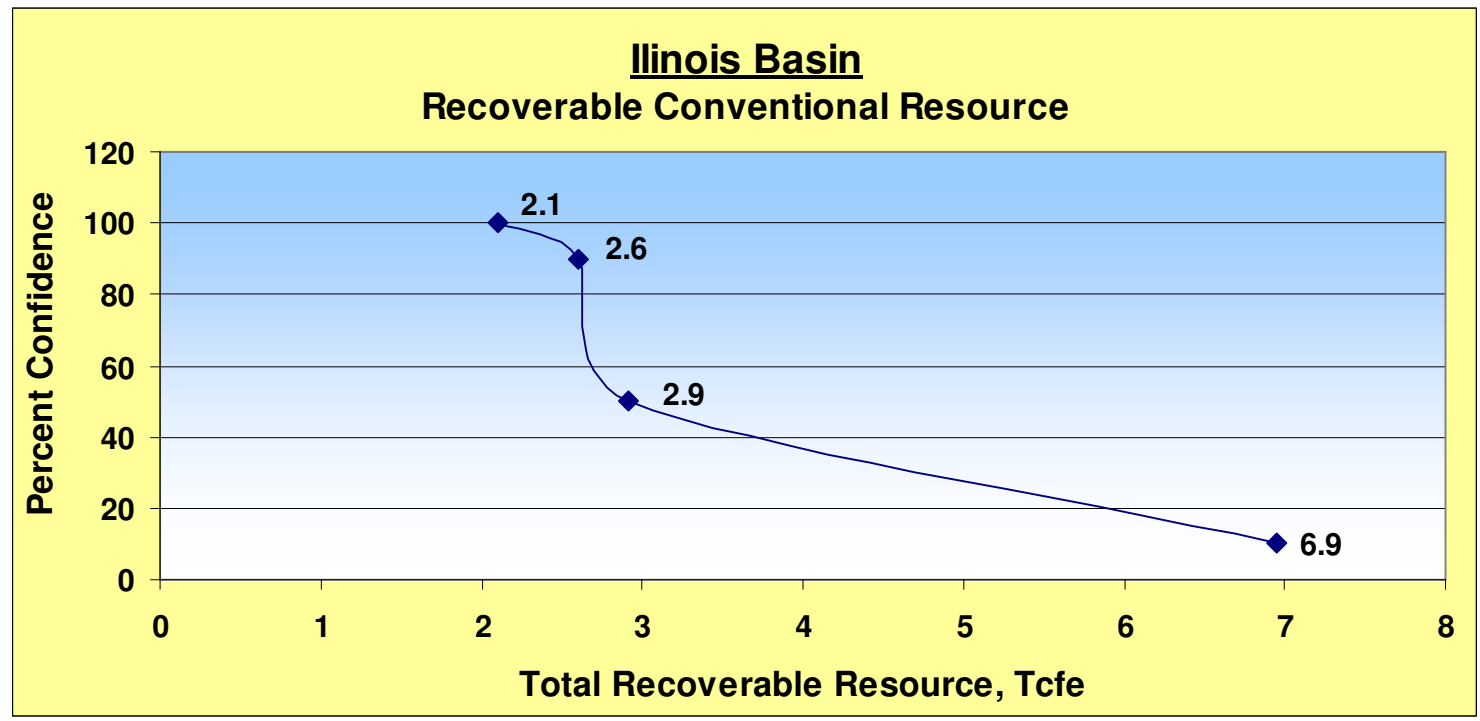

Fig. B.11: Illinois Basin Recoverable Conventional Resource Curve

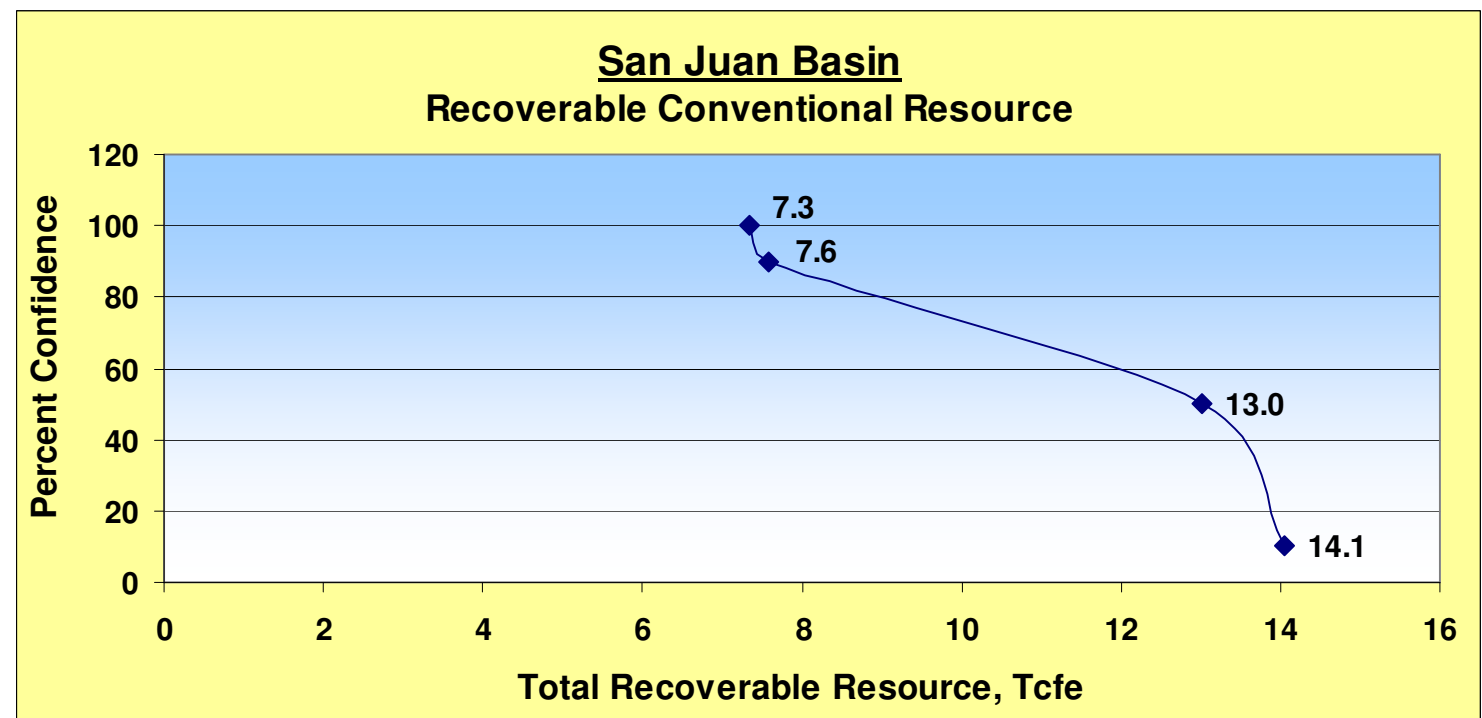

Fig. B.12: San Juan Basin Recoverable Conventional Resource Curve 


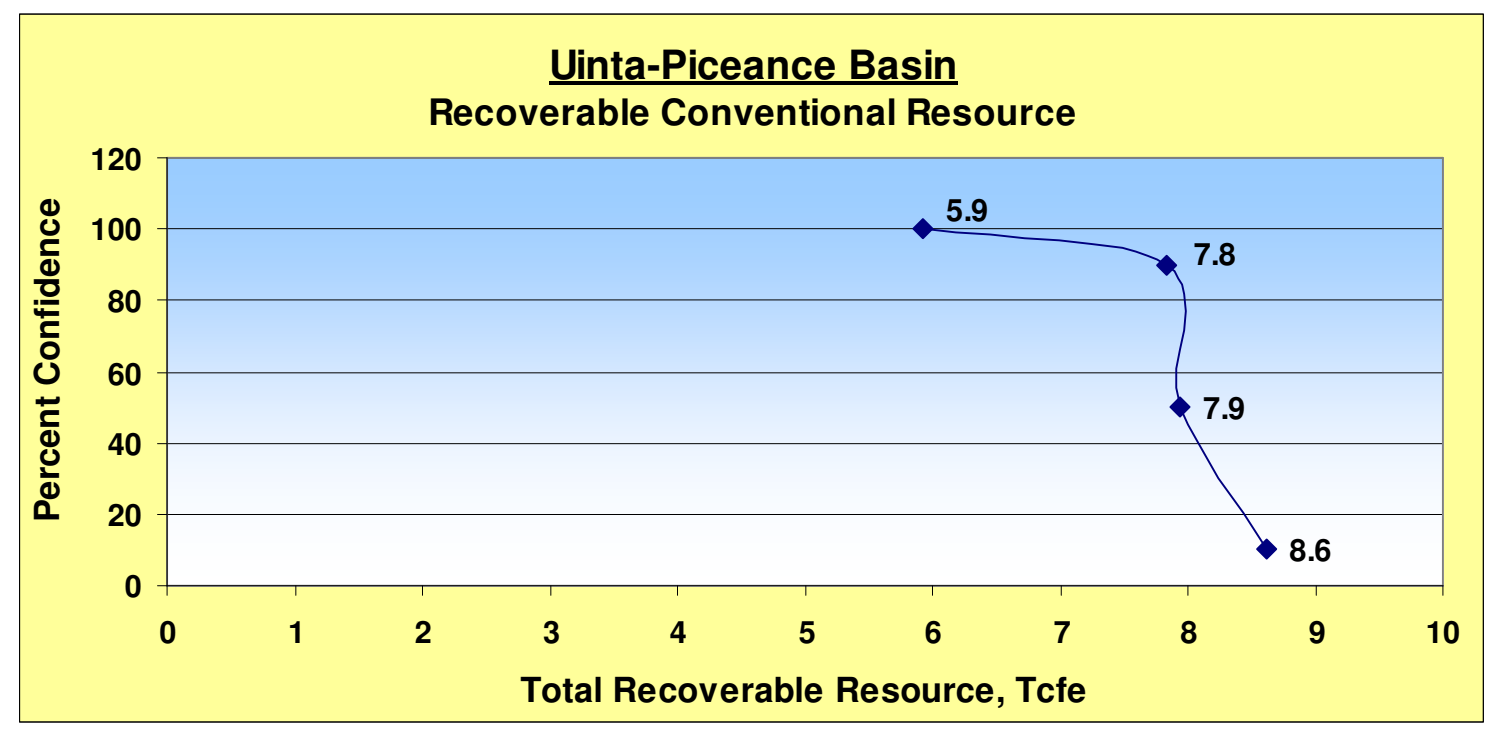

Fig. B.13: Uinta-Piceance Basin Recoverable Conventional Resource Curve

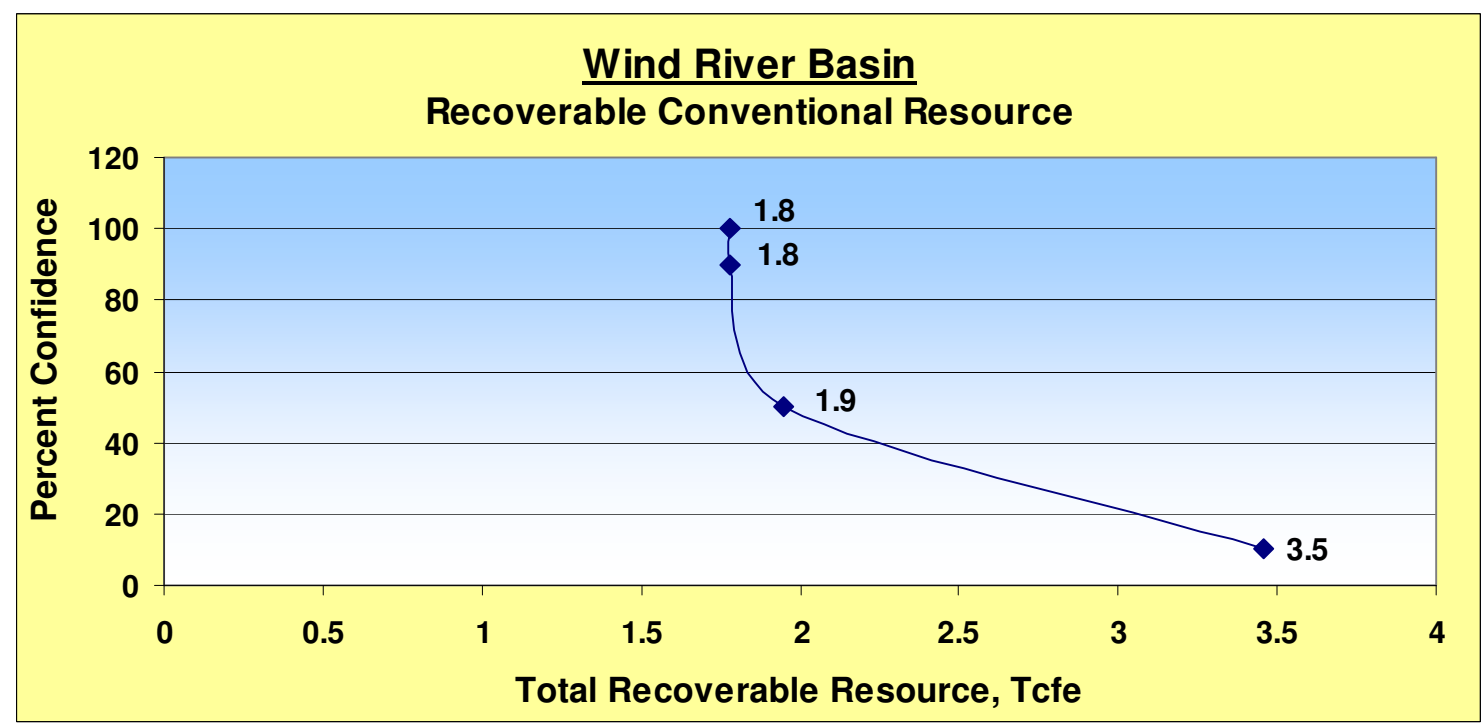

Fig. B.14: Wind River Basin Recoverable Conventional Resource Curve 


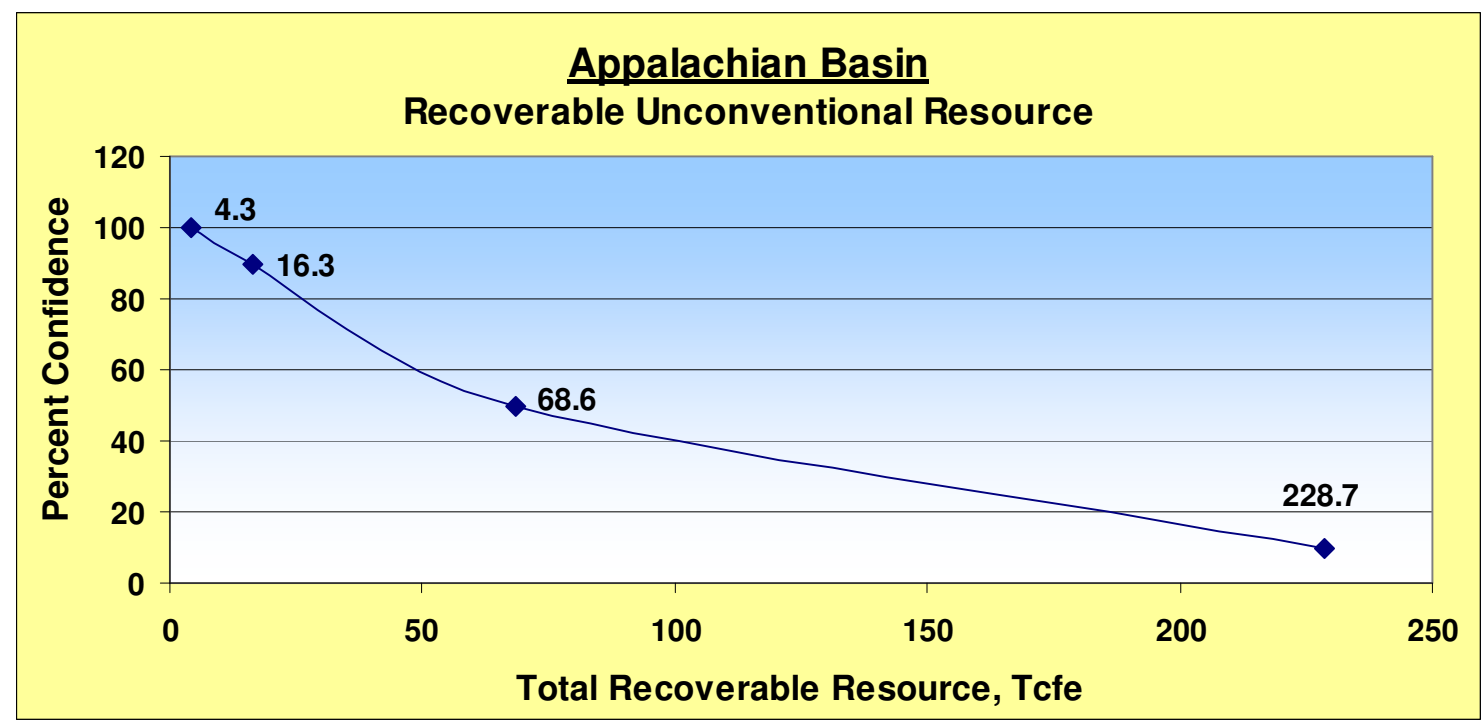

Fig. B.15: Appalachian Basin Recoverable Unconventional Resource Curve

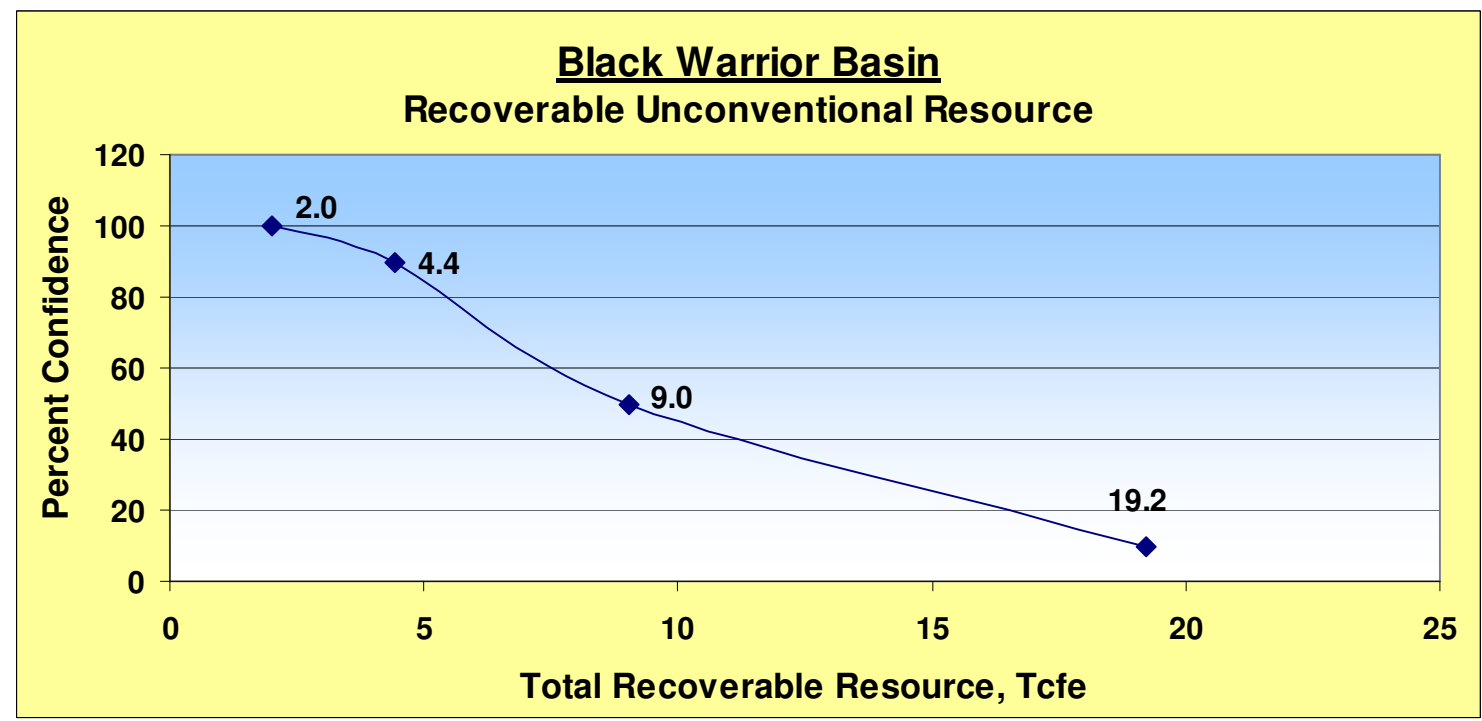

Fig. B.16: Black Warrior Basin Recoverable Unconventional Resource Curve 


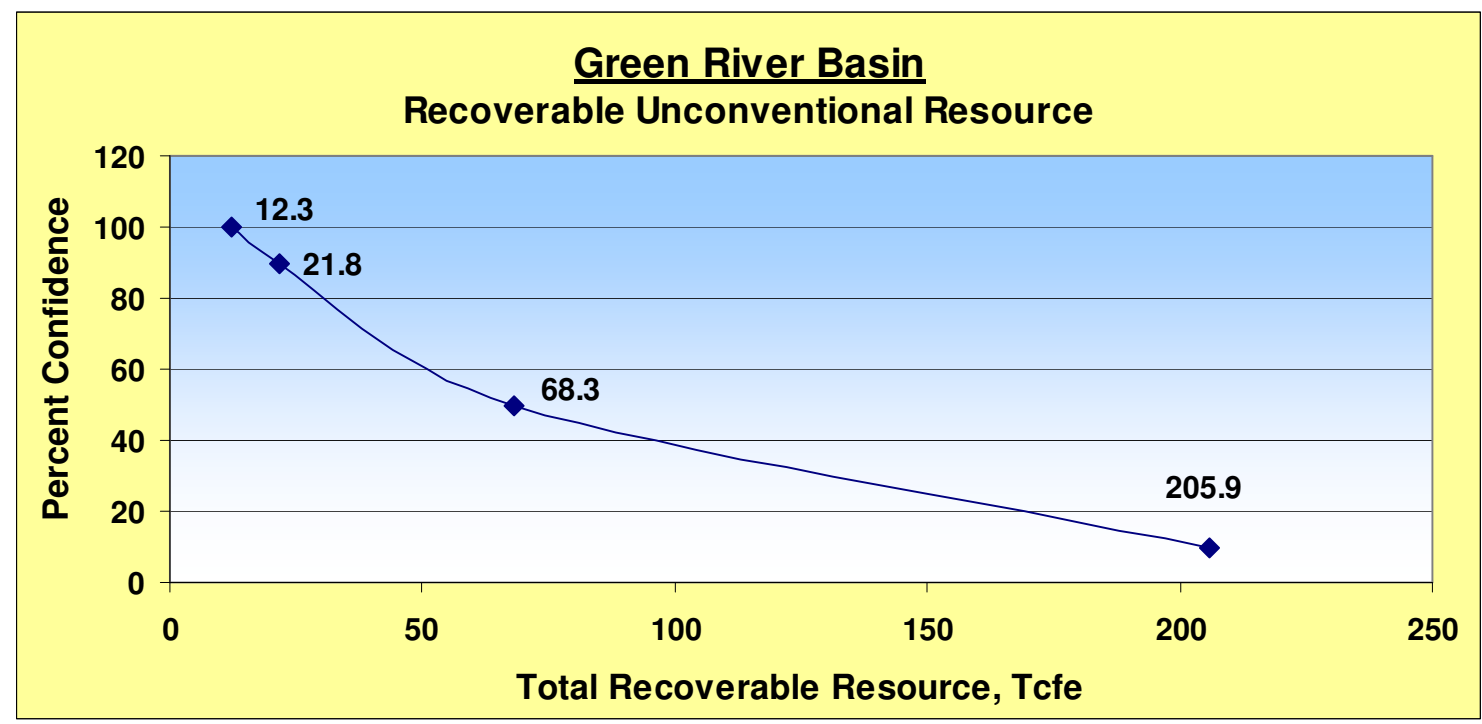

Fig. B.17: Green River Basin Recoverable Unconventional Resource Curve

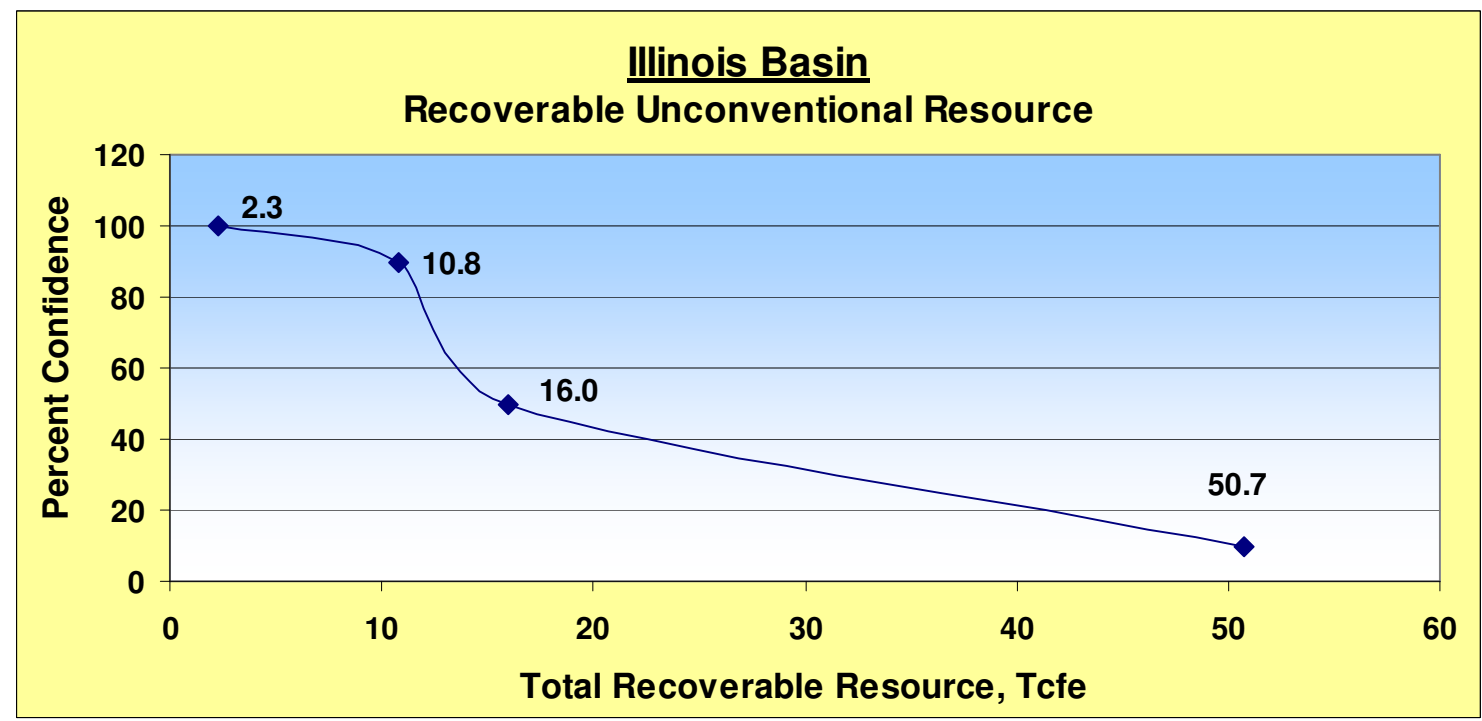

Fig. B.18: Illinois Basin Recoverable Unconventional Resource Curve 


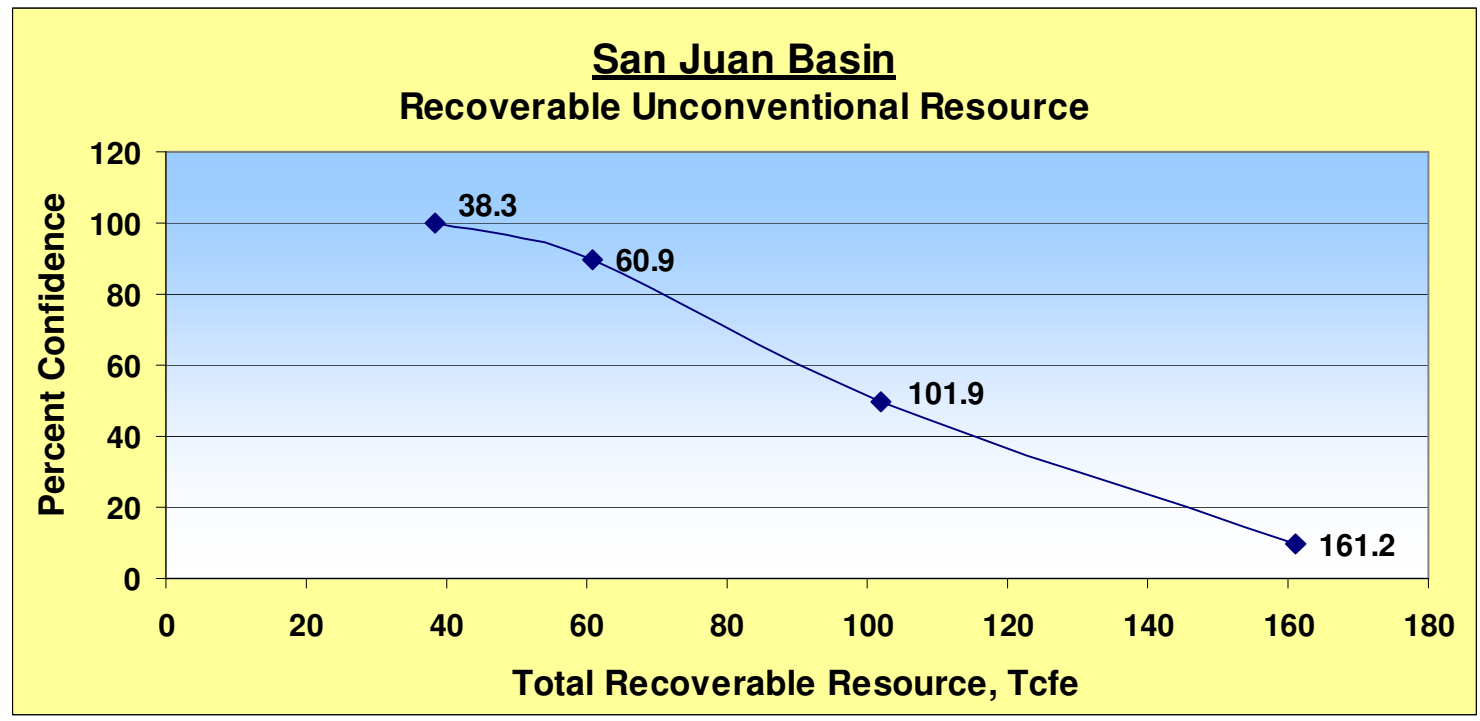

Fig. B.19: San Juan Basin Recoverable Unconventional Resource Curve

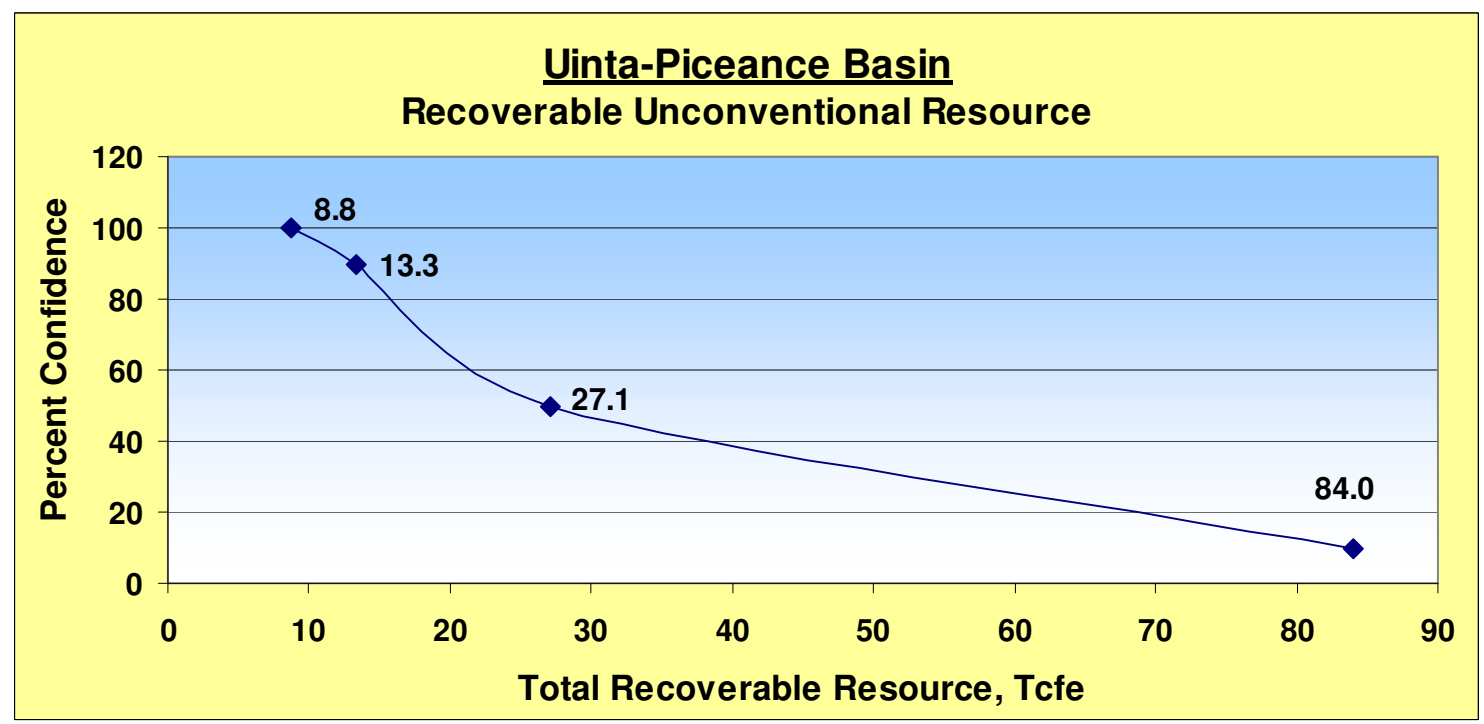

Fig. B.20: Uinta-Piceance Basin Recoverable Unconventional Resource Curve 


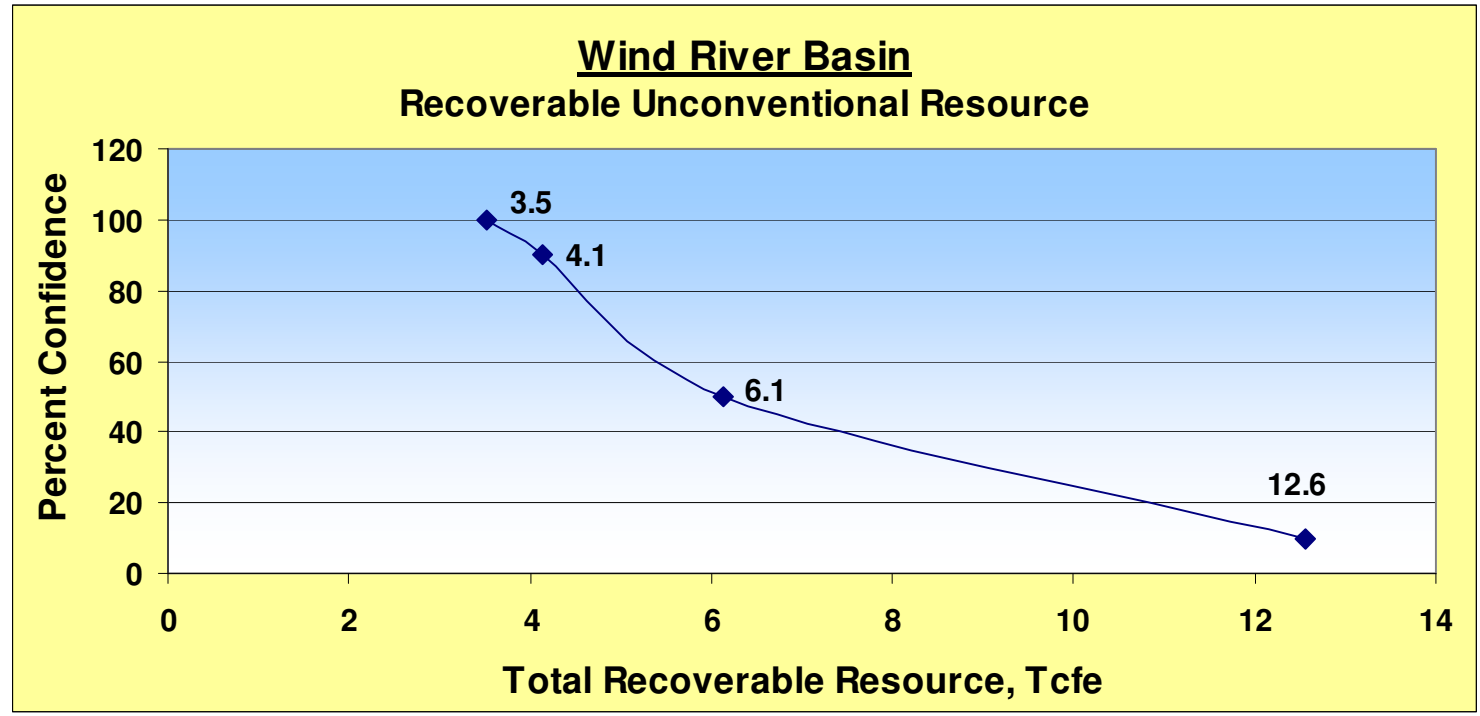

Fig. B.21: Wind River Basin Recoverable Unconventional Resource Curve

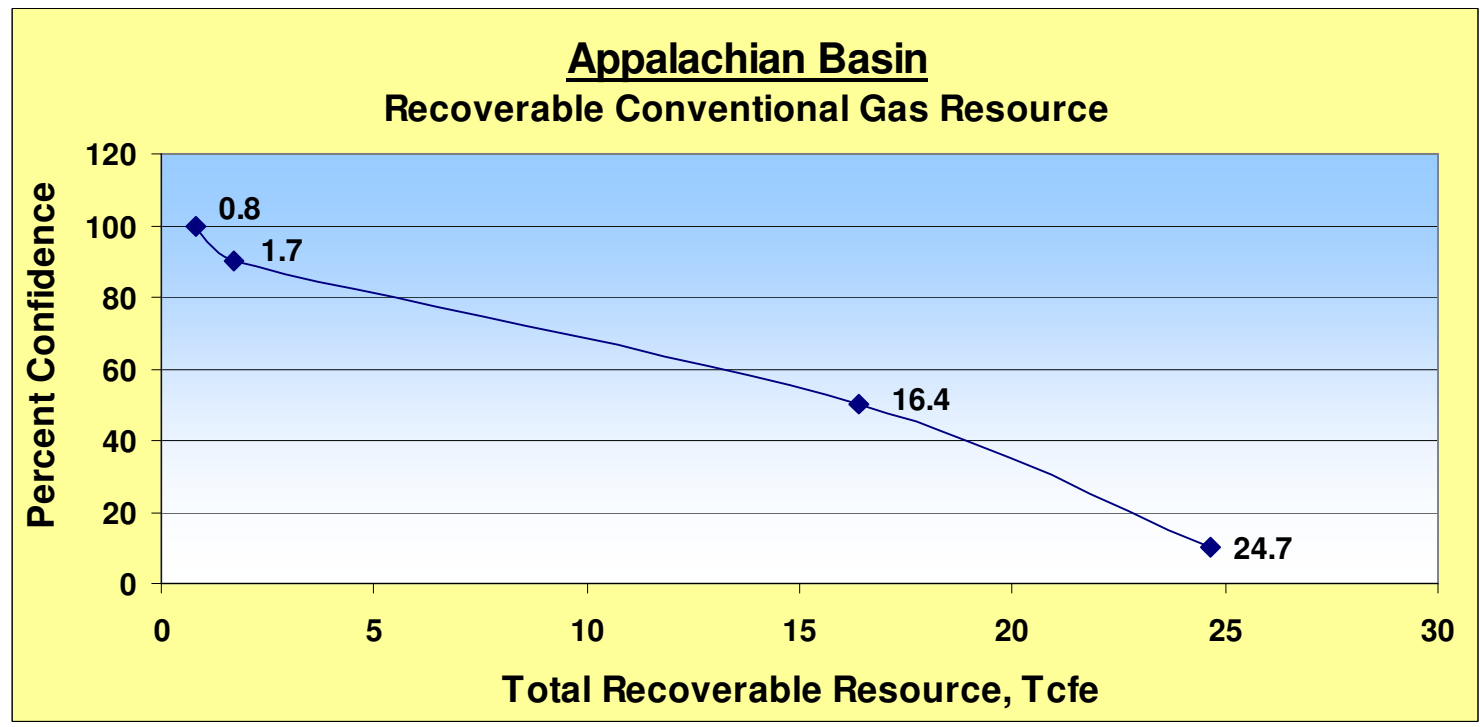

Fig. B.22: Appalachian Basin Recoverable Conventional Gas Resource Curve 


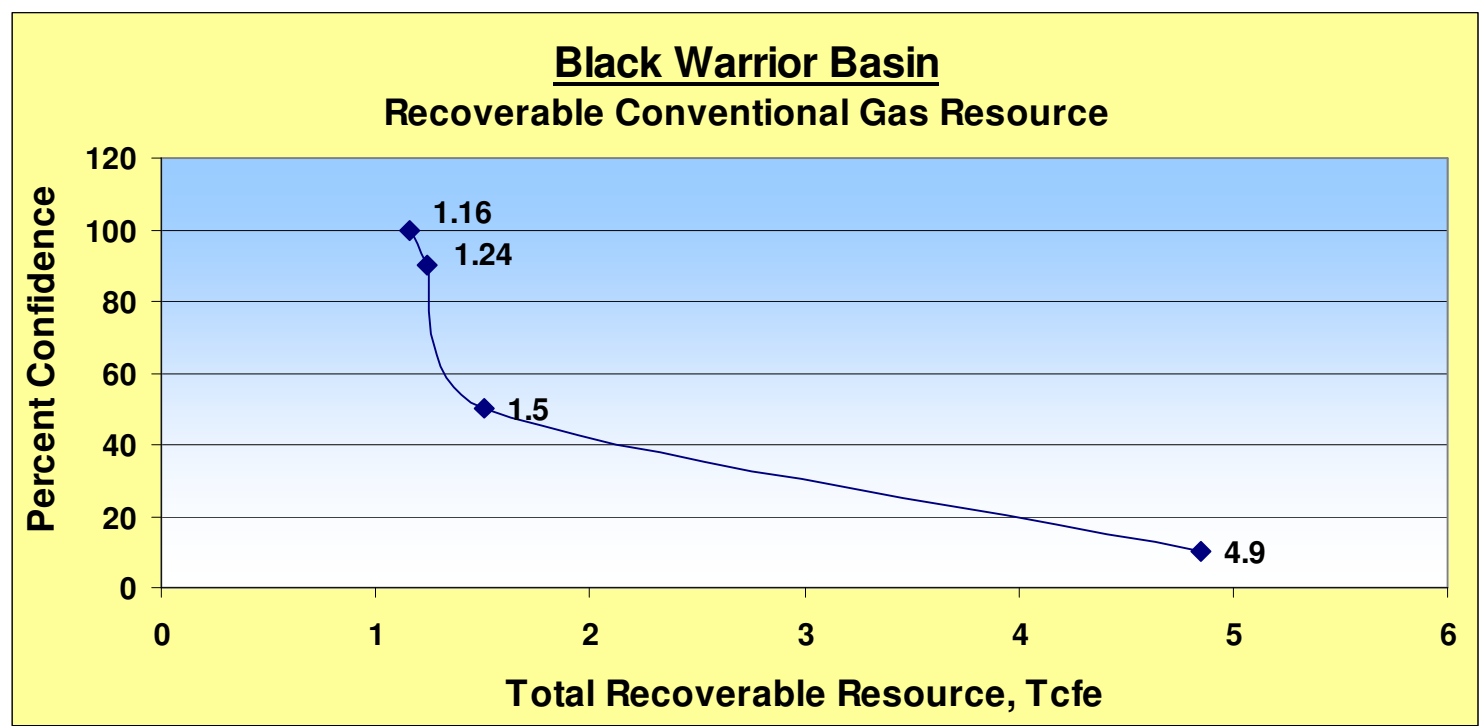

Fig. B.23: Black Warrior Basin Recoverable Conventional Gas Resource Curve

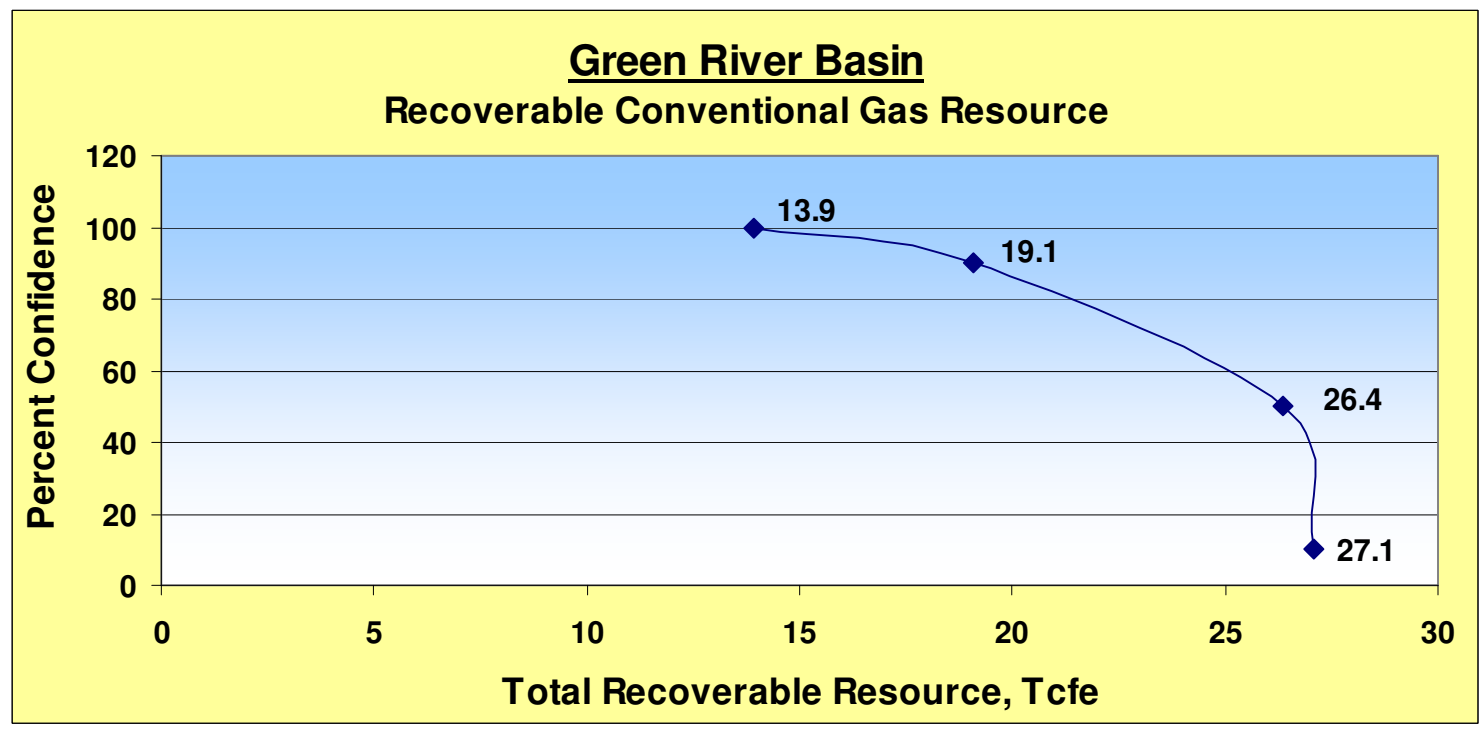

Fig. B.24: Green River Basin Recoverable Conventional Gas Resource Curve 


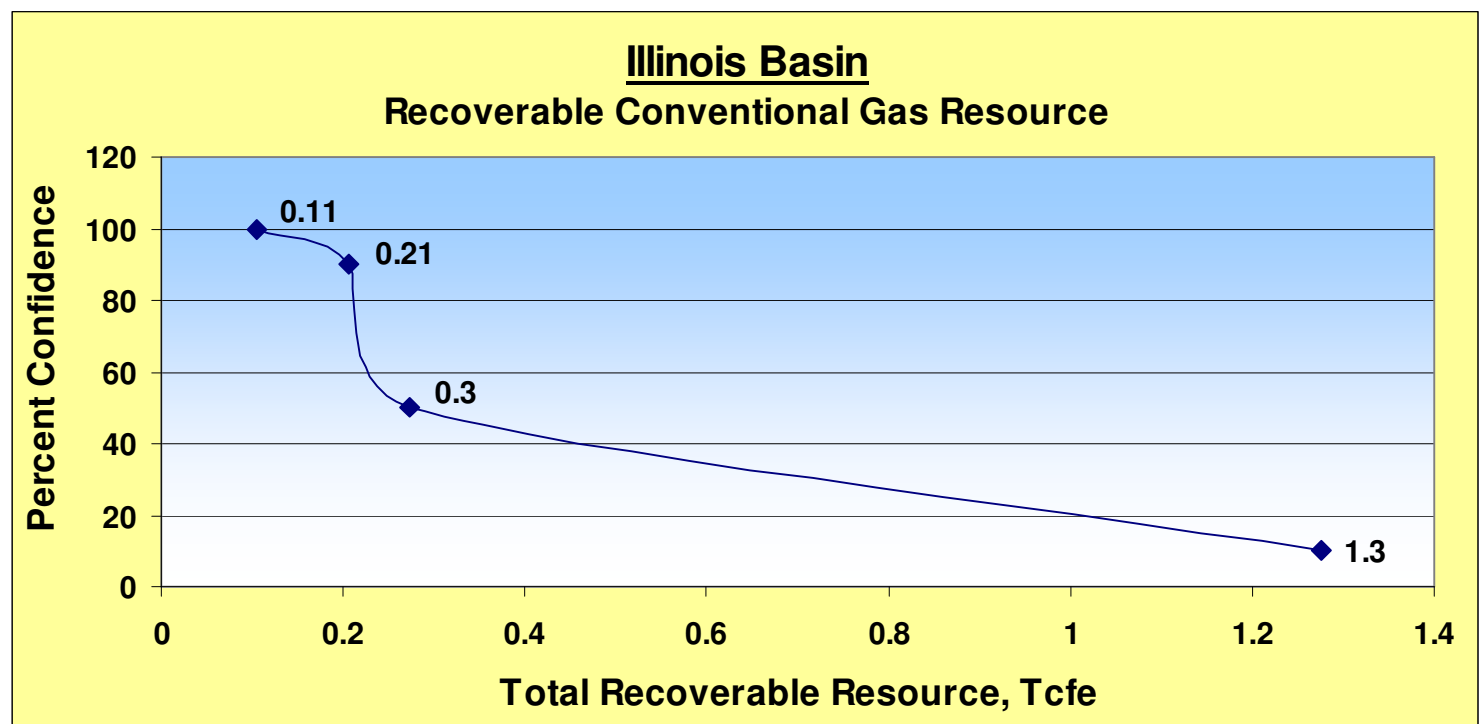

Fig. B.25: Illinois Basin Recoverable Conventional Gas Resource Curve

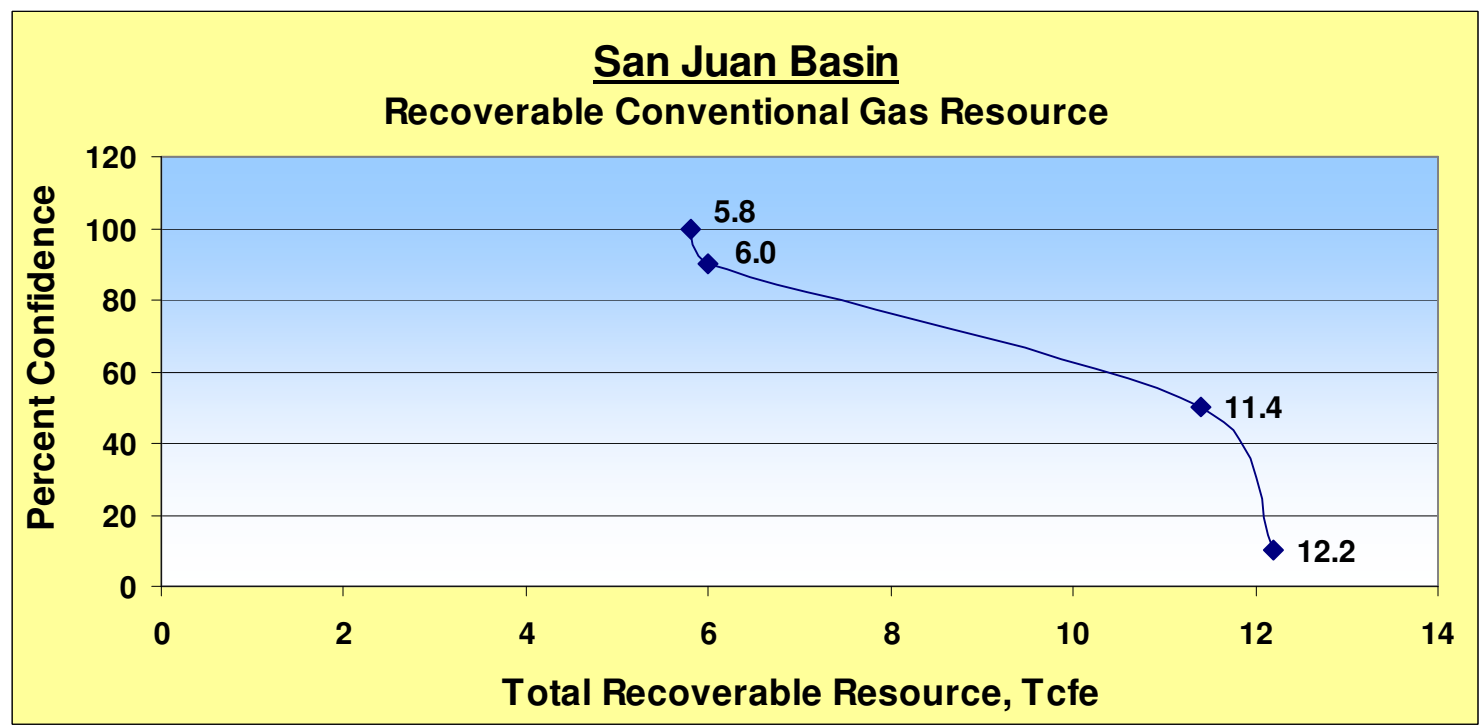

Fig. B.26: San Juan Basin Recoverable Conventional Gas Resource Curve 


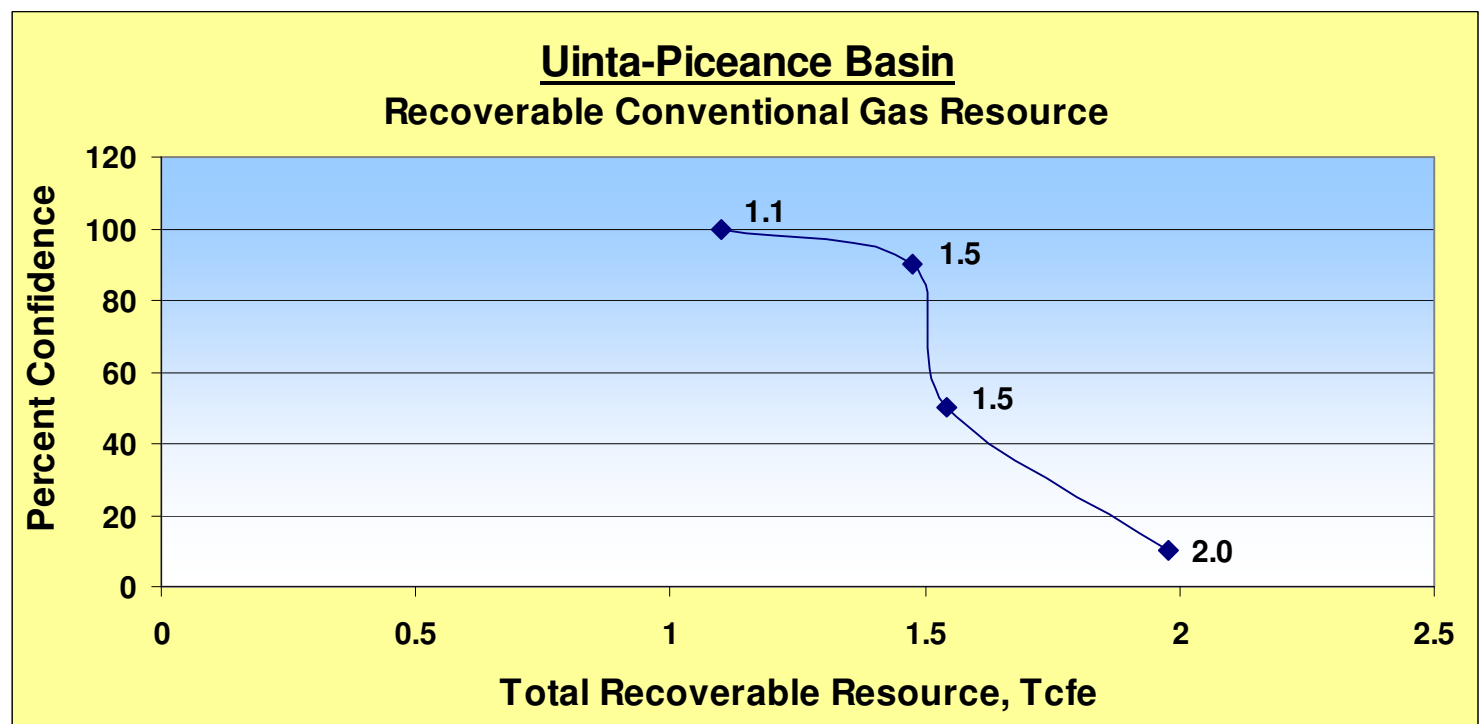

Fig. B.27: Uinta-Piceance Basin Recoverable Conventional Gas Resource Curve

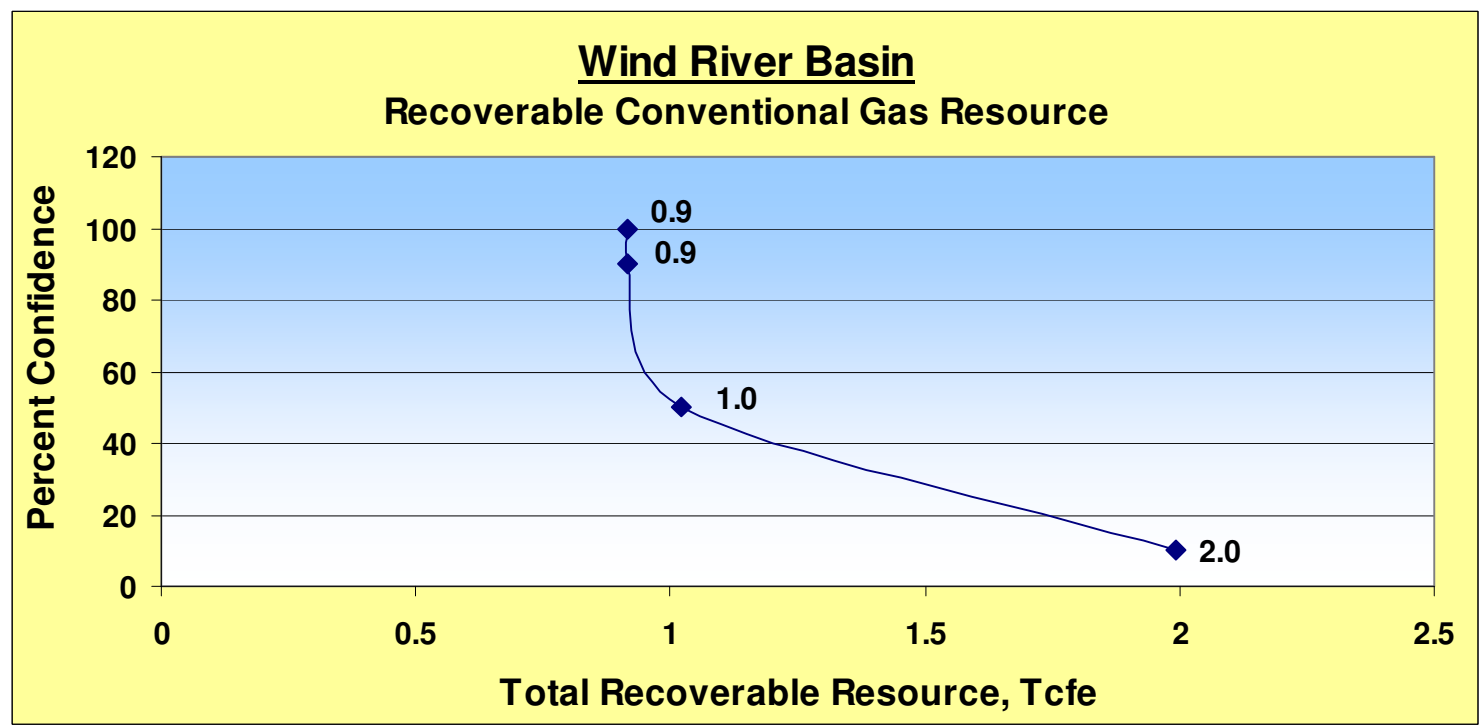

Fig. B.28: Wind River Basin Recoverable Conventional Gas Resource Curve 


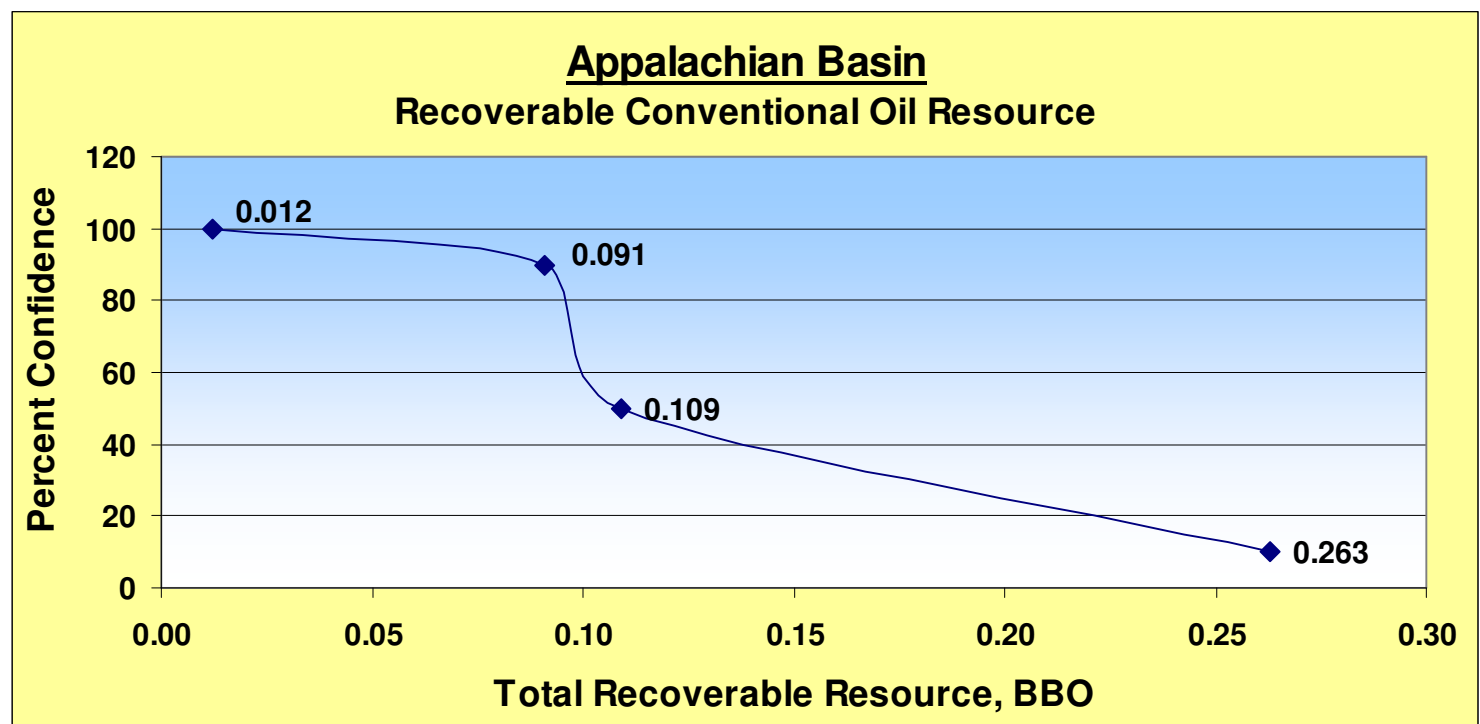

Fig. B.29: Appalachian Basin Recoverable Conventional Oil Resource Curve

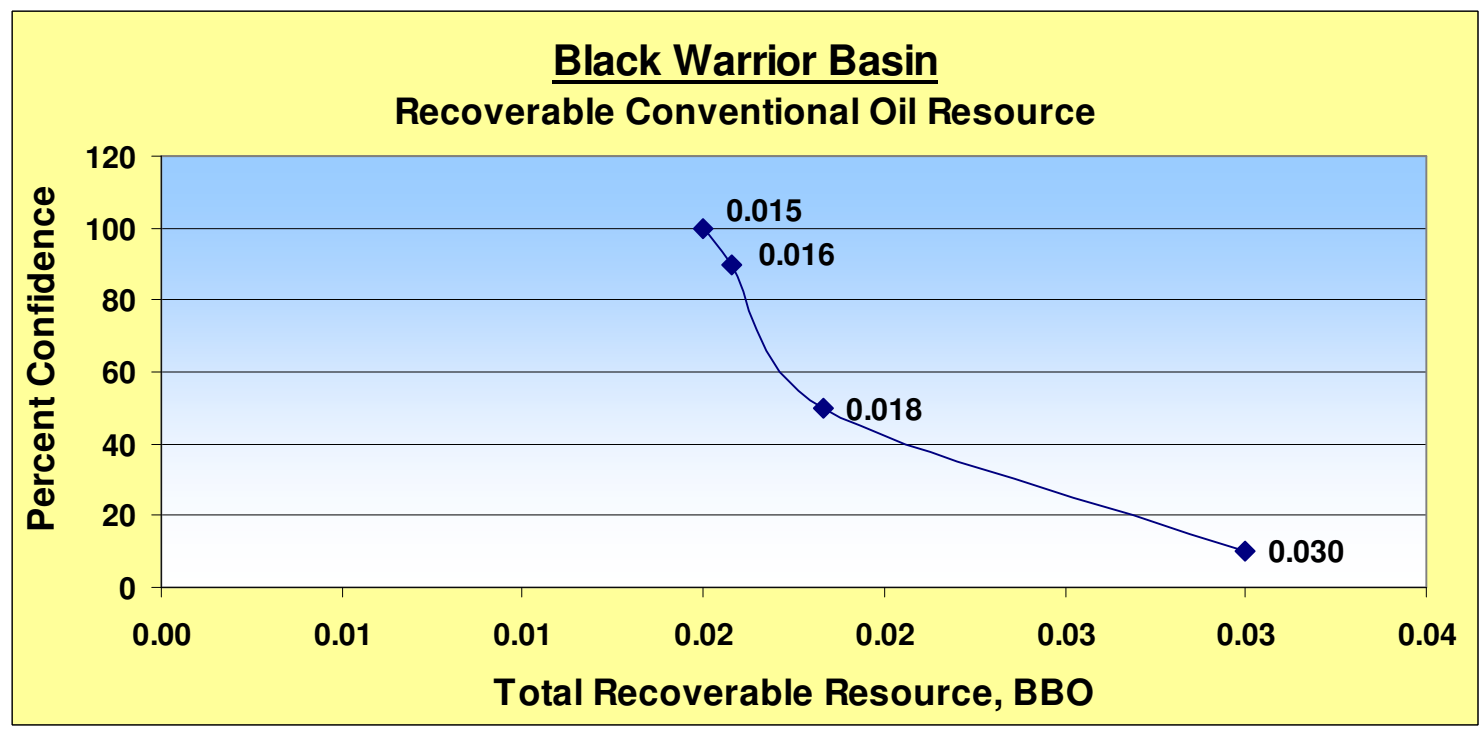

Fig. B.30: Black Warrior Basin Recoverable Conventional Oil Resource Curve 


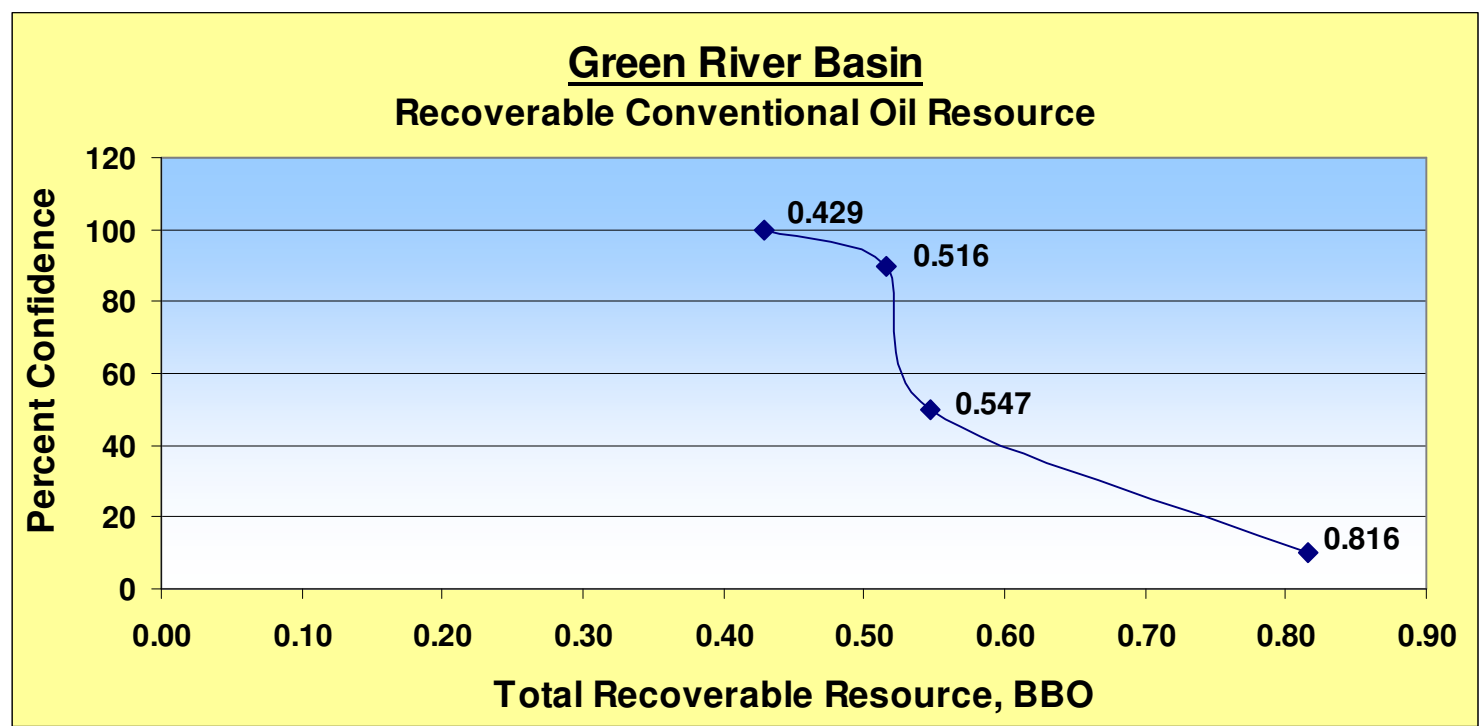

Fig. B.31: Green River Basin Recoverable Conventional Oil Resource Curve

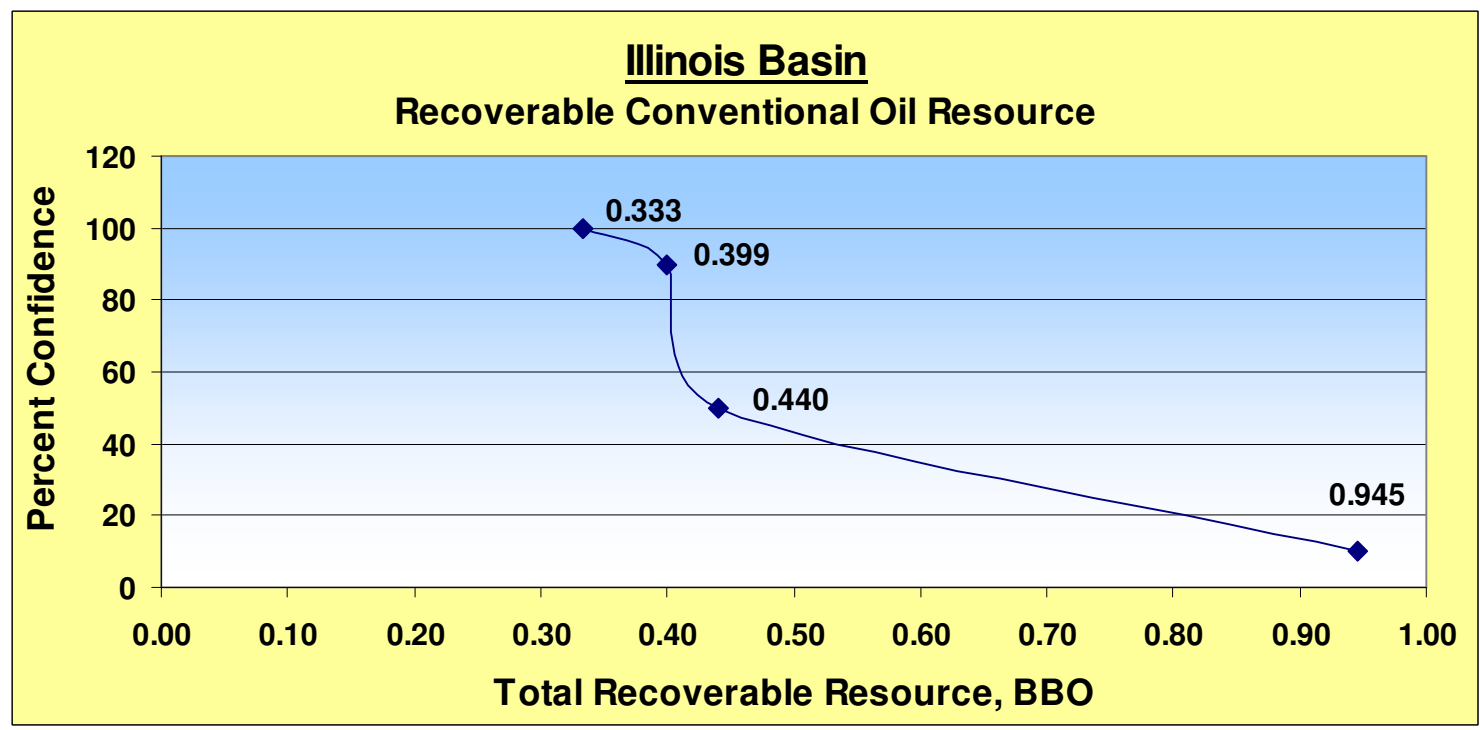

Fig. B.32: Illinois Basin Recoverable Conventional Oil Resource Curve 


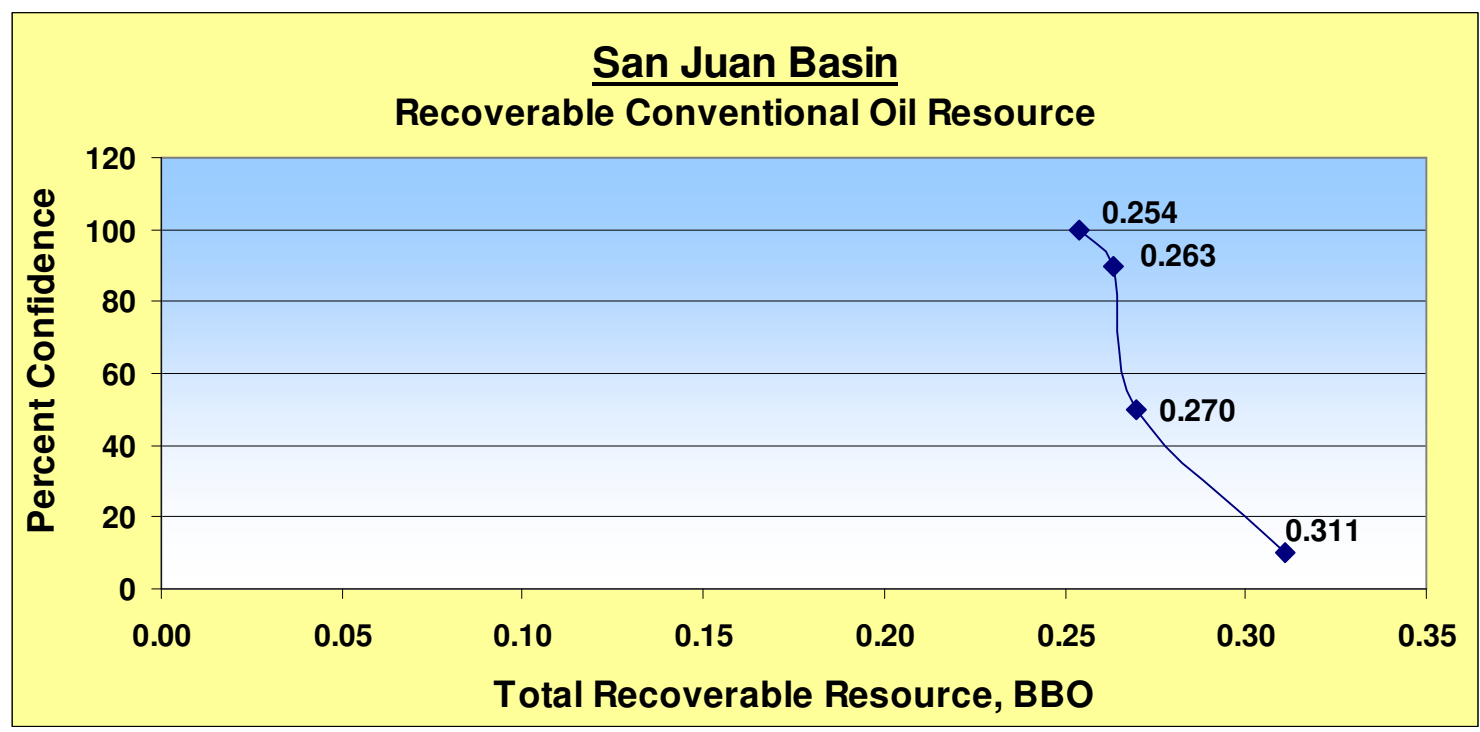

Fig. B.33: San Juan Basin Recoverable Conventional Oil Resource Curve

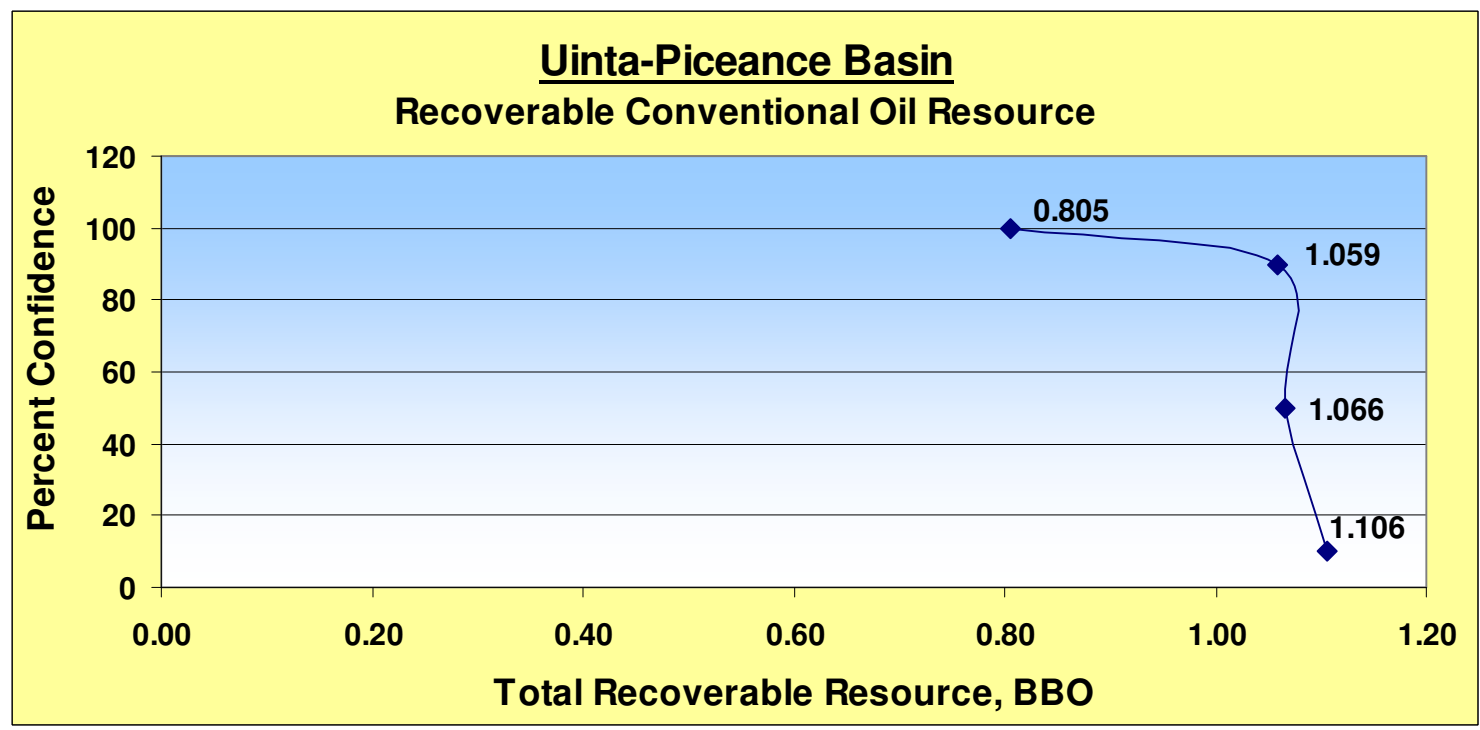

Fig. B.34: Uinta-Piceance Basin Recoverable Conventional Oil Resource Curve 


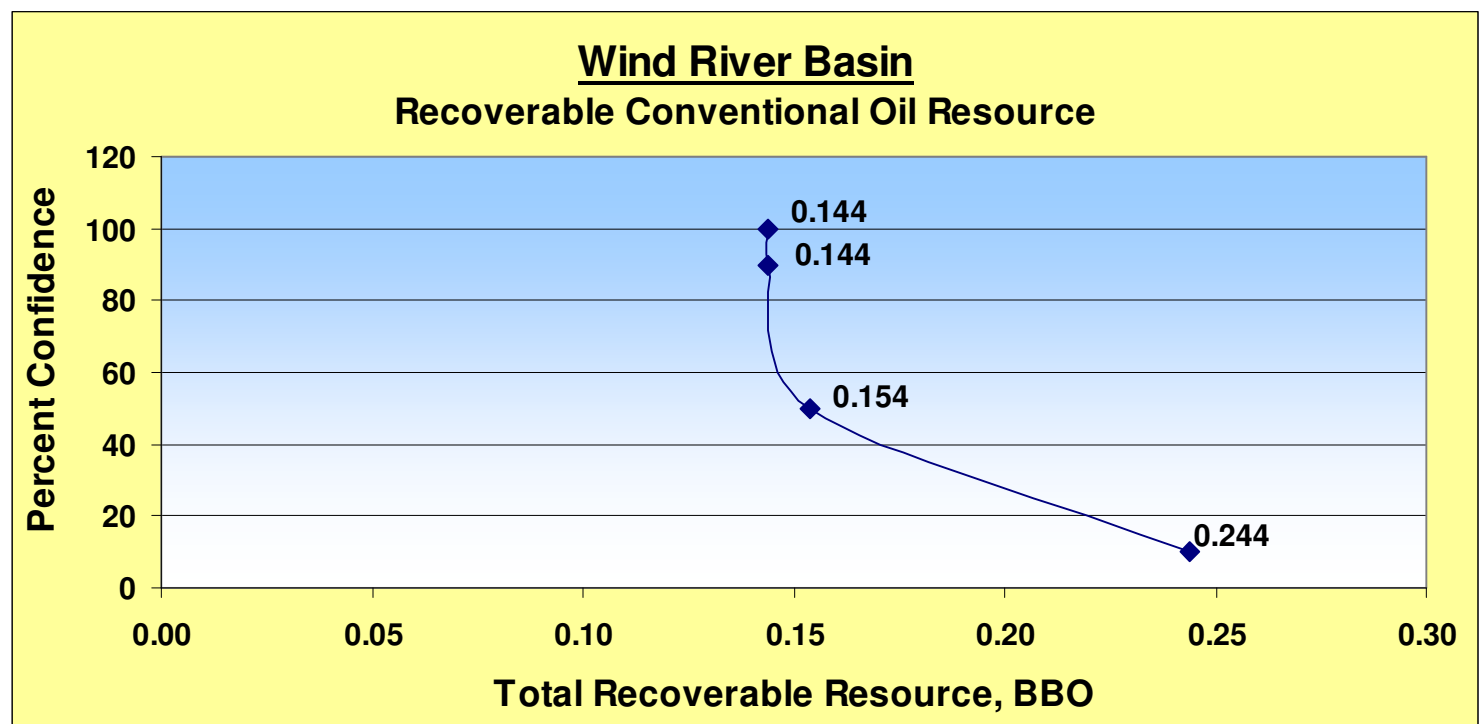

Fig. B.35: Wind River Basin Recoverable Conventional Oil Resource Curve

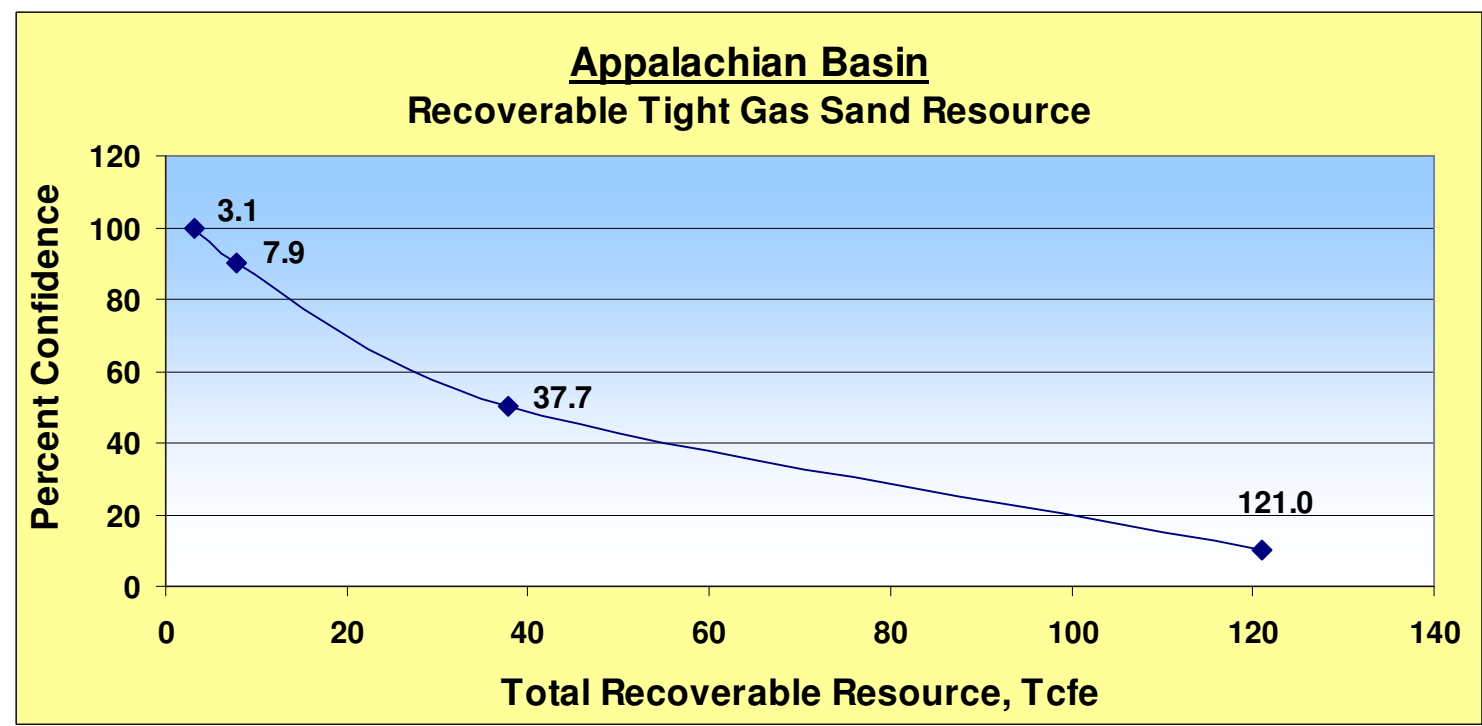

Fig. B.36: Appalachian Basin Recoverable Tight Gas Sand Resource Curve 


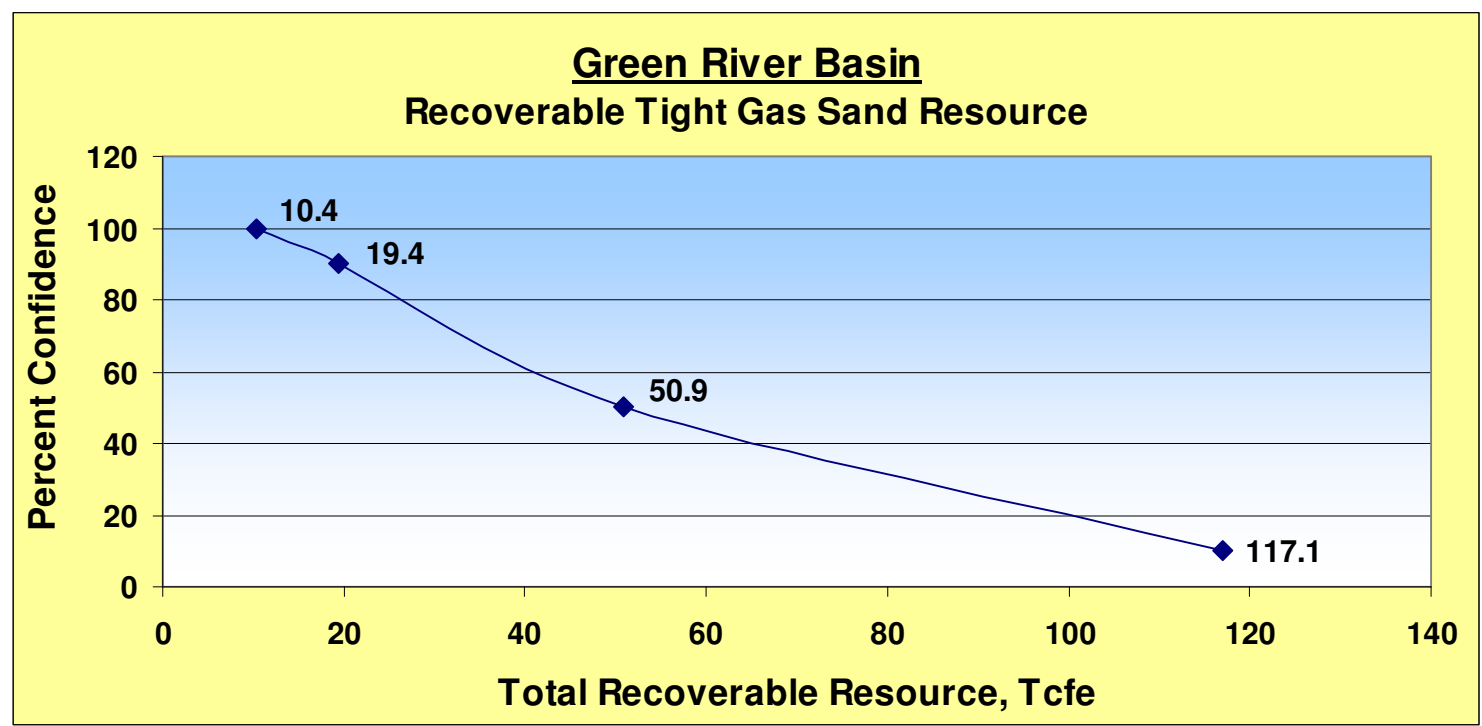

Fig. B.37: Green River Basin Recoverable Tight Gas Sand Resource Curve

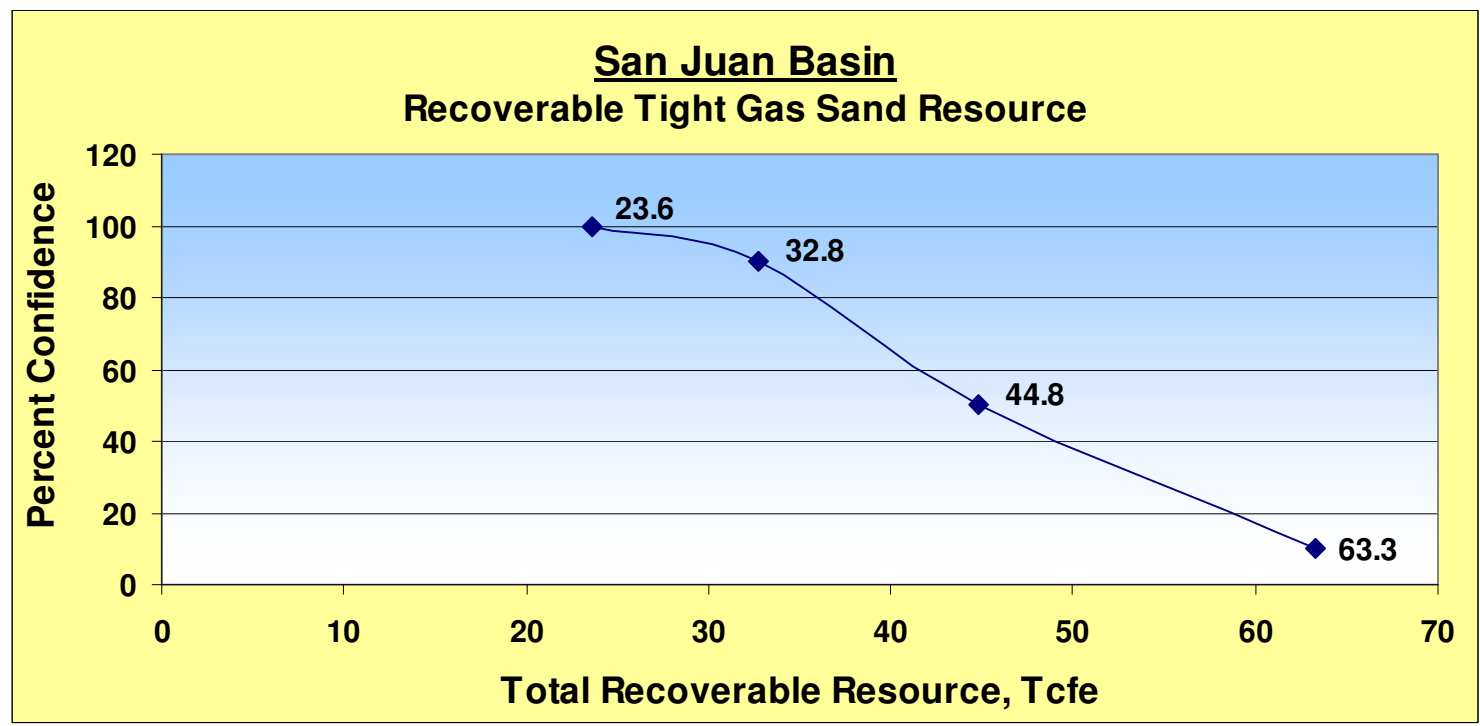

Fig. B.38: San Juan Basin Recoverable Tight Gas Sand Resource Curve 


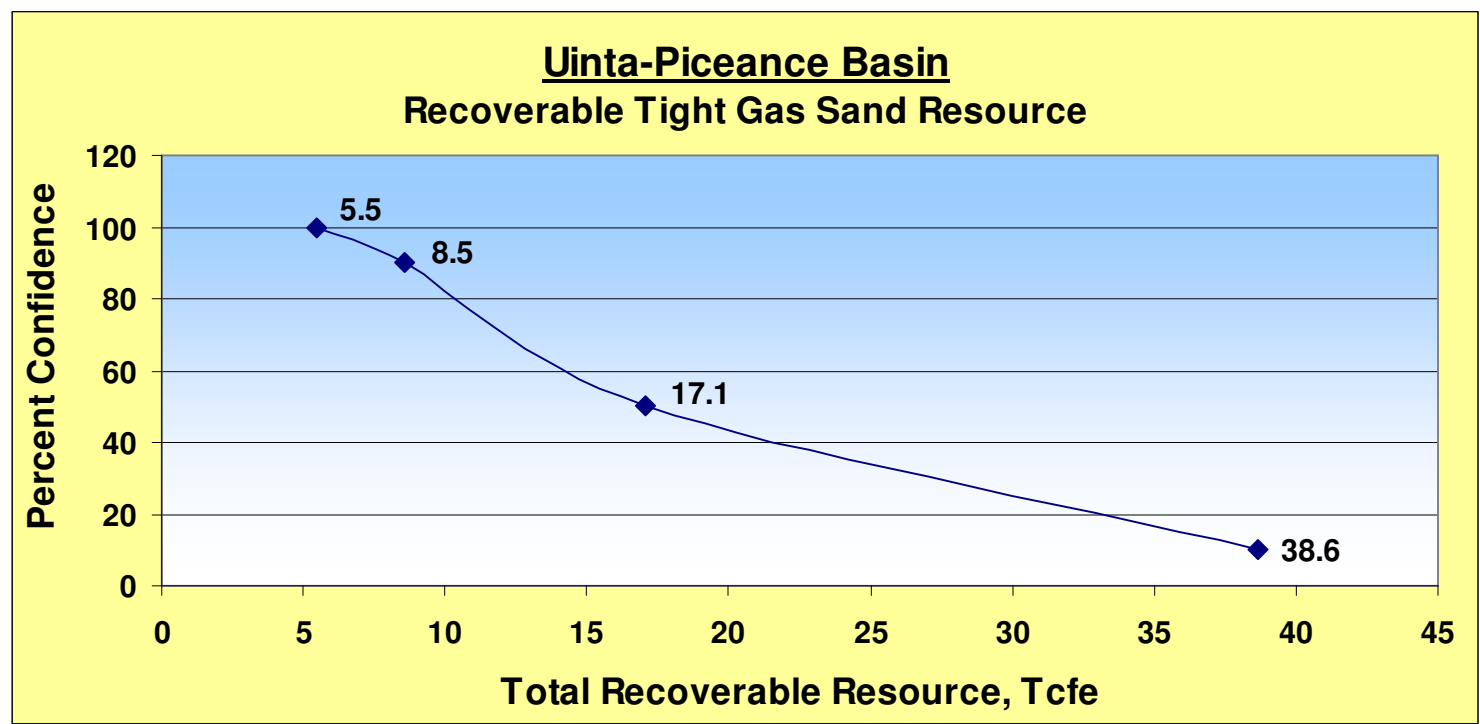

Fig. B.39: Uinta-Piceance Basin Recoverable Tight Gas Sand Resource Curve

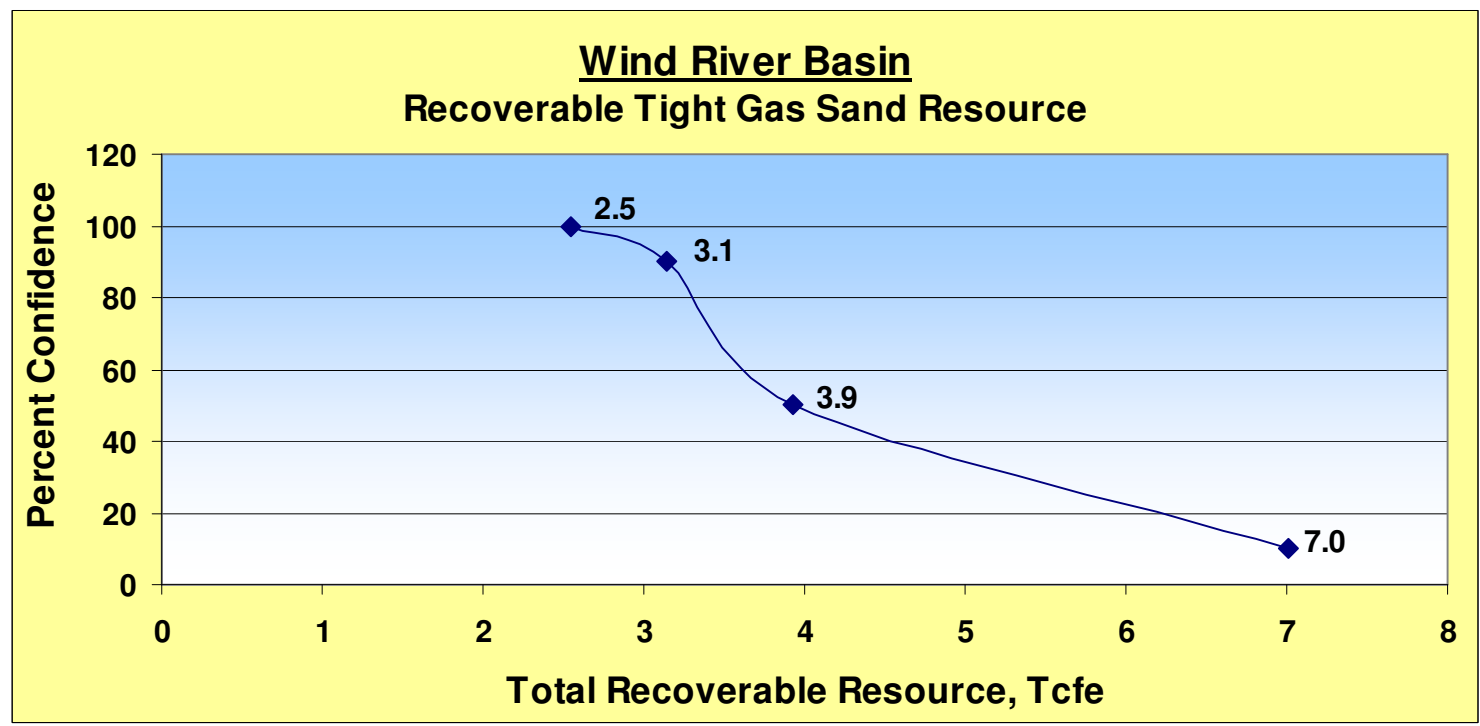

Fig. B.40: Wind River Basin Recoverable Tight Gas Sand Resource Curve 


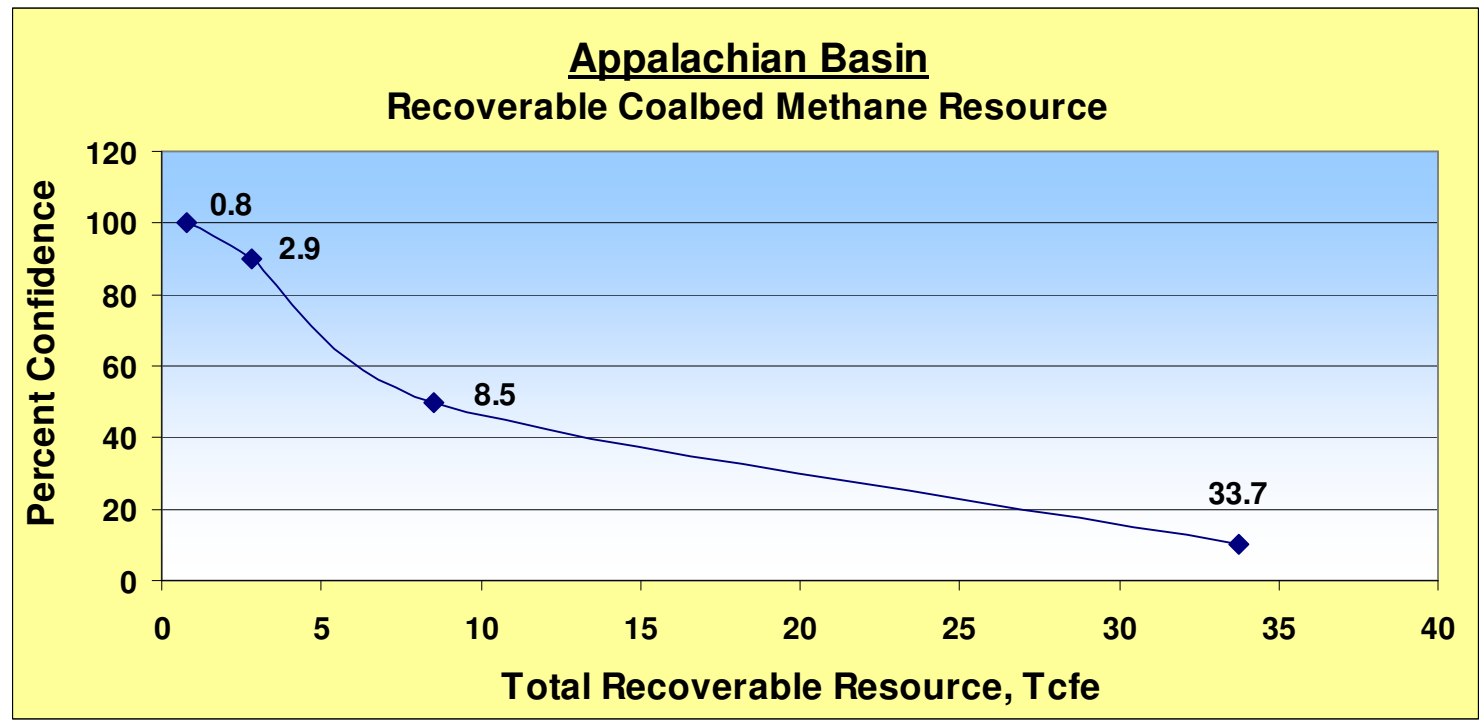

Fig. B.41: Appalachian Basin Recoverable Coalbed Methane Resource Curve

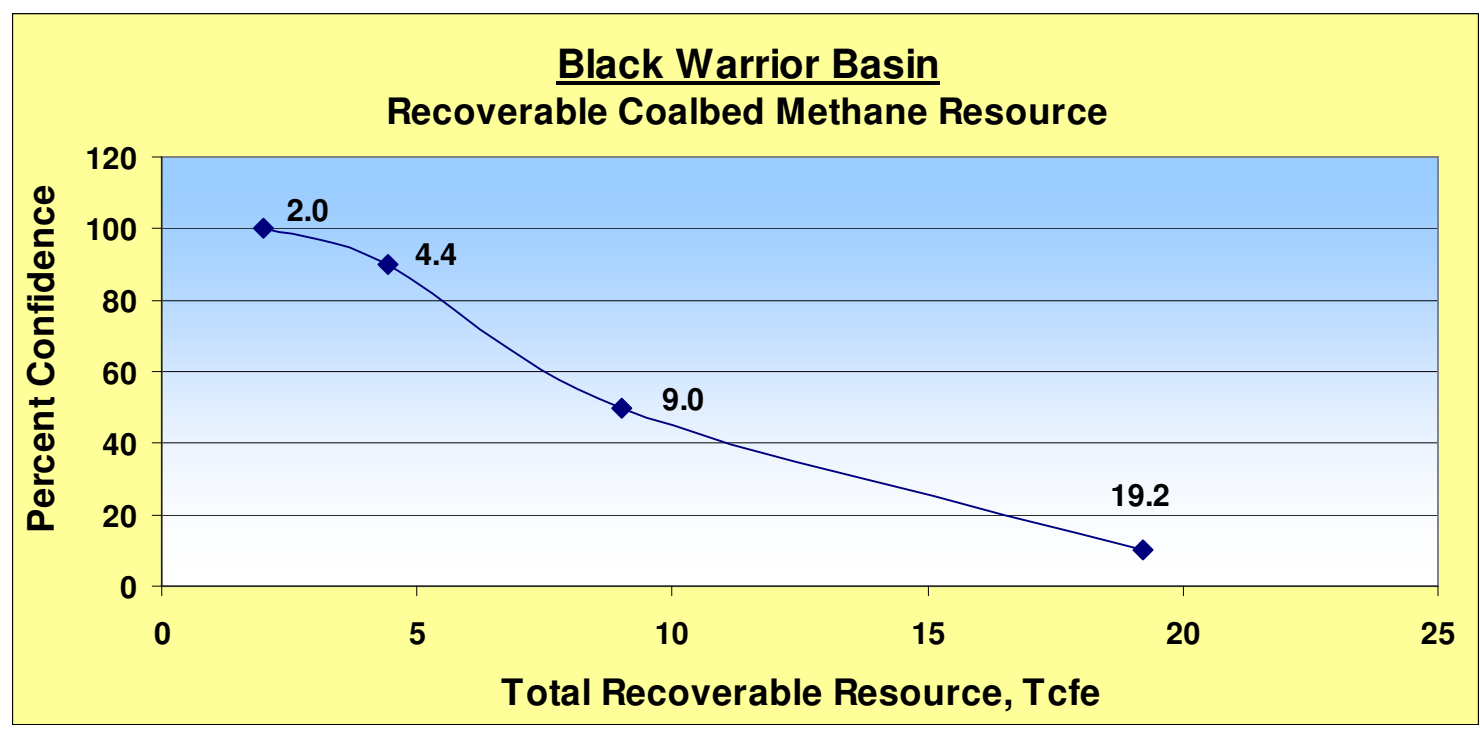

Fig. B.42: Black Warrior Basin Recoverable Coalbed Methane Resource Curve 


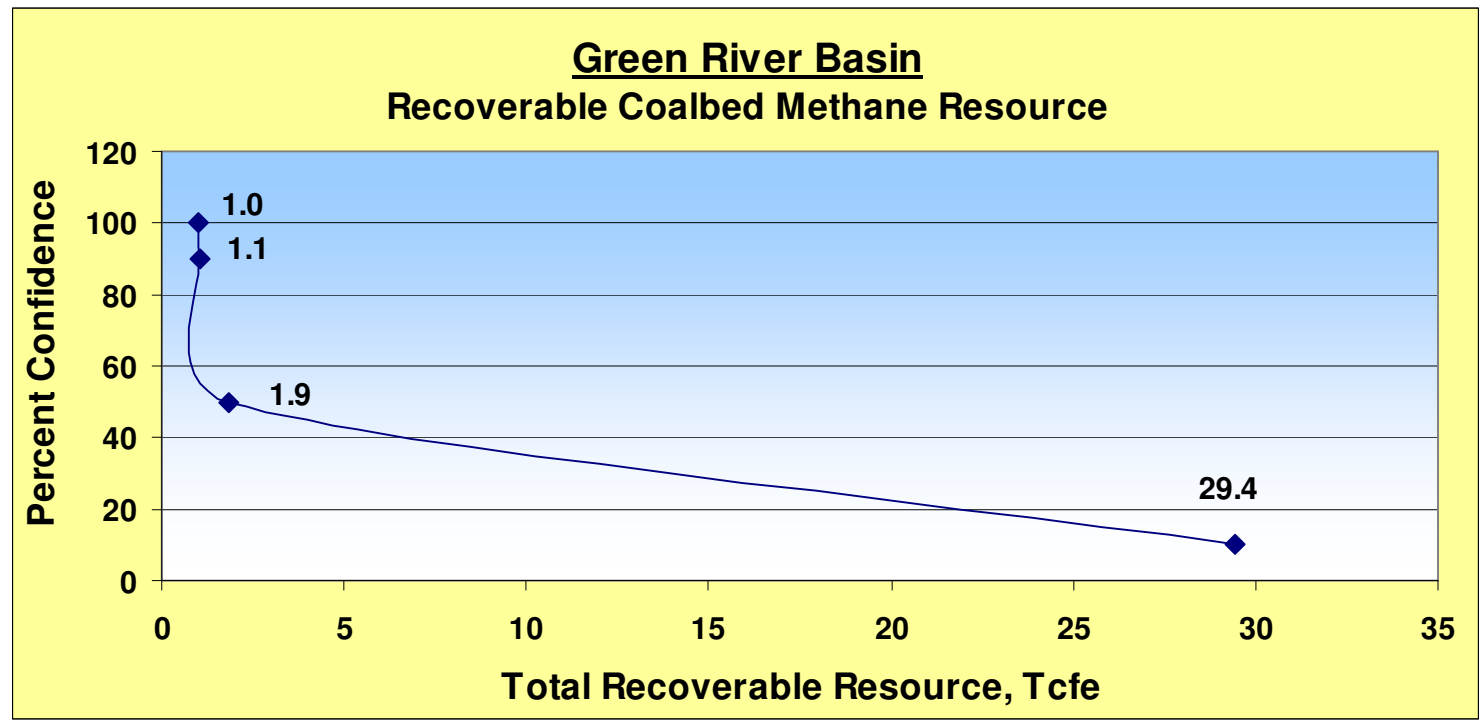

Fig. B.43: Green River Basin Recoverable Coalbed Methane Resource Curve

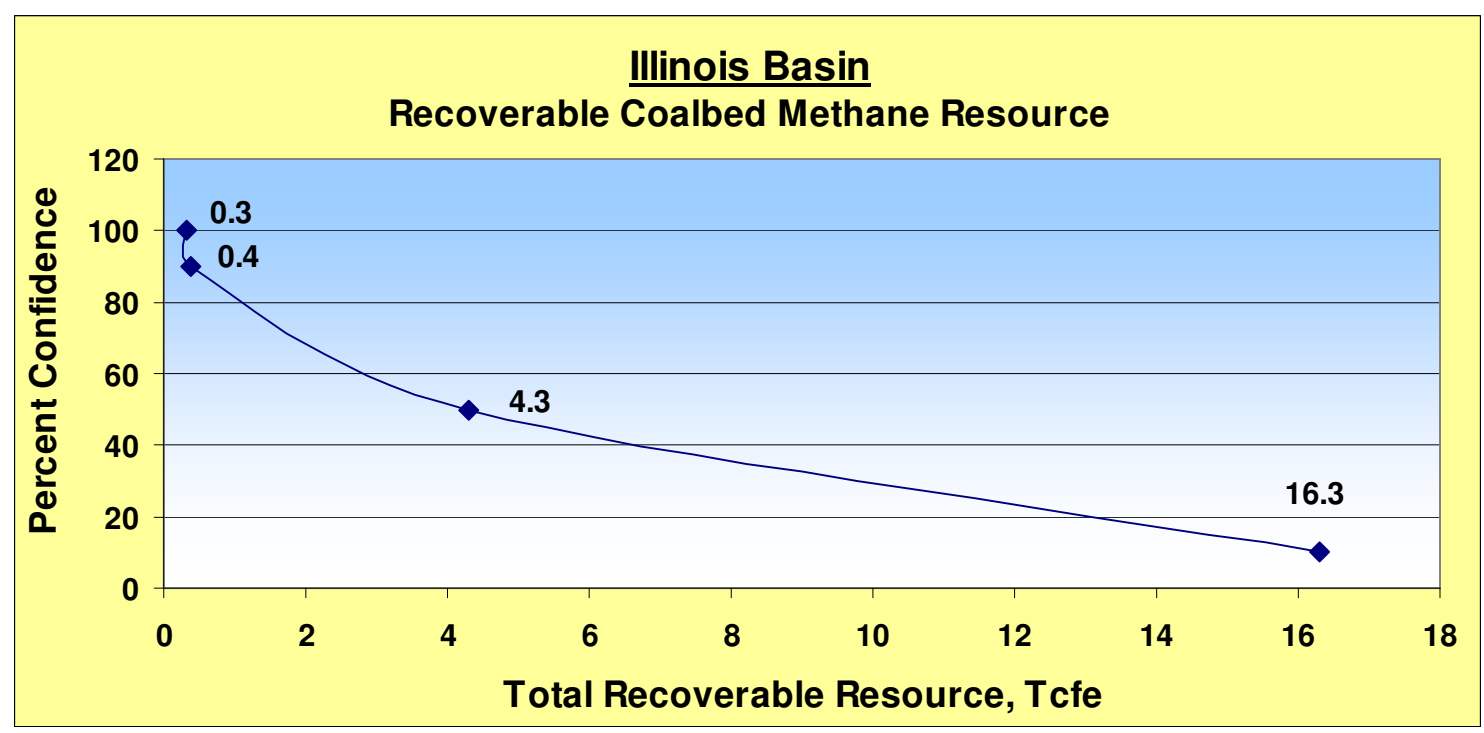

Fig. B.44: Illinois Basin Recoverable Coalbed Methane Resource Curve 


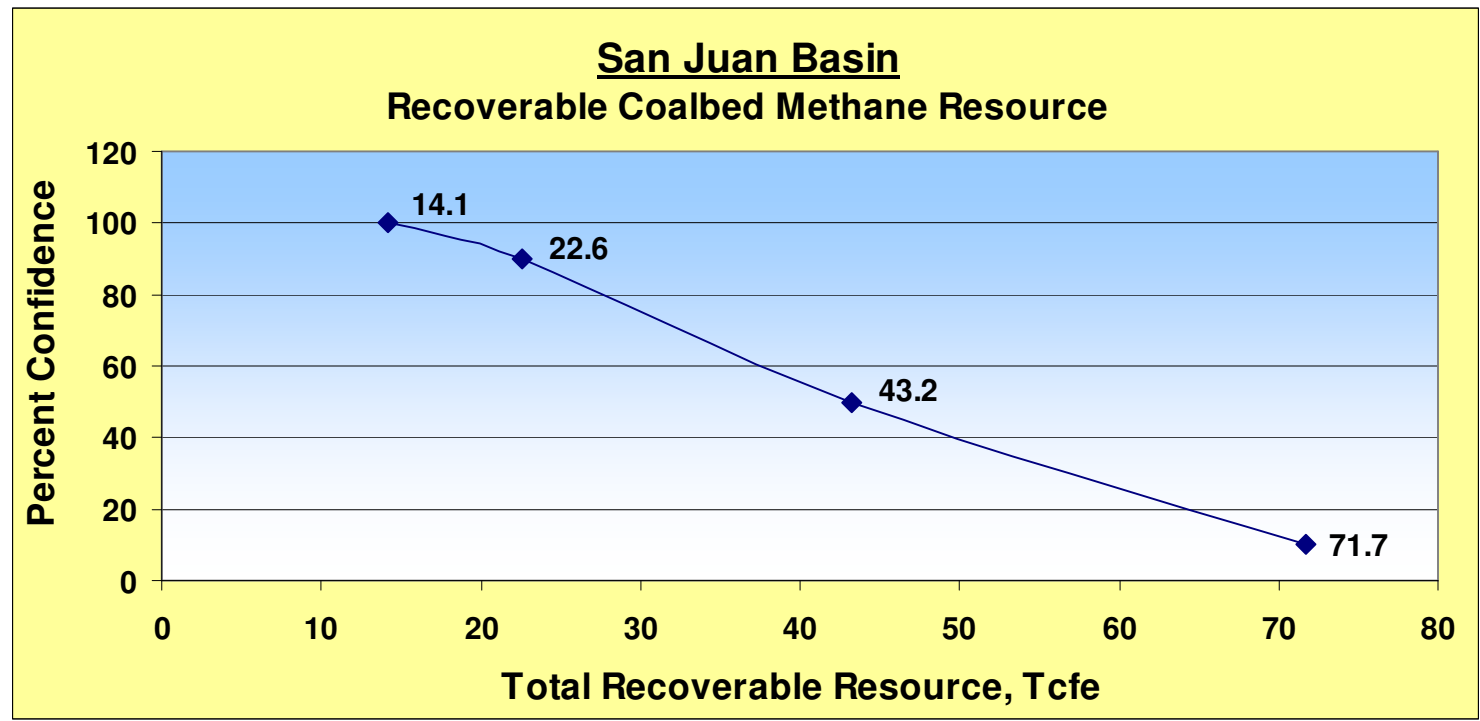

Fig. B.45: San Juan Basin Recoverable Coalbed Methane Resource Curve

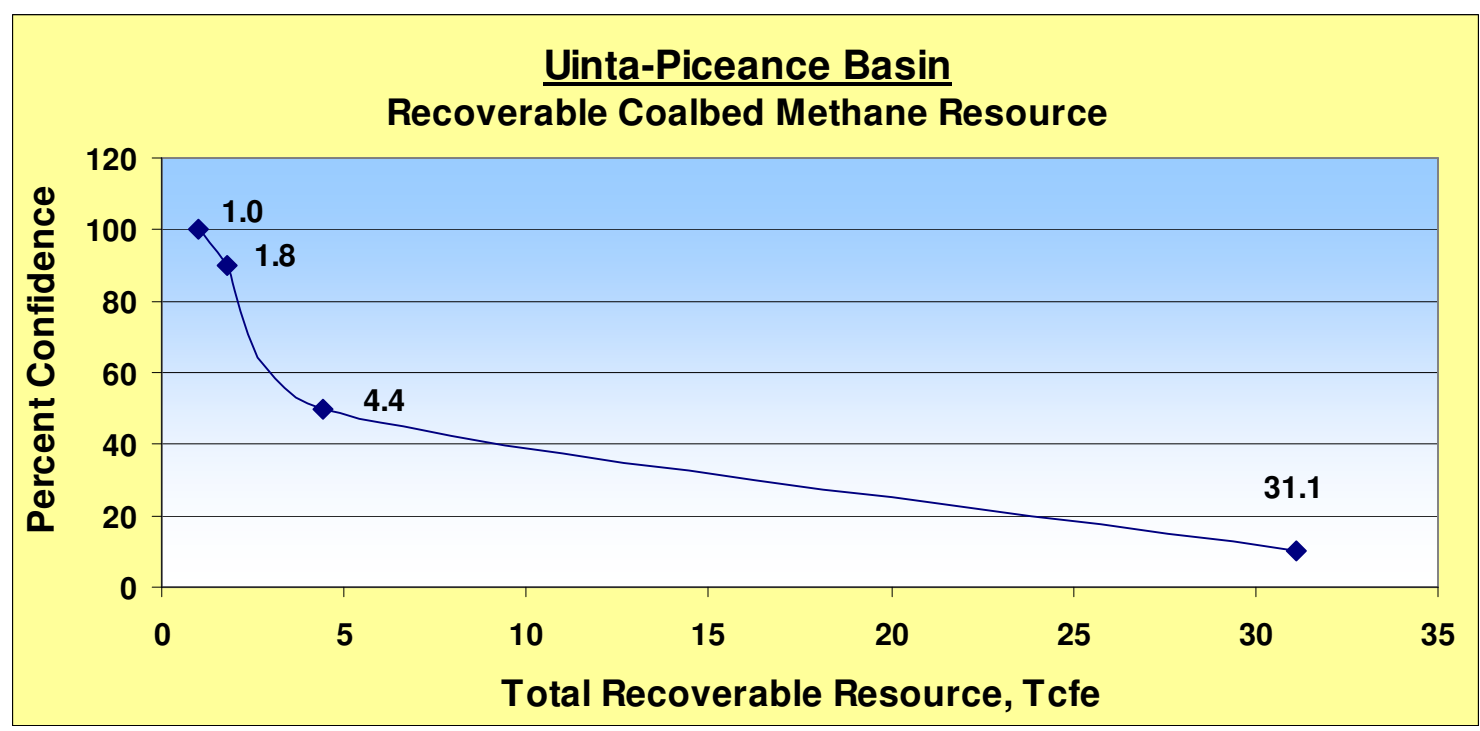

Fig. B.46: Uinta-Piceance Basin Recoverable Coalbed Methane Resource Curve 


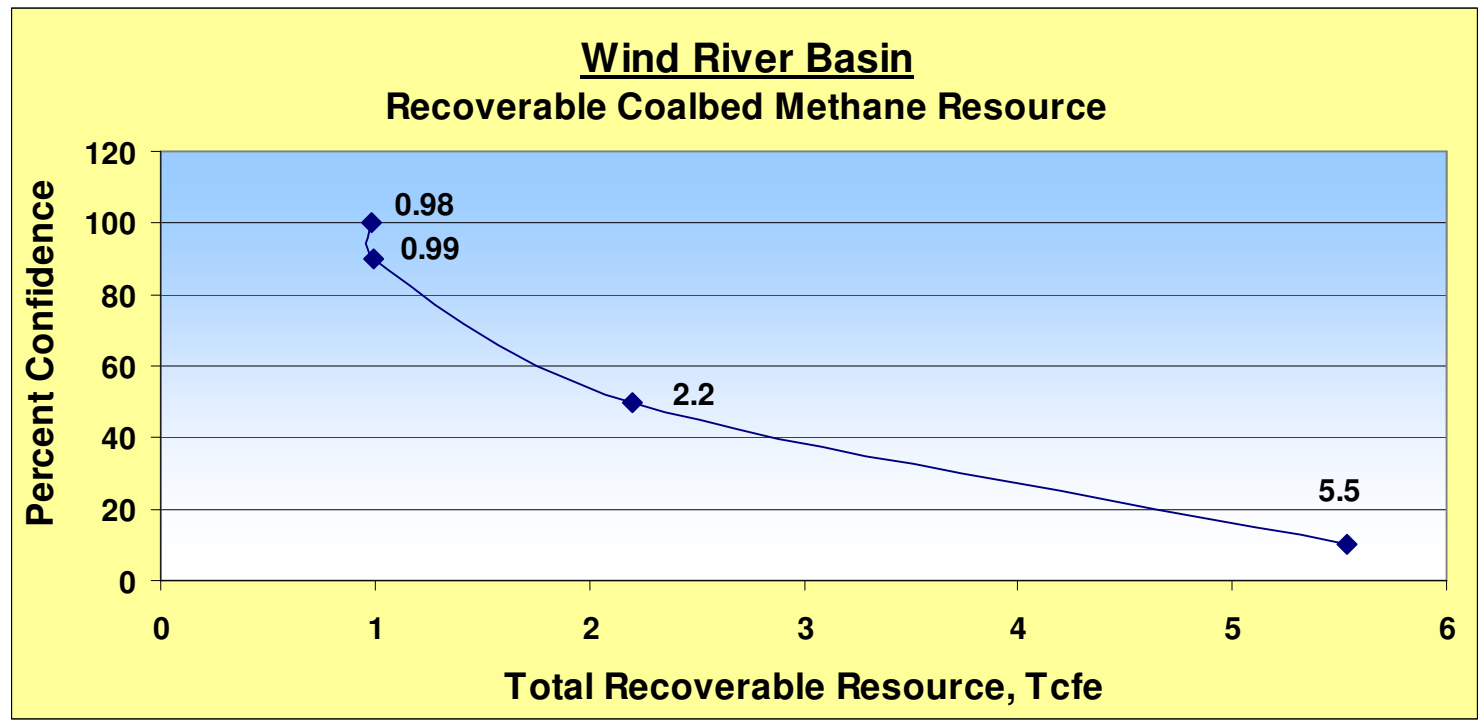

Fig. B.47: Wind River Basin Recoverable Coalbed Methane Resource Curve

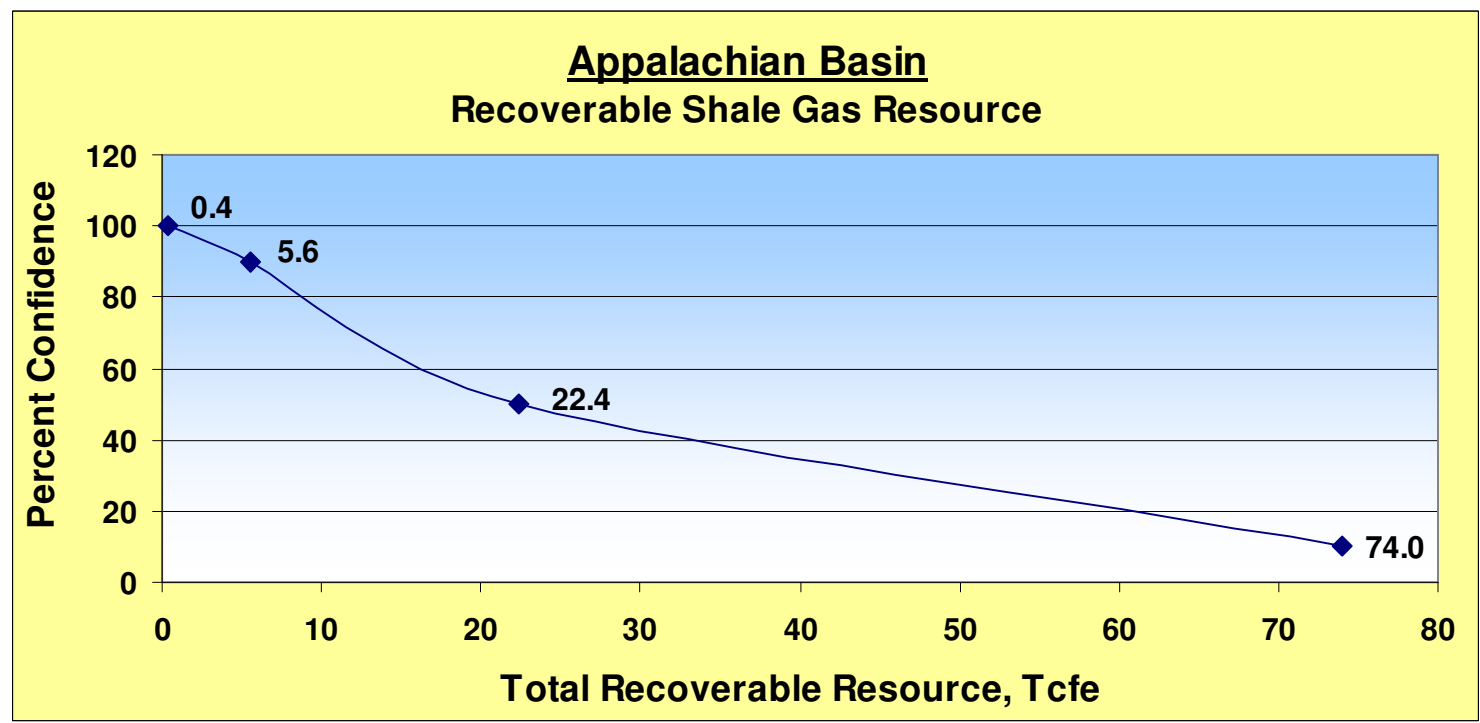

Fig. B.48: Appalachian Basin Recoverable Shale Gas Resource Curve 


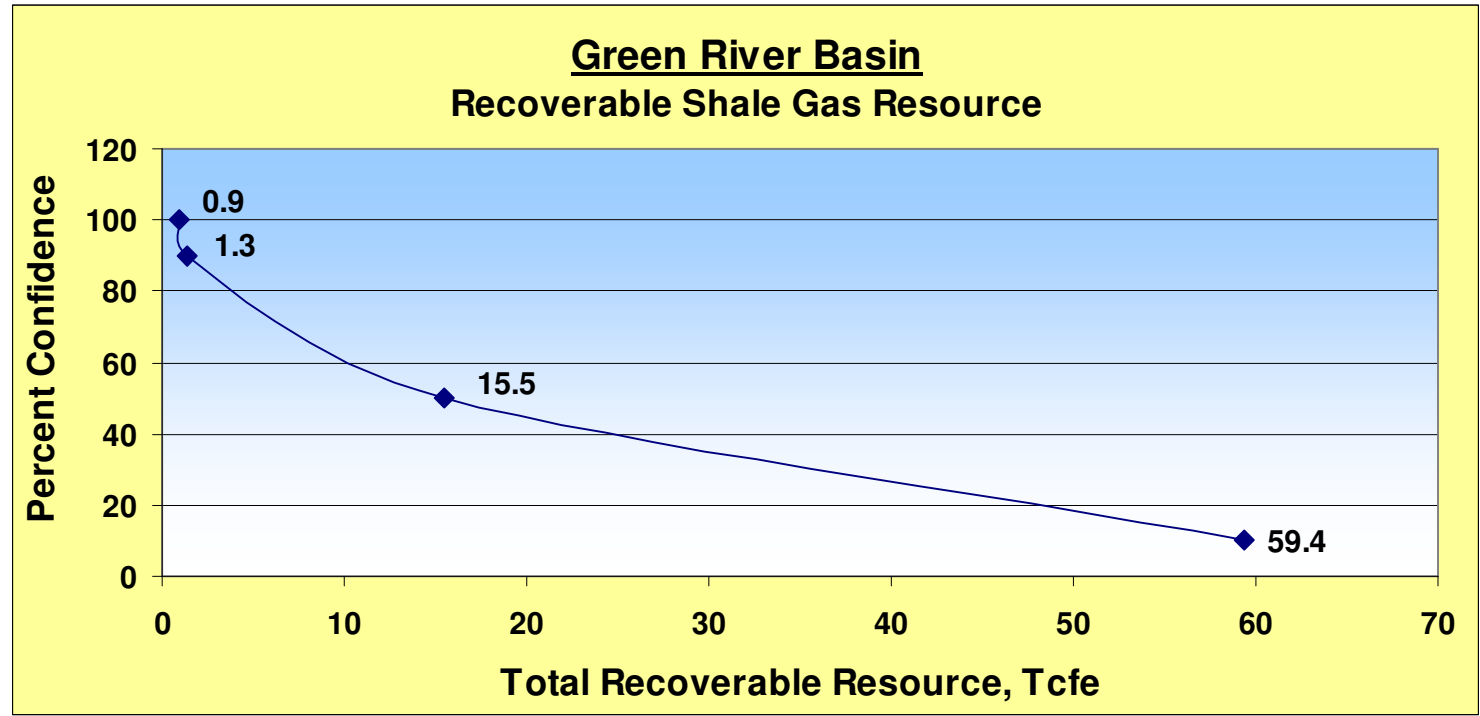

Fig. B.49: Green River Basin Recoverable Shale Gas Resource Curve

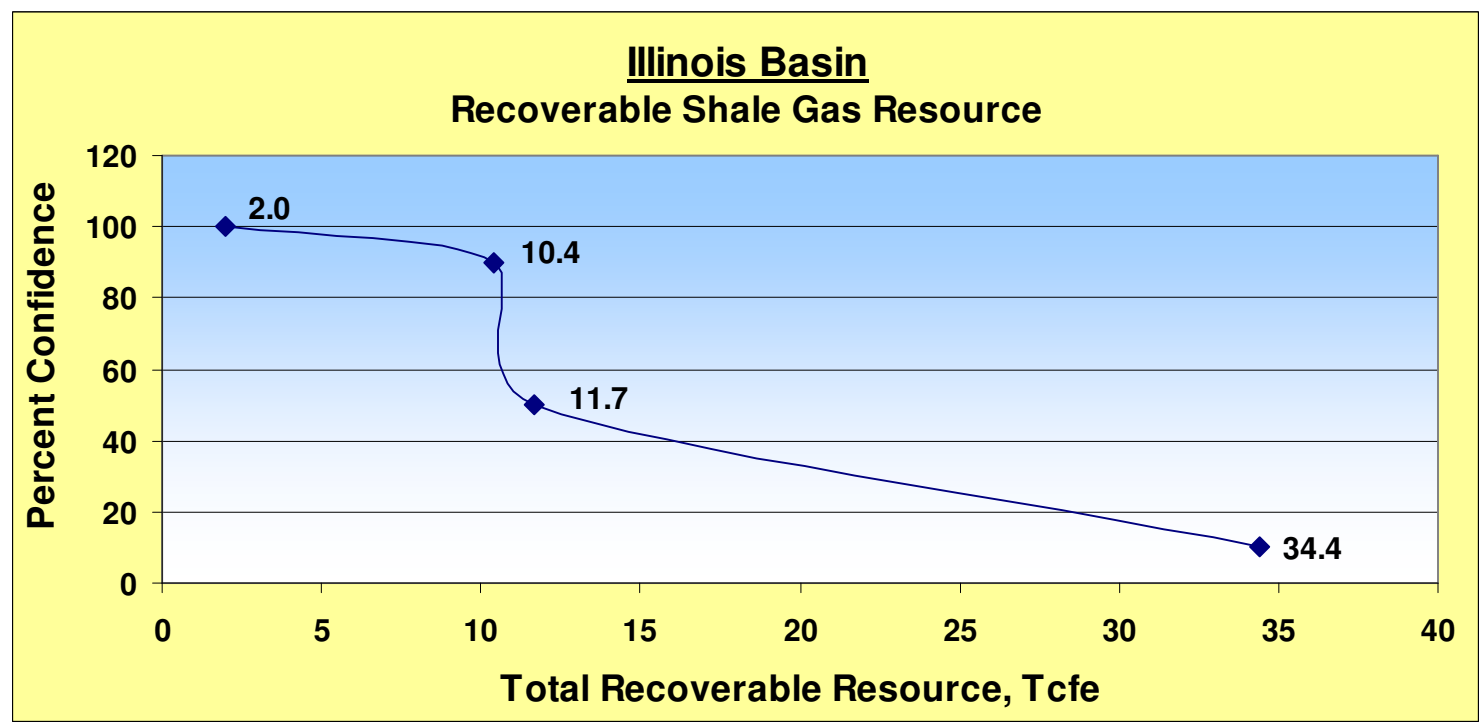

Fig. B.50: Illinois Basin Recoverable Shale Gas Resource Curve 


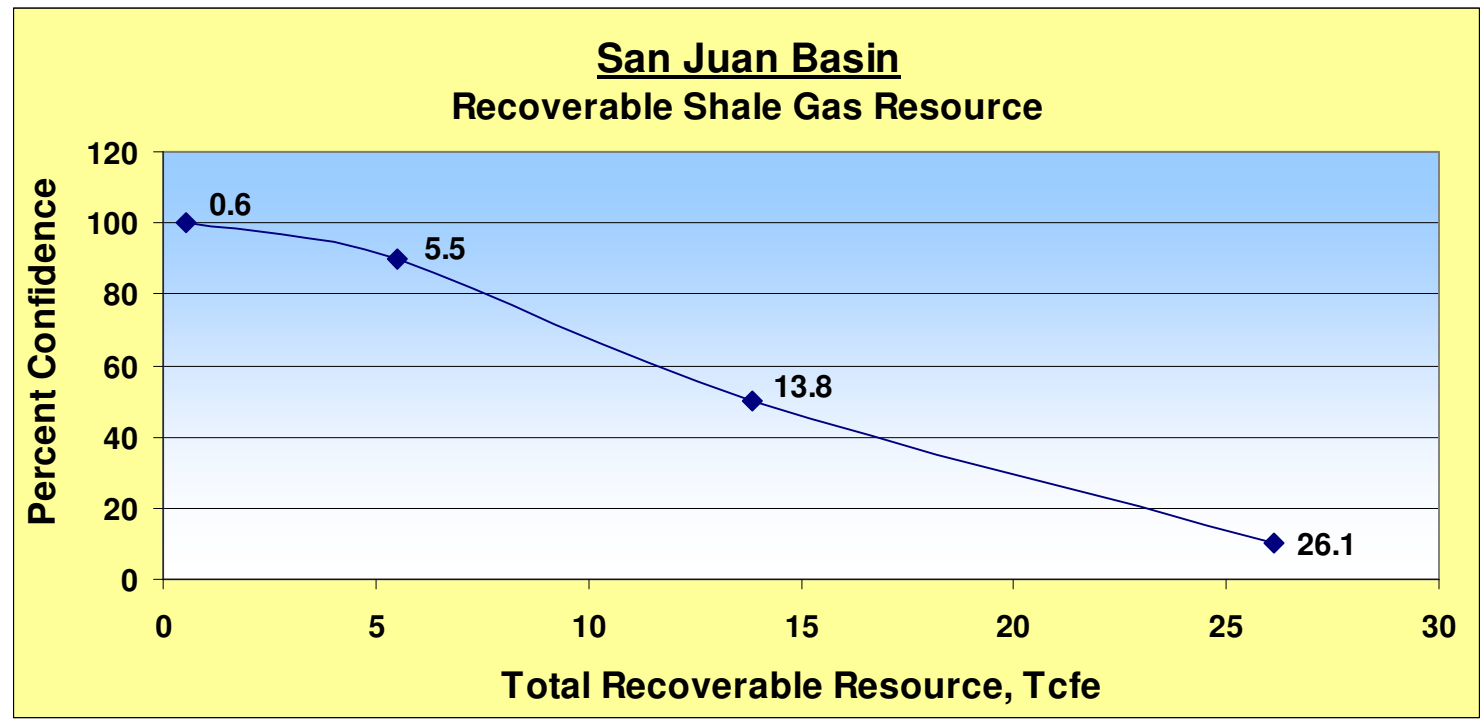

Fig. B.51: San Juan Basin Recoverable Shale Gas Resource Curve

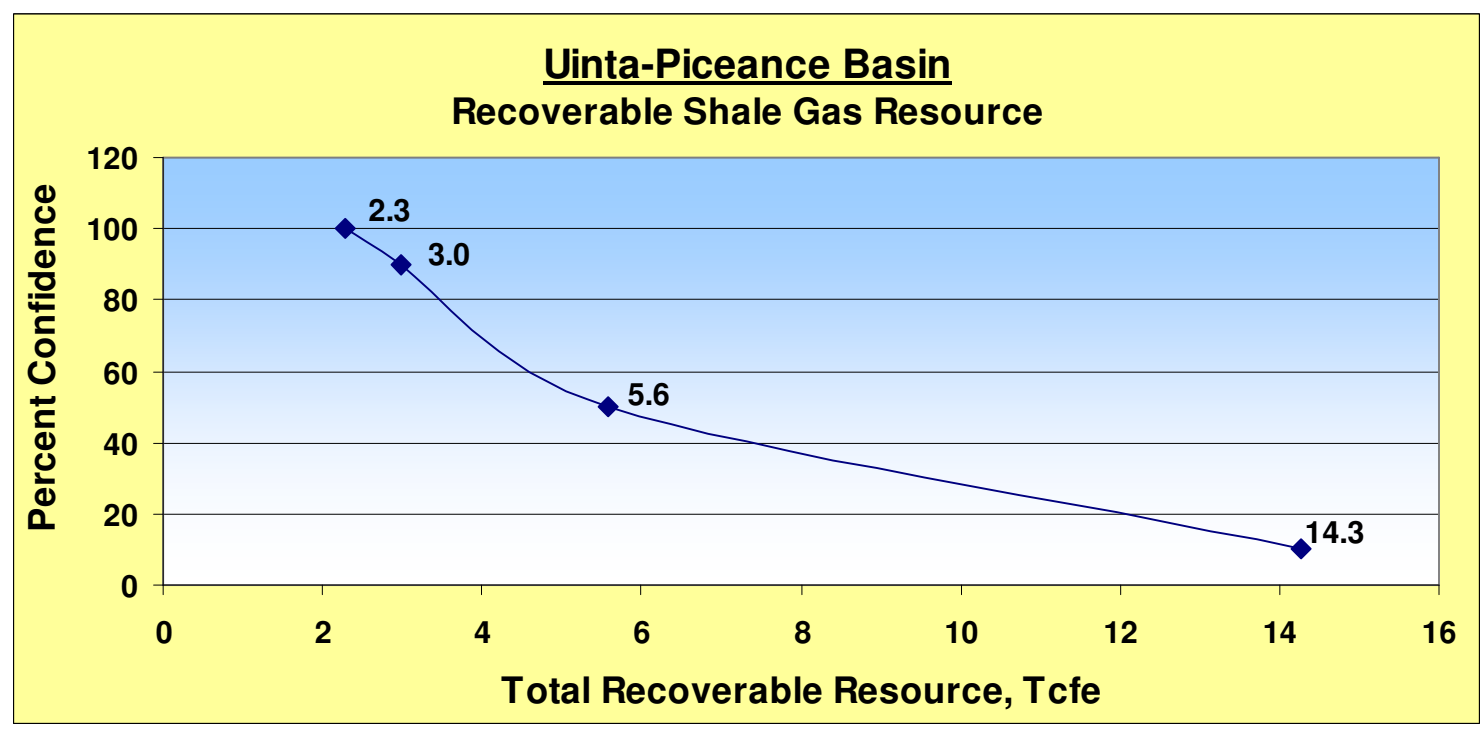

Fig. B.52: Uinta-Piceance Basin Recoverable Shale Gas Resource Curve 


\section{VITA}

Name: $\quad$ Sara Old

Address: $\quad$ Chevron North American Exploration \& Production Company 11111 S. Wilcrest Dr., Houston, TX 77099

Email Address: old.sara@gmail.com

Education: $\quad$ B.S., Geology, Texas A\&M University, 2006

M.S., Petroleum Engineering, Texas A\&M University, 2008 